\title{
A patient perspective on eHealth in primary care
}

Citation for published version (APA):

Huygens, M. W. J. (2018). A patient perspective on eHealth in primary care: Critical reflections on the implementation and use of online care services. [Doctoral Thesis, Maastricht University]. Datawyse / Universitaire Pers Maastricht. https://doi.org/10.26481/dis.20180111mh

Document status and date:

Published: 01/01/2018

DOI:

10.26481/dis.20180111mh

Document Version:

Publisher's PDF, also known as Version of record

\section{Please check the document version of this publication:}

- A submitted manuscript is the version of the article upon submission and before peer-review. There can be important differences between the submitted version and the official published version of record.

People interested in the research are advised to contact the author for the final version of the publication, or visit the DOI to the publisher's website.

- The final author version and the galley proof are versions of the publication after peer review.

- The final published version features the final layout of the paper including the volume, issue and page numbers.

Link to publication

\footnotetext{
General rights rights.

- You may freely distribute the URL identifying the publication in the public portal. please follow below link for the End User Agreement:

www.umlib.nl/taverne-license

Take down policy

If you believe that this document breaches copyright please contact us at:

repository@maastrichtuniversity.nl

providing details and we will investigate your claim.
}

Copyright and moral rights for the publications made accessible in the public portal are retained by the authors and/or other copyright owners and it is a condition of accessing publications that users recognise and abide by the legal requirements associated with these

- Users may download and print one copy of any publication from the public portal for the purpose of private study or research.

- You may not further distribute the material or use it for any profit-making activity or commercial gain

If the publication is distributed under the terms of Article $25 \mathrm{fa}$ of the Dutch Copyright Act, indicated by the "Taverne" license above, 

The research presented in this dissertation was conducted at the CAPRHI Care and Public Health Research Institute, department of Health Services Research, Maastricht University. CAPHRI is part of the Netherlands School of Primary Care Research (CARE). This research was partly funded under a grant from the Netherlands Organisation for Health Research and Development (ZonMw), grant 10-10400-98-009, and partly funded by Maastricht University.

Cover: Evelien Jagtman (www.evelienjagtman.com)

Lay-out: Martine Huygens

Printing: Datawyse, Universitaire Pers Maastricht

(C) copyright Martine Huygens, Maastricht 2017

ISBN 9789461597809 


\section{A patient perspective on eHealth in primary care}

Critical reflections on the implementation and use of online care services

\section{PROEFSCHRIFT}

ter verkrijging van de graad van doctor aan de Universiteit van Maastricht, op gezag van de Rector Magnificus, Prof. dr. Rianne M. Letschert, volgens het besluit van het College van Decanen, in het openbaar te verdedigen

op donderdag 11 januari 2018 om 14.00 uur

door

Martine Wilhelmina Johanna Huygens 


\section{Promotores}

Prof. dr. L.P. de Witte (University of Sheffield, United Kingdom)

Prof. dr. R.D. Friele (Tilburg University)

Prof. dr. O.C.P. van Schayck

\section{Co-promotor}

Dr. I.C.S. Swinkels (Nivel)

\section{Beoordelingscommissie}

Prof. dr. J.W.M. Muris (voorzitter)

Dr. P.J. Honkoop (Leiden University Medical Center)

Prof. dr. N.L.U. van Meeteren

Dr. E. van Rossum

Prof. dr. M.M.R. Vollenbroek (University of Twente) 


\section{Contents}

$\begin{array}{lll}\text { Chapter } 1 & \text { General introduction } & 7\end{array}$

Chapter 2 Internet services for communicating with the general practice: 19 barely noticed and used by patients Interact J Med Res. 2015;4:e21

Chapter 3 Expectations and needs of patients with a chronic disease toward 39 self-management and eHealth for self-management purposes BMC Health Serv Res. 2016;16:232

Chapter 4 Self-monitoring of health data by patients with a chronic disease: does disease controllability matter?

BMC Fam Pract. 2017;18:40

Chapter 5 Understanding the use of email-consultation in primary care using a retrospective observational study with data of Dutch electronic health records Accepted by BMJ open

Chapter 6 Lessons learned from a Living Lab on broad adoption of eHealth in primary health care Submitted for publication

Chapter 7 General discussion

Summary

Nederlandse samenvatting

Valorisation

Dankwoord

About the author

List of publications 


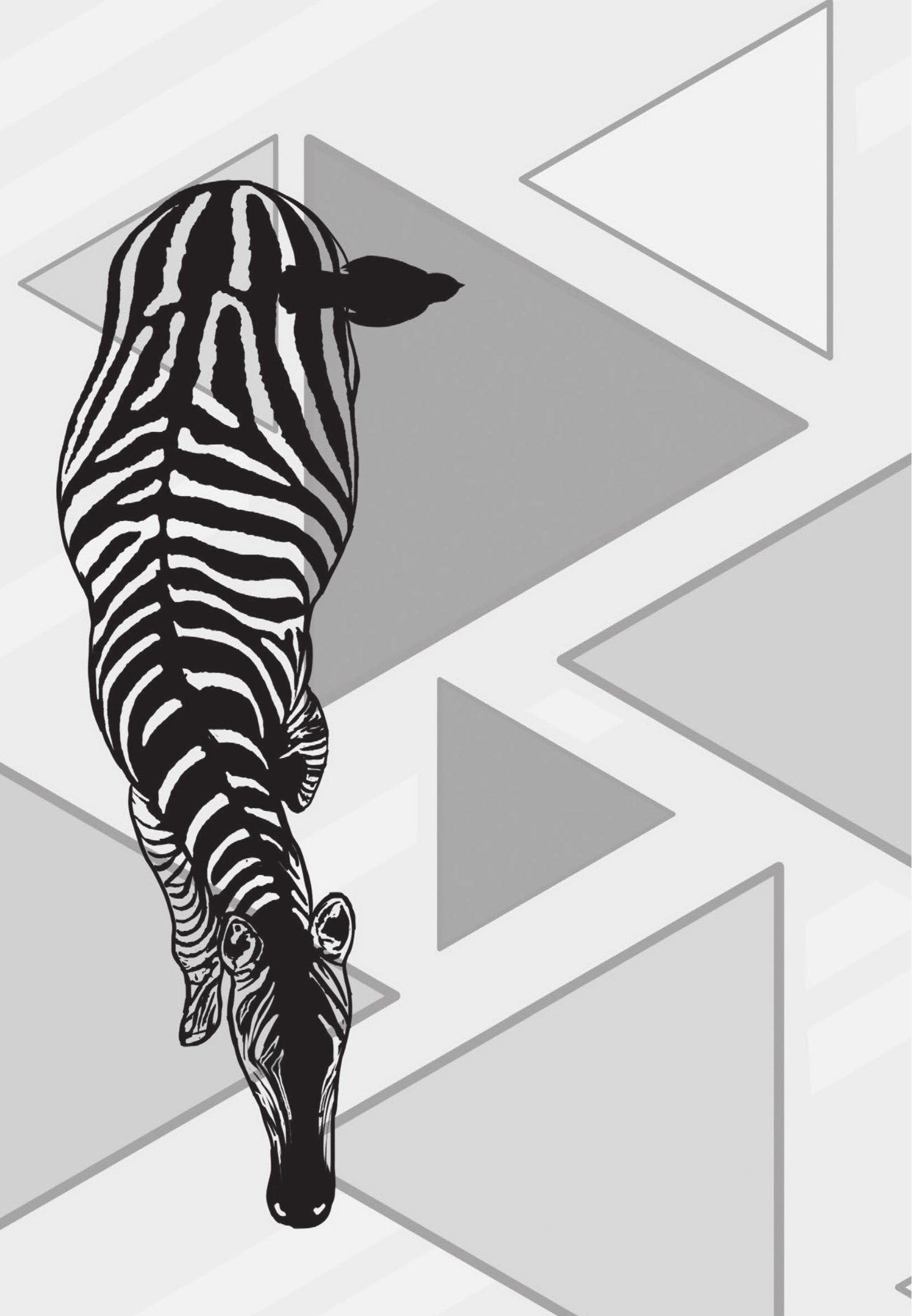




Primary care is facing challenges due to changes in Western society, including the growing number of elderly and people with a chronic condition, resulting in an increasing care demand. ${ }^{1,2}$ In addition, primary care is under pressure due to care shifting from secondary to primary care. ${ }^{3}$ Simultaneously, digitalization is in full swing. Everyday life procedures, such as mailing, shopping and banking, have been fully adopted by the Internet and smart devices are becoming more and more essential in daily life. Therefore, it is expected that digital solutions can also contribute to addressing the challenges in health care. From a technical point of view, the opportunities are immense. eHealth services, such as online coaches, monitoring applications and patient portals are rapidly being developed. They have the potential to increase both the quality and efficiency of care. ${ }^{4}$ However, as yet eHealth is not in widespread use in primary care. There are still many uncertainties regarding the broad-scale implementation of eHealth. Are patients actually interested in the use of eHealth? How can eHealth be adopted fully in daily care routines? This dissertation will focus on the patient perspective regarding eHealth needs and uses and on the broader context of eHealth implementation in the Netherlands.

\section{Dutch primary care and recent developments}

In the Netherlands, general practitioners (GPs) are the gatekeepers of health care. Hospital and specialist care (except for emergency care) require referral from a GP. Basic health insurance, which includes GP care, is obligatory for every Dutch citizen. ${ }^{3}$ In recent years, there has been a focus on shifting care from secondary to primary care, in particular care for chronic diseases. ${ }^{3}$

There are different strategies for coping with the increasing (chronic) care demand in Dutch primary care. First, practice nurses and assistants have taken over tasks from GPs related to chronic care, as in many other Western countries. ${ }^{3,5,6}$ In addition, a national strategy on chronic disease management was approved by the Ministry of Health, Welfare and Sport in 2007. In this strategy, a bundled payment was introduced to facilitate multidisciplinary collaboration in disease management programs. In 2010, the bundled payment concept was approved for nationwide implementation for chronic somatic diseases, such as diabetes, chronic obstructive pulmonary disease (COPD) and cardiovascular risk management (CVRM). ${ }^{7}$ The services covered by bundled payments have been described in disease-specific health care standards. Another strategy for coping with the increasing demand for care is that the focus has shifted from provision in the care practice to provision at home. ${ }^{3}$ Therefore, a greater emphasis is placed on the patient, who is expected to become more and more responsible for their own day-today disease management decisions. This so-called self-management requires an active role of the patient in managing symptoms, treatment, physical and psychosocial consequences and lifestyle changes. ${ }^{8}$ This trend in health care is in line with Huber's new 
definition of health, which no longer considers health care as a static situation but as the ability to adapt and to self-manage in the face of social, physical and emotional challenges. ${ }^{9}$ Promoting self-management is one of the elements included in the diseasespecific health care standards. eHealth is expected to contribute to improvements in health by supporting patients in their independence and self-management. ${ }^{10-14}$

\section{eHealth in primary care}

eHealth is a broad term which includes a diverse range of technical innovations in health care. According to the World Health Organization (WHO), eHealth is: "the use of information and communication technologies (ICT) for health". ${ }^{15}$ Eysenbach defined eHealth not as a technical development but as an emerging field at the intersection of medical informatics, public health and business, referring to health services and information delivered or enhanced through the Internet and related technologies. ${ }^{16}$ However, he also mentioned that this definition should be considered with caution because it is a dynamic field which is constantly moving. The systematic reviews of Oh et al. ${ }^{17}$ and Pagliari et al. ${ }^{18}$ underscore the lack of an uniform definition of eHealth. It is clear that the field of eHealth has a focus on health and technology. However, definitions range from the business-oriented to the more clinically focused. Hence, eHealth includes a wide range of applications that can be used for different purposes (for example, treatment, prevention, information, registration and communication) and target groups. ${ }^{19}$ In this dissertation the focus is on online communication services that can be used by the general GP population and eHealth for self-management purposes for people with a chronic somatic condition that can be used in primary care.

Online communication services in primary care have the potential to increase the efficiency of care, patient satisfaction and the quality of care. ${ }^{13,20,21}$ For instance, several studies have found that email-consultation can save time, ${ }^{22,23}$ improve communication between patients and care professionals ${ }^{24}$ and improve the accessibility of care. ${ }^{22}$ Furthermore, online access to medical records can empower patients and improve patient safety, and may aid self-care and shared decision making. ${ }^{13,25}$ However, although these potential benefits look promising, there are still many concerns regarding privacy, workflow and technical issues. ${ }^{13,20,26}$ In addition, evidence for the effect of online communication services on clinical outcomes and reductions in workload is still weak and inconclusive. ${ }^{13,14,27}$

The same holds for eHealth applications that are aimed at supporting patients in their self-management. A large variety of eHealth technologies exist that have been developed for this purposes, ${ }^{10,11,28-30}$ focusing on different aspects of self-management, such as competence (disease knowledge), illness management (making choices, acting responsibly) and independence (social participation, autonomy). ${ }^{30}$ For example, ecoaching applications can support and inform patients in managing their condition by 
providing tailored information, feedback and encouragement. ${ }^{31}$ Moreover, home telemonitoring applications can provide patients with insights using self-monitored data and can empower them, influence their attitudes and behaviours and potentially improve their medical conditions. ${ }^{28}$ However, for these eHealth applications also the evidence on health outcomes, ${ }^{29,32}$ cost effectiveness ${ }^{4,32-34}$ and independence ${ }^{30}$ is still weak.

The greatest shortcoming in the literature is the effect of eHealth in real practice. ${ }^{30,34,35}$ Most studies provide evidence of eHealth based on pilot studies and randomized controlled trials, which does not guarantee that it also works in everyday practice. Despite its potential, eHealth is not being adopted and implemented successfully in daily care routines. ${ }^{36,37}$

The Dutch Ministry of Health, Welfare and Sport acknowledges the potential benefits of eHealth and the lack of implementation and actual use. In 2014, the Minister of Health, Welfare and Sport, Edith Schippers, formulated three ambitions concerning eHealth which should be realized within five years. She stated that $80 \%$ of people with a chronic condition should have direct access to their medical data (including medication, vital functions and test results), 75\% of those with a chronic disease and frail elderly willing and able to self-monitor their health parameters independently should have the possibility of doing so and everybody receiving care support at home should have the possibility of communicating with a care professional via a video display 24 hours a day. ${ }^{38}$ Since 2013 , the actual number of people using and interested in using eHealth has been monitored annually using a national eHealth monitor, which is funded by the Dutch Ministry of Health, Welfare and Sport. ${ }^{39}$ However, research on patients' expectations and needs regarding specific technologies is scarce.

\section{Patients' opinions, needs and acceptance regarding eHealth}

Positive opinions of eHealth among patients have been found in several studies, for example related to improved access to personal health information, ${ }^{40}$ patient-provider communication, ${ }^{41}$ quality of care $^{42}$ and empowerment. ${ }^{43}$ However, many potential pitfalls have also been reported by patients, such as privacy and security issues ${ }^{40}$ and the lack of human contact. ${ }^{44}$ In addition, in studies concerning patients' experiences of eHealth technologies arguments for non-use and withdrawal have included a lack of perceived additional benefits of eHealth, ${ }^{45,46}$ technical difficulties with the equipment ${ }^{46}$ and the association between the use of eHealth and a high degree of dependency and ill health. ${ }^{46}$ In addition, in several studies patients mentioned that their regular health care was sufficient. ${ }^{45,46}$ To date, the adoption of eHealth by patients has been low. ${ }^{44,47-49} \mathrm{We}$ think that there is often a suboptimal fit between the needs of patients and the eHealth solutions. 
Before eHealth can be implemented and used effectively, it is important to involve patients by investigating their needs and requirements regarding the use of eHealth. In recent years, the importance of patient involvement has becoming increasingly recognized. However, the level of involvement and the way in which it is organized might be questioned. User-centred design (UCD) is a method frequently used to involve patients during the design and development of eHealth. ${ }^{50,51}$ Often, patients have been involved in an eHealth project after major decisions about (technological) concepts and target groups have been made by the developers. UCD is thus often used to improve the functionality and usability of a specific eHealth technology. Less effort is put into understanding those aspects concerning which patients actually need care support and which patients groups can benefit most from the use of eHealth.

To investigate whether patients are willing to use eHealth and if so which patients, the technology acceptance model (TAM) $)^{52,53}$ is frequently used. This model predicts user intention based on the main constructs perceived ease of use and perceived usefulness. Although it was originally designed in 1986 in relation to the acceptance of software applications in an occupational setting, it is still the most important model used to identify the factors that influence the adoption of information technologies in health care. $^{54}$ However, the use of TAM to predict eHealth acceptance is not without criticism. $^{53,55}$ For example, the user acceptance to which TAM refers is acceptance regarding systems that are already installed and operational. In eHealth research, however, TAM is often used to predict willingness to use eHealth. In addition, in cases in which eHealth technologies have been installed, patients might not use them at all or may not use them for their intended purposes. In this context, perceived usefulness is difficult to measure because patients might not have a clear image of the benefits the technology can bring. ${ }^{55}$ TAM has been extended and modified frequently in recent years. One such example is the Unified Theory of Acceptance and Use of Technology (UTAUT), in which the concepts social influence and facilitating conditions are also included, moderated by four individual variables. ${ }^{56}$ However, in these models eHealth tends to be analysed as technology, while we consider that there are also major non-technological factors that play a role in patients' willingness and acceptance to use eHealth.

We are of the view that one of the reasons why eHealth is barely adopted by patients when offered is that it often does not meet the needs of the patients. Understanding in what aspects patients need additional support, investigating for which patients eHealth can be best used and what factors influence their use might be the first steps that should be taken before the development and implementation process can start. In other words, it is important to listen to the voice of the patient first. 


\section{The eLabEL project}

As an end user, the patient plays an important role in eHealth implementation. However, the patient is embedded in health care organizations. The key question is how eHealth can be adopted throughout the entire care process. For optimal adoption, many other key stakeholders should be involved, such as care professionals, care organizations, eHealth entrepreneurs and health insurers. Therefore, the studies in this dissertation were undertaken in a broader context as part of the eLabEL project. The eLabEL project was conducted from September 2013 to December 2016 in the Netherlands by the Centre for Care Technology Research (CCTR). The aim of this project was to establish living labs in which integrated eHealth applications would become a part of regular health care and to study the impact in primary care, as well as technical barriers and facilitators in a real-life setting. In this project, patients, health care professionals, eHealth entrepreneurs and researchers collaborated.

\section{Objectives and outline of this dissertation}

The main aim of this dissertation is to investigate patients' interest in the use of eHealth in primary care. The secondary aim is to explore needs in relation to successful implementation of eHealth in primary care from a broader perspective. The underlying objectives for these aims are as follows:

1. To investigate patients' expectations and needs concerning eHealth in primary care.

2. To investigate patients' actual use and willingness to use eHealth in primary care.

3. To investigate aspects and characteristics that influence patients' willingness to use eHealth.

4. To investigate the lessons learned from a broad-scale eHealth implementation project.

The focus of chapters 2 and 5 concerns online communication services that can be used by the entire general practice population, the focus of chapters 3 and 4 address eHealth for self-management purposes among people with a chronic somatic condition. Chapter 6 discusses eHealth in general.

Chapter 2 describes a cross-sectional study investigating the actual use and intention to use Internet services for communication between GP practices and the general practices' populations, as well as the factors and characteristics that influence patients' intention to use such services. Chapter 3 presents the results of a qualitative study aimed at investigating the expectations and needs of people with a chronic condition regarding self-management and the use of eHealth for self-management purposes, their willingness to use eHealth and possible differences between patient groups regarding these aspects. Some findings of chapter 3 are tested in a cross-sectional study presented 


\section{CHAPTER 1}

in Chapter 4, aiming to investigate the relationship between patients' willingness to selfmonitor and a range of disease- and patient-specific variables, including controllability of disease type, patients' perceived self-efficacy and health problems. Chapter 5 describes the results of a study on the use of email-consultation by patients in primary care compared to regular GP consultations using data from the electronic health records of Dutch primary care practices. Chapter 6 reports the main lessons learned from the eLabEL project, based on in-depth process data, focusing on the perspective of patients, health care professionals, entrepreneurs and health care policymakers.

A summary of the main findings of chapters 2 to 6 is provided in Chapter 7. In addition, considerations of and reflections on the main findings, as well as recommendations for eHealth developers and entrepreneurs, care professionals, patients, policy and research are discussed. 


\section{References}

1. Blokstra A, Baan CA, Boshuizen HC, Feenstra TL, Hoogenveen RT, Picavet HSJ, et al. Vergrijzing en toekomstige ziektelast. Prognose chronische ziektenprevalentie 2005-2025. Rijksinstituut voor Volksgezondheid en Milieu (RIVM); 2007.

2. World Health Organization (WHO). Global status report on noncommunicable diseases 2014. Geneva, World Health Organization; 2014.

3. Kroneman M, Boerma W, van den Berg M, Groenewegen P, de Jong J, van Ginneken E. Netherlands: Health System Review. Health systems in transition. 2016;18(2):1.

4. Elbert NJ, van Os-Medendorp $H$, van Renselaar W, Ekeland AG, Hakkaart-van Roijen L, Raat $H$, et al. Effectiveness and cost-effectiveness of ehealth interventions in somatic diseases: a systematic review of systematic reviews and meta-analyses. J Med Internet Res. 2014;16(4):e110.

5. Maier CB, Aiken LH. Task shifting from physicians to nurses in primary care in 39 countries: a cross-country comparative study. Eur J Public Health. 2016;26(6):927-34.

6. de Bakker DH, Groenewegen PP. Primary care in the Netherlands: current situation and trends. Ital. J. Public Health. 2012;6(2).

7. Struijs JN, Baan CA. Integrating care through bundled payments-lessons from the Netherlands. N Engl J Med. 2011;364(11):990-1.

8. Barlow J, Wright C, Sheasby J, Turner A, Hainsworth J. Self-management approaches for people with chronic conditions: a review. Patient Educ Couns. 2002;48(2):177-87.

9. Huber M, Knottnerus JA, Green L, van der Horst H, Jadad AR, Kromhout D, et al. How should we define health? BMJ: Brit Med J. 2011;343.

10. Hui CY, Walton R, McKinstry B, Jackson T, Parker R, Pinnock $H$. The use of mobile applications to support self-management for people with asthma: a systematic review of controlled studies to identify features associated with clinical effectiveness and adherence. J Am Med Inform Assoc. 2016;24(3):619-632.

11. Morton K, Dennison L, May C, Murray E, Little P, McManus RJ, et al. Using digital interventions for selfmanagement of chronic physical health conditions: A meta-ethnography review of published studies. Patient Educ Couns. 2016;100(4):616-635.

12. Jones KR, Lekhak N, Kaewluang N. Using Mobile Phones and Short Message Service to Deliver SelfManagement Interventions for Chronic Conditions: A Meta-Review. Worldviews Evid Based Nurs. 2014;11(2):81-88.

13. de Lusignan S, Mold F, Sheikh A, Majeed A, Wyatt JC, Quinn T, et al. Patients' online access to their electronic health records and linked online services: a systematic interpretative review. BMJ open. 2014;4(9):e006021.

14. de Jong CC, Ros WJ, Schrijvers G. The effects on health behavior and health outcomes of Internet-based asynchronous communication between health providers and patients with a chronic condition: a systematic review. J Med Internet Res. 2014;16(1):e19.

15. World Health Organization (WHO). 2017 http://www.who.int/topics/ehealth/en/ [accessed 2017-07-25].

16. Eysenbach G. What is e-health? J Med Internet Res. 2001;3(2):e20.

17. Oh H, Rizo C, Enkin M, Jadad A. What is eHealth (3): a systematic review of published definitions. J Med Internet Res. 2005;7(1):e1.

18. Pagliari C, Sloan D, Gregor P, Sullivan F, Detmer D, Kahan JP, et al. What is eHealth (4): a scoping exercise to map the field. J Med Internet Res. 2005;7(1):e9.

19. Krijgsman J, Klein Wolterink G. Ordening in de wereld van eHealth. Den Haag, Nationaal ICT Instituut in de Zorg (Nictiz); 2012.

20. Ye J, Rust G, Fry-Johnson Y, Strothers H. E-mail in patient-provider communication: A systematic review. Patient Educ Couns. 2010;80(2):266-73.

21. Hickson R, Talbert J, Thornbury WC, Perin NR, Goodin AJ. Online medical care: the current state of "eVisits" in acute primary care delivery. Telemed J E Health. 2015;21(2):90-6.

22. Rosen P, Kwoh CK. Patient-physician e-mail: an opportunity to transform pediatric health care delivery. Pediatrics. 2007;120(4):701-6. 
23. Houston TK, Sands DZ, Nash BR, Ford DE. Experiences of physicians who frequently use e-mail with patients. Health Commun. 2003;15(4):515-25.

24. Leong SL, Gingrich D, Lewis PR, Mauger DT, George JH. Enhancing doctor-patient communication using email: a pilot study. J Am Board Fam Med. 2005;18(3):180-8.

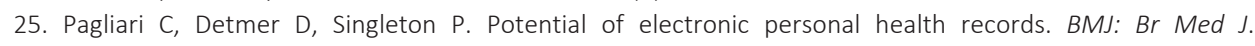
2007;7615:330.

26. Kruse CS, Argueta DA, Lopez L, Nair A. Patient and provider attitudes toward the use of patient portals for the management of chronic disease: a systematic review. J Med Internet Res. 2015;17(2):e40.

27. Atherton H, Sawmynaden P, Sheikh A, Majeed A, Car J. Email for clinical communication between patients/caregivers and healthcare professionals. The Cochrane Library Syst Rev. 2012;3.

28. Paré G, Jaana M, Sicotte C. Systematic review of home telemonitoring for chronic diseases: the evidence base. J Am Med Inform Assoc. 2007;14(3):269-77.

29. Eland-de Kok P, van Os-Medendorp H, Vergouwe-Meijer A, Bruijnzeel-Koomen C, Ros W. A systematic review of the effects of e-health on chronically ill patients. J Clin Nurs. 2011;20(21-22):2997-3010.

30. Peeters JM, Wiegers TA, Friele RD. How technology in care at home affects patient self-care and selfmanagement: a scoping review. Int J Environ Res Public Health. 2013;10(11):5541-64

31. Lisa Marsch SL, Dallery J. Behavioral health care and technology: using science-based innovations to transform practice. New York: Oxford University Press; 2015.

32. Black AD, Car J, Pagliari C, Anandan C, Cresswell K, Bokun T, et al. The impact of eHealth on the quality and safety of health care: a systematic overview. PLoS Med. 2011;8(1):e1000387.

33. Henderson C, Knapp M, Fernández J-L, Beecham J, Hirani SP, Cartwright M, et al. Cost effectiveness of telehealth for patients with long term conditions (Whole Systems Demonstrator telehealth questionnaire study): nested economic evaluation in a pragmatic, cluster randomised controlled trial. BMJ: Brit Med J. 2013;346:f1035.

34. Flodgren G, Rachas A, Farmer AJ, Inzitari M, Shepperd S. Interactive telemedicine: effects on professional practice and health care outcomes. The Cochrane Library Syst Rev. 2015.

35. Wildevuur SE, Simonse LW. Information and communication technology-enabled person-centered care for the "big five" chronic conditions: scoping review. J Med Internet Res. 2015;17(3):e77.

36. Broens TH, Vollenbroek-Hutten MM, Hermens HJ, van Halteren AT, Nieuwenhuis LJ. Determinants of successful telemedicine implementations: a literature study. J Telemed Telecare. 2007;13(6):303-9.

37. Van Dyk L. A review of telehealth service implementation frameworks. Int J Environ Res Public Health. 2014;11(2):1279-98.

38. Schippers E and van Rijn MJ. Kamerbrief e-health en zorgverbetering. 2014.

39. Nederlands instituut voor onderzoek van de gezondheidszorg (nivel) and Nationaal ICT Instituut in de Zorg (Nictiz). eHealth-monitor. https://www.nictiz.nl/ehealth/ehealth-monitor [accessed 2017-07-25].

40. Ware P, Bartlett S, Paré G, Symeonidis I, Tannenbaum C, Bartlett G, et al. Using eHealth Technologies: Interests, Preferences, and Concerns of Older Adults. Interact J Med Res. 2017;6(1):e3.

41. Gray CS, Miller D, Kuluski K, Cott C. Tying eHealth tools to patient needs: exploring the use of ehealth for community-dwelling patients with complex chronic disease and disability. JMIR Res Protoc. 2014;3(4):e67.

42. Bertelsen P, Tornbjerg K, editors. Danish Citizens' Expectations to the Use of eHealth. ITCH. 2015;78-82.

43. Woods SS, Schwartz E, Tuepker A, Press NA, Nazi KM, Turvey CL, et al. Patient experiences with full electronic access to health records and clinical notes through the My HealtheVet Personal Health Record Pilot: qualitative study. J Med Internet Res. 2013;15(3):e65.

44. Flynn D, Gregory P, Makki H, Gabbay M. Expectations and experiences of eHealth in primary care: a qualitative practice-based investigation. Int J Med Inform. 2009;78(9):588-604.

45. Subramanian U, Hopp F, Lowery J, Woodbridge P, Smith D. Research in home-care telemedicine: challenges in patient recruitment. Telemed J E Health. 2004;10(2):155-61.

46. Sanders C, Rogers A, Bowen R, Bower P, Hirani S, Cartwright M, et al. Exploring barriers to participation and adoption of telehealth and telecare within the Whole System Demonstrator trial: a qualitative study. BMC Health Serv Res. 2012;12(1):220. 
47. Nijland N, van Gemert-Pijnen JE, Boer H, Steehouder MF, Seydel ER. Increasing the use of e-consultation in primary care: results of an online survey among non-users of e-consultation. Int J Med Inform. 2009;78(10):688-703.

48. Hofstede J, de Bie J, van Wijngaarden B, Heijmans M. Knowledge, use and attitude toward eHealth among patients with chronic lung diseases. Int J Med Inform. 2014;83(12):967-74.

49. Makai P, Perry M, Robben SH, Schers HJ, Heinen MM, Rikkert MGO, et al. Evaluation of an eHealth intervention in chronic care for frail older people: why adherence is the first target. J Med Internet Res. 2014;16(6):e156.

50. Dabbs ADV, Myers BA, Mc Curry KR, Dunbar-Jacob J, Hawkins RP, Begey A, et al. User-centered design and interactive health technologies for patients. Comput Inform Nurs. 2009;27(3):175.

51. LeRouge C, Wickramasinghe N. A review of user-centered design for diabetes-related consumer health informatics technologies. J Diabetes Sci Technol. 2013;7(4):1039-56.

52. Davis FD. A Technology acceptance model for empirically testing new end-user information systems: theory and results [PhD dissertation]. Cambridge, MA: Massachusetts Institute of Technology; 1985.

53. Holden RJ, Karsh B-T. The technology acceptance model: its past and its future in health care. J Biomed Inform. 2010;43(1):159-72.

54. Garavand A, Mohseni M, Asadi H, Etemadi M, Moradi-Joo M, Moosavi A. Factors influencing the adoption of health information technologies: a systematic review. Electron Physician. 2016;8(8):2713.

55. Bouwhuis D, Meesters L, Sponselee A. Models for the acceptance of tele-care solutions: Intention vs behaviour. Gerontechnology. 2012;11(1):45-55.

56. Venkatesh V, Morris MG, Davis GB, Davis FD. User acceptance of information technology: toward a unified view. MIS Quart. 2003;27:425-478. 


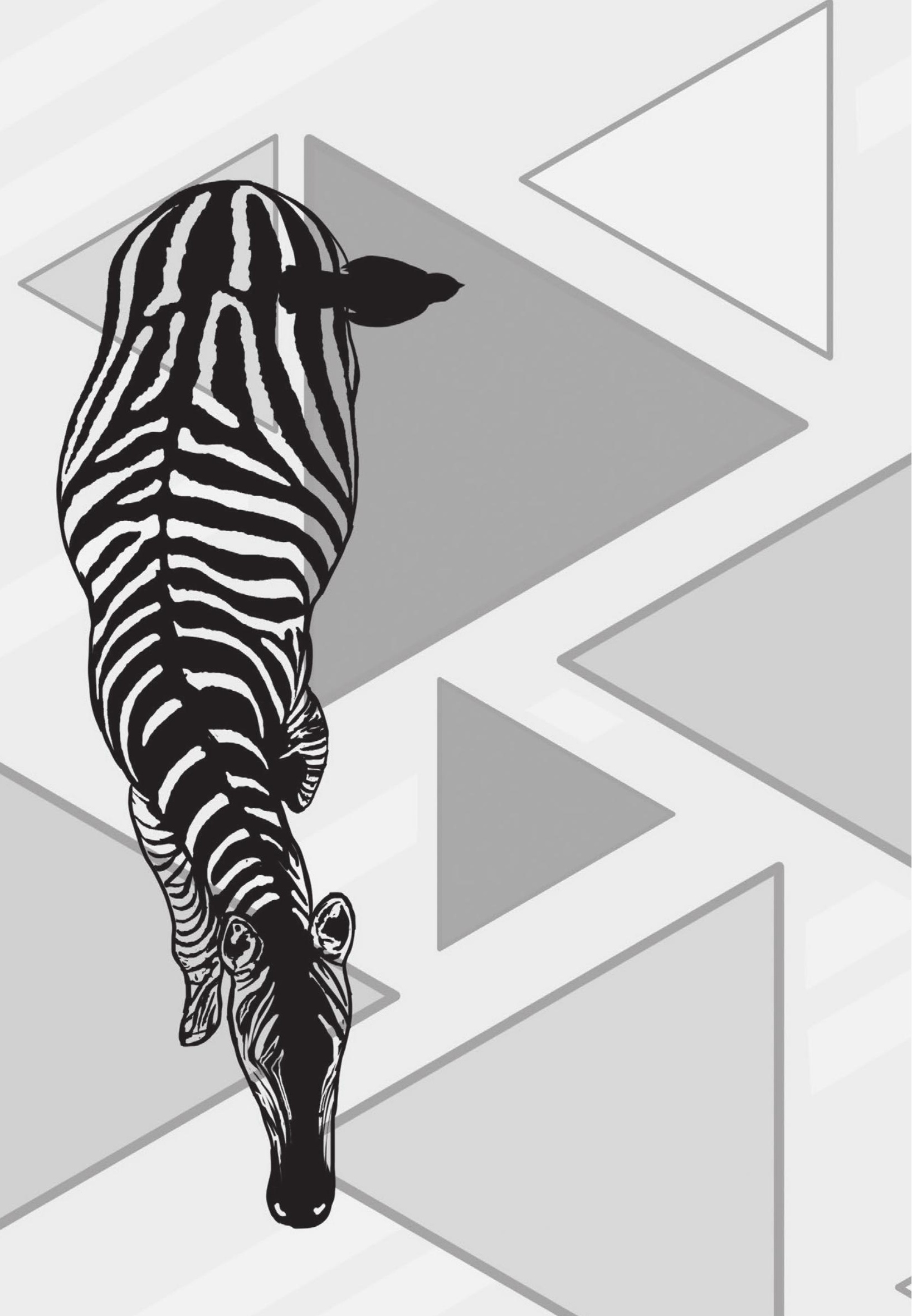




\section{CHAPTER 2 \\ Internet services for communicating with the general practice: barely noticed and used by patients}

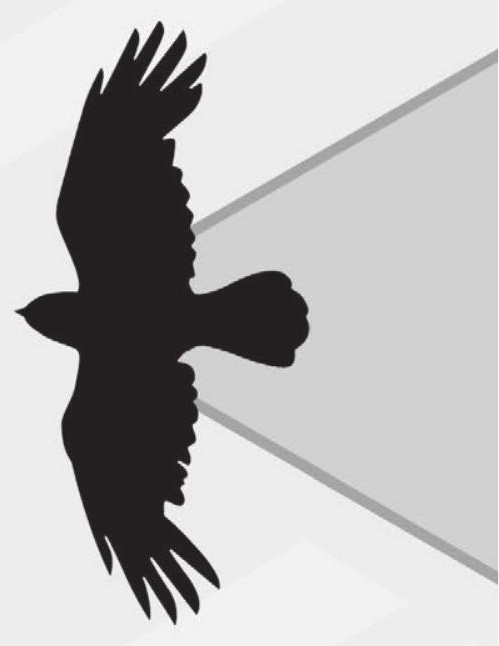




\section{Abstract}

Background The Netherlands is one of the frontrunners of eHealth in Europe. Many general practices offer Internet services, which can be used by patients to communicate with their general practice. In promoting and implementing such services, it is important to gain insight into patients' actual use and intention toward using.

Objective The objective of the study is to investigate the actual use and intention toward using Internet services to communicate with the general practice by the general practice population. The secondary objective is to study the factors and characteristics that influence their intention to use such services.

Methods There were 1500 members of the Dutch Health Care Consumer Panel, age over 18 years, that were invited to participate in this cross-sectional study. People who had contacted their general practitioner at least once in the past year were included. Participants were asked to fill out a questionnaire about the following services: Internet appointment planning, asking questions on the Internet, email reminders about appointments, Internet prescription refill requests, Internet access to medical data, and Internet video consultation. Participants indicated whether they had used these services in the past year, they would like to use them, and whether they thought their general practice had these services. For the first two services, participants rated items based on the unified theory of acceptance and use of technology complemented with additional constructs. These items were divided into six subscales: effort expectancy, performance expectancy, trust, attitude, facilitating conditions, and social influence.

Results There were 546 participants that were included in the analyses out of 593 who met the inclusion criteria. The participants had a mean age of 53 years (SD 15.4), 43.6\% $(n=238)$ were male, and $66.8 \%(n=365)$ had at least one chronic illness. Actual use of the services varied between $0 \%$ ( $n=0$, video consultation) and $10.4 \%$ ( $n=57$, requesting prescription refill by Internet). The proportion of participants with a positive intention to use the service varied between $14.7 \%$ ( $n=80$, video consultation) and $48.7 \%$ ( $n=266$, Internet access to medical data). For each service, approximately half indicated that they did not know whether the service was available. Univariate logistic regression analyses revealed that all the constructs as well as age, level of education, and Internet usage had a significant association with intention toward using Internet appointment planning and asking questions by Internet.

Conclusions Internet communication services to contact the general practice are not yet frequently used by this population. Although a substantial number of persons have a positive intention toward using such services, not all people who receive primary care seem willing to use them. The lack of awareness of the availability and functionality of such services might play an important role. 


\section{Introduction}

\section{Internet communication services for patients in primary care}

In primary care, there is a growing emphasis on Internet information and communication services (or eHealth) for providing patients with Internet access to the general practice and their medical data. Moving from "traditional care" toward eHealth is a key goal of the European Union. In the digital agenda for Europe, three specific actions are stated: widespread deployment of telemedicine, patients' access to their medical data, and interoperability. ${ }^{1}$ The Netherlands, Denmark, Sweden, Finland, and the United Kingdom are frontrunners in the field of eHealth in Europe. ${ }^{2}$ Of these frontrunners, the Netherlands leads in the percentage of households with an Internet connection and broadband connection. In addition, the Netherlands has the highest percentage of people who are regular Internet users and who use eGovernment services. ${ }^{2}$ A recently published eHealth monitor (a part of which provided the data for this study) describes the development and progress of eHealth in the Netherlands. ${ }^{3}$ It reported that 91\% of 304 surveyed general practitioners (GPs) offered one or more Internet services to their patients by which they could contact their GP or the general practice. The most frequently offered services were Internet prescription refill requests $(66 \%)$ and the ability to ask questions via email or websites (56\%). In addition, $14 \%$ of the GPs indicated that they offered services to plan appointments on the Internet and $25 \%$ indicated that they intended to implement this service within one year.

The implementation of Internet communication services in primary care is expected to have positive effects because these services can increase the efficiency of care, patient satisfaction, and quality of care. ${ }^{4-8}$ For instance, previous research has indicated that the use of an Internet messaging system or the use of email for communication in primary care practice can reduce the number of office visits (but not phone consultations), ${ }^{4}$ can improve the communication between health care providers and patients, ${ }^{5,7}$ and is assessed by patients as convenient, time saving, and useful. ${ }^{6}$

\section{Investigating internet services for patients}

Although these results are promising, previous research has shown that these services are not routinely used ${ }^{9}$ and not frequently accepted by patients. ${ }^{10}$ To predict patients' willingness to use a service, physical, psychological, and social factors, and the needs of patients, have to be understood. ${ }^{10}$ To improve future adoption, the actual use of Internet communication services and the factors that influence the intention to use such services should be investigated.

The technology acceptance model (TAM) ${ }^{11}$ is the most well-known and robust model for testing technology acceptance. The TAM model theorizes that beliefs about perceived ease of use and perceived usefulness are the main constructs predicting user 
intention. In recent years, this model has been extended and modified in a dozen studies. One of the extended TAM models is the unified theory of acceptance and use of technology (UTAUT). ${ }^{12}$ Besides ease of use (in this model called "effort expectancy") and perceived usefulness (called "performance expectancy"), two other key constructs are added in the UTAUT model: social influence and facilitating conditions. In addition, gender, age, experience, and voluntariness of use are included in this model as moderators that influence the key constructs on intention to use. The TAM and UTAUT models have been frequently applied in health care research. ${ }^{13}$ However, they are not often utilized to investigate patient acceptance of eHealth services. ${ }^{10}$ These TAMs are constantly evolving. Or and Karsh ${ }^{10}$ suggested in their review that, besides the before mentioned constructs, the influence of trust on patients' acceptance should be further explored, because trust is found to be a predictor of technology acceptance in research outside the field of health care. In addition, attitude is not a direct determinant in the original UTAUT model of Venkatesh. ${ }^{12}$ However, several studies suggest that there is a relation between attitude and intention, for example. ${ }^{14}$

The primary objective of this study is to investigate the actual use and intention toward using Internet services to communicate with the general practice by the general practice population. The secondary objective is to get insight into characteristics and factors that influence the intention to use such services by the general practice population. The goal of the study was not to develop and validate a new model to predict patients' intention to use Internet communication services. For the secondary objective, two services are specifically studied: making an appointment on the Internet (related to the Internet accessibility of the general practice) and asking a question via email or a website (related to gathering information about health content on the Internet). These services are relatively easy to access, but can have a major impact on daily care routines. The focus was on these two services because many general practices already offer them to their patients or intend to implement these services in the near future.

\section{Methods}

\section{Design and Participants}

There were 1500 participants of the Dutch Health Care Consumer Panel, ${ }^{15}$ aged over 18 years, who were invited to take part in this cross-sectional study. This panel was established by the Netherlands Institute for Health Services Research (NIVEL) and the Dutch Consumer Association. The sample was representative of the Dutch population in terms of age and gender based on data of Statistics Netherlands. ${ }^{16}$ People who contacted the GP at least once in the past year were included in this study. Questionnaires were used for data collection. The panel members could choose whether they wanted to receive a questionnaire by post or email. The questionnaires were issued in April 2013. 


\section{Measurements}

\section{Participant Characteristics}

The background characteristics of the members of the health care consumer panel had already been gathered using a questionnaire that was completed at the start of their membership. For this study, the following characteristics were used: gender, age, level of education, and whether they had none or at least one chronic disease. Furthermore, participants indicated whether they rated Internet use as easy or difficult on a 5-point Likert scale, ranging from 1 (very difficult) to 5 (very easy). In addition, they could indicate that they did not use the Internet.

\section{Use, Intention to Use, and Availability of Internet Services}

Participants were asked to fill out a questionnaire regarding the use of the following 6 Internet services to communicate with the general practice: (1) Internet appointment planning, (2) asking questions by Internet via email or a website, (3) email reminders about appointments, (4) Internet prescription refill requests, (5) Internet access to medical data, and (6) Internet video consultation. Participants were asked to indicate whether they had used these services in the past year. If they had not used the service in the past year, the participants were asked about their intention toward using the service (either positive or negative intention). They could also indicate that they did not know whether they would like to use the service. Furthermore, the participants indicated whether they thought these services were available at their general practice or not, or that they did not know whether this service was available.

\section{Factors Influencing Intention to Use Internet Services}

To study which factors influence the intention to use Internet appointment planning and the asking of questions by Internet via email or a website, participants rated items on a 4-point Likert scale, ranging from 1 (strongly disagree) to 4 (strongly agree). For these questions, the option of "don't know" was added. For both services, participants rated items that were divided according to the following 6 subscales: effort expectancy (2 items), trust (2 items), attitude (1 item), facilitating conditions ( 1 item), social influence ( 1 item), and performance expectancy (3 items). For the service of asking questions via email or a website, 2 items were added to the performance expectancy scale. The items regarding effort expectancy, facilitating conditions, social influence, and performance expectancy were mainly based on the validated UTAUT model, ${ }^{12}$ as well as on recommendations of studies by Or and Karsh (trust) ${ }^{10}$ and Spil and Schuring (attitude). ${ }^{14}$ First, the items of the 6 subscales were asked for Internet appointment planning, and, subsequently, for the service of asking questions by Internet. Participants' mean scores on each subscale were calculated. A list of all the items is presented in Appendix 1. 


\section{Statistical Analyses}

Descriptive analyses were conducted to study participant characteristics and to investigate participants' actual use, intention toward using, and awareness of availability regarding the six Internet services. Only participants who filled out all items regarding each of these were included in the analyses. The outcomes are expressed in percentages or in means and SDs.

Linear correlation analyses were conducted to identify multicollinearity in the six constructs of effort expectancy, trust, attitude, facilitating conditions, social influence, and performance expectancy for the two Internet services: Internet appointment planning and asking questions via email or a website. Items based on the UTAUT model, which were scored as "don't know," were analysed as missing data. In addition, variance inflation factors (VIFs) were calculated to assess multicollinearity. Correlation coefficients above 0.8 were considered high, and VIF values above $10^{17}$ were considered to be unacceptable. Therefore, constructs with a VIF value above 10 were left out of further analyses.

To test which characteristics and factors influence participants' intention toward using the 2 services, univariate logistic regression analyses were conducted. In these analyses, intention to use ( $1=$ users + nonusers with a positive intention, $0=$ nonusers with a negative intention) was the dependent variable. For each of the 2 services, 6 univariate logistic regression analyses were conducted with the mean scores of the following subscales as independent variables: effort expectancy, performance expectancy, trust, attitude, facilitating conditions, and social influence. In addition, 5 univariate logistic regression analyses were conducted with the following characteristics as independent variables: gender ( $1=$ male, $0=$ female), age $(1=\geq 65$ years, $0=<65$ years), chronic condition ( $1=$ at least one, $0=$ none), level of education (low, middle, and high), and Internet usage ( $1=$ easy and very easy, $0=$ nonuser, very difficult, difficult, and neutral). Outcomes were expressed in odds ratios (OR) and 95\% confidence intervals $(\mathrm{Cl})$. Bonferroni correction is applied to reduce the bias of multiple testing. All effects are reported at a $P=0.05$.

\section{Results}

\section{Participants}

Figure 1 shows a flowchart of the process of the inclusion of participants. Out of 1500 participants, 769 responded to the questionnaire $(63.3 \%, 487$ of these participants responded by Internet). Of these participants, 176 were excluded because they had not contacted their GP in the past year $(n=165)$ or did not respond to the question concerning GP visits $(n=11)$. Furthermore, participants were excluded from further analyses if they did not fill out all items regarding actual use, intention toward using, and awareness of availability of all 6 services $(n=47)$. This resulted in a total sample of 546 participants. Table 1 shows the characteristics of the study sample. 


\section{Use, Intention to Use, and Awareness of Availability of Internet Services}

Overall, the actual usage of Internet services to communicate with the general practice is low. Not one of the participants had an Internet video consultation with the GP in the past year, $0.4 \%$ (2/546) had Internet access to their medical data, 0.6\% (3/546) received email reminders about appointments, 2.2\% (12/546) planned an appointment by Internet, and $2.9 \%(16 / 546)$ asked a question via email or a website. Requesting a prescription refill by Internet was the most frequently used service (10.4\%, 57/546). Figure 2 shows an overview of the results.

Invited: $\mathrm{n}=1500$ (members of a Dutch health care consumer panel)

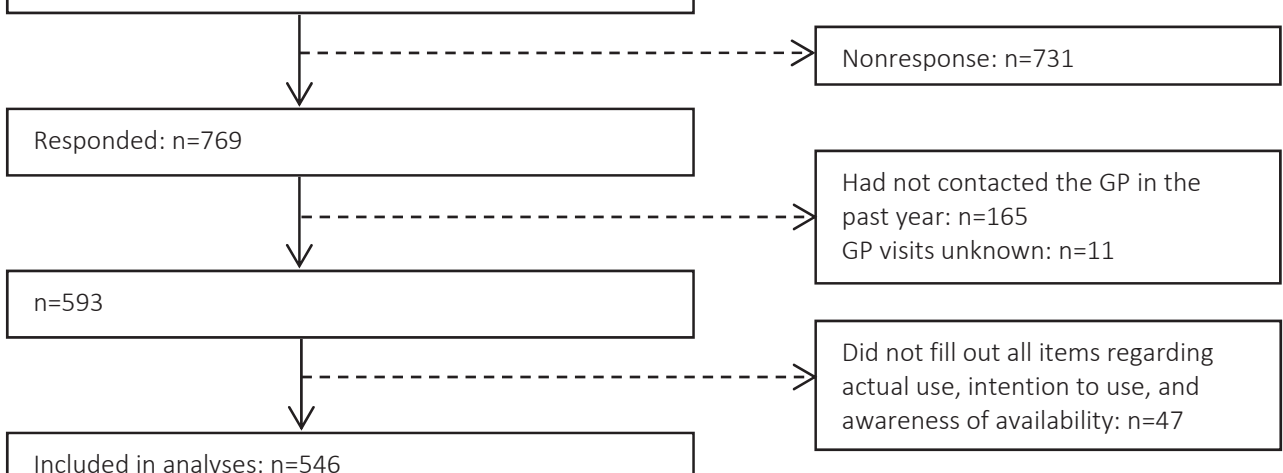

Figure 1 Flowchart of participants included in the study. GP: general practitioner

Table 1 Characteristics of the study sample $(n=546)$

\begin{tabular}{lll}
\hline Characteristics & & Mean (SD) or $n(\%)$ \\
\hline Age in years & Men & $53.14(15.4)$ \\
Gender & Women & $238(43.6 \%)$ \\
& Low & $308(56.4 \%)$ \\
\hline \multirow{2}{*}{ Level of education } & Medium & $69(12.6 \%)$ \\
& High & $306(56.0 \%)$ \\
& Unknown & $156(28.6 \%)$ \\
Chronic condition (self-reported) & None & $15(2.8 \%)$ \\
& At least one & $132(24.2 \%)$ \\
& Unknown & $365(66.8 \%)$ \\
Internet usage & No internet & $49(9.0 \%)$ \\
& (Very) difficult or neutral (score 1, 2, 3) & $35(6.4 \%)$ \\
& (Very) easy (score 4, 5) & $141(25.8 \%)$ \\
& Unknown & $352(64.5 \%)$ \\
Data collection & By post & $18(3.3 \%)$ \\
& Online & $189(34.6 \%)$ \\
& & $357(65.4 \%)$ \\
\hline
\end{tabular}




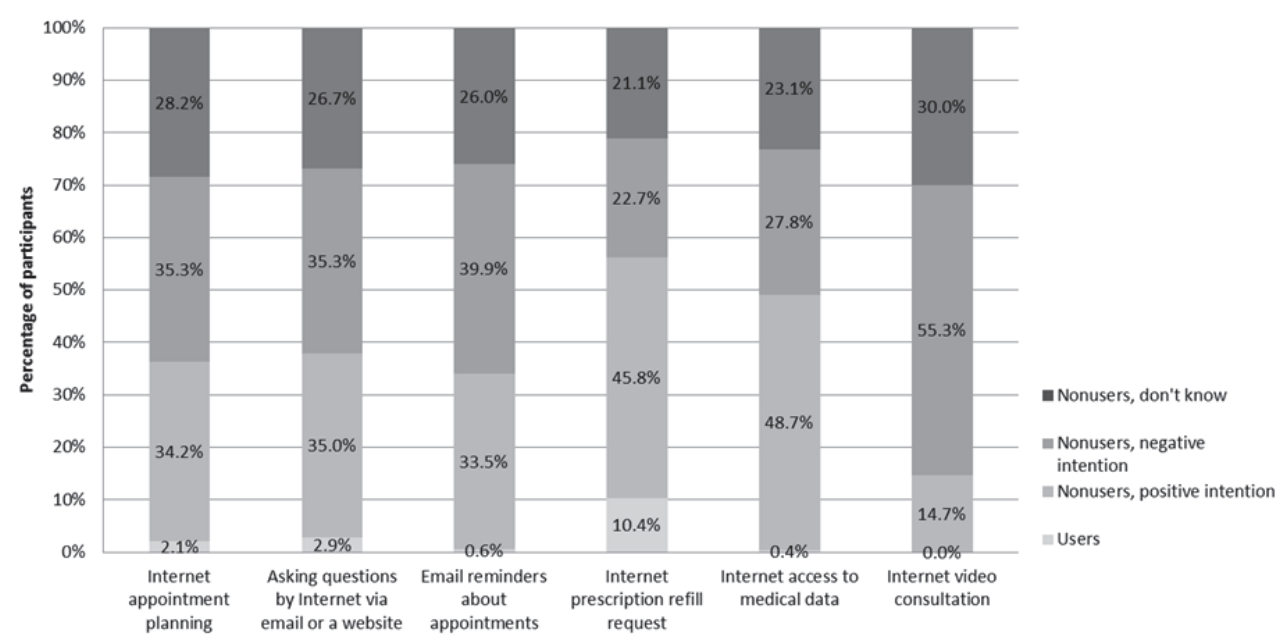

Figure 2 Percentage of participants who had used the Internet care service in the past year, and participants' intention toward the use of the Internet services.

Participants who had not used the Internet service in the past year could indicate whether they would like to use the service in the future. These results are also presented in Figure 2. The percentage of participants who had a positive intention toward Internet video consultation was 14.7\% (80/546). Approximately one third of the participants had a positive intention toward receiving email reminders about appointments (33.5\%, 183/546), Internet appointment planning (34.2\%, 187/546), and asking questions via email or a website $(35.0 \%, 191 / 546)$. The highest percentages of participants with a positive intention were found for Internet prescription refill requests $(45.8 \%, 250 / 546)$ and having access to medical data $(48.7 \%, 266 / 546)$. The percentage of participants with a negative intention varied between $22.7 \%$ (124/546, Internet prescription refill requests) and 55.3\% (302/546, Internet video consultation). For each service, more than one fifth of the participants responded that they did not know whether they would like to use the Internet service, ranging from 21.1\% (115/546, Internet prescription refill requests) to $30.0 \%$ (164/546, Internet video consultation).

Figure 3 shows the percentage of people who either knew or did not know whether each of the Internet services was available at their general practice. There were $1.3 \%$ (7/546) of the participants who responded that Internet video consultation was possible at their GP, and $20.7 \%$ (113/546) responded that requesting a prescription refill by Internet was possible. However, those who indicated that Internet services were not available at their general practice ranged from $31.7 \%(173 / 546)$ of the sample, who indicated that requesting prescription refills by Internet was not available, to $44.0 \%$ (240/546), who indicated that Internet video consultation was not available. In addition, for each Internet service, approximately half of the participants did not know whether the service was available at their primary care centre. 


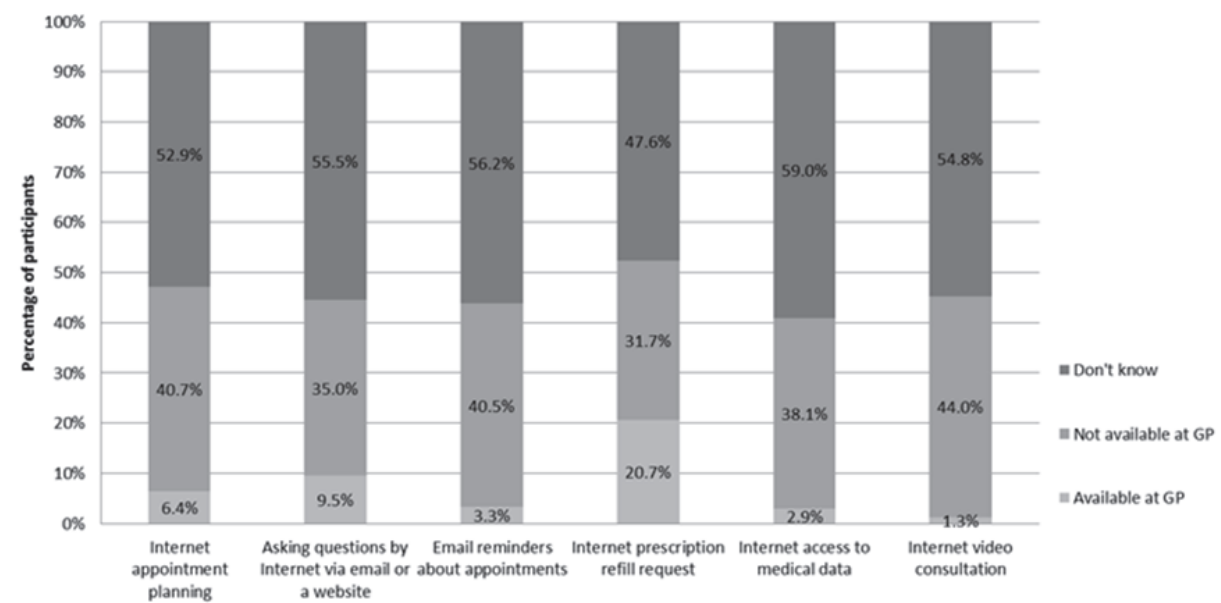

Figure 3 Participants' awareness of the availability of Internet care services at their primary care practice. GP: general practitioner.

\section{Associations between factors and intention to use Internet services}

Tables 2 and 3 show the correlation matrices of the constructs (effort expectancy, performance expectancy, trust, attitude, facilitating conditions, and social influence). The number of participants included in separate correlation analyses differs, due to many "don't know" responses to items. There were 115 participants who answered all the items $(n=10)$ regarding the constructs that can influence intention to use Internet appointment planning, without using the "don't know" option; 94 participants did this regarding asking questions by Internet via email or a website (12 items). The correlations between all constructs were statistically significant and higher than or equal to $r=.45$ $(P<.001)$ for both services. Of the correlation coefficients between the independent constructs that could influence Internet appointment planning, 6 correlation coefficients exceeded the value of .80 , which is considered to be high: trust was related to effort expectancy $(r=.82)$, attitude $(r=.81)$, and social influence $(r=.81)$; and attitude was related to facilitating conditions $(r=.85)$ and social influence $(r=.86)$. VIFs were calculated to identify the extent to which the constructs were interrelated. Not one of the VIF values exceeded the cutoff point of 10 , indicating that the assumption of multicollinearity was not violated. For constructs influencing the intention toward using a service to ask questions via email or website, 2 correlation coefficients were found which exceeded the value of .80: trust was related with effort expectancy $(r=.86)$ and facilitating conditions $(r=.85)$. In addition, the VIF value for trust was 12.92, which exceeds the cutoff point. Therefore, the construct trust was left out of the univariate logistic regression analysis. 
Table 2 Matrix of linear correlations and variance inflation factor values between the independent constructs that could influence intention to use Internet appointment planning

\begin{tabular}{|c|c|c|c|c|c|c|}
\hline & $\mathrm{EE}$ & $\mathrm{PE}$ & TR & AT & $\mathrm{FC}$ & VIF value \\
\hline 1. Effort expectancy (EE) & & & & & & 7.25 \\
\hline 2. Performance expectancy (PE) & $\begin{array}{l}.45 \\
n=314\end{array}$ & & & & & 1.75 \\
\hline 3. Trust (TR) & $\begin{array}{l}.82 \\
n=263\end{array}$ & $\begin{array}{l}.56 \\
n=259\end{array}$ & & & & 7.08 \\
\hline 4. Attitude (AT) & $\begin{array}{l}.71 \\
n=283\end{array}$ & $\begin{array}{l}.61 \\
n=312\end{array}$ & $\begin{array}{l}.81 \\
n=249\end{array}$ & & & 8.84 \\
\hline 5. Facilitating conditions (FC) & $\begin{array}{l}.73 \\
n=314\end{array}$ & $\begin{array}{l}.53 \\
n=347\end{array}$ & $\begin{array}{l}.75 \\
n=261\end{array}$ & $\begin{array}{l}.85 \\
n=308\end{array}$ & & 4.56 \\
\hline 6. Social influence (SI) & $\begin{array}{l}.78 \\
n=162\end{array}$ & $\begin{array}{l}.63 \\
n=186\end{array}$ & $\begin{array}{l}.81 \\
n=154\end{array}$ & $\begin{array}{l}.86 \\
n=167\end{array}$ & $\begin{array}{l}.80 \\
n=176\end{array}$ & 4.05 \\
\hline
\end{tabular}

All results are found to be significant at the P<.01 level. EE: effort expectancy, PE: performance expectancy, TR: trust, AT: attitude, FC: facilitating conditions, SI: social influence, VIF: variance inflation factor

Table 3 Matrix of linear correlations and variance inflation factor values between the independent constructs that could influence intention to ask questions by Internet via email or a website

\begin{tabular}{|c|c|c|c|c|c|c|}
\hline & $\mathrm{EE}$ & $\mathrm{PE}$ & TR & AT & FC & VIF value \\
\hline 1. Effort expectancy (EE) & & & & & & 7.35 \\
\hline 2. Performance expectancy (PE) & $\begin{array}{l}.56 \\
n=307\end{array}$ & & & & & 2.93 \\
\hline 3. Trust (TR) & $\begin{array}{l}.86 \\
n=244\end{array}$ & $\begin{array}{l}.63 \\
n=247\end{array}$ & & & & 12.92 \\
\hline 4. Attitude (AT) & $\begin{array}{l}.60 \\
n=259\end{array}$ & $\begin{array}{l}.69 \\
n=307\end{array}$ & $\begin{array}{l}.77 \\
n=221\end{array}$ & & & 4.42 \\
\hline 5. Facilitating conditions (FC) & $\begin{array}{l}.79 \\
n=287\end{array}$ & $\begin{array}{l}.64 \\
n=319\end{array}$ & $\begin{array}{l}.85 \\
n=237\end{array}$ & $\begin{array}{l}.70 \\
n=279\end{array}$ & & 6.98 \\
\hline 6. Social influence (SI) & $\begin{array}{l}.73 \\
n=142\end{array}$ & $\begin{array}{l}.76 \\
n=158\end{array}$ & $\begin{array}{l}.80 \\
n=132\end{array}$ & $\begin{array}{l}.78 \\
n=144\end{array}$ & $\begin{array}{l}.74 \\
n=142\end{array}$ & 4.65 \\
\hline
\end{tabular}

All results are found to be significant at the $P<.01$ level. EE: effort expectancy, PE: performance expectancy, TR: trust, AT: attitude, FC: facilitating conditions, SI: social influence, VIF: variance inflation factor

Table 4 shows the results of the univariate logistic regression analyses. All constructs (effort expectancy, performance expectancy, trust, attitude, facilitating conditions, and social influence) had a significant association with intention to use Internet appointment planning and asking questions via email or a website. For Internet appointment planning, the ORs varied between $3.28(95 \% \mathrm{Cl} 2.21-4.86)$ for effort expectancy and $8.51(95 \% \mathrm{Cl}$ 5.15-8.51) for attitude. For asking questions via email or a website, the ORs varied between 5.46 (95\% Cl 4.34-7.86) for social influence and 7.91 (95\% Cl 4.53-13.82) for facilitating conditions.

Looking into characteristics of participants, age, level of education, and Internet usage had a significant association with intention to use Internet appointment planning and asking questions via email or a website. The ORs for age were $0.172(95 \% \mathrm{Cl} 0.10$ 0.29 ) and 0.14 (95\% $\mathrm{Cl} 0.084-0.24)$, respectively. The ORs for level of education were 2.53 (95\% Cl 1.78-3.60) and 2.24 (95\% Cl 1.58-3.17), respectively. ORs for Internet usage were $7.98(95 \% \mathrm{Cl} 4.74-13.44)$ and 7.97 (95\% Cl 4.97-13.23), respectively. 
Table 4 Univariate association of constructs and characteristics with intention toward using Internet appointment planning and asking questions by Internet via email or a website. All constructs and characteristics had a significant association with intention to use both services, except for gender and chronic condition

\begin{tabular}{|c|c|c|c|c|}
\hline \multirow[t]{2}{*}{ Independent variable } & \multicolumn{2}{|c|}{$\begin{array}{l}\text { Dependent variable: intention to use } \\
\text { online appointment planning }\end{array}$} & \multicolumn{2}{|c|}{$\begin{array}{l}\text { Dependent variable: intention to use a } \\
\text { service to ask questions online (via e- } \\
\text { mail or a website) }\end{array}$} \\
\hline & $n$ & OR $(95 \% \mathrm{CI})$ & $n$ & OR $(95 \% \mathrm{Cl})$ \\
\hline Perceived ease of use & 264 & $3.28(2.21-4.86)$ & 252 & $5.46(3.27-9.13)$ \\
\hline Perceived usefulness & 301 & $3.98(2.58-6.14)$ & 284 & $5.47(3.44-8.70)$ \\
\hline Trust & 226 & $5.16(3.21-8.15)$ & - & - \\
\hline Attitude & 263 & 8.51 (5.15-14.07) & 238 & $5.85(3.63-9.43)$ \\
\hline Facilitating conditions & 283 & $5.32(3.51-8.08)$ & 254 & $7.91(4.53-13.82)$ \\
\hline Social influence & 150 & $4.80(2.83-8.16)$ & 119 & $4.34(2.46-7.68)$ \\
\hline Gender & 392 & $0.90(.06-1.33)$ & 400 & $0.92(.62-1.37)$ \\
\hline Age & 392 & $0.172(.10-.29)$ & 400 & $0.14(.084-.24)$ \\
\hline Level of education & 380 & $2.53(1.78-3.60)$ & 387 & $2.24(1.58-3.17)$ \\
\hline Chronic condition & 357 & $0.79(.49-1,26)$ & 361 & $0.71(.44-1.14)$ \\
\hline Internet usage & 381 & $7.98(4.74-13.44)$ & 389 & 7.97 (4.97-13.23) \\
\hline
\end{tabular}

\section{Discussion}

\section{Principal results and comparison with previous work}

This study indicates that Internet communication services used for contacting the general practice by the general practice population are not yet frequently used in the Netherlands. Of the participants who had not used the service in the previous year, the percentage of participants with a positive intention toward using a service varied between approximately 15\% (Internet video consultation) and approximately 50\% (having access to medical data). Many participants were not aware of the availability of such services at their general practice, as approximately half of the participants did not know whether such a service was available at their primary care centre. Possible factors and characteristics that influence intention to use Internet communication services were investigated in this study. Univariate logistic regression analyses revealed that the following constructs had a significant influence on intention to use Internet appointment planning and asking questions via email or a website: effort expectancy, performance expectancy, trust, attitude, facilitating conditions, social influence, the characteristics of age, level of education, and Internet usage. However, many participants responded with "don't know" to items regarding intention. In addition, high correlations are found between the constructs. This indicates that the Dutch population has no strong view regarding the use and possibilities of Internet services for communicating with the general practice.

In this study, it is found that the use of the Internet to communicate with the general practice is still low. This is in line with findings of previous research., ${ }^{9}, 20$ 
Although the actual use of such Internet services is low, the Internet is frequently used for health purposes in Europe. ${ }^{18}$ It is even the main source of health-related information for the Dutch population. ${ }^{21}$ Access to the Internet and the availability of Internet communication services are the key preconditions for successful uptake and usage of Internet services. These conditions seem to be promising in the Netherlands: $94 \%$ of households have access to the Internet at home, and 55\% of people between 65 and 75 years of age access the Internet almost every day. ${ }^{16}$ In addition, more than $90 \%$ of GPs offer Internet communication services to their patients. ${ }^{3}$ One of the reasons that the actual use of these services is not as high as expected might be that the general practice population is not aware of the availability of the Internet services offered by their primary care practice. In this study, less than $20.7 \%$ (113/546) of participants indicated that an Internet service was available at their general practice. Moreover, at least $47.6 \%$ $(260 / 546)$ of the study sample did not know if an Internet service was available at their primary care practice. This is in contrast with the high number of primary care practices that offer such services. ${ }^{3}$ Our study confirms the findings of previous research, which has concluded that often patients do not know about the existence of eHealth applications or they are not aware of the possibilities of the applications. ${ }^{22}$ Moreover, Mair et al. $^{23}$ concluded in their review of factors that promote or inhibit the implementation of eHealth services that specifying the purposes, benefits, and values of eHealth services to users during the implementation (the "sense-making" process) is not well covered in previous studies. The fact that the general practice population is not well informed about the availability and possibilities of Internet services might explain the high number of "don't know" responses in our study.

Effort expectancy, performance expectancy, trust, attitude, facilitating conditions, and social influence are found to be constructs that influence the intention to use Internet communication services by the general practice population. However, in looking into the relationships between the independent constructs in this study, moderate to high correlations were found. Although the assumption of multicollinearity is only violated for 1 variable (trust), it should be questioned whether these subscales measure different constructs. Although the UTAUT model is frequently applied in health research, ${ }^{13}$ it is not yet frequently used to investigate patients' intention toward using Internet services in health care. ${ }^{10}$ In the few studies that have applied (a modified version of) this model to predict patient acceptance of Internet services that support self-management, high correlations between the independent constructs were either not reported ${ }^{24,25}$ or not found. ${ }^{26}$ Furthermore, in studies that have applied the UTAUT model to examine health care professionals' acceptance of eHealth services, low to moderate correlations between constructs have been found, for example. ${ }^{27,28}$ It might be the case that Internet services for communicating with the general practice is not a major issue in Dutch society and therefore participants had no strong opinion about these services. Further research is recommended to investigate whether the UTAUT 
model is applicable for the investigation of intention to use Internet communication services by the general practice population.

The influence of patient characteristics on intention to use eHealth services is well studied. ${ }^{10}$ In this study, an older age, lower level of education, and the rating of Internet usage as difficult, is associated with a negative intention. This is in line with most, but not all, previous research which is studied in the review by Or and Karsh. ${ }^{10}$ Some researchers argue that the negative association between age and information and communication technology (ICT) usage will disappear within a few years as the older generation become more familiar with using it; however, a recent study by Heart and Kalderon ${ }^{29}$ found that although there is an increase in ICT adoption among older people, they are not yet ready to adopt health-related ICT. In their study, "no need" to use ICT was found to be the most prevalent reason for nonuse, and therefore, it is suggested that health care providers should clearly demonstrate the benefits of Internet services to their customers. In this study, no association between gender and intention to use Internet communication services in primary care was found, which corroborates most previous studies. ${ }^{10}$ Having no, or at least one, chronic condition was not associated with intention to use. The effect of patient health status on the use of eHealth services has yielded mixed results in previous research: ${ }^{10}$ some studies have found no association between these constructs, for example, ${ }^{30}$ whereas others have found increased acceptance in people with a better, for example, ${ }^{31}$ or a poorer health status, for example. $^{32,33}$ Furthermore, Heart and Kalderon ${ }^{29}$ found that health status moderated the effect of age on use. In this study, participants could indicate their chronic conditions using a questionnaire. However, having one or more chronic condition(s) does not automatically result in different health-seeking behaviours. The number of general practice visits might indicate this better. Future research is recommended to investigate whether this has an influence on intention to use Internet communication services in primary care.

\section{Strengths and Limitations}

A strength of this study is that it aimed to investigate the actual use and intention to use Internet communication services, which are currently being implemented in primary care practices. A high number of participants $(n=546)$ between 18 and 83 years of age participated in this study. However, this was not a representative sample of the actual Dutch patient population, which visits the GP at least once a year. ${ }^{34}$ There was an underrepresentation of elderly people, which could have led to an overestimation of the intention to use Internet services, because age is found to be associated with intention to use.

Another limitation of this study is that participants who actually used an Internet service were not asked whether they had a positive or negative intention toward using the service in the future. However, because they should have had a positive intention 
toward using it in the past, these participants were analysed as having a positive intention. In addition, the true availability of the Internet communication services was not investigated in this study. While the overall percentage of primary care practices that offer such services is known, it is not known whether these services were also available for participants of this study.

The main content of the questionnaire to investigate intention to use the service of Internet appointment planning and asking questions by Internet is based on the validated UTAUT model. ${ }^{12}$ The subscales of trust and attitude are not validated. However, the goal of the secondary objective was not to develop a new validated model that predicts patients' intention to use Internet care services. In addition, it is not claimed that the included factors are the only predictors of intention to use Internet care services. The goal was to get insight into possible predictors of intention to use Internet communication services by the general practice population by applying suggested predictors found in literature.

Participants could choose to receive the questionnaire on paper or via the Internet. The use of a mixed data collection methodology could be seen as a limitation of this study. However, based on previous research, it is not expected that this significantly influenced the results. ${ }^{35,36}$ In addition, by giving the participants the choice to fill out the questionnaire on paper or via the Internet, a broader study sample was covered.

No multivariate logistic regression analyses could be performed, due to too many "don't know" responses to items that could influence intention to use Internet communication services in primary care, which were analysed as missing data. Therefore, it could not be indicated which of the studied constructs has the strongest association with intention to use. Moreover, due to the fact that "don't know" responses were analysed as missing data, the studied sample only consists of people who actually had an opinion (positive or negative) about the Internet communication services. This could have led to a misrepresentation of the sample. An alternative option for dealing with missing data due to "don't know" responses is to impute the mean score of a subscale to the missing value of that subscale. However, this method could not be applied because 3 subscales consisted of 1 item and many participants filled out "don't know" to all items in 1 subscale. Another option is imputing a neutral response (score 2.5) for missing data. Although the authors believe that this is not the same as "don't know," repeating the univariate analyses with this response option did not change the results. In addition, the high number of "don't know" responses to the items suggests that people have difficulties in evaluating their expectations of the use of Internet communication services in primary care. By giving them the option of "don't know," they were not forced to choose between agree and disagree, resulting in a more reliable set of responses. 


\section{Conclusion}

This study has found that Internet communication services to contact the general practice are not yet frequently used by the general practice population. Many participants indicated that they did not know whether such a service was available at their primary care centre. In addition, although a substantial number of people had a positive intention toward using such services, the entire general practice population did not seem willing to use them. Informing the general practice population about the availability and possibility of such services during their implementation might be important for stimulating the uptake and usage of Internet communication services in primary care.

\section{Acknowledgments}

The data of this study were gathered as part of the Dutch National eHealth Monitor, conducted by The National ICT Institute for Healthcare and NIVEL, and funded by the Dutch Ministry of Health, Welfare, and Sport. 


\section{References}

1. European Commission. Digital Agenda for Europe: A Europe 2020 Initiative. Brussels, Belgium: European Commission; 2014. URL: http://ec.europa.eu/digital-agenda/en [accessed 2015-10-09].

2. Currie WL, Seddon JJ. A cross-national analysis of eHealth in the European Union: Some policy and research directions. Infor Manage. 2014;51(6):783-797.

3. Krijgsman J, de Bie JD, Burghouts A, de Jong JD, Cath G, van Gennip LV. eHealth, verder dan je denkt: eHealth monitor 2013. 2013. http://www.nictiz.nl/page/Publicaties/eHealth-monitor [accessed 2015-0105].

4. Bergmo TS, Kummervold PE, Gammon D, Dahl LB. Electronic patient-provider communication: Will it offset office visits and telephone consultations in primary care? Int J Med Inform. 2005;74(9):705-710.

5. McGeady D, Kujala J, Ilvonen K. The impact of patient-physician web messaging on healthcare service provision. Int J Med Inform. 2008;77(1):17-23.

6. Wallwiener M, Wallwiener CW, Kansy JK, Seeger H, Rajab TK. Impact of electronic messaging on the patient-physician interaction. J Telemed Telecare. 2009;15(5):243-250.

7. Ye J, Rust G, Fry-Johnson Y, Strothers H. E-mail in patient-provider communication: A systematic review. Patient Educ Couns. 2010;80(2):266-273.

8. Chaudhry B, Wang J, Wu S, Maglione M, Mojica W, Roth E, et al. Systematic review: Impact of health information technology on quality, efficiency, and costs of medical care. Ann Intern Med. 2006;144(10):742-752

9. Santana S, Lausen B, Bujnowska-Fedak M, Chronaki C, Kummervold PE, Rasmussen J, et al. Online communication between doctors and patients in Europe: Status and perspectives. J Med Internet Res. 2010;12(2):e20.

10. Or Calvin K L, Karsh B. A systematic review of patient acceptance of consumer health information technology. J Am Med Inform Assoc. 2009;16(4):550-560.

11. Davis FD. A Technology Acceptance Model for Empirically Testing New End-User Information Systems: Theory and Results [PhD dissertation]. Cambridge, MA: Massachusetts Institute of Technology; 1985.

12. Venkatesh V, Morris M, Davis GB, Davis FD. User acceptance of information technology: Toward a unified view. MIS Q. 2003;27(3):425-478.

13. Holden RJ, Karsh BT. The technology acceptance model: Its past and its future in health care. J Biomed Inform 2010;43(1):159-172.

14. Spil TAM, Schuring RW. E-health Systems Diffusion and Use: The innovation, the User and the Use it Model. 1st Edition. London, UK: Idea Group Publishing; 2006.

15. Brabers AEM, van Dijk M, Reitsma-van Rooijen M, de Jong JD. Consumentenpanel Gezondheidszorg: Basisrapport Met Informatie over Het Panel. 2014. URL: http://www.nivel.nl/node/2430?database=Choice Publicat\&priref=1002474 [accessed 2015-01-04]

16. Statistics Netherlands (CBS). 2014. URL: http://www.cbs.nl/nl-NL/menu/home/default.htm [accessed 2015-01-05].

17. Myers R. Classical and Modern Regression with Applications (Duxbury Classic). Pacific Grove, CA: Duxbury Press; 1990.

18. Andreassen HK, Bujnowska-Fedak MM, Chronaki CE, Dumitru RC, Pudule I, Santana S, et al. European citizens' use of E-health services: A study of seven countries. BMC Public Health. 2007;7:53.

19. de LS, Ross P, Shifrin M, Hercigonja-Szekeres M, Seroussi B. A comparison of approaches to providing patients access to summary care records across old and new europe: An exploration of facilitators and barriers to implementation. Stud Health Technol Inform 2013;192:397-401.

20. Peeters J, Wiegers T, de Bie J, Friele R. Nog een Wereld te Winnen!. 2013. NIVEL Overzichtstudies: Technologie in de zorg thuis URL: http://www.nivel.nl/sites/default/files/bestanden/Rapport-Technologiein-de-zorg-thuis.pdf [accessed 2015-01-05].

21. Van de Belt TH, Engelen LJ, Berben AA, Teerenstra S, Samsom M, Schoonhoven L. Internet and social media for health-related information and communication in health care: Preferences of the Dutch general population. J Med Internet Res. 2013;15(10):e220. 
22. Alpay LL, Henkemans OB, Otten W, Rövekamp TA, Dumay AC. E-health applications and services for patient empowerment: Directions for best practices in The Netherlands. Telemed J E Health. 2010;16(7):787-791.

23. Mair FS, May C, O'Donnell C, Finch T, Sullivan F, Murray E. Factors that promote or inhibit the implementation of e-health systems: An explanatory systematic review. Bull World Health Organ. 2012;90(5):357-364.

24. Or CK, Karsh BT, Severtson DJ, Burke LJ, Brown RL, Brennan PF. Factors affecting home care patients acceptance of a web-based interactive self-management technology. I Am Med Inform Assoc. 2011;18(1):51-59.

25. Lee J, Rho MJ. Perception of influencing factors on acceptance of mobile health monitoring service: A comparison between users and non-users. Healthc Inform Res. 2013;19(3):167-176

26. Rho MJ, Kim HS, Chung K, Choi IY. Factors influencing the acceptance of telemedicine for diabetes management. Cluster Comput. 2014;18(1):321-331.

27. Wills M, El-Gayar O, Bennett D. Issues in Information Systems. 2008. Examining healthcare professionals' acceptance of electronic medical records using UTAUT URL: http://iacis.org/iis/2008/S2008_1053.pdf [accessed 2015-10-20].

28. Kijsanayotin B, Pannarunothai S, Speedie SM. Factors influencing health information technology adoption in Thailand's community health centers: Applying the UTAUT model. Int J Med Inform. 2009;78(6):404416.

29. Heart T, Kalderon E. Older adults: Are they ready to adopt health-related ICT? Int J Med Inform 2013;82(11):e209-e231.

30. Wilson EV, Lankton NK. Modeling patients' acceptance of provider-delivered e-health. J Am Med Inform Assoc .2004;11(4):241-248.

31. Chae YM, Park HJ, Cho JG, Hong GD, Cheon KA. The reliability and acceptability of telemedicine for patients with schizophrenia in Korea. J Telemed Telecare. 2000;6(2):83-90.

32. Millard RW, Fintak PA. Use of the Internet by patients with chronic illness. Dis Manage Health Out. 2002;10(3):187-194.

33. Houston TK, Allison JJ. Users of Internet health information: Differences by health status. J Med Internet Res. 2002;4(2):e7.

34. Zwaanswijk M, Ursum J, Spronk I, Stirbu I. Gebruik van Huisartsenzorg in de Nederlandse Bevolking. Utrecht, The Netherlands: NIVEL Zorgregistraties eerste lijn; 2013. URL:http://www.nivel.nl/NZR/overzichtstabel [accessed 2015-01-05].

35. Fouladi RT, Mccarthy CJ, Moller NP. Paper-and-pencil or online?: Evaluating mode effects on measures of emotional functioning and attachment. Assessment. 2002;9(2):204-215.

36. Riva G, Teruzzi T, Anolli L. The use of the internet in psychological research: Comparison of online and offline questionnaires. Cyberpsychol Behav. 2003;6(1):73-80. 


\section{CHAPTER 2}

Appedix 1 Items related to the constructs that influence intention to use Internet services

Items related to the constructs that influence intention to use Internet services, rated on a four-point Likert scale ranging from 1 (strongly disagree) to 4 (strongly agree).

Making an Internet appointment / asking a question by Internet via email or a website is:

Effort expectancy

1. Easy to use

2. Easy to learn

Trust

3. Is reliable

4. Works properly

Attitude

5. Is a pleasant way

Facilitating conditions

6. Is easy to combine with my daily activities

Social influence

7. Is something that my family / friends would like to use

Performance expectancy

8. Ensures that I can make an appointment / ask a questions more easily

9. Ensures that I can make an appointment / ask a question more often

10. Ensures that I can decide myself if an appointment is necessary ${ }^{a}$

11. Ensures that I can easily ask questions about a given answer ${ }^{b}$

12. Ensures that I can properly think about a question I would like to ask ${ }^{b}$

13. Ensures that I get more personal attention from my GP

${ }^{a}$ Only asked for the service of Internet appointment planning

${ }^{b}$ Only asked for the service of asking questions by Internet via email or a website 


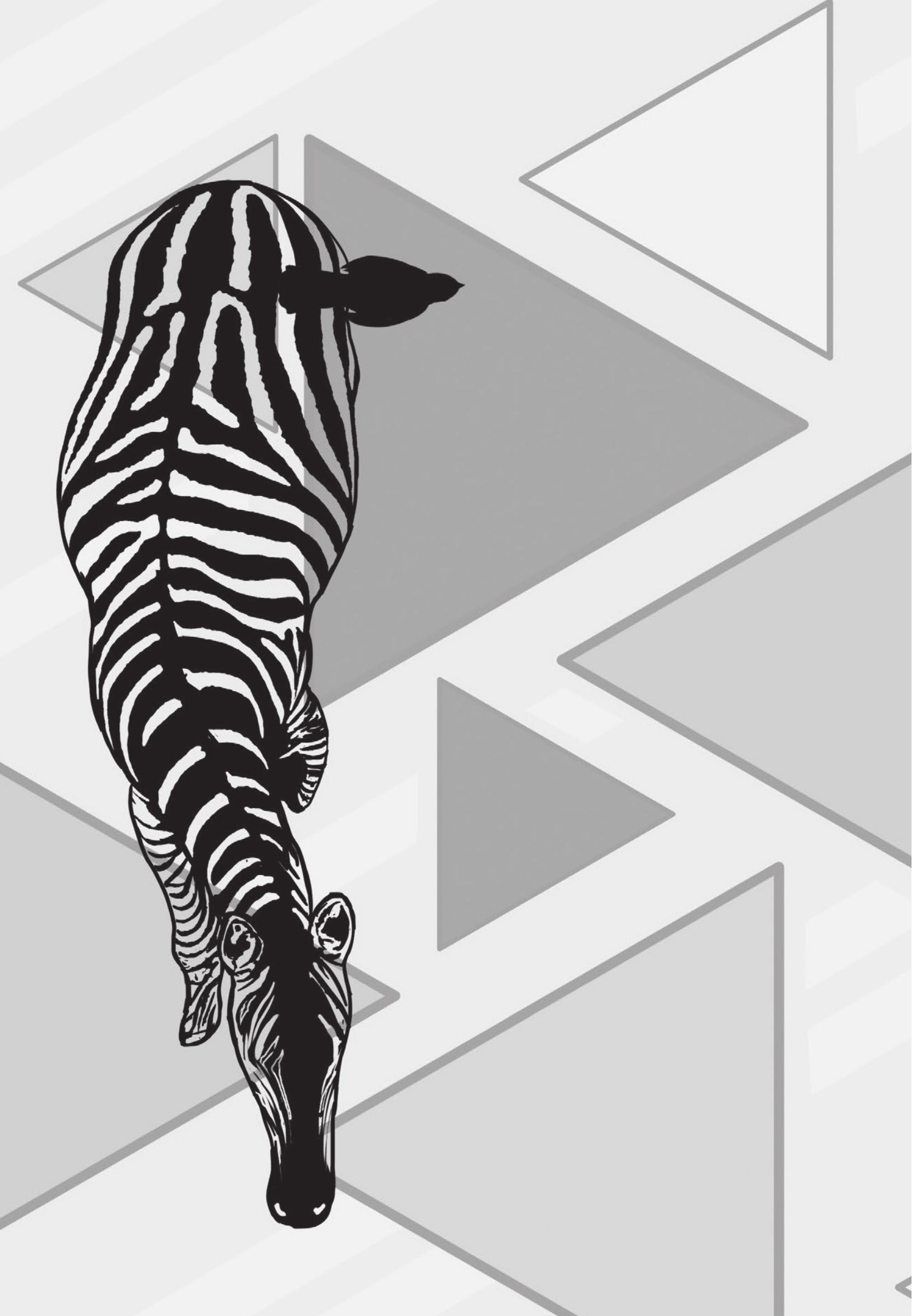




\section{CHAPTER 3}

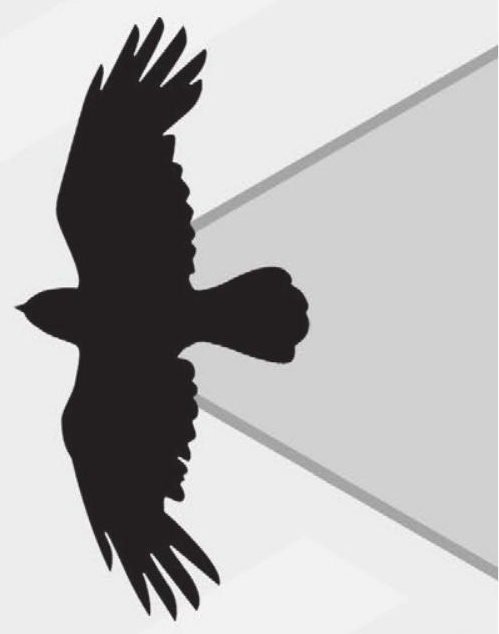

Expectations and needs of patients with a chronic disease toward self-management and eHealth for self-management purposes

This chapter was published as:

Huygens MWJ, Vermeulen J, Swinkels ICS, Friele RD, van Schayck OCP, and de Witte LP. Expectations and needs of patients with a chronic disease toward self-management and eHealth for self-management purposes. BMC Health Serv Res. 2016;16:232 


\section{Abstract}

Background Self-management is considered as an essential component of chronic care by primary care professionals. eHealth is expected to play an important role in supporting patients in their self-management. For effective implementation of eHealth it is important to investigate patients' expectations and needs regarding self-management and eHealth. The objectives of this study are to investigate expectations and needs of people with a chronic condition regarding self-management and eHealth for selfmanagement purposes, their willingness to use eHealth, and possible differences between patient groups regarding these topics.

Methods Five focus groups with people with diabetes $(n=14), \operatorname{COPD}(n=9)$, and a cardiovascular condition $(n=7)$ were conducted in this qualitative research. Separate focus groups were organized based on patients' chronic condition. The following themes were discussed: 1) the impact of the chronic disease on patients' daily life; 2) their opinions and needs regarding self-management; and 3) their expectations and needs regarding, and willingness to use, eHealth for self-management purposes. A conventional content analysis approach was used for coding.

Results Patient groups seem to differ in expectations and needs regarding selfmanagement and eHealth for self-management purposes. People with diabetes reported most needs and benefits regarding self-management and were most willing to use eHealth, followed by the COPD group. People with a cardiovascular condition mentioned having fewer needs for self-management support, because their disease had little impact on their life. In all patient groups it was reported that the patient, not the care professional, should choose whether or not to use eHealth. Moreover, participants reported that eHealth should not replace, but complement personal care. Many participants reported expecting feelings of anxiety by doing measurement themselves and uncertainty about follow-up of deviant data of measurements. In addition, many participants worried about the implementation of eHealth being a consequence of budget cuts in care.

Conclusion This study suggests that aspects of eHealth, and the way in which it should be implemented, should be tailored to the patient. Patients' expected benefits of using eHealth to support self-management and their perceived controllability over their disease seem to play an important role in patients' willingness to use eHealth for selfmanagement purposes. 


\section{Introduction}

Self-management is considered as an essential component of chronic care by primary care professionals. People with a chronic disease, such as diabetes, chronic obstructive pulmonary disease (COPD) or a cardiovascular condition, have to make day-to-day decisions to manage their own disease. Self-management requires an active role of the patient in managing one's symptoms, treatment, physical and psychosocial consequences and lifestyle changes. ${ }^{1}$ For example, patients make decisions about medication intake, participation in sports and daily activities and about other lifestyle behaviour, such as adhering to a special diet or giving up smoking. In addition, they have to deal with emotions such as anger, frustration, and depression, which are often inherent to living with a chronic disease. Patients who engage in optimal self-management behaviour improve their quality of life and health outcomes. ${ }^{1-3}$

Performing optimal self-management behaviour is difficult and demands a substantial effort from the patient. Previous research has shown that patients with a chronic condition perceive many barriers to engaging in active self-management, ${ }^{4}$ such as controlling weight, exercising regularly, fatigue, pain, depression, lack of family support and poor communication with physicians.

eHealth technologies that patients can use at home are expected to play an important role in supporting patients in their self-management. eHealth is a broad term which includes a diverse range of technical innovations in health-care. Eysenbach defined it as 'an emerging field in the intersection of medical informatics, public health and business, referring to health services and information delivered or enhanced through the internet and related technologies .... ${ }^{5}$ However, this should be considered with caution, because he also argues that it is very difficult to set up a clear definition of eHealth because of its dynamic environment; 'stamping a definition on something like eHealth is somewhat like stamping a definition on 'the Internet': It is defined how it is used - the definition cannot be pinned down, as it is a dynamic environment, constantly moving, ${ }^{.5}$

A diverse range of eHealth technologies are aimed to support patients in their selfmanagement. For example, e-coaching and activity monitoring applications can support and inform patients regarding diet, exercise and weight control by providing insight into self-monitored data, tailored information and feedback, and encouragement. ${ }^{6}$ In addition, e-coaching applications can assist patients with depression and anxiety ${ }^{7}$ and electronic communication enables patients to communicate effectively with their health-care professionals., ${ }^{8,9}$ Moreover, home telemonitoring applications for people with a chronic condition can produce accurate and reliable data, empower patients, influence their attitudes and behaviours and potentially improve their medical conditions. ${ }^{10}$ Although expectations of the use of eHealth are positive, Peeters et al. ${ }^{11}$ conclude that up until now there is not enough convincing evidence that care technologies have a positive effect on patient self-management. 
In addition, often eHealth is not being adopted successfully in daily care routines. ${ }^{12}$ One of the reasons for this is the non-use of eHealth by patients. Reported arguments for non-use and withdrawal by patients are the lack of perceived additional benefits of eHealth, the view that the regular health care is sufficient, ${ }^{13,14}$ technological difficulties with the equipment and the association of eHealth with a high degree of dependency and ill health. ${ }^{14}$

Another problem is that eHealth is often not tailored to individual patients. ${ }^{12}$ Before implementing new eHealth technologies it is important to take into account how individuals currently manage their disease and the ways they adapt to their chronic condition. Van Houtum et al. ${ }^{15}$ found in a quantitative study that self-management tasks are partly disease-specific and partly generic. People with diabetes or a neurological disease perceive more daily self-management tasks compared with people with another chronic condition such as COPD or a cardiovascular disease. Understanding the fit between everyday routines and eHealth is an essential part for a successful uptake and use. $^{12}$

Before eHealth can be effectively implemented and used, it is important to involve patients in investigating their needs and requirements regarding the use of eHealth. User-centred design (UCD) is a frequently used method to involve patients during the design and development of eHealth. ${ }^{16,17}$ Most studies have used UCD to improve the functionality and usability of an eHealth technology. However, less effort has been put into the step before design and eHealth development. In what aspects of selfmanagement do people with a chronic condition need additional support, and if they need support, are they actually willing to use eHealth?

The aims of the current study are to investigate the expectations, opinions and needs of people with a chronic disease regarding aspects of self-management in which they prefer additional support, and toward eHealth for self-management purposes. In addition, the aim is to investigate patients' willingness to use such kinds of eHealth technologies. To investigate possible differences between patient groups, patients with 1) COPD, 2) diabetes and 3) a cardiovascular condition were included. These patient groups are included because they belong to the main chronic disease types worldwide, ${ }^{18}$ care standards for these diseases are developed in the Netherlands (see Appendix 1) and these groups might benefit from eHealth for self-management purposes.

\section{Methods}

\section{Recruitment and design}

People with diabetes, COPD, and a cardiovascular condition were invited to participate in a focus group. They were recruited in four primary care centres in the Netherlands by their care professional. Inclusion criteria were: patients had to be aged over 18 and 
diagnosed with COPD, diabetes or a cardiovascular disease. Exclusion criteria were: severe psychiatric illness or cognitive impairment, or an insufficient mastery of the Dutch language leading to not understanding the information about the study. People who were interested received an information letter, informed consent form and a questionnaire. The questionnaire was used to collect some background information of the participants and consisted of three short questions: 'What kind of chronic diseases do you have?'; 'Have you already used care technology (for example searching for information about your disease on the Internet, using an online coach or using a selfmonitoring system)?'; and 'How easy or difficult do you find using the Internet?'.

Focus groups were planned when at least six participants with the same chronic condition agreed to participate. The goal was to organize two focus group interviews for each chronic condition. A researcher $(\mathrm{MH})$ or a care professional contacted the participants to schedule a date and time for the focus group. After the recruitment of people with diabetes in one primary care centre, only four individuals agreed to participate. Therefore, three individuals with diabetes who were under treatment in another primary care practice were invited by the researcher to participate in that group. All participants provided written informed consent and filled out the questionnaire. The study was approved by the Medical Ethical Committee Atrium Orbis Zuyd (METC number: 14-N-86).

Five focus groups were conducted between October 2014 and May 2015. Each focus group took place in the primary care centres where the participants were recruited.

\section{Procedure}

All focus groups were moderated by $\mathrm{MH}$ and an assistant moderator (JV or a research assistant). After an introduction about the goal and procedure, the following themes were discussed: 1) the impact of the chronic disease on patients' daily life; 2) their opinions and needs regarding self-management; and 3) their expectations and needs regarding, and willingness to use, eHealth for self-management purposes. With regard to this last theme, three different types of eHealth applications were discussed: 1) self-monitoring tools in which patients can monitor their own health data and share these with their health-care professionals via the Internet; 2) online coaches in which patients can get advice about their disease or lifestyle; and 3) online communication applications, such as online video consultation or email-consultation. By discussing this theme, participants were first asked whether they had ever used technologies or the Internet for health purposes and what they knew about the possibilities of other eHealth technologies. The different eHealth technologies that participants came up with were discussed. The moderator added other possibilities of eHealth technologies to make sure that the three different types of eHealth technologies were similarly discussed in every focus group.

The moderator's role was to briefly introduce the themes, to encourage participants to share their thoughts and to ask follow-up questions for clarifying opinions. 
Each focus group lasted approximately two hours, was audiotape recorded, and the assistant moderator collected written field notes.

\section{Data analysis}

All focus groups discussions were transcribed verbatim by a research assistant. Afterwards, $\mathrm{MH}$ checked the transcripts against the audio recordings. First, two researchers ( $\mathrm{MH}$ and $\mathrm{JV}$ ) independently analysed one transcript of a diabetes, COPD and cardiovascular group. Because of the exploratory nature of the focus group set-up, a conventional content analysis approach ${ }^{19}$ was used for coding. The researchers checked for consensus of the different codes in the three transcripts. $\mathrm{MH}$ used this coding scheme for the remaining two transcripts. New codes were added when necessary. Then, $\mathrm{MH}$ and $\mathrm{JV}$ clustered the codes and agreed on the main- and sub-themes of the coding scheme. The transcripts were coded using NVivo version 9.

\section{Results}

\section{Participants}

A total of 30 participants with a mean age of 68 years (range $50-83$ ) took part in the focus groups. Of these, $73 \%$ were male. Two focus groups were conducted with people with diabetes ( $n=7$ and $n=7)$, two with people with COPD ( $n=4$ and $n=5)$ and one with people with a cardiovascular condition $(n=7)$. Four individuals with COPD did not show up (one with a given reason). Table 1 presents an overview of the characteristics of the participants.

Participants with COPD mentioned that they visited the practice nurse or general practitioner (GP) one to two times a year. Most of them had a mild to moderate severity of COPD. One participant suffered from COPD GOLD (Global Initiative on Obstructive Lung Disease) stage IV, which means a very severe COPD. This participant visited the pulmonologist four times a year (P4). Four participants reported that they had been under treatment by a physiotherapist (P1, P2, P6 and P8). All participants reported that they used oral medication one or two times a day in forms of pills and/or inhalers. One participant had once had an email-consultation (P6). The others had never used an eHealth technology.

Participants with diabetes reported that they visited the practice nurse or GP two to four times a year. Five participants injected insulin (P2, P3, P4, P8 and P9), eight participants took only oral drugs, and one participant did not use medication (P1). Four participants had had email contact with their care professional (P3, P4, P7, and P8). One participant used a diabetes manager application to get overviews of blood glucose values, which could be sent to his practice nurse, and a medication reminder application 
(P3). One participant had used an online diabetes coach whereby he could insert his blood glucose values to get advice (P8). Two participants used a food diary application (P13 and P14).

Participants with a cardiovascular condition reported that they visited the practice nurse or GP one to four times a year. Most of them reported having an annual check with the GP. Three participants mentioned that they visited the cardiologist once a year (P1, P3 and P6). Four participants reported having high blood pressure and a high level of cholesterol (P1, P2, P3 and P7), one participant also had a heart rhythm disorder and had received cardioversion (P3). Three participants had a stent placed and/or had received angioplasty (P4, P5 and P6), of whom one had suffered a heart attack (P5). All participants used oral medication. One participant had had email contact with a care professional (P3). None of the others had used an eHealth technology.

\section{Themes}

Based on the analyses, four main themes are identified: 1) opinions and needs regarding self-management support; 2) general requirements regarding eHealth usage; 3) general requirements regarding the implementation of eHealth; and 4) costs and budget cuts in care. Table 2 presents an overview of all main- and sub-themes.

Table 1 Characteristics of the study sample

\begin{tabular}{|c|c|c|}
\hline Characteristics & & Mean (range) or $n(\%)$ \\
\hline \multirow{3}{*}{ Age in years } & People with diabetes & $67.1(51-79)$ \\
\hline & People with COPD & $60.3(50-81)$ \\
\hline & $\begin{array}{l}\text { People with a cardiovascular } \\
\text { disease or CVRM }\end{array}$ & $72.1(55-83)$ \\
\hline \multirow{3}{*}{$\begin{array}{l}\text { Gender: number and percentage } \\
\text { of males }\end{array}$} & People with diabetes & $11(78.6 \%)$ \\
\hline & People with COPD & $6(66.7 \%)$ \\
\hline & $\begin{array}{l}\text { People with a cardiovascular } \\
\text { disease or CVRM }\end{array}$ & $5(71.4 \%)$ \\
\hline \multirow[t]{15}{*}{ Internet usage } & People with diabetes & \\
\hline & Did not use the Internet & - \\
\hline & Very difficult or difficult & $2(14.3 \%)$ \\
\hline & Neutral & - \\
\hline & Easy or very easy & $12(85.7 \%)$ \\
\hline & People with COPD & \\
\hline & Did not use the Internet & $1(11.1 \%)$ \\
\hline & Very difficult or difficult & - \\
\hline & Neutral & $5(55.6 \%)$ \\
\hline & Easy or very easy & $3(33.3 \%)$ \\
\hline & $\begin{array}{l}\text { People with a cardiovascular } \\
\text { disease or CVRM }\end{array}$ & \\
\hline & Did not use the Internet & $1(14.3 \%)$ \\
\hline & Very difficult or difficult & $1(14.3 \%)$ \\
\hline & Neutral & - \\
\hline & Easy or very easy & $5(71.4 \%)$ \\
\hline
\end{tabular}

$C O P D=$ chronic obstructive pulmonary disease, $C V R M=$ cardiovascular risk management . 
Table 2 An overview of the identified main- and sub-themes with the associated topics

\begin{tabular}{|c|c|c|}
\hline Main theme & Sub-themes & Topics \\
\hline \multirow[t]{7}{*}{$\begin{array}{l}\text { Opinions and needs } \\
\text { regarding self- } \\
\text { management support }\end{array}$} & Information & $\begin{array}{l}\text { - Need for information (treatment, } \\
\text { complications, medication and life style) } \\
\text { - Sources of information }\end{array}$ \\
\hline & Drug management support & $\begin{array}{l}\text { - Need for drug management support } \\
\text { - Determining whether medication is } \\
\text { necessary } \\
\text { - Forgetting to take medication }\end{array}$ \\
\hline & Symptom management support & $\begin{array}{l}\text { - Need for symptom management } \\
\text { support } \\
\text { - Need for self-monitoring support } \\
\text { - Insight into health status }\end{array}$ \\
\hline & $\begin{array}{l}\text { Support for management of } \\
\text { psychological consequences }\end{array}$ & $\begin{array}{l}\text { - Anxiety regarding further complications } \\
\text { - Disease acceptance } \\
\text { - Anxiety regarding self-monitoring }\end{array}$ \\
\hline & Lifestyle & $\begin{array}{l}\text { - Sports } \\
\text { - Nutrition and diet } \\
\text { - Smoking } \\
\text { - Motivation for lifestyle changes }\end{array}$ \\
\hline & Social support & - Using support of family and relatives \\
\hline & Communication & $\begin{array}{l}\text { - Current communication with care } \\
\text { professionals } \\
\text { - Opinions regarding online } \\
\text { communication } \\
\text { - Need for (online) communication }\end{array}$ \\
\hline $\begin{array}{l}\text { General requirements } \\
\text { regarding eHealth usage }\end{array}$ & $\begin{array}{l}\text { - Usability } \\
\text { - Reliability of technology } \\
\text { - Trust in the Internet } \\
\text { - Unable to use the Internet }\end{array}$ & \\
\hline $\begin{array}{l}\text { General requirements } \\
\text { regarding the } \\
\text { implementation of } \\
\text { eHealth }\end{array}$ & $\begin{array}{l}\text { - eHealth should support care } \\
\text { - Using eHealth should be the choice } \\
\text { of the patient } \\
\text { - Clear instruction should be given }\end{array}$ & \\
\hline $\begin{array}{l}\text { Costs and budget cuts in } \\
\text { care }\end{array}$ & $\begin{array}{l}\text { - Current costs in care } \\
\text { - Costs of eHealth } \\
\text { - Budget cuts in care }\end{array}$ & \\
\hline
\end{tabular}

\section{Opinions, expectations and needs regarding self-management support}

Information In general, the majority of participants mentioned that at the moment they had no need for more information about their disease. Most information was gathered from care professionals, and many participants reported that they gathered information on the Internet and in brochures. Many participants responded that there is sufficient information available, especially on the Internet; it is down to the patient to search for it and to decide what to do with the information. Most people agreed that the patient, not the care professional, is most responsible for their health.

'We [practice nurse and patient] discuss together what seems to be the best, and I feel comfortable with that. But of course I look on the Internet, and of course I read brochures and books, and of course I listen to what they [care professionals] say. 
Nevertheless, I try to use my own sense and think: well, it is my body. So that's the combination I'm looking for. I feel comfortable with that.' Diabetes, P6

'There is no lack of information; you can gather information everywhere, from the Internet, for example. But what we need is a little bit of discipline. Yes, I don't have It myself, but I know I need it.' Diabetes, P11

A few participants with diabetes or a cardiovascular disease mentioned that they wished they had been better informed about the risks and consequences of their disease when it was diagnosed, so they could have been more aware of the consequences of their lifestyle at that time, and thus further complaints could have been prevented.

Several participants in all patient groups mentioned getting anxious from the information they find online. Particularly when reading information about complications that could occur in a later stage of their disease.

Drug management Differences are found in experiences and needs regarding drug management between patient groups.

The majority of participants mentioned that taking medication is a daily routine now, although they reported that they frequently forgot to take their medication during the first period of their disease. However, participants with mild complaints of COPD reported that they still frequently forget to take their medication, because they do not feel that it has any effect on their condition. Because of this, some just decided to stop using the medication. Others have discussed it with their carer.

One participant with diabetes used a medication management application on his mobile phone, which reminded him to take medication. He mentioned that due to this application, having diabetes was no issue for him. Several others in all patient groups liked the idea of using a medication management application. Some already used a pillbox to manage their medication.

Drug management played an important role in the life of people with diabetes. Most participants who inject insulin measured their blood glucose level daily. People with a stable blood glucose level for a long period of time, or people who used oral medication, only monitored their blood glucose level at moments when feeling not well. Participants who measured their blood glucose level discussed these values during regular consultations with the GP or practice nurse. Participants who frequently measured their blood glucose level often consulted the practice nurse in between consultations by email or phone to check whether the level of insulin intake needed changing. These people responded that they had a need for an application that automatically sends their blood glucose data to their practice nurse, so he or she could respond to it. In this way, participants mentioned, insulin intake could be adapted sooner to their actual health status. Customized or individual care was a frequently mentioned benefit of sending selfmeasured data and receiving feedback on this. 
'If you can monitor automatically, you get customized care more quickly. Currently, you're going to the care practice four times a year, and in the period in between you stay at the same value [of insulin], while you maybe should have changed it in the meantime, but you didn't know that.' Diabetes, P8

One participant with diabetes had used an online diabetes coach whereby he could insert his blood glucose values to get advice. Although he mentioned that this could be really useful, especially for people who are just starting to use insulin injections, or when blood glucose values highly fluctuate, he did not use it anymore because it was not working properly.

The general view of people with a cardiovascular condition about medication intake was that they just did it, because it was advised by their care professional.

Symptom management Expectations and needs regarding symptom management differed between patient groups.

Participants with COPD had mixed opinions regarding monitoring lung function or saturation at home and getting more insight into their health status. Some mentioned that they are interested in using self-monitoring tools at home to check how it is going and to investigate declines to prevent further complaints. These participants liked the idea that care professionals also have insight into these data, so they can advise them whether they should go to a consultation. In contrast, others mentioned that they did not perceive any benefits in monitoring lung data at home. They commented that they could feel if there was something wrong and at such moments they could immediately make an appointment with their GP or practice nurse.

'You can probably detect your complaints a little earlier and prevent getting such pulmonary constrictions. I think prevention is an important advantage.' COPD, P6

'At a certain moment you know your own body so well, you know your lungs, you know your breathing, you know your sputum, so you just know at a certain moment that it's going in the wrong direction. Then, you just call the care professional, and he or she takes immediate action, so why should I do all of this at home?' COPD, P4

Most people with diabetes who inject insulin monitored their blood glucose level regularly, made overviews of these data and sent it by email to their practice nurse. One participant used a diabetes manager application that tracked his blood glucose values in logbooks and showed him overviews of these data, which could be sent to his practice nurse. He found this application very useful. Many participants suggested that the option of automatically sending data of every measurement to the care practice would be useful because the care professional then has up-to-date data and can respond to it when there are deviations in that data. Most participants with diabetes mentioned the 
benefits of tracking and sending blood glucose values to their practice nurse. The most frequently reported benefits were: preventing further complaints, getting advice on whether a consultation was needed, and doing more at home instead of going to consultations in the care practice.

'By taking measurements every day and sending them to the care practice, for Mister $X$ [a person who has a stable blood glucose level for years] no alarm bells will ring, but for me they probably will, if it [the blood glucose level] is low and then high again, and when I'm dizzy, then the practice nurse could say, hey, that's not going well. She could notice that at her computer screen in the morning, so she doesn't have to read all those emails.' Diabetes, P13

The majority of participants with a cardiovascular condition reported that the disease had little impact on their daily life and that they had few complaints. Most of them commented that they perceived no benefits in measuring symptoms at home. The regular health checks at the practice nurse or GP were sufficient for them. One participant mentioned that he did not have the feeling of being a patient. By measuring blood data at home he would be more aware of his condition, which he perceived as a negative feeling.

Management of psychological consequences Mixed opinions are found regarding the management of psychological consequences in all patient groups. Some participants with COPD and diabetes mentioned having had a panic attack due to severe health complaints of their chronic disease (e.g. hypoglycaemia and exacerbation attacks). In particular, attacks during the first period of their disease were accompanied with high feelings of anxiety, because they did not know what to do.

Several participants with COPD and diabetes reported being anxious about further complications of their disease. Participants with COPD in particular mentioned that they had experienced a decline in energy levels. Some participants with COPD or diabetes mentioned knowing from relatives, acquaintances or the Internet what could happen in the next stage of their disease (e.g. insulin injections, supplemental oxygen intake or death) and were wondering how their condition would further develop in the upcoming years.

'You also become mentally tired of it - knowing that you have a disease, that disease will never disappear - but where will this end? This disease stays on your mind. More than you actually want.' COPD, P6

In addition, a few participants with COPD and diabetes blamed themselves for having the chronic disease because of an unhealthy lifestyle. Participants with a cardiovascular condition were least concerned about their chronic condition. 
Talking about self-monitoring applications, participants with COPD and a cardiovascular condition reported that they would expect to feel increased feelings of anxiety due to monitoring health data at home. Anxiousness because of doing the measurements themselves, and not knowing what to do with deviant data were frequently mentioned as expected negative consequences of self-monitoring at home. In addition, many participants in all patient groups reported the disadvantage of frequently being reminded of having a chronic condition.

'It will also cause disturbance, when you have to do all of this at home [monitoring]. Imagine doing that in the evening at 10 o'clock and then you feeling unwell, what should you do? Then you have to wait the entire night, because there will be nobody here [in the primary care practice]. I really don't like that idea.' COPD, P3

'The disadvantage is that I'm feeling more like a patient [because of frequently monitoring]: man suffers most from the suffering he fears.' Cardiovascular condition, P7

Lifestyle The types of lifestyle behaviour that were most frequently discussed differed between patient groups. Furthermore, the role that a healthy lifestyle played in participants' lives differed among patient groups.

Exercising and giving up smoking were frequently discussed lifestyle behaviours among participants with COPD. Although most of them were aware that this is important for their health, some had difficulties in keeping this up.

Nutrition and diet were most discussed by participants with diabetes. They mentioned that nutrition immediately affected their blood glucose level and thus their health status. A few of them were treated by a dietician. Two participants used an online food diary application which effectively helped them to choose what to eat.

Participants with a cardiovascular condition mentioned the importance of a healthy lifestyle, but this played a less important role in their daily life compared with participants with diabetes and COPD.

Many participants in all patient groups reported that enough sources are available to raise awareness of how to live a healthy life. Advice is gathered from care professionals, brochures or the Internet. Many of them had no interest in using an online coach to motivate and stimulate them to change their lifestyle, such as an online coach to help give up smoking or a food diary application. Intrinsic motivation to give up smoking, lose weight or do more physical exercises was seen as most important.

Several participants in all patient groups reported that when they were diagnosed they had been warned that they should change their lifestyle to prevent further complications. However, at that time they were less aware of the risks and consequences, and therefore they did not change. They mentioned that it is really 
important that care professionals create awareness of the risks and consequences of the chronic disease.

'She [the practice nurse] mentioned that it is bad for the organs if you eat sugar and that sort of things, and that's it... And then you just continue your life, and then you get a pill... Then the pressure is not that high. But eventually you have to use insulin, and yes, that could be prevented, I think, if that awareness happened earlier.' Diabetes, P8

Social support Using the help and knowledge of relatives was frequently reported by participants in all patient groups. Some participants had family members with a medical background or the same chronic disease who advised them. Others had family members who reminded them to take their medication, or searched for them on the Internet for information about their chronic disease. In addition, several persons mentioned that they contacted their children or grandchildren when they needed help with technical problems with computers or the Internet.

On the other hand, a few participants with COPD and diabetes mentioned that they did not want to show others that they have a chronic disease, and were afraid of scaring people by using a self-monitoring application. In addition, some people with COPD had difficulties in explaining to family members that they have limited energy to do activities due to their COPD. Many participants in all patient groups expected that support from relatives and family members would become more important because of cuts in care.

Communication Many participants in all patient groups mentioned that they have found the regular number of practice visits convenient. In particular, communicating with the practice nurse was perceived as agreeable. In between the regular consultations, there was always the possibility of calling or emailing the practice nurse or GP, and if necessary to visit the care practice within short notice.

Only a few people had experiences with online communication with care professionals. Participants with diabetes most frequently reported that they had email contact with the practice nurse about their self-measured blood glucose level. They had found this convenient.

Many participants reported that they expected having an e-consultation (asking a question via email or an online program) would be very impersonal and cold, because of the lack of eye contact and interaction. They also questioned within what time span they would receive answers. In addition, they mentioned that it would be difficult to describe their complaints and fears by typing. An online video consultation using a webcam was expected to be more convenient compared with an e-consultation, because of the direct contact with the care professional. However, many participants mentioned that when they urgently need a care professional, they would prefer visiting him or her in real life. 
Several participants added that the 'older generation' is just not used to communicating over the Internet.

I think I find it more pleasant to have eye contact with the care professional, so when I ask a question I can see their face, and what he or she thinks of it... . And I also think, will I get an answer immediately or in two days?' COPD, P4

Reported needs for (online) communication were that communication should be direct, understandable, tailored to the patient, and conducted by a human, not by a preprogramed application.

\section{General requirements regarding eHealth usage}

Many participants in all patient groups responded that eHealth should be easy to use, and should require as few actions as possible, in particular for older people who are not familiar with the Internet or modern technologies. In addition, self-monitoring tools should be easy to carry. Moreover, eHealth should be reliable and function properly. The unreliability of home blood pressure meters and non-functioning websites were mentioned as bad examples.

A well-discussed topic in all patient groups was trust in the Internet. Most participants reported having no problems with sending and sharing data over the Internet. Many participants talked about the advantages of a national electronic health record (which has not yet been introduced in the Netherlands). However, in every patient group a few people did not trust the Internet because of previous experiences or rumours in the media about data leakage. In addition, some worried that non-medical people would get access to their health data, such as insurance companies and managers.

'Yes I'm using the Internet and so on, but I don't use it for everything that is personal... I don't trust it. Maybe I'm old-fashioned, but I don't trust it. Sometimes I read in the newspaper that DigiD [digital identity for Dutch governmental websites] is already unsafe.' Diabetes, P12

'When I have to go to the night care clinic, or when I have an accident, it's totally fine that they [care professionals] have access to my medical data. But what I don't want is that my health and safety officer gets insight to see my medical data, and tells everything to my manager' COPD, P4

Moreover, a few participants mentioned that they were not able to use computers or the Internet, or are not interested in using it. Others referred to friends or family members of a similar age who did not have the right skills or interests. 


\section{General requirements regarding the implementation of eHealth}

The general view about the implementation of eHealth was that it should not be compulsory: the patient should be allowed to choose whether or not to use it. Some participants mentioned being afraid that patients will be forced to use care over the Internet, and compared it with online banking and the Dutch tax authority's website (in the Netherlands an extra amount has to be paid for not banking online, and the standard procedure for arranging tax returns is via the Internet). In addition, participants reported that patients who use eHealth should also be given the opportunity to receive regular, and in particular personal care; eHealth should support care, but not replace personal care.

'It should be nuanced and individualized: those who are able to do it, and like it, yes okay, but if someone is not yet ready for it, or doesn't like it, give them the opportunity to fill it in in a different way.' Cardiovascular condition, P1

Several participants mentioned that because of the rapid development of modern technology, the implementation of eHealth cannot be stopped. Some were concerned about this, while others liked the idea of implementing innovations in health care.

'We are moving in that direction anyway, whether we like it or not... 10 or 15 years ago we did not even know what a bank card was, and now it's very common, now we pay by card at the cash register. And that's also how it will go with care technology, I'm convinced about that. And if we don't follow that trend we've got it wrong.' Diabetes, P7

If eHealth is to be introduced and offered, participants preferred that the care professional would clearly show how it can be used. Furthermore, clear instructions should be given via digital or written manuals or via YouTube videos.

\section{Costs and budget cuts in care}

Costs and budget cuts in care were frequently mentioned topics in all focus groups. Many participants complained that nowadays health-care costs are higher compared with several years ago. They expected that costs would continue to rise in the coming years because of budget cuts in care. Several participants mentioned that they expected that costs would increase because of the implementation of eHealth. Several participants expected that health insurance companies would decide what kind of eHealth patients should use, like they do now in the choice of medication because of deals between pharmaceutical companies and insurance companies. Others reported that they had heard that eHealth has been developed because of budget cuts in care and because of its cost-effectiveness. 
'In whose interest is it to develop these technologies and innovative things anyway? It's the result of less money and fewer doctors.' Cardiovascular condition, P1

\section{Discussion}

\section{Principal results}

This qualitative research showed indications of differences between patient groups in their expectations and needs regarding self-management and eHealth for selfmanagement purposes. In general, people with diabetes reported the most needs and benefits regarding self-management aspects and were most willing to use eHealth, followed by the COPD group. In contrast, people with a cardiovascular condition mentioned having fewer needs for self-management support because their chronic condition had little impact on their daily life. Each patient group reported similar general requirements for eHealth. In addition, it was reported that the patient, not the care professional, should choose whether or not to use eHealth. Moreover, participants reported that eHealth should support care and not replace personal care.

All self-management constructs identified in Barlow et al. ${ }^{1}$ were identified in the current study as sub-themes regarding self-management. In general, more opinions were investigated regarding information, drug management, symptom management, communication and lifestyle than regarding management of psychological consequences and social support. Participants might have been less open to share their personal experiences and needs regarding disease acceptance and emotional consequences inherent to living with a chronic condition. In addition, the main focus of the Dutch approach to self-management, as in many other European countries, is on medical and behavioural management, and less on helping patients in dealing with emotional consequences. ${ }^{20}$ Participants were therefore maybe less focused on these topics when talking about their experiences of dealing with their chronic disease.

The differences between people with COPD, diabetes and a cardiovascular condition in expectations and needs regarding self-management and eHealth might be related to differences in treatment, symptoms and degree of manageability among the disease types. Many people with diabetes were already familiar with self-monitoring applications for measuring blood glucose level. In addition, people with diabetes reported that nutrition, weight loss (to achieve a normal weight) and medication directly influenced their health. Therefore, they might perceive that their disease is more controllable by their own behaviour, which could influence their interests in eHealth for selfmanagement purposes. In contrast, people with a cardiovascular condition mentioned having few complaints and reported that their disease had little impact on their daily life. Therefore, many people commented that they perceived no need for eHealth for selfmanagement purposes. People with COPD had mixed opinions regarding self- 
management support. Although psychological consequences of the chronic illness were less discussed, people with COPD more frequently mentioned that their health status had declined during the past years, and were wondering how their disease would further develop in the upcoming years. This might indicate the feeling of having less control over their disease, which could limit the added value of using eHealth for self-management support.

Patients' expected benefits of using eHealth to support self-management might be the most important predictor of patients' willingness to use such kind of eHealth. The factor 'perceived usefulness' is included in widely used technology acceptance models. ${ }^{21,22}$ Based on this study, it can be suggested that the perceived benefits should outweigh the negative consequence of frequently having to take action to deal with the disease, which reminds patients about having a chronic condition. In addition, it seems that when patients already function in (social) systems that provide them sufficient knowledge and support, they will be less interested to use an eHealth technology for these purposes. In this research this was meanly found for social support and lifestyle. It can be argued that, in the case the (social) system is insufficient or radically changing, patients' perceived benefits and likewise their interests in eHealth might improve.

Moreover, it is indicated that different patient groups have different needs regarding additional self-management support. Therefore, patients' perceived benefits could increase when eHealth is tailored to the patient group. In addition, previous research has found that people with COPD who had no experience with eHealth had no clear ideas about the advantages. ${ }^{23}$ Therefore, it should be important to clearly inform patients about the possible benefits of using eHealth when introducing it.

Moreover, patients' interest in self-management support might be dependent on the controllability patients believe to have over their disease. The concept of health controllability, better known as health locus of control, is found to be a factor that influences health-related behaviour. ${ }^{24,25}$ Some studies suggest that patients with a high internal locus of control may be more attracted to self-management interventions. ${ }^{26,27}$ Future research should be performed to investigate the relation between patients' believed controllability over their disease and their willingness to use self-management support technologies.

Many participants reported that they expected feelings of anxiety by taking measurements themselves, or because of not knowing what to do with deviant data of those measurements. Therefore, it is recommended that health-care professionals should clearly inform and show patients how to use eHealth and inform them how to interpret the results. In addition, many participants associated the implementation of eHealth with budget cuts in care, and some expected that its use would be imposed by health insurance companies. Giving patients the choice of whether or not to use it, and clearly informing them about the reasons for its implementation will be important. In addition, independent sources, such as patient associations and health-care organizations, could play an important role in informing and stimulating patients to use 
eHealth. However, even when these recommendations are taken into consideration, it is important to keep in mind that not all patients are willing to use eHealth. Several participants mentioned that they did not want to use the Internet for health purposes, that they are not able to use eHealth, or that they are just not interested in using it.

\section{Strengths and limitation}

In previous studies, the expectations and needs of patients regarding the use of eHealth to support self-management have been frequently investigated for specific applications. The strength of this study is its focus on self-management and eHealth in general; people with a chronic condition could express their own ideas, needs and interests. In addition, by using a qualitative methodology participants were not forced to value their needs from fixed options, but they could respond and explain their needs using their own words and ideas. ${ }^{28}$ Moreover, a strength of this study is that people with the same chronic condition participated in one focus group, resulting in in-depth discussions in which disease-specific needs could be investigated.

A limitation of this study is that only one focus group with people with a cardiovascular condition was conducted. Some care professionals were not able to recruit enough participants with this condition, or preferred to organize a focus group with people with diabetes or COPD. Another limitation is the high percentage of males who participated in this study. One reason might be that the word 'care technology' had a deterrent effect on female patients that were invited. In addition, lower reported Internet skills were found in the COPD group compared with the other two groups. Although most of these participants were still familiar with the Internet, this could have influenced the results concerning willingness to use eHealth, since it is found that the degree of computer and Internet skills has an influence on technology acceptance. ${ }^{29}$

\section{Conclusion}

Differences are found in expectations and needs between different patient groups regarding self-management and eHealth for self-management purposes, suggesting that eHealth and its implementation should be tailored to the patient group. Patients' expected benefits of eHealth and their perceived controllability over their disease seem to be important in patients' willingness to use eHealth for self-management purposes. Informing patients clearly in a well-considered way about the possibilities, usage and reasons for implementation are important for stimulating the uptake of eHealth in primary care. However, when offering eHealth to patients it should be taken into account that not every patient is willing to use it. 


\section{Acknowledgment}

The authors would like to thank the practice nurses, nurse assistants and general practitioners for the recruitment of patients in their general practice. In addition, they would like to thank all participants of the focus groups for their contribution to this study. Furthermore, April Boessem is acknowledged for her assistance in moderating and transcribing the focus groups. Wendy Oude Nijeweme - d'Hollosy is acknowledged for her assistance in moderating a focus group.

This study was conducted within the context of the eLabEL project, which aims to contribute to solutions to improve the implementation of telecare technologies and eHealth applications by establishing primary care 'Living Labs' in which such technologies will be implemented and evaluated. More information can be found at www.caretechnologyresearch.nl/elabel. The eLabEL project is part of the Centre for Care Technology Research (CCTR: www.caretechnologyresearch.nl). 


\section{References}

1. Barlow J, Wright C, Sheasby J, Turner A, Hainsworth J. Self-management approaches for people with chronic conditions: a review. Patient Educ Couns. 2002;48(2):177-187.

2. Ryan P, Sawin KJ. The individual and family self-management theory: background and perspectives on context, process, and outcomes. Nurs Outlook. 2009;57(4):217-225.

3. Lorig KR, Holman HR. Self-management education: history, definition, outcomes, and mechanisms. Ann Behav Med. 2003;26(1):1-7.

4. Jerant AF, von Friederichs-Fitzwater MM, Moore M. Patients' perceived barriers to active selfmanagement of chronic conditions. Patient Educ Couns. 2005;57(3):300-307.

5. Eysenbach G. What is e-health? J Med Internet Res. 2001;3(2):e20.

6. Lisa Marsch SL, Dallery J. Behavioral health care and technology: using science-based innovations to transform practice. 1st ed. New York: Oxford University Press; 2015.

7. Wade AG. Use of the Internet to assist in the treatment of depression and anxiety: a systematic review. Prim Care Companion J Clin Psychiatry. 2010; 12(4).

8. Allen M, lezzoni LI, Huang A, Huang L, Leveille SG. Improving patient - clinician communication about chronic conditions: description of an Internet-based nurse E-coach intervention. Nurs Res. 2008;57(2):107112 .

9. de Jong CC, Ros WJ, Schrijvers G. The effects on health behavior and health outcomes of Internet-based asynchronous communication between health providers and patients with a chronic condition: a systematic review. J Med Internet Res. 2014;16(1):e19.

10. Paré G, Jaana M, Sicotte $C$. Systematic review of home telemonitoring for chronic diseases: the evidence base. J Am Med Inform Assoc. 2007;14(3): 269-277.

11. Peeters JM, Wiegers TA, Friele RD. How technology in care at home affects patient self-care and selfmanagement: a scoping review. Int J Environ Res Public Health. 2013;10(11):5541-5564.

12. May CR, Finch TL, Cornford J, Exley C, Gately C, Kirk S, et al. Integrating telecare for chronic disease management in the community: what needs to be done? BMC Health Serv Res. 2011;11(1):131.

13. Subramanian U, Hopp F, Lowery J, Woodbridge P, Smith D. Research in home-care telemedicine: challenges in patient recruitment. Telemed J E Health. 2004;10(2):155-161.

14. Sanders C, Rogers A, Bowen R, Bower P, Hirani S, Cartwright M, et al. Exploring barriers to participation and adoption of telehealth and telecare within the Whole System Demonstrator trial: a qualitative study. BMC Health Serv Res. 2012;12(1):220.

15. van Houtum L, Rijken M, Heijmans M, Groenewegen P. Patient- perceived self-management tasks and support needs of people with chronic illness: generic or disease-specific? Ann Behav Med. 2014;49(2): 221-229.

16. Dabbs ADV, Myers BA, Mc Curry KR, Dunbar-Jacoc J, Hawkins RP, Begey A, et al. User-centered design and interactive health technologies for patients. Comput Inform Nurs. 2009;27(3):175-183.

17. LeRouge C, Wickramasinghe N. A review of user-centered design for diabetes-related consumer health informatics technologies. Diabetes Sci Technol. 2013;7(4):1039-1056.

18. World Health Organization. Global status report on noncommunicable diseases. 2014

19. Hsieh H-F, Shannon SE. Three approaches to qualitative content analysis. Qual Health Res. 2005;15(9):1277-1288.

20. Elissen A, Nolte E, Knai C, Brunn M, Chevreul K, Conklin A, et al. Is Europe putting theory into practice? A qualitative study of the level of self-management support in chronic care management approaches. $B M C$ Health Serv Res. 2013;13(1):117.

21. Davis FD. A technology acceptance model for empirically testing new end-user information systems: theory and results. Cambridge: Massachusetts Institute of Technology; 1985.

22. Venkatesh V, Morris MG, Davis GB, Davis FD. User acceptance of information technology: toward a unified view. MIS Quart. 2003;27:425-478.

23. Hofstede J, de Bie J, van Wijngaarden B, Heijmans M. Knowledge, use and attitude toward eHealth among patients with chronic lung diseases. Int J Med Inform. 2014;83(12):967-974. 
24. Wallston BS, Wallston KA. Locus of control and health: a review of the literature. Health Educ Behav. 1978;6(1):107-117.

25. Wallston KA, Maides S, Wallston BS. Health-related information seeking as a function of health-related locus of control and health value. J Res Pers. 1976;10(2):215-222.

26. Barlow J, Sturt J, Hearnshaw H. Self-management interventions for people with chronic conditions in primary care: examples from arthritis, asthma and diabetes. Health Educ J. 2002;61(4):365-378.

27. Theofilou P, Reyes Saborit A. Health locus of control and diabetes adherence. J Psychol Psychother. 2012;3.

28. Mack N, Woodsong C, MacQueen KM, Guest G, Namey E. Qualitative research methods: a data collectors field guide. 2005.

29. Or CK, Karsh B-T. A systematic review of patient acceptance of consumer health information technology. J Am Med Inform Assoc. 2009;16(4):550-560. 
Appendix 1 Chronic care in the Netherlands

\section{Chronic care in the Netherlands}

The provision of chronic care in the Netherlands is mainly organized in primary care. Every Dutch citizen is obliged to have a basic health-care insurance. In this basic insurance, general practice consultations are covered. In 2008, a national strategy on chronic disease management was launched by the Ministry of Health, Welfare and Sport. In this strategy, a bundled payment was introduced to facilitate multidisciplinary collaboration in disease management programmes. Moreover, care standards to stipulate the minimum required patient services to be covered and authorized by carers organizations were developed for diabetes, COPD and cardiovascular risk management (CVRM). 


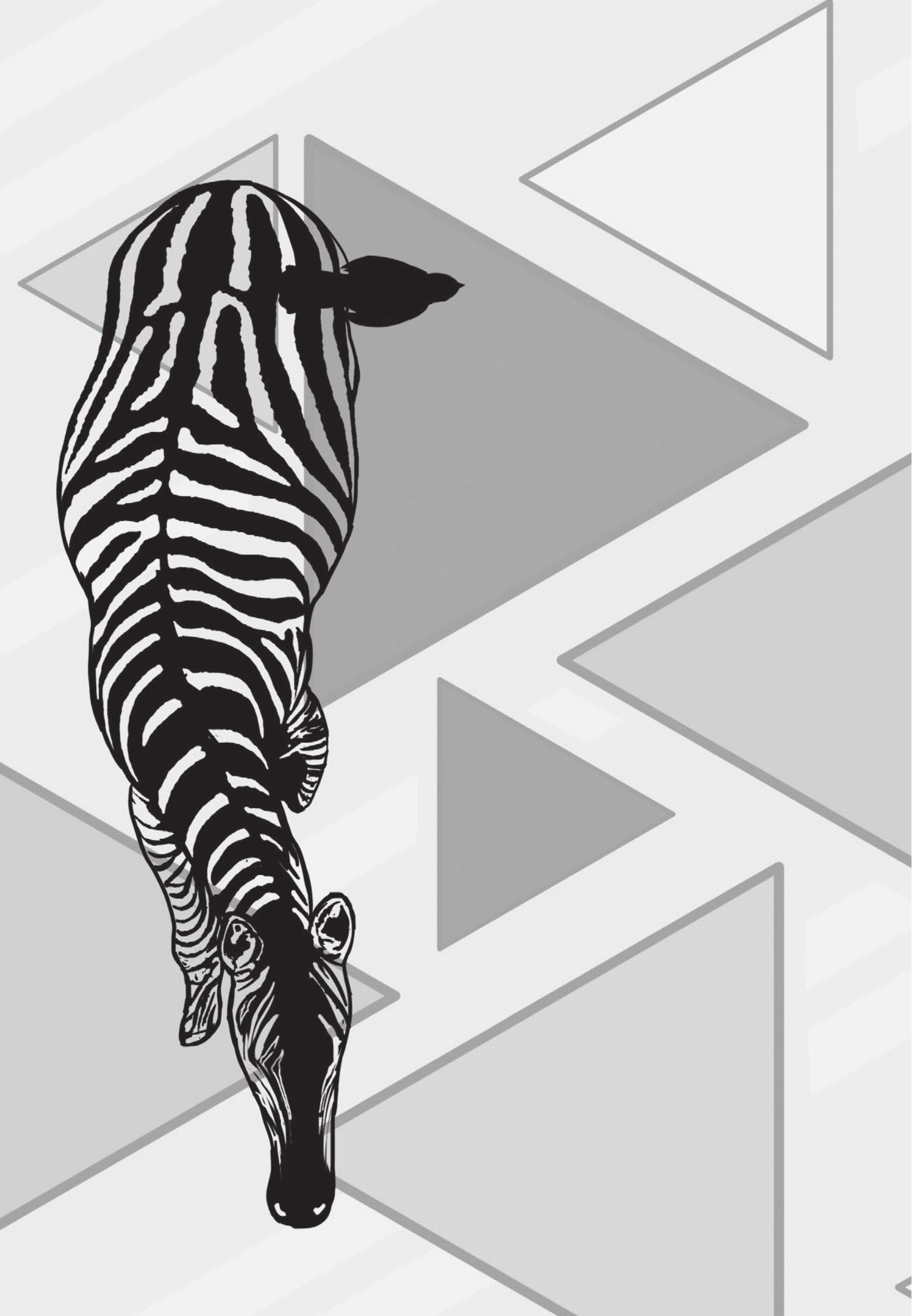




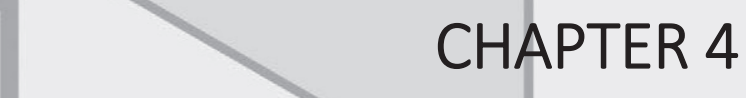

Self-monitoring of health data by patients

with a chronic disease: does disease controllability matter?

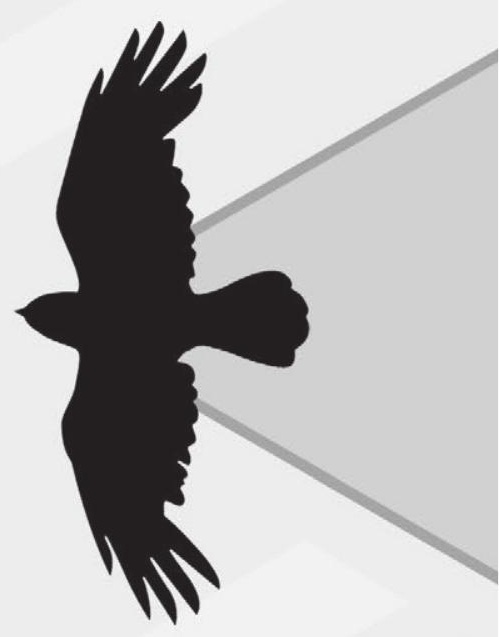




\begin{abstract}
Background There is a growing emphasis on self-monitoring applications that allow patients to measure their own physical health parameters. A prerequisite for achieving positive effects is patients' willingness to self-monitor. The controllability of disease types, patients' perceived self-efficacy and health problems could play an essential role in this. The purpose of this study is to investigate the relationship between patients' willingness to self-monitor and a range of disease and patient specific variables including controllability of disease type, patients' perceived self-efficacy and health problems.
\end{abstract}

Methods Data regarding 627 participants with 17 chronic somatic disease types from a Dutch panel of people with chronic diseases have been used for this cross-sectional study. Perceived self-efficacy was assessed using the general self-efficacy scale, perceived health problems using the Physical Health Composite Score (PCS). Participants indicated their willingness to self-monitor. An expert panel assessed for 17 chronic disease types the extent to which patients can independently keep their disease in control. Logistic regression analyses were conducted.

Results Patients' willingness to self-monitor differs greatly among disease types: patients with diabetes (71.0\%), asthma (59.6\%) and hypertension $(59.1 \%)$ were most willing to self-monitor. In contrast, patients with rheumatism (40.0\%), migraine (41.2\%) and other neurological disorders (42.9\%) were less willing to self-monitor. It seems that there might be a relationship between disease controllability scores and patients' willingness to self-monitor. No evidence is found of a relationship between general self-efficacy and PCS scores, and patients' willingness to self-monitor.

Conclusions This study provides the first evidence that patients' willingness to selfmonitor might be associated with disease controllability. Further research should investigate this association more deeply and should focus on how disease controllability influences willingness to self-monitor. In addition, since willingness to self-monitor differed greatly among patient groups, it should be taken into account that not all patient groups are willing to self-monitor. 


\section{Introduction}

In recent decades there has been a growing emphasis on self-monitoring applications in primary care. These applications allow patients to measure their own physical health parameters, such as blood pressure, blood glucose level and lung function. ${ }^{1,2,3}$ Selfmonitoring is a key aspect of patients' self-management, ${ }^{4}$ especially in diseases like diabetes, asthma and heart failure. It offers the potential to create awareness of symptoms, bodily sensations, daily activities and cognitive processes and to provide information for action. ${ }^{5}$ The effects of self-monitoring look promising: literature shows that it could improve self-management, symptom management and disease regulation, and could lead to reductions in complications, improved patients' coping and attitudes toward their disease, realistic goal setting and an enhanced quality of life. ${ }^{6}$ Selfmonitoring is a broad term, including the monitoring of clinical parameters, symptom measures and daily activities. ${ }^{5}$ In the current study we focus on individual selfmonitoring of clinical parameters (such as: weight, blood pressure, blood glucose level and lung function) with the use of technical equipment.

With the introduction of new technologies, self-monitoring has become more convenient and accessible for patients. However, a prerequisite for achieving the positive effects of self-monitoring is the willingness of patients to self-monitor. Patients' willingness to use technologies in health care is often studied with the Technology Acceptance Model (TAM). ${ }^{7,8}$ This model theorizes that beliefs about perceived ease of use and perceived usefulness are the main constructs predicting user intention. A recent review study shows that the TAM is still the most important model used to identify the factors that influence the adoption of information technologies in health care. ${ }^{9}$ This model had been extended and modified in recent years, such as in the Unified Theory of Acceptance and Use of Technology (UTAUT). ${ }^{10}$ Besides ease of use and perceived usefulness two other key constructs are included in the UTAUT model: social influence and facilitating conditions. However, we suggest that there are other underlying diseasespecific and patient-specific factors that play an essential role in patients' willingness to self-monitor.

For instance, the relevance of self-monitoring may not be the same for each disease type. For patients with diabetes and hypertension, for example, self-management goals are easy to define, such as optimizing blood glucose level and blood pressure, which are parameters that can easily be monitored by the patient. For patients with a disease like arthritis these goals are less concrete. ${ }^{11}$ Moreover, other researchers suggest that in disease types such as diabetes, the feedback between action and change is rather direct and can clearly be observed by the patient, which can trigger the sensemaking process of performing self-management behaviour. For disease types such as cancer there are less direct and easily captured indicators that can activate this process. ${ }^{12}$

Hence, it would seem that disease types differ in the extent to which they are controllable by the patients' behaviour (e.g., using medication, nutrition and physical 
activity), which could be related to patients' willingness to self-monitor. Some support for this was found in a recently performed focus group study. ${ }^{13}$ In this study we found that patients with diabetes were more interested in the use of self-monitoring than patients with a Chronic Obstructive Pulmonary Disease (COPD) and a cardiovascular condition, because they mentioned that their own behaviour (nutrition, weight loss and medication) directly influenced their health, and that self-monitoring support could help them to influence their behaviour.

However, disease controllability does not only differ between disease types, but can also differ between individuals. Patients' belief that they are capable of managing and controlling their disease is better known as self-efficacy. ${ }^{14}$ This plays an important role in performing self-management behaviour ${ }^{15}$ and might likewise influence patients' willingness to self-monitor. Previous research found that higher perceived self-efficacy was associated with better blood glucose monitoring in patients with diabetes. ${ }^{16,17}$

Besides self-efficacy, the benefits that patients experience from self-monitoring might play an important role in their willingness to self-monitor. According to the Health Belief Model, ${ }^{18}$ perceiving higher benefits in relation to costs improves the performance of health behaviour. This is also found to be related to adherence to self-monitoring in patients with diabetes. ${ }^{19}$ Experienced benefits regarding self-monitoring could be the reduction or prevention of disease symptoms. In our focus group study we found that patients with a chronic disease who experienced minimal health complaints were less willing to self-monitor because they expected fewer benefits. They did not expect improvements in their health, because their disease had little impact on their life, and were more focused on the perceived costs; the time it takes to do the self-monitoring. ${ }^{13}$ Therefore in terms of self-monitoring we argue that patients who experience more severe health problems perceive higher benefits from self-monitoring (improvements in their health) in relation to the costs (doing the self-monitoring) and might likewise be more willing to self-monitor.

Up until now self-monitoring is often not yet integrated in standard care procedures. Moreover, the role of the patient and health care professional regarding the provision of self-monitoring is not yet defined. This study aimed to get more insight in willingness to self-monitor by patients with different chronic disease types. In this study our hypotheses which were based on the results of the focus group study are tested in a wider range of disease types to answer the following research question: what is the relationship between the controllability of disease types (disease specific) and patients' perceived self-efficacy and health problems (patient specific) on the one hand, and patients' willingness to self-monitor on the other. In addition, the influence of patients' characteristics (gender, age, level of education and multimorbidity) on patients' willingness to self-monitor will be investigated. Based on the previously performed focus group study we generated three hypotheses: 
Disease-specific hypothesis:

1. The controllability of a certain type of chronic disease is related to patients' willingness to self-monitor; patients with a chronic disease that can be, in general, properly kept under control by the patient will be more interested in selfmonitoring than patients that have a disease that is less controllable by the patient.

Patient-specific hypotheses:

2. Patients' perceived self-efficacy is related to their willingness to self-monitor; patients with high perceived self-efficacy are more interested in self-monitoring than patients that perceive low self-efficacy.

3. The severity of problems that patients experience with daily functioning is related to their willingness to self-monitor; patients that have moderate problems with daily functioning are more interested in self-monitoring than patients who perceive no problems with daily functioning. This holds to a certain extent; patients who experience many problems with daily functioning might not be able to do the monitoring anymore.

We investigated these hypotheses in a Dutch nationwide study of patients with the most prevalent chronic diseases.

\section{Methods}

\section{Design and participants}

Data from 1294 participants of the National Panel of people with Chronic illness or Disability (NPCD) were used for this cross-sectional study. ${ }^{20}$ This panel was established by NIVEL (the Netherlands Institute for Health Services Research) and is a nationwide prospective panel study in the Netherlands. Participants with a chronic disease are recruited from random samples of general practices in the Netherlands. The following criteria were used for recruitment of the NPCD: being diagnosed with a somatic chronic disease (using the International Classification of Primary Care (ICPC)) by a certified medical doctor, being aged 15 or older, not being permanently institutionalized, being aware of the diagnosis, not being terminally ill (a life expectancy of more than six months according to their general practitioner), being mentally capable of participating, and having sufficient mastery of the Dutch language. Every year 500 new panel members are selected to replace panel members who have withdrawn or who have participated for the maximum term of four years. The NPCD can be considered to be representative of the chronic disease population in the Netherlands of aged 15 years and older. The NPCD is registered with the Dutch Data Protection Authority. All data are 
collected and handled in accordance with the privacy protection guidelines of the Dutch authority.

Patients voluntarily participate in the NPCD. Participation has no influence on their care. Twice a year (spring and autumn) the panel members voluntarily fill out a questionnaire. The panel members could choose whether they wanted to receive questionnaires by post, email or phone. Some items used in this study were issued in the spring questionnaire of 2014, others in the autumn questionnaire of 2014 . The questionnaire can be found in Appendix 1.

In addition, to test our hypothesis regarding self-monitoring of health data by people with different chronic disease types an expert panel of 16 medical doctors and physiotherapists was invited to participate in a questionnaire study in February and March 2016.

\section{Measurements}

\section{Participant characteristics}

The background characteristics of the members of the NPCD had already been gathered using a questionnaire that was completed at inclusion in the panel. For this study, the following characteristics were used: gender ( 1 =male, 2 =female), age and level of education ( $1=$ low (primary school or preparatory vocational training), $2=$ middle (intermediate or advanced general education or intermediate vocational training), $3=$ high (high vocational education or university)). In addition, information regarding participants' chronic disease(s) was provided at inclusion by their general practitioner.

\section{Self-monitoring of health data}

The following question regarding self-monitoring of health data was asked to participants in autumn 2014: "Did you measure certain health data by yourself in the past year, for example blood pressure, blood glucose values or lung function?" Participants could answer: 1) yes; 2), no, but I would like to do this (independently); 3), no, but I would like to do this together with a care professional; or 4), no, and I do not want to do this.

\section{Self-efficacy-patient specific}

Patients' perceived self-efficacy was collected using the Dutch version of the general self-efficacy scale ${ }^{21}$ in spring 2014 (Cronbach's alpha was 0.92). This questionnaire consists of ten questions with a four-point Likert scale ranging from 1) completely wrong to 4) completely right. For example: "When I am confronted with a problem, I can usually find several solutions" and "It is easy for me to stick to my aims and accomplish my goals". Participants with four or more missing values were excluded. Mean values were used in further analyses, in which a higher mean score indicates a higher level of self-efficacy. 


\section{Problems in daily functioning - patient specific}

The Dutch version of the Physical Health Composite Score (PCS) of the SF- $12^{22}$ was used to investigate patients' experienced problems in daily functioning in autumn 2014 (Cronbach's alpha was 0.88). The SF-12 has shown adequate validity and reliability in multiple studies. ${ }^{23}$ PCS scores were collected in spring 2014. Mean scores were calculated using QualityMetric Health Outcomes ${ }^{\text {TM }}$ Scoring Software 5.0 and could range from 0 to 100, in which 100 indicates the highest level of health.

\section{Disease control - disease specific}

To test the hypothesis, based on literature and experiences regarding self-monitoring of health data by people with different disease types (disease-specific hypothesis), nine care professionals from the expert panel (six medical doctors and three physiotherapists) out of sixteen experts who were invited, answered the following question for 17 different chronic diseases: "To what extent can people with a chronic disease, in general, independently keep their disease under control (by means of nutrition, physical activity, medication etc.) ?" Participants could respond with: 1) not at all; 2) to some extent; or 3) to a large extent. Mean scores per disease type were used in the analyses.

\section{Statistical analyses}

Descriptive analyses were conducted to study participants' characteristics per disease group. Participants were divided into 17 different disease-type categories based on the diagnosis of their first chronic disease (ischaemic heart disease, hypertension, other cardiovascular disorders, cancer, asthma, COPD, other respiratory diseases, diabetes, thyroid disorder, chronic back pain, rheumatism, osteoarthritis, other musculoskeletal disorders, migraine, other neurological disorders, digestive disorder and skin disease). The most common diseases per disease category can be found in Appendix 2.

Univariate logistic regression analyses were conducted to test the relationship between patient- and disease-specific characteristics, and patients' willingness to selfmonitor health data (dependent variable: 1=participants who did measure certain health data by themselves + participants who would like to do that (independently), $0=$ participants who would like to do that together with a care professional+participants who did not want to do that at all). The univariate logistic regression analyses were conducted with the following independent variables: mean scores of the expert panel regarding disease controllability, mean score of the general self-efficacy scale, PCS score of the SF-12 and age, gender ( 1 =male, 2 =female), level of education ( $1=$ low, 2 =middle, $3=$ high $)$ and multimorbidity ( $0=$ one disease, $1=$ two or more diseases $)$. Assumptions for logistic regression were checked. We adjusted for clustering of data within chronic disease types (patients within one disease group have the same disease control score). Finally, multivariate logistic regression analyses were performed with all the above- 
mentioned concepts (dependent variable: willingness to self-monitor). Statistical analyses were performed using STATA 14.0.

\section{Results}

\section{Participants}

Figure 1 shows a flow chart of the process of the inclusion of participants in this study. Out of 1294 participants of the NPCD, 979 responded to the questionnaire that was issued in spring 2014. Of these 979 participants, 2 had no chronic disease or a disease that did not fit in one of the 17 most prevalent chronic disease types $(n=67)$. Subsequently 101 participants were excluded because of incomplete data regarding the self-monitoring question $(n=44)$, PCS $(n=39)$ and level of education $(n=18)$. In addition 160 participants were excluded because they did not fill out the questionnaire at spring $(n=160)$ or because of incomplete data in the general self-efficacy scale $(n=22)$. This resulted in a total sample of 627 participants. Non response analyses showed no differences in characteristics between the non-responders (including people who responded but did not fill out the entire questionnaire) and the final sample, except for age (non-responders: $M=63.5, S E=0.55$; final sample: $M=65.1, S E=0.46, t(1292)=-2.15$, $p=0.03)$. So except for a sampling bias of age the sample is representative of the chronic disease population in the Netherlands.

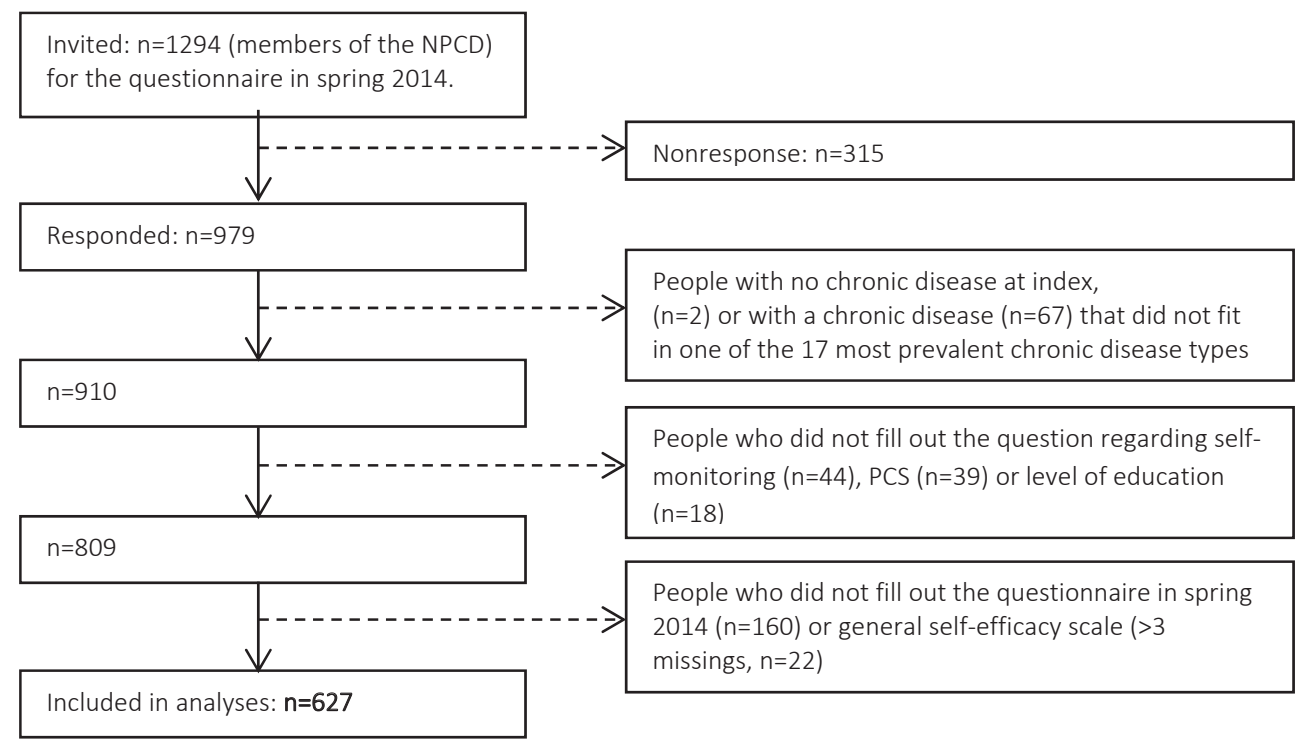

Figure 1 Flow chart of participants included in the study 
Table 1 shows the characteristics of the study sample. Diabetes (19.8\%), other cardiovascular disorders (8.9\%), ischaemic heart disease/heart failure (8.6\%) and asthma (8.3\%) were the most common chronic disease types within the sample. Almost $4 \%$ of the participants were diagnosed less than three years ago, 16.1\% three to five years ago, 31.9\% six to ten years ago and almost half (48.1\%) longer than ten years ago. More than half (51.2\%) had been diagnosed with two or more chronic diseases. All characteristics per disease group can be found in Appendix 3.

\section{Relationship of disease controllability with willingness to self-monitor}

Figure 2 represents the association between disease controllability scores (assessed by the expert panel) and the percentage of participants that is willing to self-monitor health data per disease type. Patients' willingness to self-monitor differs greatly among disease types: patients with diabetes (71.0\%), asthma (59.6\%) and hypertension (59.1\%) were most willing to self-monitor. In contrast, patients with rheumatism (40.0\%), migraine (41.2\%) and other neurological disorders (42.9\%) were less willing to self-monitor. In addition, the expert panel assessed diabetes (3.0), hypertension (2.7) and COPD and asthma (2.6) as diseases that can be kept well under control by the patient, and cancer (1.1), thyroid disorder (1.4), and other neurological disorders and migraine (1.6) as the diseases that are most difficult for the patient to keep under control. The scores of the expert panel can be found in Appendix 4 .

A relationship is found between disease controllability scores and patients' willingness to self-monitor. The correlation between disease controllability scores and the percentage of participants that is willing to self-monitor is significant $(r=0.547, p<0.05)$. In addition, looking at the univariate and multivariate logistic association of disease controllability with patients' willingness to self-monitor (first column Tables 2 and 3 respectively), a significant association is found (univariate: $\mathrm{OR}=1.589,95 \% \mathrm{Cl}=1.142-2.210$; multivariate: $\mathrm{OR}=1.639$, 95\% $\mathrm{Cl}=1.129-2.380)$.

Table 1 Characteristics of the study sample

\begin{tabular}{llll}
\hline Characteristics & & $\begin{array}{l}\text { Study sample }(n=627) \\
\text { Mean }(\mathrm{sd}) \text { or } n(\%)\end{array}$ & $\begin{array}{l}\text { Non response }(n=667) \\
\text { Mean }(\mathrm{sd}) \text { or } n(\%)\end{array}$ \\
\hline Age in years & & $65.1(\mathrm{sd}=11.6)$ & $63.5(\mathrm{sd}=14.3)$ \\
Gender & Male & $313(49.9 \%)$ & $313(46.9 \%)$ \\
Level of education & Low & $199(31.7 \%)$ & $220(32.98 \%)$ \\
& Medium & $276(44.0 \%)$ & $276(41.38 \%)$ \\
& High & $152(24.2 \%)$ & $122(18.29 \%)$ \\
& & & Missing $=49(7.4 \%)$ \\
Chronic condition (self-reported) & One & $306(48.8 \%)$ & $343(51.4 \%)$ \\
& Two of more & $321(51.2 \%)$ & Missing $=3(0.5 \%)$ \\
Data collection & & & \\
& By post & $376(60.9 \%)$ & \\
General self-efficacy & Online & $248(39.6 \%)$ & \\
Physical Health Composite Score & By telephone & $3(0.5 \%)$ & \\
Willing to self-monitor & & $3.12(\mathrm{sd}=0.6)$ & \\
\hline
\end{tabular}


Percentage of participants that are willing to self-monitor per disease controllability score

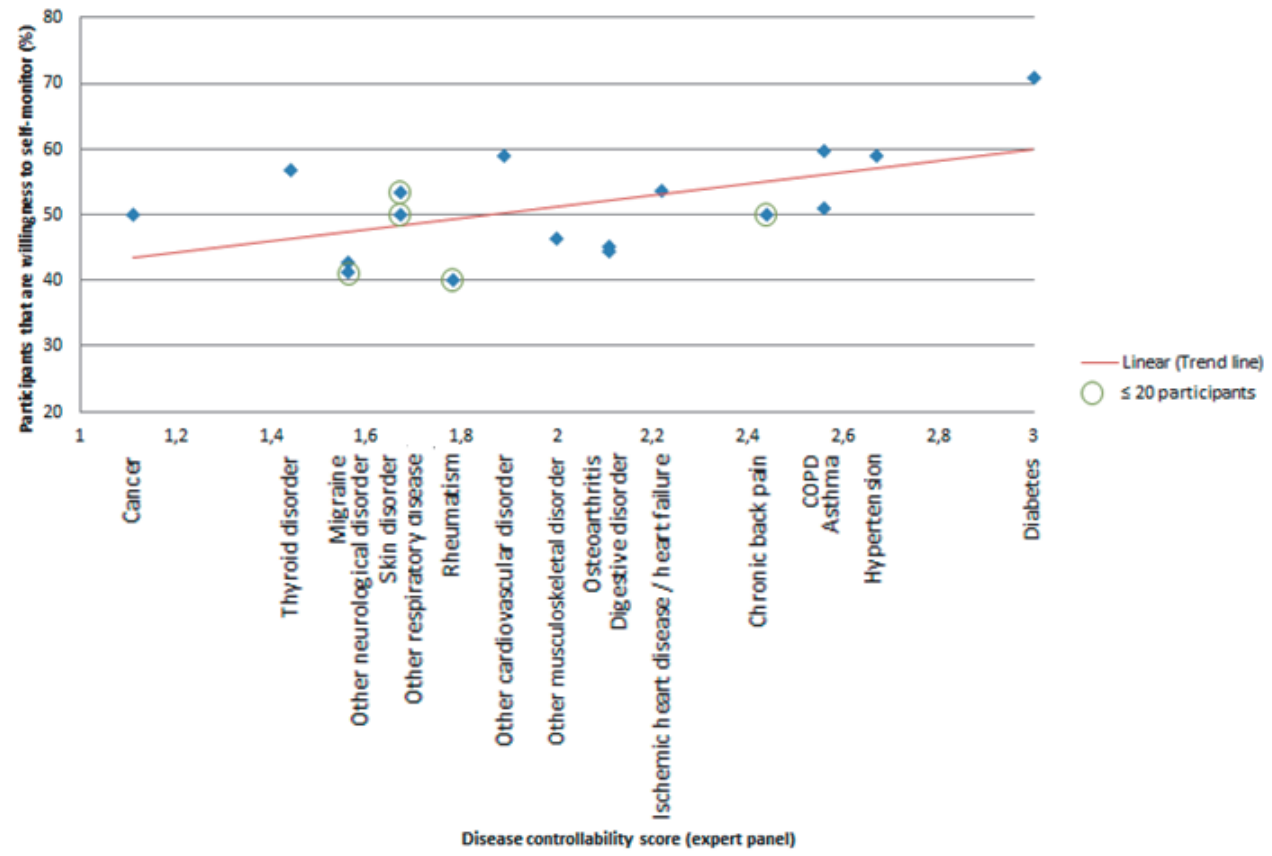

Figure 2 Mean disease controllability score (expert panel: 1 =not at all; 2 =to some extent; 3 =to a large extent) plotted against the percentage of participants that is willing to monitor independently

Table 2 Univariate logistic regression analyses with the dependent variable: willingness to monitor health data

\begin{tabular}{|c|c|c|c|c|c|c|}
\hline \multirow[t]{2}{*}{ Independent variable } & \multicolumn{2}{|l|}{$\begin{array}{l}\text { Entire sample } \\
(n=627)\end{array}$} & \multicolumn{2}{|c|}{$\begin{array}{l}\text { Sample without diabetes } \\
(n=503)\end{array}$} & \multicolumn{2}{|l|}{$\begin{array}{l}\text { Diabetes only } \\
(n=124)\end{array}$} \\
\hline & OR $(95 \% \mathrm{Cl})$ & $p$ & OR $(95 \% \mathrm{CI})$ & $p$ & OR $(95 \% \mathrm{Cl})$ & $p$ \\
\hline Age & $\begin{array}{l}0.994 \text { (0.979- } \\
1.010)\end{array}$ & 0.453 & $\begin{array}{l}0.994(0.977- \\
1.012)\end{array}$ & 0.519 & $\begin{array}{l}0.973(0.934- \\
1.014)\end{array}$ & 0.193 \\
\hline Gender (ref =male) & $\begin{array}{l}0.728(0.533- \\
0.993)\end{array}$ & 0.045 & $\begin{array}{l}0.669(0.488- \\
0.916)\end{array}$ & 0.012 & $\begin{array}{l}1.8(0.774- \\
4.187)\end{array}$ & 0.172 \\
\hline $\begin{array}{l}\text { Level of education } \\
\text { (ref=low) }\end{array}$ & - & - & - & - & - & - \\
\hline Intermediate & $\begin{array}{l}1.308(0.863- \\
1.983)\end{array}$ & 0.206 & $\begin{array}{l}1.611(1.158- \\
2.240)\end{array}$ & 0.005 & $\begin{array}{l}0.741(0.308- \\
1.784)\end{array}$ & 0.503 \\
\hline High & $\begin{array}{l}1.908(1.300- \\
2.801)\end{array}$ & 0.001 & $\begin{array}{l}2.254 \text { (1.603- } \\
3.170)\end{array}$ & $<0.001$ & $\begin{array}{l}1.256(0.435- \\
3.627)\end{array}$ & 0.673 \\
\hline $\begin{array}{l}\text { Multimorbidity (ref=one } \\
\text { disease) }\end{array}$ & $\begin{array}{l}1.076(0.816- \\
1.420)\end{array}$ & 0.604 & $\begin{array}{l}1.192(0.902- \\
1.577)\end{array}$ & 0.217 & $\begin{array}{l}0.849(0.390- \\
1.850)\end{array}$ & 0.681 \\
\hline $\begin{array}{l}\text { Disease control score } \\
\text { (expert panel) }\end{array}$ & $\begin{array}{l}1.589(1.142- \\
2.210)\end{array}$ & 0.006 & $\begin{array}{l}1.169(0.942- \\
1.451)\end{array}$ & 0.156 & - & - \\
\hline $\begin{array}{l}\text { Physical Health Composite } \\
\text { Score (PCS) }\end{array}$ & $\begin{array}{l}1.005(0.989- \\
1.020)\end{array}$ & 0.567 & $\begin{array}{l}1.002(0.984- \\
1.020)\end{array}$ & 0.823 & $\begin{array}{l}1.003(0.966- \\
1.041)\end{array}$ & 0.874 \\
\hline Self-efficacy patient & $\begin{array}{l}0.994(0.747- \\
1.322)\end{array}$ & 0.968 & $\begin{array}{l}1.062(0.760- \\
1.483)\end{array}$ & 0.724 & $\begin{array}{l}0.747(0.374- \\
1.492)\end{array}$ & 0.408 \\
\hline
\end{tabular}


Table 3 Multivariate logistic regression analyses with the dependent variable: willingness to monitor health data

\begin{tabular}{|c|c|c|c|c|c|c|}
\hline \multirow[t]{2}{*}{ Independent variable } & \multicolumn{2}{|l|}{$\begin{array}{l}\text { Entire sample } \\
(n=627)\end{array}$} & \multicolumn{2}{|c|}{$\begin{array}{l}\text { Sample without diabetes } \\
(n=503)\end{array}$} & \multicolumn{2}{|l|}{$\begin{array}{l}\text { Diabetes only } \\
(n=124)\end{array}$} \\
\hline & OR $(95 \% \mathrm{Cl})$ & $p$ & OR $(95 \% \mathrm{Cl})$ & $p$ & OR $(95 \% \mathrm{Cl})$ & $p$ \\
\hline Age & $\begin{array}{l}0.992(0.976- \\
1.008)\end{array}$ & 0.312 & $\begin{array}{l}0.993(0.974- \\
1.012)\end{array}$ & 0.468 & $\begin{array}{l}0.972(0.929- \\
1.018)\end{array}$ & 0.229 \\
\hline Gender (ref =male) & $\begin{array}{l}0.792(0.522- \\
1.203)\end{array}$ & 0.274 & $\begin{array}{l}0.655(0.468- \\
0.916)\end{array}$ & 0.013 & $\begin{array}{l}1.934(0.783- \\
4.776)\end{array}$ & 0.153 \\
\hline $\begin{array}{l}\text { Level of education } \\
\text { (ref=low) }\end{array}$ & - & - & - & - & - & - \\
\hline Intermediate & $\begin{array}{l}1.491(0.973- \\
2.284)\end{array}$ & 0.067 & $\begin{array}{l}1.804(1.256- \\
2.590)\end{array}$ & 0.001 & $\begin{array}{l}0.652(0.250- \\
1.701)\end{array}$ & 0.382 \\
\hline High & $\begin{array}{l}2.042(1.415- \\
2.950)\end{array}$ & $<0.001$ & $\begin{array}{l}2.344(1.645- \\
3.341)\end{array}$ & $<0.001$ & $\begin{array}{l}1.217(0.398- \\
3.724)\end{array}$ & 0.730 \\
\hline $\begin{array}{l}\text { Multimorbidity (ref=one } \\
\text { disease) }\end{array}$ & $\begin{array}{l}1.170(0.868- \\
1.576)\end{array}$ & 0.303 & $\begin{array}{l}1.278(0.903- \\
1.809)\end{array}$ & 0.167 & $\begin{array}{l}0.876(0.386- \\
1.988)\end{array}$ & 0.751 \\
\hline $\begin{array}{l}\text { Disease control score } \\
\text { (expert panel) }\end{array}$ & $\begin{array}{l}1.639(1.129- \\
2.380)\end{array}$ & 0.009 & $\begin{array}{l}1.164(0.908- \\
1.491)\end{array}$ & 0.230 & - & - \\
\hline $\begin{array}{l}\text { Physical Health Composite } \\
\text { Score (PCS) }\end{array}$ & $\begin{array}{l}1.001(0.984- \\
1.019)\end{array}$ & 0.916 & $\begin{array}{l}0.999(0.979- \\
1.020)\end{array}$ & 0.934 & $\begin{array}{l}1.008(0.962- \\
1.057)\end{array}$ & 0.726 \\
\hline Self-efficacy patient & $\begin{array}{l}0.862(0.655- \\
1.134)\end{array}$ & 0.288 & $\begin{array}{l}0.881(0.636- \\
1.221)\end{array}$ & 0.448 & $\begin{array}{l}0.757(0.346- \\
1.656)\end{array}$ & 0.486 \\
\hline
\end{tabular}

\section{Diabetes group - disease controllability and willingness to self-monitor}

As can be seen in Figure 2, all experts assessed diabetes as a disease that can, to a large extent, be kept under control by the patient (the maximum mean score of 3.0). In addition, the diabetes group scored remarkably high on willingness to self-monitor (71.0\%). Therefore, we decided to look more deeply into the diabetes group only $(n=124)$.

Of the 124 people with diabetes, 9 participants have type I diabetes and 103 type II (for 12 participants it is unknown what type of diabetes they have). 41 participants with diabetes use insulin (33.1\%), 65 do not use insulin (52.4\%) and for 18 participants this is unknown (14.5\%). Of the 41 participants using insulin, $95.1 \%$ are willing to self-monitor health data. In contrast, among patients who are not using insulin $46.2 \%$ are willing to do so.

In Tables 2 and 3 (second column) it can be seen that by excluding the entire diabetes group in the univariate and multivariate logistic regression analyses to investigate the relationship between disease controllability and patients' willingness to self-monitor $(n=503)$, no significant association is found (univariate: OR $=1.169,95 \%$ $\mathrm{Cl}=0.942-1.451$; multivariate: $\mathrm{OR}=1.164,95 \% \mathrm{Cl}=0.908-1.491)$. 


\section{Relationship of patient characteristics with willingness to self-monitor}

Patients' perceived problems in daily functioning (PCS) and self-efficacy have no significant association with their willingness to self-monitor (see Tables 2 and 3). Age and multimorbidity also have no relationship with willingness to self-monitor. In contrast, males and more highly educated people are significantly more willing to self-monitor their health data.

Looking at the diabetes sample only (Tables 2 and 3 third column), there was no significant association between gender and education level, and patients' willingness to self-monitor.

\section{Discussion}

\section{Principal results}

This study provides the first evidence of an association between disease controllability and patients' willingness to self-monitor health data. Against our expectations, no evidence is found for a relationship between self-efficacy and the severity of problems that patients experience with daily functioning, and patients' willingness to self-monitor. In addition, it is found that males and more highly educated people are more willing to self-monitor their health data.

The scores of the diabetes group regarding disease controllability and patients' willingness to self-monitor were remarkably high. Patients with diabetes using insulin were particularly willing to self-monitor (95.1\%). The difference between diabetes and other chronic disease types regarding self-monitoring could be explained by the fact that for diabetes patients self-monitoring is recommended as an integral component of their treatment (particularly for patients using insulin). ${ }^{24,25}$ So for many persons with diabetes, their "willingness" to self-monitor is beyond question, because they have to monitor their blood glucose level for their (optimal) treatment. Hence, as we found in this study, this is also independent of the patient characteristics they have. For other chronic disease types self-monitoring is often not yet integrated into the standard treatment. For these chronic disease types males and more highly educated people were more willing to self-monitor, which is in line with some, but not all, self-management research. ${ }^{26,27,28}$ Interestingly, we did not find a relationship between multimorbidity (having two or more chronic conditions) and willingness to self-monitor. Although many research found that performing optimal self-management behaviour may be more challenging for people with multiple chronic diseases, ${ }^{29,30}$ this study suggest that this does not influence willingness to self-monitor.

Contrary to our expectations no effect of self-efficacy on patients' willingness to self-monitor was found in this study. However, in other studies that did find an 
association between self-efficacy and self-monitoring, questionnaires were used to investigate self-efficacy regarding patients' chronic disease, such as how participants assessed their capability to monitor, plan and carry out activities for their disease (for example nutrition, physical exercises and medication). ${ }^{16,17}$ In the current study the general self-efficacy scale ${ }^{21}$ was used, which consists of generic questions such as "When I am confronted with a problem, I can usually find several solutions" and "It is easy for me to stick to my aims and accomplish my goals". It appears that patients' general selfefficacy is not related to their willingness to self-monitor. In future research it might be interesting to investigate if a chronic disease self-efficacy scale, e.g., the Chronic Diseases Self-Efficacy Scale of Lorig and colleagues $^{31}$ is related to willingness to selfmonitor.

No relationship was found between patients' perceived problems in daily functioning and self-monitoring, which is not in line with our hypothesis. Again, participants were asked to assess all their general health problems in daily functioning, and not only the physical problems related to their specific chronic disease. Although we found some support for this possible relationship in our recently performed focus group study, ${ }^{13}$ other research regarding eHealth did not find a relationship between health needs and patients' acceptance and interests of eHealth as well. ${ }^{32,33}$ It seems that patients' willingness to self-monitor health data is not directly related to their perceived health problems. In future research it might be interesting to investigate if a disease specific health scale (such as Quality of life Disease Impact Scale) ${ }^{34}$ has an influence on patients' willingness to self-monitor. In addition, although we did not ask participants to indicate their expected or perceived benefits of self-monitoring health data, it might be expected that willingness to self-monitor is more related to the overall concepts of "perceived benefits" and "perceived usefulness", which are well-studied concepts in care technology acceptance research. ${ }^{8,19,35-37}$ It might be that patients are more willing to self-monitor when they believe that self-monitoring can convey (health) benefits.

This study provides the first evidence that patients' willingness to self-monitor might be associated with disease controllability. Further research should investigate this association more deeply and should focus on how disease controllability influences willingness to self-monitor. In the current study disease controllability is investigated using one general question in an expert panel ("To what extent can people with a chronic disease, in general, independently keep their disease under control (by means of nutrition, physical activity, medication etc.) for the following chronic diseases?"). It is recommended to first define the concept of disease controllability and to investigate what factors and mechanisms play a role in this. Secondly, it should be investigated how disease controllability influences patients' willingness to self-monitor, for example by using qualitative methodology focusing on behavioural and motivational aspects of patients. Thirdly, it should be investigated how self-monitoring applications for different disease types can be adapted to improve this. In addition, it should be investigated what other disease- and patient specific factors play a role in patients' willingness to self- 
monitor, such as disease effects, patients' perceived controllability of symptoms and patients' coping and attitudes toward their disease. This study shows that the percentage of participants that is willing to self-monitor health data differed greatly between disease types. Hence, while developing and offering self-monitoring applications it should be kept in mind that not all patient groups are willing to selfmonitor their health data.

\section{Strengths and limitations}

The strength of this study is its general focus on patients' willingness to self-monitor health data in a broad sample $(n=627)$ of people with the most common chronic somatic disease types (17 chronic disease types). The panel used for this study was representative of the Dutch chronic disease population (except for age). The overall response of this panel is high and participants were not recruited for the specific topic of this study which minimizes selection bias; items used for this study were a part of a panel questionnaire. In addition, this study is conducted to test our hypotheses, which were based on the results of a recently performed focus group study. ${ }^{13}$ Moreover, to the best of our knowledge, this is the first study to investigate the relationship between the controllability of certain chronic disease types and patients' willingness to self-monitor.

As mentioned before, one limitation of this study is that data from general questionnaires have been used to investigate patients' self-efficacy and physical problems that were not specifically related to patients' chronic disease. In addition, the dependent variable 'patients' willingness to self-monitor' was based on one nonvalidated question. Furthermore, patients' willingness to self-monitor and their Physical health Composite Scores (PCS) were collected in autumn 2014, in contrast to general self-efficacy scores, which were investigated in spring 2014. However, it is expected that these scores did not significantly change within six months. In addition, the number of people within a disease type highly differed from $n=6$ (chronic back pain) to $n=124$ (diabetes). Five chronic disease types had only 20 or less participants. In addition, in the analyses with the diabetes group only, no relationships were found between gender and education level, and patients' willingness to self-monitor. This might be explained by the lower number of participants compared with the entire sample ( $n=124$ vs $n=627$ ). Moreover, no relationship between multimorbidity and patients' willingness to selfmonitor was found in this study. We defined multimorbidity as having two or more chronic conditions. It might be that this does not reflect the complexity of this problem, in particular not for people with a high number of conditions.

Another limitation is that people that had done self-monitoring in the previous year and those that wanted to do so independently were recoded as being willing to selfmonitor. Additional separate analyses were performed to investigate differences between the association of the actual self-monitoring group or the willing to selfmonitor group on the one hand, and disease controllability on the other. Although 
similar positive associations between the actual and willing to self-monitor group, and disease controllability were found, no valid statements could be made due to the small number of people in each (disease) group. In addition, it is assumed that the actual selfmonitoring group were also willing to self-monitor in the first place. Moreover, participants that wanted to do self-monitoring with the help of a care professional and participants that did not want to do self-monitoring at all were recoded as being not willing to self-monitor, because we were particularly interested in people that were willing to self-monitor independently. This because we consider self-monitoring as a core element of self-management and by monitoring independently the required effects of self-monitoring (improving symptom management, disease regulation, patients' coping and attitudes toward their disease, realistic goal setting and an enhanced quality of (ife) $)^{6}$ will be most effective.

\section{Conclusion}

This study provides the first evidence that patients' willingness to self-monitor might be associated with disease controllability. Further research should investigate this association more deeply and should focus on how disease controllability influences willingness to self-monitor. In addition, it should be investigated what other disease- and patient specific factors play a role in patients' willingness to self-monitor. No evidence is found of a relationship between self-efficacy and the severity of problems that patients experience with daily functioning, and patients' willingness to self-monitor. Since the percentage of participants that is willing to self-monitor health data differed greatly between disease types, it should be taken into account that not all patient groups are willing to self-monitor their health data.

\section{Acknowledgement}

The authors would like to thank Geeke Waverijn for her help in setting up the data set and Lucas van der Hoek for his statistical advice. 


\section{References}

1. McAndrew L, Schneider SH, Burns E, Leventhal H. Does patient blood glucose monitoring improve diabetescontrol? A systematic review of the literature. Diabetes Educ. 2007;33(6):991-1010.

2. Dixon LC, Ward DJ, Smith J, Holmes S, Mahadeva R. New and emerging technologies for the diagnosis and monitoring of chronic obstructive pulmonary disease. A horizon scanning review. Chron Respir Dis. 2016;13(4):321-36.

3. Bray EP, Holder R, Mant J, McManus RJ. Does self-monitoring reduce blood pressure? Meta-analysis with meta-regression of randomized controlled trials. Ann Med. 2010;42(5):371-86.

4. Barlow J, Wright C, Sheasby J, Turner A, Hainsworth J. Self-management approaches for people with chronic conditions: a review. Patient Educ Couns. 2002;48(2):177-87.

5. Wilde MH, Garvin S. A concept analysis of self-monitoring. J Adv Nurs. 2007;57(3):339-50.

6. Richard AA, Shea K. Delineation of self-care and associated concepts. J Nurs Scholarsh. 2011;43(3):255-64.

7. Davis Jr FD. A technology acceptance model for empirically testing new end-user information systems: theory and results [PhD dissertation]. Cambridge: Massachusetts Institute of Technology; 1986.

8. Holden RJ, Karsh B-T. The technology acceptance model: its past and its future in health care. J Biomed Inform. 2010;43(1):159-72.

9. Garavand A, Mohseni M, Asadi H, Etemadi M, Moradi-Joo M, Moosavi A. Factors influencing the adoption of health information technologies: a systematic review. Electron Phys. 2016;8(8):2713-8.

10. Venkatesh V, Morris M, Davis GB, Davis FD. User acceptance of information technology: toward a unified view. MISQ. 2003;27(3):425-78.

11. Warsi A, Wang PS, LaValley MP, Avorn J, Solomon DH. Self-management education programs in chronic disease: a systematic review and methodological critique of the literature. Arch Intern Med. 2004;164(15):1641-9.

12. Mamykina L, Smaldone AM, Bakken SR. Adopting the sensemaking perspective for chronic disease selfmanagement. J Biomed Inform. 2015;56:406-17.

13. Huygens MWJ, Vermeulen J, Swinkels ICS, Friele RD, van Schayck OCP, de Witte LP. Expectations and needs of patients with a chronic disease toward self-management and eHealth for self-management purposes. BMC Health Serv Res. 2016;16(1):1-11.

14. Bandura A. Self-efficacy: the exercise of control. New York: Freeman; 1997.

15. Lorig KR, Holman HR. Self-management education: history, definition, outcomes, and mechanisms. Ann Behav Med. 2003;26(1):1-7.

16. Aljasem LI, Peyrot M, Wissow L, Rubin RR. The impact of barriers and self-efficacy on self-care behaviors in type 2 diabetes. Diabetes Educ. 2001;27(3):393-404.

17. Al-Khawaldeh OA, Al-Hassan MA, Froelicher ES. Self-efficacy, self-management, and glycemic control in adults with type 2 diabetes mellitus. J Diabet Complications. 2012;26(1):10-6.

18. Rosenstock IM. Historical origins of the health belief model. Health Educ Behav. 1974;2(4):328-35.

19. Aalto A-M, Uutela A. Glycemic control, self-care behaviors, and psychosocial factors among insulin treated diabetics: a test of an extended health belief model. Int J Behav Med. 1997;4(3):191-214.

20. Rijken M, Bensing J. Het nationaal Patiëntenpanel Chronisch Zieken: een onderzoeksinfrastructuur [The National Panel of Patients with Chronic Diseases. An infrastructure for patient-centered research]. TSG Tijdschrift Voor Gezondheidswetenschappen. 2000;78:93-100.

21. Teeuw B, Schwarzer R, Jerusalem M. Dutch adaptation of the general self-efficacy scale. Berlin: Freie Universität; 1994

22. Ware Jr JE, Kosinski M, Keller SD. A 12-Item Short-Form Health Survey: construction of scales and preliminary tests of reliability and validity. Med Care. 1996;34(3):220-33.

23. Cheak-Zamora NC, Wyrwich KW, McBride TD. Reliability and validity of the SF-12v2 in the medical expenditure panel survey. Qual Life Res. 2009;18(6):727-35.

24. Association AD. Standards of medical care in diabetes-2015 abridged for primary care providers. Clin Diab. 2015;33(2):97-111. 
25. National Institute for Clinical Excellence. Management of type 2 diabetes: management of blood glucose. London: NICE; 2002.

26. Cameron J, Worrall-Carter L, Riegel B, Lo SK, Stewart S. Testing a model of patient characteristics, psychologic status, and cognitive function as predictors of self-care in persons with chronic heart failure. Heart Lung. 2009;38(5):410-8.

27. Hibbard JH, Mahoney ER, Stockard J, Tusler M. Development and testing of a short form of the patient activation measure. Health Serv Res. 2005;40(6p1):1918-30.

28. Bos-Touwen I, Schuurmans M, Monninkhof EM, Korpershoek Y, Spruit-Bentvelzen L, Ertugrul-van der Graaf I, et al. Patient and disease characteristics associated with activation for self-management in patients with diabetes, chronic obstructive pulmonary disease, chronic heart failure and chronic renal disease: a crosssectional survey study. PLOS ONE. 2015;10(5):e0126400.

29. Liddy C, Blazkho V, Mill K. Challenges of self-management when living with multiple chronic conditions Systematic review of the qualitative literature. Can Fam Physician. 2014;60(12):1123-33.

30. Coventry PA, Fisher L, Kenning C, Bee P, Bower P. Capacity, responsibility, and motivation: a critical qualitative evaluation of patient and practitioner views about barriers to self-management in people with multimorbidity. BMC Health Serv Res. 2014;14(1):536.

31. Lorig K, Stewart A, Ritter P, Gonzalez V, Laurent D, Lynch J. Outcome measures for health education and other health care interventions. Thousand Oaks: Sage Publications; 1996.

32. Edwards L, Thomas C, Gregory A, Yardley L, O'Cathain A, Montgomery AA, et al. Are people with chronic diseases interested in using telehealth? A cross-sectional postal survey. J Med Internet Res. 2014;16(5):e123.

33. Wilson EV, Lankton NK. Modeling patients' acceptance of provider-delivered e-health. J Am Med Inform Assoc. 2004;11(4):241-8.

34. Ware JE, Gandek B, Guyer R, Deng N. Standardizing disease-specific quality of life measures across multiple chronic conditions: development and initial evaluation of the QOL Disease Impact Scale (QDIS $\left.{ }^{\circledR}\right)$. Health Qual Life Outcomes. 2016;14(1):84.

35. Huang J-C, Lin S-P. Exploring the key factors in the choice of home telehealth by using the health belief model. Telemed J E Health. 2009;15(1):87-92.

36. Gammon D, Johannessen L, Sørensen T, Wynn R, Whitten P. An overview and analysis of theories employed in telemedicine studies. Methods Inf Med. 2008;47:260-9.

37. Huang J-C. Remote health monitoring adoption model based on artificial neural networks. Expert Syst Appl. 2010;37(1):307-14. 
Appendix 1 Items of the questionnaire for NPCD panel members

Question regarding self-monitoring

1. Did you measure certain health data by yourself in the past year, for example blood pressure, blood glucose values or lung function?

Response format: 1=yes, 2=no, but I would like to do this (independently), 3=no, but I would like to do this together with a care professional, 4=no, and I do not want to do this.

General self-efficacy scale

1. I can always manage to solve difficult problems if I try hard enough.

2. If someone opposes me, I can find the means and ways to get what I want.

3. It is easy for me to stick to my aims and accomplish my goals.

4. I am confident that I could deal efficiently with unexpected events.

5. Thanks to my resourcefulness, I know how to handle unforeseen situations.

6. I can solve most problems if I invest the necessary effort.

7. I can remain calm when facing difficulties because I can rely on my coping abilities.

8. When I am confronted with a problem, I can usually find several solutions.

9. If I am in trouble, I can usually think of a solution.

10. I can usually handle whatever comes my way.

Response Format: 1=Not at all true, 2=Hardly true, 3=Moderately true, 4=Exactly true

\section{SF-12 health survey}

1. In general, how would you call your health?

Response Format: 1=Excellent, 2=Very good, 3=Good, 4=Fair, 5= Poor

- The following questions are about activities you might do on a typical day. Does your health limit you a lot, a little or not at all during these activities?

Response Format: $1=Y e s$, limited a lot, 2=Yes, limited a little, 3=No, not limited at all

2. In moderate activities, such as moving a table, pushing a vacuum cleaner, cycling?

3. How about climbing several flights of stairs?

4. During the past four weeks, have you accomplished less than you would like as a result of your physical health?

Response Format: 1=Yes, 2=No

5. During the past four weeks, were you limited in the kind of work or other activities you could do as a result of your physical health?

Response Format: 1=Yes, 2=No

6. During the past four weeks, have you accomplished less than you would like as a result of your emotional health (such as feeling depressed or anxious).

Response Format: 1=Yes, 2=No

7. During the past four weeks, were you limited in the kind of work or other activities you could do as a result of your emotional health (such as feeling depressed or anxious).

Response Format: $1=Y e s, 2=$ No

8. During the past four weeks, how much did pain interfere with your normal work, including both work outsight the home and housework).

Response Format: 1=Yes, 2=No

9. During the past four weeks, how often have you felt calm and peach full?

Response Format: $1=$ all of the time, $2=$ most of the time, $3=a$ good bit of the time, $4=$ some of the time, $5=a$ little of the time, $6=$ none of the time.

10. During the past four weeks, how often did you have a lot of energy?

Response Format: $1=$ all of the time, $2=$ most of the time, $3=a$ good bit of the time, $4=$ some of the time, $5=a$ little of the time, $6=$ none of the time.

11. During the past four weeks, how often have you felt downhearted or blue? 
Response Format: $1=$ all of the time, $2=$ most of the time, $3=a$ good bit of the time, $4=$ some of the time, $5=a$ little of the time, $6=$ none of the time.

12. During the past four weeks, how much of the time has your physical health and emotional problems interfered with your social activities (like visiting friends and relatives)?

Response Format: $1=$ all of the time, $2=$ most of the time, $3=a$ good bit of the time, $4=$ some of the time, 5=a little of the time, $6=$ none of the time. 
CHAPTER 4

Appendix 2 Most common chronic diseases per disease category

\begin{tabular}{|c|c|c|}
\hline Disease category & ICPC & Name \\
\hline \multirow[t]{4}{*}{ Ischemic heart disease } & K74 & Ischaemic heart disease $\mathrm{w}$. angina \\
\hline & K75 & Acute myocardial infarction \\
\hline & K76 & Ischaemic heart disease w/o angina \\
\hline & K77 & Heart failure \\
\hline \multirow[t]{2}{*}{ Hypertension } & K86 & Hypertension uncomplicated \\
\hline & K87 & Hypertension complicated \\
\hline \multirow[t]{4}{*}{ Other cardiovascular disorder } & K78 & Atrial fibrillation/flutter \\
\hline & K84 & Heart disease other \\
\hline & K90 & Stroke/cerebrovascular accident \\
\hline & K92 & Atherosclerosis/PVD \\
\hline \multirow[t]{5}{*}{ Cancer } & $x 76$ & Malignant neoplasm breast female \\
\hline & $x 77$ & Malignant neoplasm genital other ( $f$ ) \\
\hline & D75 & Malignant neoplasm colon/rectum \\
\hline & Y77 & Malignant neoplasm prostate \\
\hline & U76 & Malignant neoplasm of bladder \\
\hline Asthma & R96 & Asthma \\
\hline \multirow[t]{2}{*}{ COPD } & R95 & Chronic obstructive pulmonary dis \\
\hline & R91 & Chronic bronchitis/bronchiectasis \\
\hline Other respiratory disease & R97 & Allergic rhinitis \\
\hline Diabetes & T90 & Diabetes \\
\hline \multirow[t]{2}{*}{ Thyroid disorder } & T85 & Hyperthyroidism/thyrotoxicosis \\
\hline & T86 & Hypothyroidism/myxoedema \\
\hline \multirow[t]{3}{*}{ Chronic back pain } & LO2 & Back symptom/complaint \\
\hline & L03 & Low back symptom/complaint \\
\hline & L86 & Back syndrome with radiating pain \\
\hline Rheumatism & L88 & Rheumatoid/seropositive arthritis \\
\hline \multirow[t]{2}{*}{ Osteoarthritis } & L90 & Osteoarthrosis of knee \\
\hline & L91 & Osteoarthrosis other \\
\hline \multirow[t]{2}{*}{ Other musculoskeletal disorder } & L95 & Osteoporosis \\
\hline & L99 & Musculoskeletal disease, other \\
\hline Migraine & N89 & Migraine \\
\hline \multirow[t]{3}{*}{ Other neurological disorder } & N86 & Multiple sclerosis \\
\hline & N88 & Epilepsy \\
\hline & N99 & Neurological disease, other \\
\hline \multirow[t]{3}{*}{ Digestive disorder } & D92 & Diverticular disease \\
\hline & D93 & Irritable bowel syndrome \\
\hline & D94 & Chronic enteritis/ulcerative colitis \\
\hline \multirow[t]{2}{*}{ Skin disease } & S91 & Psoriasis \\
\hline & S87 & Dermatitis/atopic eczema \\
\hline
\end{tabular}




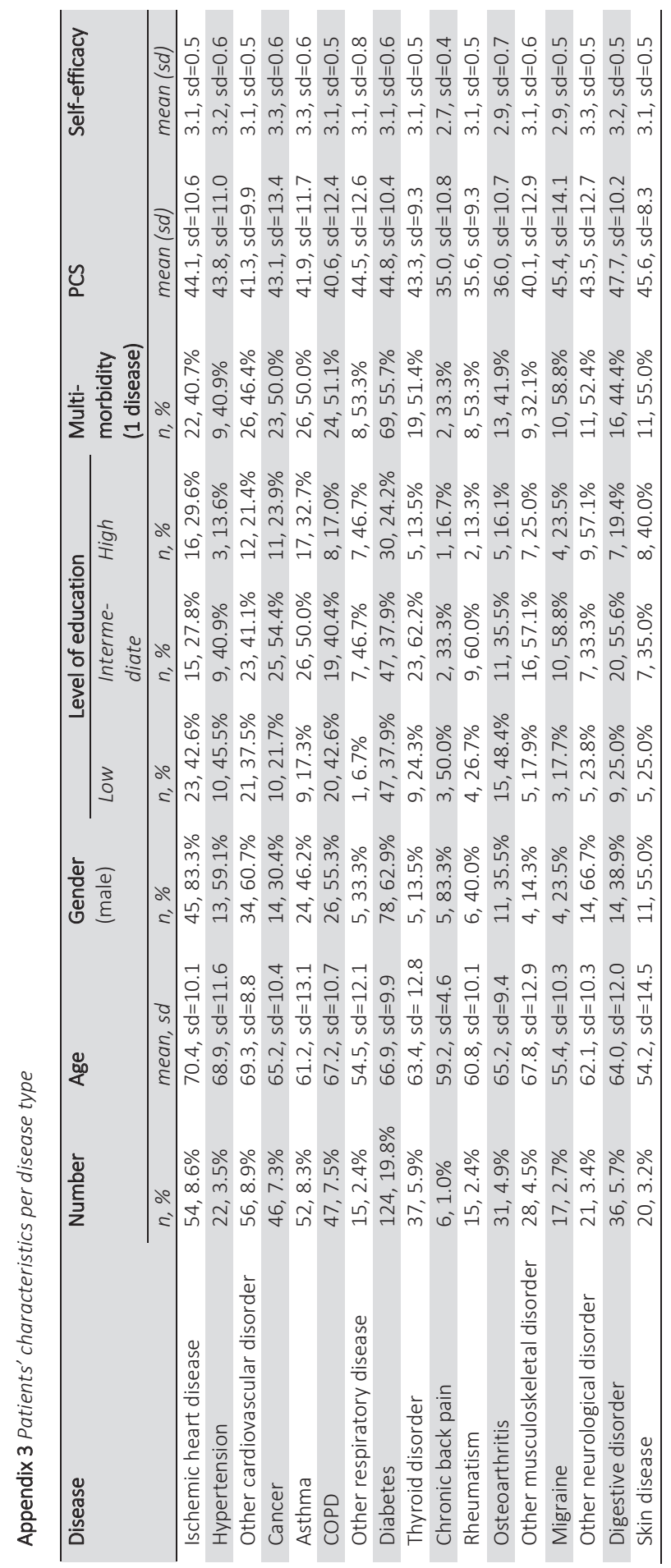


Appendix 4 Results of the expert panel of disease controllability per disease category

To what extent can people with a chronic disease, in general, independently keep their disease under control (by means of nutrition, physical activity, medication etc.)?

1. Number of experts per score

\begin{tabular}{llll}
\hline Disease type & not at all & to some extent & to a large extent \\
\hline Cancer & 8 & 1 & \\
\hline Thyroid disorder & 5 & 4 & \\
\hline Other neurological disorder & 4 & 5 & \\
Migraine & 4 & 5 & 1 \\
\hline Skin disorder & 4 & 4 & 1 \\
\hline Other respiratory disease & 4 & 4 & \\
Rheumatism & 2 & 7 & 1 \\
\hline Other cardiovascular disorder & 2 & 6 & 2 \\
\hline Other musculoskeletal disorder & 2 & 5 & 3 \\
\hline Osteoarthritis & 2 & 4 & 3 \\
\hline Digestive disorder & 2 & 4 & 2 \\
Ischemic heart disease / heart failure & & 7 & 5 \\
\hline Chronic back pain & 1 & 3 & 5 \\
COPD & & 4 & 6 \\
Asthma & 1 & 2 & 6 \\
\hline Hypertension & & 3 & 9 \\
\hline Diabetes & & & \\
\hline
\end{tabular}

2. Calculated mean scores and standard deviation

\begin{tabular}{|c|c|c|c|c|c|}
\hline Disease type & $\begin{array}{l}\text { not at all } \\
\text { (1) }\end{array}$ & $\begin{array}{l}\text { to some } \\
\text { extent (2) }\end{array}$ & $\begin{array}{l}\text { to a large } \\
\text { extent (3) }\end{array}$ & Mean score & $\mathrm{Sd}$ \\
\hline Cancer & 8 & 2 & & 1.11 & .33 \\
\hline Thyroid disorder & 5 & 8 & & 1.44 & .53 \\
\hline Other neurological disorder & 4 & 10 & & 1.56 & .53 \\
\hline Migraine & 4 & 10 & & 1.56 & .53 \\
\hline Skin disorder & 4 & 8 & 3 & 1.67 & .71 \\
\hline Other respiratory disease & 4 & 8 & 3 & 1.67 & .71 \\
\hline Rheumatism & 2 & 14 & & 1.78 & .44 \\
\hline Other cardiovascular disorder & 2 & 12 & 3 & 1.89 & .60 \\
\hline Other musculoskeletal disorder & 2 & 10 & 6 & 2.00 & .71 \\
\hline Osteoarthritis & 2 & 8 & 9 & 2.11 & .78 \\
\hline Digestive disorder & 2 & 8 & 9 & 2.11 & .78 \\
\hline $\begin{array}{l}\text { Ischemic heart disease / heart } \\
\text { failure }\end{array}$ & & 14 & 6 & 2.22 & .44 \\
\hline Chronic back pain & 1 & 6 & 15 & 2.44 & .73 \\
\hline COPD & & 8 & 15 & 2.56 & .53 \\
\hline Asthma & 1 & 4 & 18 & 2.56 & .73 \\
\hline Hypertension & & 6 & 18 & 2.67 & .50 \\
\hline Diabetes & & & 27 & 3.00 & 0 \\
\hline
\end{tabular}




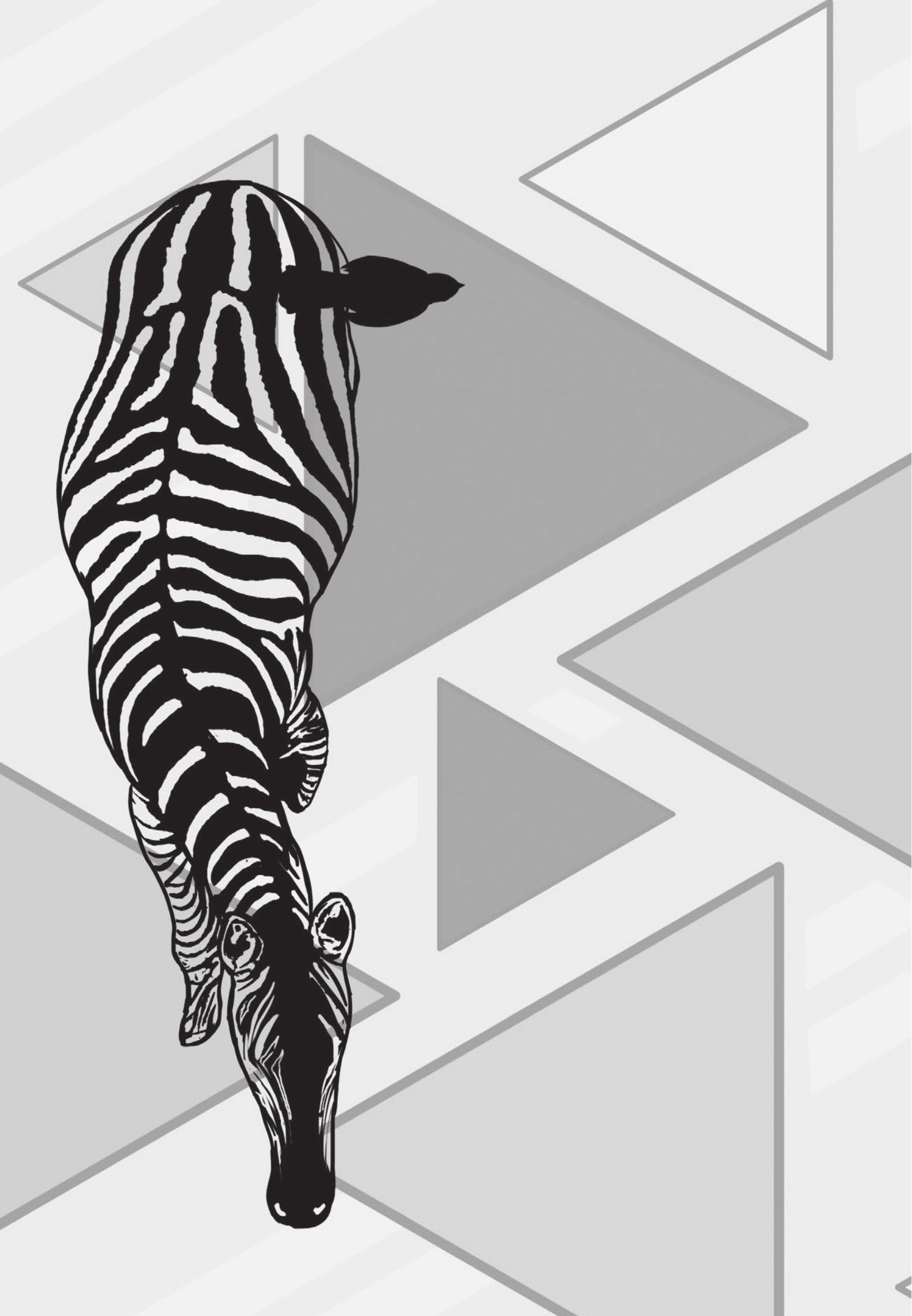




\section{CHAPTER 5}

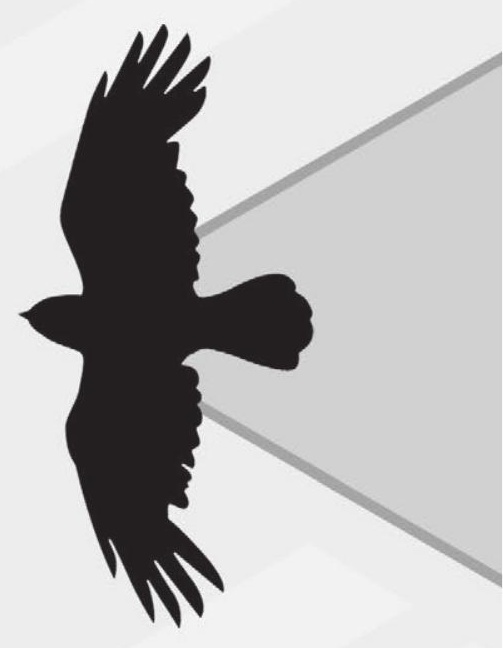

Understanding the use of email-consultation in primary care using a retrospective observational study with data of Dutch electronic health records

This chapter was accepted by BMJ open as:

Huygens MWJ, Swinkels ICS, Verheij RA, Friele RD, van Schayck OCP, and de Witte LP. Understanding the use of email-consultation in primary care using a retrospective observational study with data of Dutch electronic health records 


\begin{abstract}
Objectives It is unclear why the use of email-consultation is not more widespread in Dutch general practice (GP), particularly because, since 2006, its costs can be reimbursed. To encourage its further implementation, it is needed to understand the current use of email-consultations. This study aims to understand the use of emailconsultation in primary care by different patient groups, compared to other GP consultations.
\end{abstract}

Setting For this retrospective observational study we used routine electronic health record data obtained from NIVEL Primary Care Database for the years 2010 and 2014.

Participants 200 general practices were included in 2010 (734 122 registered patients), 434 in 2014 (1 630386 registered patients).

Primary outcome measures The number and percentage of email-consultations, and patient characteristics (age, gender, neighbourhood socioeconomic status (NSES) and diagnoses) of email-consultation users were investigated and compared to those who had a telephone or face-to-face consultation. General practice characteristics were also taken into account.

Results $32.0 \%$ of the Dutch general practices had at least one email-consultation in 2010, rising to $52.8 \%$ in 2014 . In 2014 , only $0.7 \%$ of the GP consultations were by email (the others comprised home visits, telephone, and face-to-face consultations). Its use highly varied among GP's. Most email-consultations were done for psychological (14.7\%), endocrine, metabolic, nutritional (10.9\%) and circulatory (10.7\%) problems. These diagnosis categories appeared less frequently in telephone and face-to-face consultations. Patients who had an email-consultation were older than patients who had a telephone or face-to-face consultation. In contrast, patients with diabetes who had an email-consultation were younger.

Conclusion Even though email-consultation was done in half the general practices in the Netherlands in 2014, the actual use of it is extremely low. Patients who had an emailconsultation differ from those that had a telephone or face-to-face consultation. In addition, the use of email-consultation by patients is dependent on its provision by GPS. 


\section{Introduction}

In the past decade, interest has grown in digital services for communication in primary care between patients and health care professionals. ${ }^{1-3}$ In several European countries, between 19 (United Kingdom) to 51 (Denmark) percent of patients sent or received an email from their doctor, nurse or health care organisation. ${ }^{1}$ Email-consultation is an asynchronous way of communication by which patients can consult their health care professional at any time of the day, and health care professionals can respond when it is suitable for them. Email-consultations are consistent with the trend in primary care towards care processes being performed more efficiently, by shifting tasks from the general practitioner to the primary care nurse. ${ }^{4,5}$ However, in many countries, the use of email-consultation is not yet structurally embedded in daily care routines and is often not yet encouraged by national policies. ${ }^{6}$

Numerous studies have been conducted to investigate the concerns and benefits regarding email-consultation. Identified concerns include an increase in the workload of physicians, ${ }^{7-9}$ privacy and safety issues, ${ }^{9,10}$ and the exacerbation of existing inequalities in access to health care. ${ }^{7,9}$ In contrast, other studies found that email-consultation is timesaving, ${ }^{11,12}$ and that it can offer increased opportunities for marginalised groups to access health care. ${ }^{13}$ In addition, it is expected that, by the introduction of emailconsultation, general practice consultations can be reduced, particularly telephone consultations; however, studies have shown inconsistent effects regarding this suggested reduction. ${ }^{14}$ In general, evidence is still inconclusive regarding the impact of email-consultations. ${ }^{15}$

Studies examining the consulting pattern of patient groups using email-consultation, in comparison with office consultations, are scarce. ${ }^{1}$ The few studies that have investigated the characteristics of frequent email-consultation users have shown mixed results; some found that email-consultation was used more by the younger ${ }^{1,16,17}$ and higher educated groups, ${ }^{1}$ while others found that age ${ }^{3}$ and employment status ${ }^{16}$ did not seem to influence its use. In addition, little is known about the health issues about which patients communicate using email. It seems that patients use email to pose questions about biomedical concerns, medication, test results and to inform or update healthcare professionals about non-urgent health issues ('for your information' messages). ${ }^{3,18}$ For further implementation, insight is needed to clearly understand the feasibility and acceptability of email-consultation by different patient populations and to compare these with other GP consultations. ${ }^{6}$

In contrast to many other countries, since 2006 the costs of email-consultation in primary care can be reimbursed by the health insurance in the Netherlands. The Dutch Ministry of Health, Welfare and Sport acknowledges the potential benefits of eHealth and stimulate the use of online communication in health care. ${ }^{19}$ In addition, the Dutch College of General Practitioners set up guidelines for the use of email-consultation and stimulates the use of it. ${ }^{20}$ Nevertheless, the actual use of email-consultation seems low. ${ }^{2}$ 
In addition, the effectiveness of email-consultation and the benefits it can bring are unclear. Understanding for which patients, and for what reasons, email is currently used might be important to maximise the benefits it can bring. ${ }^{9}$

This study aims to acquire insights into the current status of email-consultation usage in the Netherlands, by using data from electronic health records of Dutch primary care practices. In particular, the focus is on the number of email-consultations done by different patient groups (in terms of age, gender, socioeconomic status and health conditions) as registered by primary care professionals. First, the email-consultation rates in the Netherlands in 2010 and 2014 will be investigated. Second, it will be investigated which patients (age, gender, and socioeconomic status) had an emailconsultation and for what health problems; these characteristics will be compared to those that had telephone or face-to-face consultations in 2014. Third, for the patient group who had the most email-consultations (as percentage of al GP consultations in that group), characteristics will be investigated together with the impact of emailconsultation (in terms of its percentage of use in comparison with telephone and faceto-face consultations) within this patient group. Because the use of email-consultation by patients might be dependent on its provision by the general practice, the general practice characteristics will also be taken into account.

\section{Methods}

\section{Design, participants and care setting}

We used routine electronic health record data from general practices, collected by NIVEL Primary Care Database ${ }^{21}$ in 2010 and 2014. Representative data of 200 general practices in 2010, and 434 general practices in 2014 were used, representing on average 734122 and 1630386 inhabitants, respectively $(4.4 \%$ and $9.7 \%$ of the Dutch population). We used only data from practices that met certain criteria regarding data quality; only general practices were included that recorded more than $70 \%$ of their consultations with International Classification of Primary Care (ICPC) codes and provided data for the entire calendar year. Primary care practices voluntarily participate in NIVEL Primary Care Database.

All Dutch residents are registered in one general practice. Health insurance is mandatory, in which GP consultations are fully covered. The general practitioner is the gatekeeper for hospital- and specialist care. Since 2006, an email-consultation can be reimbursed: 1) when it is done by a patient who is registered at the general practice, 2) in the case of an existing treatment relationship, 3) when it is not the first consultation for a health condition, and 4 ) when it is a substitute for a regular consultation. ${ }^{22}$

Dutch law allows the use of electronic health records for research purposes under certain conditions. According to this legislation, neither obtaining informed consent from 
patients nor approval by a medical ethics committee is obligatory for this type of study containing no directly identifiable data (Dutch Civil Law, Article 7:458). This study has been approved according to the governance code of NIVEL Primary Care Database, under number NZR-00315.062.

\section{Measurements}

\section{Characteristics of general practices}

The following general practice characteristics were included: average number of registered patients per general practice and level of urbanisation (from 1 being highly urban, to 5 being not urban).

\section{General practice consultation}

To compare the utilisation rate of email-consultation with other GP consultations, the following were included: email-consultations, short face-to-face consultations (20 minutes or less), long face-to-face consultations (more than 20 minutes), short home visits (less than 20 minutes), long home visits (more than 20 minutes) and telephone consultations (consultation types according to reimbursement codes determined by the Dutch Healthcare Authority ${ }^{23}$ ).

To investigate and compare the patient characteristics of those who had an emailconsultation with those who underwent another type of GP consultation, only emailconsultations, telephone consultations and face-to-face consultations (short + long) were included. For every consultation, the date and diagnosis were included. Consultations and corresponding diagnoses were coded according to the International Classification of Primary Care (ICPC- 1$).{ }^{24}$ Only consultations with a single ICPC were included in the analyses.

\section{Patient characteristics}

Age and gender were included as patient characteristics. In addition, neighbourhood status scores were provided by the Netherlands Institute for Social Research at postal code level (PC4). This score reflects the socioeconomic status score of a neighbourhood, compared to other neighbourhoods in the Netherlands ${ }^{25}$ and is a common indicator of neighbourhood socioeconomic status (NSES) in the Netherlands. ${ }^{26}$ The socioeconomic status scores were assessed in 2010 and 2014 and comprised four indicators: the average household income per particular postal code, the proportion of residents with low family income, the proportion of low-educated residents and the proportion of unemployed residents per postal code. A higher score means a higher status for the area of residence. Scores ranged from -6.75 to 3.06. The average NSES in the Netherlands is 0.0 . 


\section{Statistical analyses}

Three data sets were used for this study. First, to investigate the consultation rates in 2010 and 2014, all general practices in these years (from our dataset) were included and the following consultation types were analysed: email-consultation, face-to-face consultation, long face-to-face consultation, home visits, long home visits and telephone consultation. Descriptive analyses were conducted to calculate the consultation rate per 1000 registered patients (counted from the average number of registered patients per year) in 2010 and 2014, and to count the general practices that registered emailconsultations in these years.

Second, to investigate which patient groups had email-consultations, and for what health problems, and to compare this with patients that had another GP consultation, only data from general practices in 2014 were used. The following consultation types were analysed: email-consultation, face-to-face consultation (short and long) and telephone consultation. Patients and consultations with incomplete datasets were excluded. This included observations with missing patient characteristics or consultations with none or two or more ICPC codes. $31.6 \%$ of the observations were excluded of which $28.6 \%$ due to consultations with none or two or more ICPCS). Because the use of email-consultation by patients is dependent on its provision by the general practice, the dataset was split into three groups based on the number of emailconsultations that general practices had in 2014; 1) general practices that did not register any email-consultation, 2) general practices that registered a few emailconsultations $(n<100)$ and 3$)$ general practices that registered many email-consultations $(n \geq 100)$. Descriptive analyses were used to investigate general practice characteristics (the average number of registered patients per general practice and level of urbanisation) and patient characteristics (age, gender and NSES). The diagnosis categories for which email-consultations, telephone consultations and face-to-face consultations (short + long) were done were calculated using descriptive analyses.

Every diagnosis category consisted of specific diagnoses. In the third dataset we included the patient group in which email-consultations, as percentage of all GP consultations in that group, were most often used. The following consultation types were analysed: email-consultation, face-to-face consultation (short + long) and telephone consultation. This dataset was split into three, based on the number of emailconsultations that general practices registered for that specific diagnosis in 2014: 1) general practices that did not register any email-consultation for that diagnosis, 2) general practices that registered a few email-consultations for that diagnosis $(n<25)$ and 3 ) general practices that registered many email-consultations for that diagnosis $(n \geq 25)$. Descriptive analyses were used to investigate general practice characteristics (the average number of registered patients per general practice and level of urbanisation) and patient characteristics (age, gender and NSES).

To identify significant differences of general practice characteristics between the three groups of practices, two-way Anova with Bonferroni correction (average number of 
registered patients, mean age and NSES of the general practice patient population and level of urbanisation per general practice) were conducted. Differences in patient characteristics within the three groups of general practices (patients who had an email, telephone- or face-to-face consultation) were not tested for statistical significance because of the large sample size. In large samples, small differences can be detected as significant, even though they are not practically relevant. Therefore, only relevant differences are reported. The statistical package STATA (version 14.0) was used to conduct the analyses.

\section{Results}

\section{Study population}

\section{Dataset 1}

In 2010, data from 200 general practices were used, including 2708191 general practice consultations (577 487 patients). The mean age of the study population was 41.7 (sd=23.1, missing data $n=4207), 45.5 \%$ male, and the mean NSES was -0.10 ( $s d=1.19$, missing data $n=$ 93 193). In 2014, data from 434 general practices were collected including 6473921 general practice consultations (1 307822 patients). The mean age of the study population was 43.1 ( $s d=23.4$, missing data $n=9298$ ), 45.7\% male (missing data $n=98$ ), and the mean NSES was 0.08 ( $s d=1.10$, missing data $n=28$ 209). The characteristics of these general practices can be found in Table 1.

Table 1 Characteristics of general practices (GP) in 2010 and 2014

\begin{tabular}{lll}
\hline General practice characteristics & 2010 Mean $(s d)$ or n (\%) & 2014 Mean (sd) or $n(\%)$ \\
\hline n GP & 200 & 434 \\
n registered patients & 734122 & 1630386 \\
n GP consultations & 2708191 & 6473921 \\
n patients who had a GP consultation & 577487 & 1307822 \\
Average $n$ of registered patients per GP & $3671(\mathrm{sd}=2501)$ & $3757(\mathrm{sd}=2384)$ \\
Level of urbanisation & & \\
Very urban & $40(20.0 \%)$ & $89(20.5 \%)$ \\
High & $46(23.0 \%)$ & $99(22.8 \%)$ \\
Moderate & $38(19.0 \%)$ & $84(19.4 \%)$ \\
Little & $42(21.0 \%)$ & $85(19.6 \%)$ \\
Not urban & $32(16.0 \%)$ & $75(17.3 \%)$ \\
Missing & $2(1.0 \%)$ & $2(0.5 \%)$ \\
n GPs that registered email-consultations & $64(32.0 \%)$ & $229(52.8 \%)$ \\
\hline
\end{tabular}

\section{Dataset 2}

In dataset 2, data from 2014 were used. Home visits, and patients and consultations with incomplete data were excluded. 429 general practices were included. Non-response analyses showed no differences after exclusion (compared to the complete dataset without home visits) regarding patient characteristics (age, gender and NSES) and general practice 
characteristics (average number of registered patients per general practice and level of urbanization). Characteristics of the general practices in the total dataset 2 , and of the general practices that registered none, a few $(<100)$ and many $(\geq 100)$ email-consultations can be found in Appendix 1.

Examination of the differences in general practice characteristics between these three groups showed differences in number of registered patients per general practice $(F=7.11$, $p<0.01)$, level of urbanization $(F=11.81, p<0.01)$ and age $(F=4.40, p=0.01)$. General practices that registered email-consultations had a higher number of registered patients per general practice, were located in more urban areas and had a younger patient population. No significant difference of NSES was found between these three groups ( $F=1.94, p=0.14$ ).

\section{Data set 1: the use of email-consultation in 2010 and 2014}

The number of general practices that used email-consultation increased from $32.0 \%$ in 2010 to $52.8 \%$ in 2014. The consultation rates per consultation type for 2010 and 2014 can be found in Table 2. The utilisation of email-consultation increased from 8.4 per 1000 registered patients in 2010 to 17.6 in 2014. In comparison, 1033.9 telephone consultations per 1000 registered patients were carried out in 2010, and 1140.6 in 2014. In general practices that registered email-consultations, $0.6 \%(n=5494)$ of the total GP consultations were by email in 2010; in 2014, this was $0.7 \%(n=24556)$.

Table 2 Consultation rate per 1000 registered patients per year

\begin{tabular}{lllllllll}
\hline Year & General practices & $\mathrm{n}$ & $\begin{array}{l}\text { Email- } \\
\text { consul- } \\
\text { tation }\end{array}$ & $\begin{array}{l}\text { Face- } \\
\text { to-face }\end{array}$ & $\begin{array}{l}\text { Face- } \\
\text { to-face } \\
\text { long }\end{array}$ & $\begin{array}{l}\text { Home } \\
\text { visit }\end{array}$ & $\begin{array}{l}\text { Home } \\
\text { visit } \\
\text { long }\end{array}$ & $\begin{array}{l}\text { Tele- } \\
\text { phone }\end{array}$ \\
\hline 2010 & All general practices & 200 & 8.4 & 2325.0 & 374.6 & 147.4 & 73.3 & 1033.9 \\
2014 & $\begin{array}{l}\text { All general practices } \\
2014\end{array}$ & 434 & 17.6 & 2299.6 & 532.6 & 128.9 & 89.2 & 1140.6 \\
\hline $\begin{array}{l}\text { GP that did not register } \\
\text { email-consultations }\end{array}$ & 205 & - & 2241.3 & 510.8 & 145.0 & 94.5 & 1058.6 \\
$\begin{array}{l}\text { GP that registered } \\
\text { <100 email-consultations }\end{array}$ & 163 & 8.1 & 2404.2 & 563.2 & 120.4 & 89.2 & 1176.3 \\
\hline $\begin{array}{l}\text { GP that registered } \geq 100 \\
\text { email-consultations }\end{array}$ & 66 & 95.8 & 2222.2 & 524.9 & 99.7 & 72.5 & 1307.3 \\
\hline
\end{tabular}

For 2014, the consultation rate per consultation type was calculated for general practices that did not register any email-consultations, that registered a few email-conconsultations $(n<100)$ and that registered many email-consultations $(n \geq 100)$. In general practices that registered many email-consultations, the utilization of email-consultations was 95.8 per 1000 registered patients.

Data set 2: characteristics of email, telephone and face-to-face consultation users

Table 3 shows the characteristics of patients who had at least one email, telephone, or face-to-face consultation, distributed in terms of general practices that performed none, 
a few, or many email-consultations. In general practices that had a few emailconsultations, $0.6 \%$ of the patients who had at least one GP consultation had an emailconsultation. This was $4.8 \%$ in general practices that had many email-consultations.

In general practices that registered email-consultations, relevant differences were found in age between patients who had an email versus a telephone or face-to-face consultation; patients that had an email-consultation seemed to be older. In general practices that registered a few email-consultations, the mean age of patients that did an email-consultation was 46.4 . This was 45.7 and 42.0 for patients that did a telephone and face-to-face consultation respectively. In general practices that registered many email-consultations the mean age of patients that did an email-consultation was 46.4 . This was 45.2 and 42.1 for patients that did a telephone and face-to-face consultation respectively. 


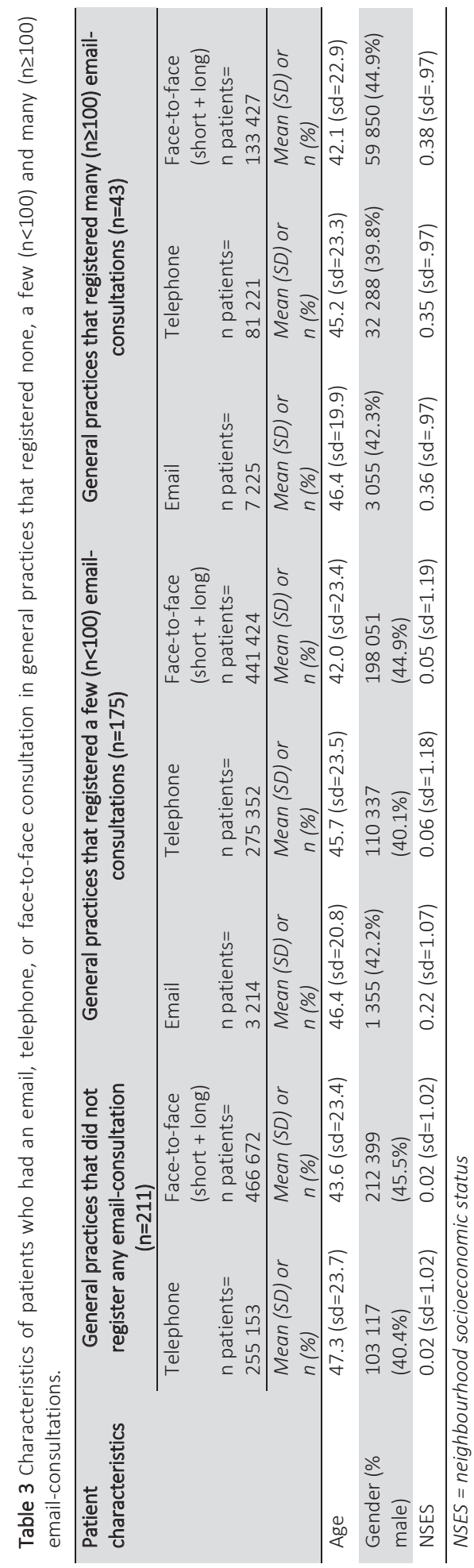




\section{Data set 2: diagnosis categories of email-consultations vs telephone and face-to-face consultations}

The diagnosis categories for which patients had an email, telephone or face-to-face consultation in 2014 can be found in Table 4 (listed from the most to the least frequently used diagnosis category). Most email-consultations were associated with the following diagnosis categories: psychological (14.7\%), endocrine, metabolic, nutritional (10.9\%) and circulatory (10.7\%). In comparison with other GP consultations, these diagnosis categories were less frequently associated with telephone consultations (psychological: 9.1\%; endocrine, metabolic, nutritional: 7.3\%; and circulatory: 8.2\%) and face-to-face consultations (psychological: 5.8\%; endocrine, metabolic, nutritional: 4.4\%; and circulatory: 9.1\%).

Considering specific diagnoses, the highest number of email-consultations were done for hypertension (5.3\%, $\mathrm{n}=873$ consultations), diabetes $(5.0 \%, \mathrm{n}=835$ consultations) and depression (2.5\%, $\mathrm{n}=409$ consultations). This involved 1.8\% (diabetes), 1.6\% (depression), and $1.0 \%$ (hypertension) within the total number of GP consultations for diabetes, depression and hypertension, respectively, in general practices that registered emailconsultations.

\section{Data set 3: email-consultations for diabetes}

As described in the previous paragraph, the highest percentage of email-consultations was performed within diabetes consultations (1.8\% of all GP consultations for diabetes).. Therefore, in-depth analyses were carried out for this diagnosis group.

In 2014, 37409 patients had at least one GP consultation for diabetes (80 867 GP consultations). The mean age of the study population was 66.4 ( $\mathrm{sd}=13.7), 51.5 \%$ male and the mean NSES was $-0.15(s d=1.14)$. Characteristics of the general practices in the total dataset 3 , and of the general practices that registered none, a few $(<25)$ and many $(\geq 25)$ email-consultations for diabetes, can be found in Appendix 2. Examination of the differences in general practice characteristics between these three groups showed differences in number of registered patients per general practice $(F=17.44, p<0.01)$ and level of urbanization $(F=5.72, p<0.01)$. General practices that registered emailconsultations for diabetes had a significantly higher average number of registered patients and were located in more urban areas. No significant difference was found in mean age $(F=1.17, p=0.31)$ and NSES ( $F=1.99, p=0.14)$. 
Table 4 Diagnosis categories associated with email, telephone, or face-to-face consultations in general practices that registered at least one email-consultation in 2014 ( $n$ general practices=218), listed from the most to the least frequently used diagnosis category

\begin{tabular}{|c|c|c|c|c|c|c|}
\hline & \multicolumn{2}{|c|}{$\begin{array}{l}\text { Email-consultations } \\
n \text { consultations }=16558\end{array}$} & \multicolumn{2}{|c|}{$\begin{array}{l}\text { Telephone consultations } \\
n \text { consultations }=770103\end{array}$} & \multicolumn{2}{|c|}{$\begin{array}{l}\text { Face-to-face consultations (short } \\
+ \text { long) } \\
\text { n consultations }=1609157\end{array}$} \\
\hline & Diagnosis category & $n(\%)$ & Diagnosis category & $n(\%)$ & Diagnosis category & $n(\%)$ \\
\hline 1 & Psychological & $\begin{array}{l}2434 \\
(14.7 \%)\end{array}$ & Musculoskeletal & $\begin{array}{l}109115 \\
(14.2 \%)\end{array}$ & Skin & $\begin{array}{l}259034 \\
(16.1 \%)\end{array}$ \\
\hline 2 & $\begin{array}{l}\text { Endocrine, } \\
\text { metabolic, } \\
\text { nutritional }\end{array}$ & $\begin{array}{l}1802 \\
(10.9 \%)\end{array}$ & Digestive & $\begin{array}{l}75508 \\
(9.8 \%)\end{array}$ & Musculoskeletal & $\begin{array}{l}245441 \\
(15.3 \%)\end{array}$ \\
\hline 3 & Circulatory & $\begin{array}{l}1777 \\
(10.7 \%)\end{array}$ & Respiratory & $\begin{array}{l}74819 \\
(9.7 \%)\end{array}$ & Respiratory & $\begin{array}{l}172494 \\
(10.7 \%)\end{array}$ \\
\hline 4 & Musculoskeletal & $\begin{array}{l}1609 \\
(9.7 \%)\end{array}$ & $\begin{array}{l}\text { General/ } \\
\text { Unspecified }\end{array}$ & $\begin{array}{l}70539 \\
(9.2 \%)\end{array}$ & Circulatory & $\begin{array}{l}145828 \\
(9.1 \%)\end{array}$ \\
\hline 5 & Skin & $\begin{array}{l}1428 \\
(8.6 \%)\end{array}$ & Psychological & $\begin{array}{l}70297 \\
(9.1 \%)\end{array}$ & Digestive & $\begin{array}{l}106511 \\
(6.6 \%)\end{array}$ \\
\hline 6 & $\begin{array}{l}\text { General/ } \\
\text { Unspecified }\end{array}$ & $\begin{array}{l}1423 \\
(8.6 \%)\end{array}$ & Circulatory & $\begin{array}{l}62924 \\
(8.2 \%)\end{array}$ & Ear & $\begin{array}{l}97412 \\
(6.1 \%)\end{array}$ \\
\hline 7 & Respiratory & $\begin{array}{l}1274 \\
(7.7 \%)\end{array}$ & Skin & $\begin{array}{l}56879 \\
(7.4 \%)\end{array}$ & Psychological & $\begin{array}{l}93820 \\
(5.8 \%)\end{array}$ \\
\hline 8 & Digestive & $\begin{array}{l}1213 \\
(7.3 \%)\end{array}$ & $\begin{array}{l}\text { Endocrine, } \\
\text { metabolic, nutritional }\end{array}$ & $\begin{array}{l}55952 \\
(7.3 \%)\end{array}$ & $\begin{array}{l}\text { General/ } \\
\text { Unspecified }\end{array}$ & $\begin{array}{l}92600 \\
(5.8 \%)\end{array}$ \\
\hline 9 & Female Genital & $\begin{array}{l}649 \\
(3.9 \%)\end{array}$ & Female Genital & $\begin{array}{l}40276 \\
(5.2 \%)\end{array}$ & Urological & $\begin{array}{l}90444 \\
(5.6 \%)\end{array}$ \\
\hline 10 & $\begin{array}{l}\text { Pregnancy, } \\
\text { Childbearing, family } \\
\text { Planning }\end{array}$ & $\begin{array}{l}574 \\
(3.5 \%)\end{array}$ & Neurological & $\begin{array}{l}24262 \\
(3.2 \%)\end{array}$ & $\begin{array}{l}\text { Endocrine, } \\
\text { metabolic, nutritional }\end{array}$ & $\begin{array}{l}70548 \\
(4.4 \%)\end{array}$ \\
\hline 11 & Neurological & $\begin{array}{l}554 \\
(3.4 \%)\end{array}$ & $\begin{array}{l}\text { Pregnancy, } \\
\text { childbearing, family } \\
\text { Planning }\end{array}$ & $\begin{array}{l}22347 \\
(2.9 \%)\end{array}$ & Female Genital & $\begin{array}{l}47670 \\
(3.0 \%)\end{array}$ \\
\hline 12 & Social Problems & $\begin{array}{l}380 \\
(2.3 \%)\end{array}$ & Eye & $\begin{array}{l}17894 \\
(2.3 \%)\end{array}$ & Eye & $\begin{array}{l}43327 \\
(2.7 \%)\end{array}$ \\
\hline 13 & Urological & $\begin{array}{l}367 \\
(2.2 \%)\end{array}$ & Blood & $\begin{array}{l}13757 \\
(1.8 \%)\end{array}$ & Neurological & $\begin{array}{l}42980 \\
(2.7 \%)\end{array}$ \\
\hline 14 & Male Genital & $\begin{array}{l}348 \\
(2.1 \%)\end{array}$ & Ear & $\begin{array}{l}12812 \\
(1.7 \%)\end{array}$ & $\begin{array}{l}\text { Pregnancy, } \\
\text { Childbearing, family } \\
\text { Planning }\end{array}$ & $\begin{array}{l}32618 \\
(2.0 \%)\end{array}$ \\
\hline 15 & Eye & $\begin{array}{l}288 \\
(1.7 \%)\end{array}$ & Social Problems & $\begin{array}{l}12124 \\
(1.6 \%)\end{array}$ & Blood & $\begin{array}{l}29950 \\
(1.9 \%)\end{array}$ \\
\hline 16 & Blood & $\begin{array}{l}242 \\
(1.5 \%)\end{array}$ & Male Genital & $\begin{array}{l}11648 \\
(1.5 \%)\end{array}$ & Male Genital & $\begin{array}{l}19839 \\
(1.2 \%)\end{array}$ \\
\hline 17 & Ear & $\begin{array}{l}196 \\
(1.2 \%)\end{array}$ & Urological & $\begin{array}{l}3895 \\
(5.1 \%)\end{array}$ & Social Problems & $\begin{array}{l}18641 \\
(1.2 \%)\end{array}$ \\
\hline
\end{tabular}


Dataset 3: Characteristics of patients with diabetes who had a consult by email, telephone, or face-to-face

Characteristics of patients who had a diabetes consultation with their GP by email, telephone, or face-to-face in general practices that registered none, a few, or many email-consultations can be found in Table 5. In general practices that registered emailconsultations for diabetes, relevant differences were found in age of patients with diabetes who had an email-consultation versus a telephone and face-to-face consultation; patients that had an email-consultation seemed to be younger.

In general practices that registered many email-consultations for diabetes, $12.5 \%$ $(n=233)$ of the patients with diabetes had at least one email-consultation, and in general practices that registered a few email-consultations for diabetes this was $1.8 \%(n=132)$. In addition, in general practices that registered many email-consultations for diabetes, $13.8 \%$ ( $n=560$ ) of the GP consultations for diabetes were by email. In comparison, $29.0 \%$ ( $n=1$ 180) of the consultations were by telephone, and $57.2 \%$ ( $n=2327)$ face-to-face. In general practices that did not register email-consultations for diabetes, $40.1 \%$ ( $n=23$ 722) were telephone and 59.9\% ( $n=35$ 448) face-to-face consultations.

In general practices that registered many email-consultations for diabetes, $12.5 \%$ $(n=233)$ of the patients with diabetes had at least one email-consultation, and in general practices that registered a few email-consultations for diabetes this was $1.8 \%(n=132)$. In addition, in general practices that registered many email-consultations for diabetes, $13.8 \%$ ( $n=560$ ) of the GP consultations for diabetes were by email. In comparison, $29.0 \%$ ( $n=1$ 180) of the consultations were by telephone, and $57.2 \%$ ( $n=2327$ ) face-to-face. In general practices that did not register email-consultations for diabetes, $40.1 \%$ ( $n=23$ 722) were telephone and 59.9\% ( $n=35$ 448) face-to-face consultations. 


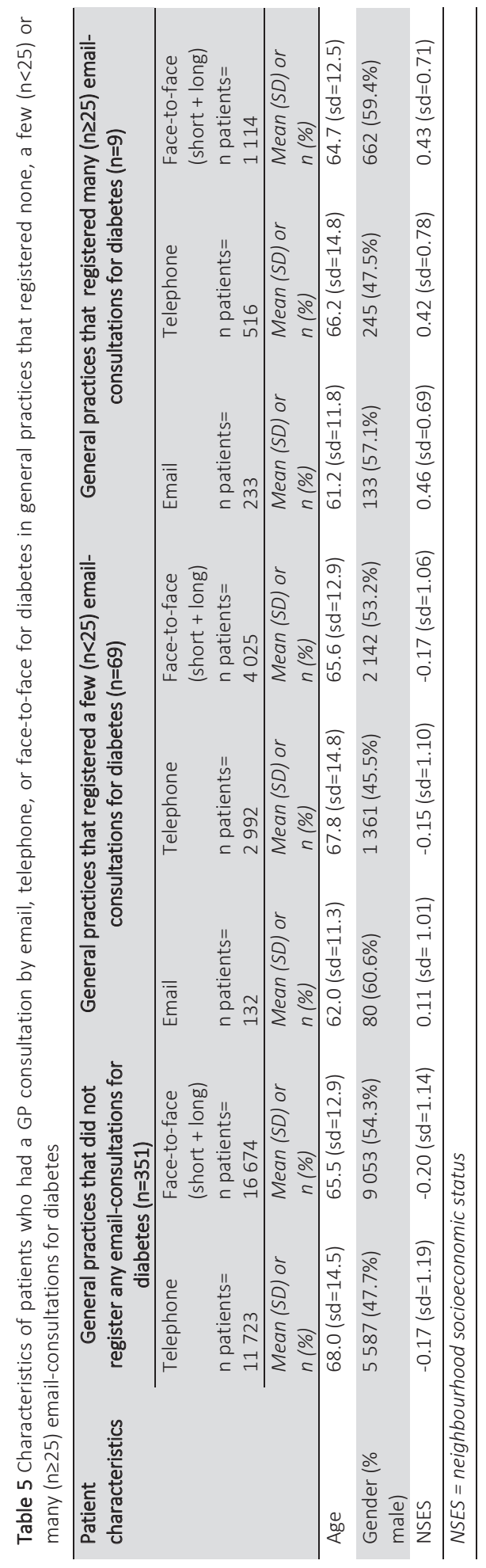




\section{Discussion}

\section{Principal findings}

This study aimed to acquire insights into the current status of email-consultation usage in the Netherlands, with a focus on the patient perspective. $32.0 \%$ of the general practices studied used email-consultations in 2010; this was more than half $(52.8 \%)$ in 2014. However, in 2014 email-consultations comprised still less than one percent of the total number of GP consultations (home visits, face-to-face-, telephone- and emailconsultations) in general practices that registered at least one email-consultation. Patients who had an email-consultation with their GP in 2014 were older compared to patients who had a telephone or face-to-face consultation. Furthermore, in general practices that registered many $(\geq 100)$ email-consultations, almost $5 \%$ of the patients who had at least one GP consultation (face-to-face, telephone, or email-consultation), had an email-consultation. Most patients had an email-consultation with their GP for issues related to psychological, endocrine, metabolic, nutritional and circulatory health problems. These diagnosis categories seemed to appear less frequently in telephone and face-to-face consultations. The highest percentage of email-consultations in comparison with all GP consultations within one specific disorder was related to diabetes. Interestingly, patients with diabetes who had an email-consultation were younger. In general practices that registered many $(\geq 25)$ email-consultations for diabetes, $12.5 \%$ of the patients with diabetes had at least one email-consultation for this condition. Patients' email-consultation usage is also dependent on its provision by the general practice: in general practices with a higher number of registered patients, located in more urban areas and with a younger patient population, email-consultation was more often used.

\section{Strengths and weaknesses}

The main strength of this study is that data were used from a large nationwide database comprising the electronic health records of Dutch general practices. This database is representative for the Dutch (general practice) population. ${ }^{21}$ General practices that did not fulfil the criteria for completeness of registration were excluded; however, this caused minimal selection bias. Email-consultations are recorded just as any other consultation in the Dutch electronic health record systems and thus are fully integrated. As there are clear financial incentives we assume that email consultations that fit the claims requirements, will be claimed, and thus recorded in the electronic health record systems. We assumed that all registered consultations included in this study are actually performed according to the rules of national declaration policy of the Dutch College of General Practitioners ${ }^{22}$ and the Dutch Healthcare Authority. ${ }^{23}$ However, within the scope of this study we could not check if this was really the case with all included 
consultations. Nevertheless, using data from registered consultations of electronic health records seems to be the most representative source for the investigation of actual email-consultation usage.

To reduce variation between general practices, we split the dataset into three groups of general practices: those registering none, a few, or many email-consultations. The observation that general practices registered no email-consultations does not indicate whether these general practices actually offered a service to perform emailconsultations. Although we do not have information about the online services offered in the general practices of our dataset, the annually published eHealth monitor about the status of eHealth in the Netherlands revealed that $49 \%$ of the surveyed general practices reported offering email-consultation in $2014 .^{27}$ In comparison, 52.8\% of the general practices in our dataset registered at least one email-consultation in 2014.

It might be expected that general practices only offer email-consultation for specific diagnoses (for example due to diagnosis specific procedures or applications); however, we found that all general practices in our dataset registered email-consultations for a wide range of diagnoses, which suggests that it could be used for all kinds of health problems. However, due to requirements for reimbursement of email-consultation, it should be noted that not every email-consultation can be claimed. In addition, some health questions cannot be addressed by email. In our analyses, we did not make a distinction between consultations that could be done by email or not, because it is currently unclear what questions are appropriate for this type of consultation. A limitation is that we excluded consultations with none or two or more conditions, due to methodological reasons. However, by redoing the analyses with these consultations included, results did not highly differ.

Another limitation of the study is that socioeconomic status was assessed at district level (postal code area); patients' individual socioeconomic status was unknown. Therefore, neighbourhood socioeconomic status (NSES) cannot be purely seen as an individual characteristic and is dependent on the area where the general practice is located. Furthermore, in this study, data of 2010 and 2014 were used. More recent data would probably show higher email-consultation rates. The annual Dutch eHealth monitor reported that the number of general practices that offer email-consultations increased from 49\% in 2014 to $60 \%$ in $2016 .{ }^{28}$ Nevertheless, there are no indications that email-consultation is used by other patient groups.

\section{Comparison with existing literature}

Half of the Dutch general practices in our dataset registered email-consultation in 2014; in comparison, it is only offered in $6 \%$ of the general practices in the United Kingdom, ${ }^{29}$ but to all citizens in Denmark via a public health portal. ${ }^{30}$ Even though it seems that email-consultation is offered by half the general practices in the Netherlands, its actual use is extremely low. This is not the case in Denmark, where, in 2013, more than 4 
million GP email-consultations were done (in comparison to about 20 million face-toface consultations), ${ }^{21,32}$ and a questionnaire study $(n=684)$ showed that $52 \%$ of the respondents (or their closest relative) had used an email-consultation. ${ }^{31}$

The lack of reimbursement is frequently mentioned as reason why eHealth is not yet fully adopted in primary care. A recently conducted systematic review of the factors influencing the implementation of eHealth found that cost related factors were mentioned by most studies as important barriers for the implementation of eHealth. ${ }^{33}$ However, our study shows that funding for eHealth does not directly guarantee eHealth use.

Overall, patients that had an email-consultation were older. Studies have found that a younger age is associated with email-consultation usage. ${ }^{1,16}$ This is not found when analysing the entire patient population, however looking into the diagnosis group that had the most email-consultations (patients with diabetes), we found that emailconsultation users seemed to be younger, compared to patients of this diagnose group who had a telephone or face-to-face consultation with their GP. It should be noted that email-consultations in the Netherlands can only be reimbursed when it is not the first consultation for a health condition; this might explain the observation that, overall, patients who had an email-consultation were older, as the number of people with a prolonged or chronic disease was greater in the higher age groups.

This study focuses on the consulting pattern of patient groups using emailconsultation, in comparison with other GP consultations. The use of email-consultation by patients, however, highly varies among general practices. Patients' email-consultation usage seems therefore partly dependent on its provision by the general practice. Therefore, the patient perspective cannot be studied in isolation; it is probably dependent on how general practices offer, promote and use it. ${ }^{34,35}$

Interestingly, email-consultations were most frequently used for diagnoses related to psychological (14.7\%), endocrine, metabolic, nutritional (10.9\%) and circulatory $(10.7 \%)$ concerns, which were less frequently the topic of telephone and face-to-face consultations. In the scarce research that have been performed regarding the content of online consultations, it was found that, using an online patient-provider portal, more psychosocial messages were sent via the portal than by telephone. ${ }^{36}$ In addition, a review of the impact of digital communication on marginalised groups suggests that online communication may reduce patients' inhibitions and sense of intimidation, resulting in more disclosure and asking of questions. ${ }^{13}$ Moreover, a study of electronic health records with the possibility of exchanging secure messages showed that this was most frequently used by patients with a chronic condition. ${ }^{37}$ In the current study, emailconsultation was most used by patients with diabetes. It seems that this disease is highly convenient for the use of email-consultation, because of the prolonged characteristic of the disease and the frequency of contact with the GP. The latter might suggest that these patients have a well-established and trusting relationship with their GP, which is found to be related to successful digital communication among patients and care professionals. ${ }^{13}$ In addition, it has been noted that patients use email to report a change 
in their condition or to discuss laboratory results, new conditions, changes in prescription dose, the need for new prescriptions or other requests for actions regarding medications or treatments; ${ }^{37,39}$ all of these are frequently seen in diabetes management. In our study, we did not have information about the content of the email-consultations; only the type of diagnosis. This should be further investigated in future research.

\section{Implications for research and practice}

Email-consultation has the potential to become a routinely used communication service for patient-GP interaction, similarly to telephone consultations; it seem to be an appropriate service in this day and age, when digital communication plays an important part in many individuals' daily lives. However, this study has shown that, in the Netherlands, the actual use of email-consultation is extremely low.

It seems that email-consultation is not just a service that can be merely installed. Without clear implementation strategies, including promotion strategies and defining for which patients it can be best used, it might not be adopted by patients. In this study, we found that email-consultation is most used by people with psychological, endocrine or circulatory concerns. Focusing on these target groups first, and investigating the effectiveness of email-consultation and the benefits it can bring for these patient groups, might be important to stimulate broader uptake among GPs and patients. In addition, investigating reasons why patients do not use email-consultation might provide important insights about patients' views regarding email-consultation and the barriers that need to be overcome. Experiencing the benefits of the use of email-consultation can be the drive for its routine use, for both patients and care professionals. Moreover, the use of email-consultation by patients highly varies among general practices. It is recommended to qualitatively study the use of email-consultation in general practices that use many email-consultations and in general practices that offer it, but use it less frequently. Investigating why it works in 'good practices' and why it is less frequently used in others will give more insight in the process that is needed to successfully implement and use email-consultation. These studies should be focused on the twolayered issue; from both perspectives of patients and providers.

\section{Acknowledgements}

We would like to thank Rodrigo Davids for helping in processing the data and Lucas van der Hoek and Peter Spreeuwenberg for their statistical advice and helping with statistical analyses. 


\section{References}

1. Newhouse N, Lupiáñez-Villanueva F, Codagnone C, Atherton H. Patient use of email for health care communication purposes across 14 European countries: an analysis of users according to demographic and health-related factors. J Med Internet Res. 2014;17(3):e58.

2. Huygens MWJ, Vermeulen J, Friele RD, van Schayck OCP, de Jong JD, de Witte LP. Internet services for communicating with the general practice: barely noticed and used by patients. Interact J Med Res. 2015;4(4):e21.

3. de Jong CC, Ros WJ, Schrijvers G. The effects on health behavior and health outcomes of Internet-based asynchronous communication between health providers and patients with a chronic condition: a systematic review. J Med Internet Res. 2014;16(1):e19.

4. Maier CB, Aiken LH. Task shifting from physicians to nurses in primary care in 39 countries: a cross-country comparative study. Eur J Public Health. 2016;26(6):927-34.

5. Kroneman M, Boerma W, van den Berg M, Groenewegen P, de Jong J, and van Ginneken E. Netherlands: Health system review. Health Syst Transit. 2016;18(2):1-240.

6. Antoun J. Electronic mail communication between physicians and patients: a review of challenges and opportunities. Fam Pract. 2015;33(2):121-126.

7. Hanna L, May C, Fairhurst K. The place of information and communication technology-mediated consultations in primary care: GPs' perspectives. Fam Pract. 2011;29(3):361-366.

8. Bishop TF, Press MJ, Mendelsohn JL, Casalino LP. Electronic communication improves access, but barriers to its widespread adoption remain. Health Aff. 2013;32(8):1361-7.

9. Atherton H, Pappas Y, Heneghan C, Murray E. Experiences of using email for general practice consultations: a qualitative study. Br J Gen Pract. 2013;63(616):e760-e7.

10. Goodyear-Smith F, Wearn A, Everts H, Huggard P, Halliwell J. Pandora's electronic box: GPs reflect upon email communication with their patients. J Innov Health Inform. 2005;13(3):195-202.

11. Rosen P, Kwoh CK. Patient-physician e-mail: an opportunity to transform pediatric health care delivery. Pediatrics. 2007;120(4):701-6.

12. Houston TK, Sands DZ, Nash BR, Ford DE. Experiences of physicians who frequently use e-mail withpatients. Health Commun. 2003;15(4):515-25.

13. Huxley CJ, Atherton H, Watkins JA, Griffiths F. Digital communication between clinician and patient and the impact on marginalised groups: a realist review in general practice. Br J Gen Pract. 2015;65(641):e813e21.

14. de Lusignan S, Mold F, Sheikh A, Majeed A, Wyatt JC, Quinn T, et al. Patients' online access to their electronic health records and linked online services: a systematic interpretative review. BMJ open. 2014;4(9):e006021.

15. Atherton H, Sawmynaden P, Sheikh A, Majeed A, Car J. Email for clinical communication between patients/caregivers and healthcare professionals. Cochrane Database Syst Rev. 2009;3.

16. Mehrotra A, Paone S, Martich GD, Albert SM, Shevchik GJ. Characteristics of patients who seek care via eVisits instead of office visits. Telemed and e-Health. 2013;19(7):515-9 .

17. Ye J, Rust G, Fry-Johnson Y, Strothers H. E-mail in patient-provider communication: A systematic review. Patient Educ Couns. 2010;80(2):266-73.

18. Byrne JM, Elliott S, Firek A. Initial experience with patient-clinician secure messaging at a VA medical center. J Am Med Inform Assoc. 2009;16(2):267-70.

19. NIVEL. Primary Care Database http://www.nivel.nl/en/dossier/nivel-primary-care-database [accessed 2017-07-05].

20. Nederlands Huisartsen Genootschap (NHG). NHG-Checklist e-consult. 2014.

21. The Dutch Healthcare Authority (NZa) https://www.nza.nl/organisatie/sitewide/english/ [accessed $2017-$ 07-05].

22. Lamberts H, Wood M. International classification of primary care. Oxford: Oxford University Press, 1987.

23. Knol F, Veldheer V. Neighbourhood status development in the Netherlands 1998-2010, 2012 


\section{CHAPTER 5}

24. Galobardes B, Shaw M, Lawlor D, Smith G, Lynch J. Indicators of Socioeconomic Position: Methodsin Social Epidemiology. J Epidemiol Community Health. 2006;60:47-85.

25. Krijgsman J, Peeters J, Burghouts A, Brabers A, Jong Jd, Beenkens F, et al. Op naar meerwaarde! eHealthmonitor 2014, 2014.

26. Krijgsman J, Swinkels I, Lettow van B, Jong de J, Out K, Friele R, et al. More than technology. eHealhtmonitor 2016, 2016.

27. Brant H, Atherton H, Ziebland S, McKinstry B, Campbell JL, Salisbury C. Using alternatives to face-to-face consultations: a survey of prevalence and attitudes in general practice. Br J Gen Pract. 2016;66(648):e460-e6.

28. Kierkegaard P. eHealth in Denmark: a case study. J Med Syst. 2013;37(6):9991.

29. Bertelsen P, Petersen LS, editors. Danish Citizens and General Practitioners' Use of ICT for theirMutual Communication. In MedInfo. 2015:376-379.

30. Danmarks Statestik. SYGK: Lægebesøg mv. med offentlig tilskud efter område, ydelsesart, alder, køn og socioøkonomisk status 2006-2013. 2015.

31. Ross J, Stevenson F, Lau R, Murray E. Factors that influence the implementation of e-health: a systematic review of systematic reviews (an update). Implement Sci. 2016;11(1):146.

32. Wolcott V, Agarwal R, Nelson DA. Is Provider Secure Messaging Associated With Patient Messaging Behavior? Evidence From the US Army. J Med Internet Res. 2017;19(4):e103.

33. Wells S, Rozenblum R, Park A, Dunn M, Bates DW. Organizational strategies for promoting patient and provider uptake of personal health records. J Am Med Inform Assoc. 2014;22(1):213-22.

34. Lin C-T, Wittevrongel L, Moore L, Beaty BL, Ross SE. An Internet-based patient-provider communication system: randomized controlled trial. J. Med. Internet Res. 2005;7(4):e47.

35. Serrato CA, Retecki S, Schmidt DE. MyChart-a new mode of care delivery: 2005 personal health link research report. Perm J. 2007;11(2):14-20. 
Appendix 1 General practice characteristics of data set 2 and of the three general practice groups of dataset 2

\begin{tabular}{|c|c|c|c|c|}
\hline \multirow[t]{3}{*}{ Characteristics } & Data set 2 (total) & $\begin{array}{l}\text { GP's that did } \\
\text { not register any } \\
\text { email- } \\
\text { consultations }\end{array}$ & $\begin{array}{l}\text { GP's that } \\
\text { registered a few } \\
(<100) \text { email- } \\
\text { consultations }\end{array}$ & $\begin{array}{l}\text { GP's that } \\
\text { registered many } \\
(\geq 100) \text { email- } \\
\text { consultations }\end{array}$ \\
\hline & $n=429$ & $n=211$ & $n=175$ & $n=43$ \\
\hline & $\begin{array}{l}\text { Mean (sd) or } \\
n(\%)\end{array}$ & $\begin{array}{l}\text { Mean (sd) or } \\
n(\%)\end{array}$ & $\begin{array}{l}\text { Mean (sd) or } \\
n(\%)\end{array}$ & $\begin{array}{l}\text { Mean (sd) or } \\
n(\%)\end{array}$ \\
\hline $\begin{array}{l}\text { Average number of } \\
\text { registered patients per } \\
\text { general practice }\end{array}$ & $\begin{array}{l}3752.2 \\
(s d=2387.4)\end{array}$ & $\begin{array}{l}3371.5 \\
(s d=1735.625)\end{array}$ & $\begin{array}{l}3975.7 \\
(s d=2593.1)\end{array}$ & $\begin{array}{l}4710.8 \\
(s d=3645.1)\end{array}$ \\
\hline $\begin{array}{l}\text { n general practice } \\
\text { consultations }\end{array}$ & 4207538 & 1811720 & 1856205 & 539613 \\
\hline $\begin{array}{l}\text { n patients that had a general } \\
\text { practice consultation }\end{array}$ & 1177123 & 511947 & 516039 & 149137 \\
\hline \multicolumn{5}{|l|}{ Level of urbanization } \\
\hline - Very urban & $89(20.8 \%)$ & $31(14.7 \%)$ & $47(26.9 \%)$ & $11(25.6 \%)$ \\
\hline - High & $96(22.4 \%)$ & $40(19.0 \%)$ & $42(24.0 \%)$ & $14(32.6 \%)$ \\
\hline - Moderate & $84(19.6 \%)$ & $39(18.5 \%)$ & $35(20.0 \%)$ & $10(23.3 \%)$ \\
\hline - Little & $85(19.8 \%)$ & $54(25.6 \%)$ & $27(15.4 \%)$ & $4(9.3 \%)$ \\
\hline - Not urban & $73(17.0 \%)$ & $47(22.3 \%)$ & $22(12.6 \%)$ & $4(9.3 \%)$ \\
\hline - Missing & $2(0.5 \%)$ & & $2(1.1 \%)$ & \\
\hline Age of the study population & $43.1(s d=23.5)$ & $43.9(s d=23.6)$ & $42.4(s d=23.4)$ & $42.3(\mathrm{sd}=23.0)$ \\
\hline $\begin{array}{l}\text { Gender ( } \% \text { male) of the } \\
\text { study population }\end{array}$ & $532217(45.2 \%)$ & $232793(45.5 \%)$ & 232466 (45.1\%) & 66958 (44.9\%) \\
\hline NSES of the study population & $.08(s d=1.10)$ & $.03(s d=1.02)$ & $.05(s d=1.19)$ & $.37(\mathrm{sd}=.98)$ \\
\hline
\end{tabular}

NSES = neighbourhood status scores 


\section{CHAPTER 5}

Appendix 2 General practice characteristics of data set 3 and of the three general practice groups of dataset 3 (patients with diabetes)

\begin{tabular}{|c|c|c|c|c|}
\hline \multirow[t]{3}{*}{ Characteristics } & Data set 3 (total) & $\begin{array}{l}\text { GPs that did not } \\
\text { register any } \\
\text { email- } \\
\text { consultations } \\
\text { for diabetes }\end{array}$ & $\begin{array}{l}\text { GPs that } \\
\text { registered a few } \\
(<25) \text { email- } \\
\text { consultations } \\
\text { for diabetes }\end{array}$ & $\begin{array}{l}\text { GPs that } \\
\text { registered many } \\
(\geq 25) \text { email- } \\
\text { consultations for } \\
\text { diabetes }\end{array}$ \\
\hline & $n=429$ & $n=351$ & $\mathrm{n}=69$ & $n=9$ \\
\hline & $\begin{array}{l}\text { Mean (sd) or } \\
n(\%)\end{array}$ & $\begin{array}{l}\text { Mean (sd) or } \\
n(\%)\end{array}$ & $\begin{array}{l}\text { Mean (sd) or } \\
n(\%)\end{array}$ & $\begin{array}{l}\text { Mean (sd) or } \\
n(\%)\end{array}$ \\
\hline $\begin{array}{l}\text { Average number of } \\
\text { registered patients per } \\
\text { general practice }\end{array}$ & $\begin{array}{l}3752.2 \\
(s d=2387.4)\end{array}$ & $\begin{array}{l}3486.7 \\
(s d=1982.2)\end{array}$ & $\begin{array}{l}4661.5 \\
(s d=3227.4)\end{array}$ & $7132.6(4627.6)$ \\
\hline $\begin{array}{l}\text { n general practice } \\
\text { consultations for diabetes }\end{array}$ & 80867 & 59170 & 17630 & 4067 \\
\hline $\begin{array}{l}\text { n patients that performed a } \\
\text { general practice consultation } \\
\text { for diabetes }\end{array}$ & 37409 & 28397 & 7149 & 1863 \\
\hline \multicolumn{5}{|l|}{ Level of urbanization } \\
\hline - Very urban & $89(20.8 \%)$ & $66(18.8 \%)$ & $21(30.4 \%)$ & $2(22.2 \%)$ \\
\hline - High & $96(22.4 \%)$ & $74(21.1 \%)$ & $19(27.5 \%)$ & $3(33.3 \%)$ \\
\hline - Moderate & $84(19.6 \%)$ & $68(19.4 \%)$ & $15(21.7 \%)$ & $1(11.1 \%)$ \\
\hline - Little & $85(19.8 \%)$ & $75(21.4 \%)$ & $9(13.0 \%)$ & $1(11.1 \%)$ \\
\hline - Not urban & $73(17.0 \%)$ & $66(18.8 \%)$ & $5(7.3 \%)$ & $2(22.2 \%)$ \\
\hline - Missing & $2(0.5 \%)$ & $2(0.6 \%)$ & & \\
\hline Age of the study population & $66.4(\mathrm{sd}=13.7)$ & $66.5(\mathrm{sd}=13.7)$ & $66.4(s d=13.77)$ & $64.7(s d=13.15)$ \\
\hline $\begin{array}{l}\text { Gender ( } \% \text { male) of the } \\
\text { study population }\end{array}$ & $19263(51.5 \%)$ & $14640(51.6 \%)$ & $3583(50.1 \%)$ & $1040(55.8 \%)$ \\
\hline NSES of the study population & $-.15(\mathrm{sd}=1.14)$ & $-.19(\mathrm{sd}=1.16)$ & $-.16(\mathrm{sd}=1.08)$ & $.43(\mathrm{sd}=.73)$ \\
\hline
\end{tabular}

NSES = neighbourhood status scores 


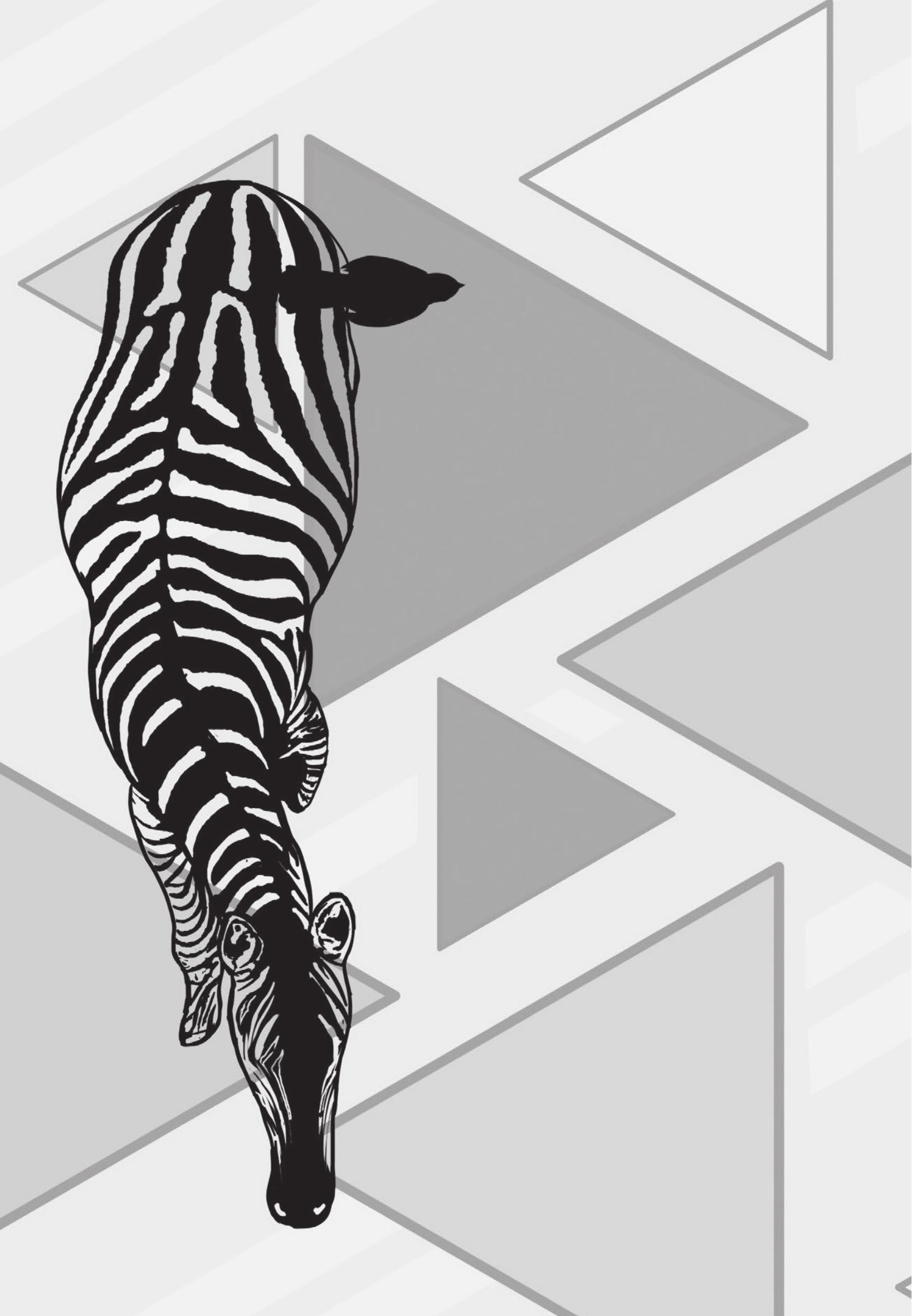




\section{CHAPTER 6 \\ Lessons learned from a Living Lab on broad adoption of eHealth in primary health care}
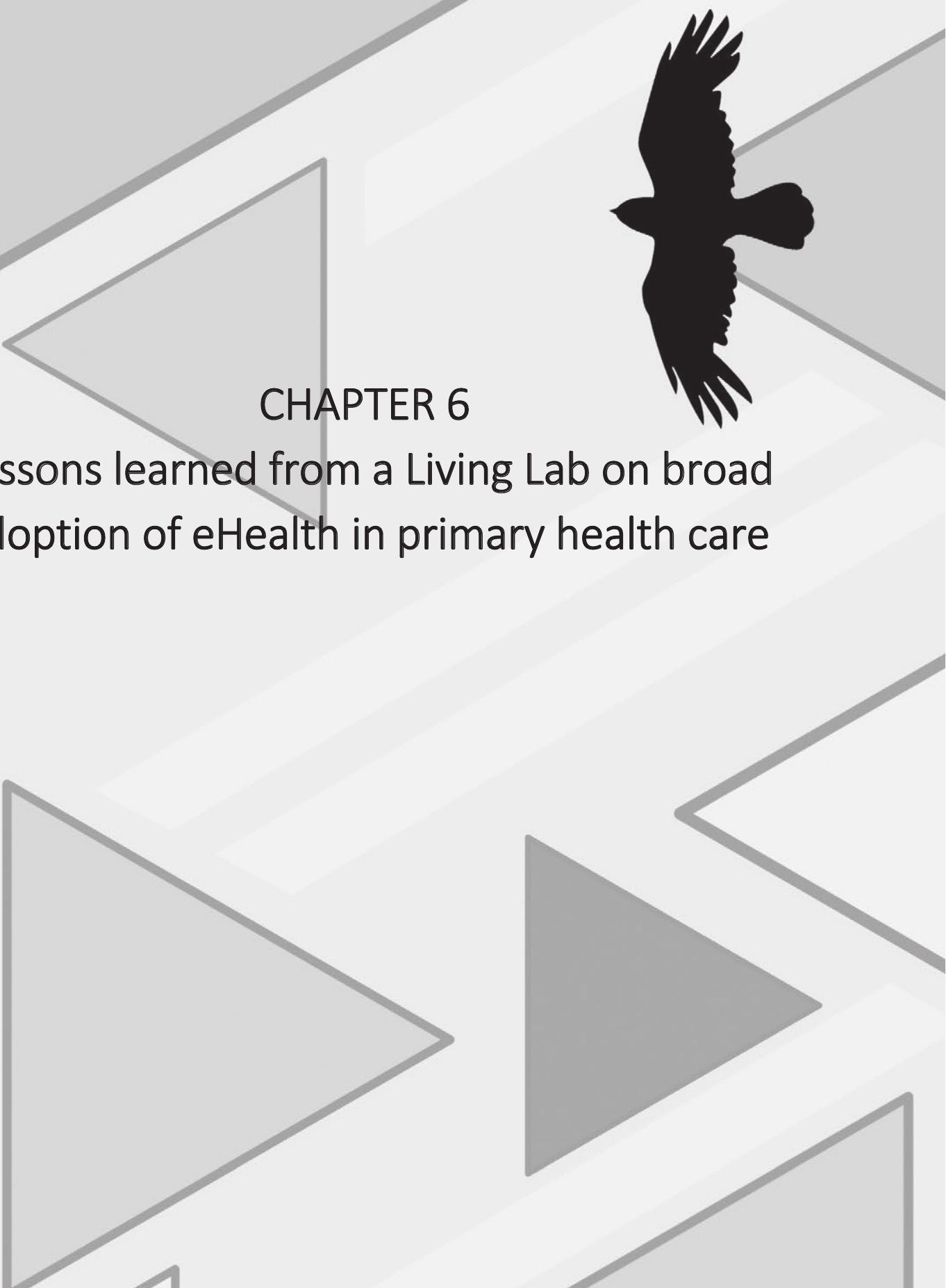


\section{Abstract}

eHealth solutions are considered to relieve current and future pressure on the sustainability of primary healthcare systems. However, evidence of the effectiveness of eHealth in daily practice is absent. Furthermore, eHealth solutions are often not implemented structurally after a pilot phase, even if successful during this phase. Although many studies on barriers and facilitators were published in recent years, including theoretical models on implementation of innovations, eHealth implementation still progresses only slowly. To further unravel the slow implementation process in primary healthcare and accelerate the implementation of eHealth, a three-year Living Lab project was set up in the Netherlands, resulting in in-depth information on the development and adoption of eHealth. In the Living Lab, called eLabEL, patients, healthcare professionals, small- and medium-sized enterprises (SMEs) and research institutes collaborated to select and integrate fully mature eHealth technologies for implementation in primary healthcare. Seven primary healthcare centres, ten SMEs, and four research institutes participated. Reflective and process-based notes from all meetings of the project partners, interview data and data of focus groups were analysed systematically using four theoretical models to study the adoption of eHealth in primary care. The results showed that large-scaled implementation of eHealth depends on the effort of and interaction and collaboration among four groups of stakeholders: patients, healthcare professionals, enterprises, and those responsible for healthcare policy (healthcare insurers and policy makers). These stakeholders are all acting within their own contexts and with their own values and expectations. In the eLabEL project we experienced that patients reported expected benefits regarding the use of eHealth for self-management purposes, and healthcare professionals stressed the potential benefits of eHealth and were interested in using eHealth to distinguish themselves from other care organisations. In addition, eHealth entrepreneurs valued the intensive collaboration among SME's as they were not big enough to enter the healthcare market on their own and valued the collaboration with research institutes. Furthermore, healthcare insurers and policymakers shared the ambition and need for the development and implementation of an integrated eHealth infrastructure. However, we learned that for optimal and sustainable use of eHealth, patients should be actively involved, primary healthcare professionals need to be reinforced in their management, entrepreneurs should work closely with healthcare professionals and patients, and the government needs to focus on new healthcare models stimulating innovations. Only when all these parties act together, starting in local communities with a small range of eHealth tools, the potential of eHealth will be enforced. 


\section{Introduction}

eHealth solutions are expected to empower patients and maintain or improve health outcomes, while generating cost effective gains and lowering primary healthcare professionals' workload. ${ }^{1,2}$ However, it appears to be difficult to embed them in daily healthcare routines. ${ }^{3}$ Often, use of eHealth services stops when research projects are finished, even when successful. Moreover, there is still uncertainty about their effectiveness in daily practice. ${ }^{2,4,5}$ Therefore, the success rate to date of eHealth in primary healthcare is low. ${ }^{6}$ Current evidence on eHealth and care technologies is mainly based on clinical trials and isolated eHealth applications. Van Gemert-Pijnen et al. (2011) suggest that evaluations should not focus exclusively on measuring outcome variables (via randomised controlled trials), but should also include in-depth process data concerning the usage of eHealth. ${ }^{7}$

It is suggested that successful implementation of eHealth asks for a complex innovation approach. ${ }^{6}$ Numerous factors are related to its success, including characteristics of the end-users, the function and usability of the intervention, the technical infrastructure, change management of healthcare organisations, the healthcare system, and financial business models. ${ }^{2,4,6,7}$ It can be stated that four groups of stakeholders are responsible for a successful implementation of eHealth solutions: patients, healthcare professionals, entrepreneurs, and those responsible for healthcare policy (policy makers and healthcare insurers). Eysenbach (2001) stated in 2001 that eHealth is an emerging field at the intersection of medical informatics, public health and businesses. ${ }^{8}$ However, literature combining the views of these different fields and describing their challenges systematically is scarce. With this paper, we aim to fill this gap and will describe the challenges that arose when patients, healthcare professionals and entrepreneurs collaborated in a Living Lab setting to select, integrate, implement and evaluate eHealth in primary healthcare. Hereby, our aim is not to test the relationships and interactions between different factors and stakeholders. Rather, we aim to study, in a qualitative way, the process of adoption of eHealth in primary care from the perspective of different stakeholders. This provides a real-word view on how such a process occurs, including successes and failures related to the different perspectives. Our paper serves as an illustration that underlines the importance of including all four stakeholders, having a shared vision statement, and enabling all partners to invest time or money, as only then can the expected potential of eHealth solutions be reached. After providing the rationale for our Living Lab project and a short description of our methods, we reflect upon our findings in four sections - patients as stakeholders; healthcare professionals as stakeholders; entrepreneurs as stakeholders; and healthcare insurers and policymakers as stakeholders. Based on these findings, we have been able to develop lessons learned which seem to be important in positively shaping the outcome of eHealth implementation and adoption in future primary health care. 


\section{Rationale for the Living Lab project 'eLabEL'}

In 2012/2013, when writing the grant proposal for the eLabEL project, it was already known that much of the eHealth technology being developed did not reach primary care practice because of a suboptimal fit between the needs in primary care and the technical solutions. ${ }^{9}$ Simultaneously, there was very little knowledge about what it takes to bring such technologies into practice. With eLabEL, we aimed to contribute to this knowledge, and to bridge technology and implementation. We believed, and still believe, that incorporating eHealth into daily practice is needed for optimal effects on quality and efficiency of healthcare. In other words, traditional healthcare should change to 'technology-supported healthcare'. For such a change, not only a technological innovation, but also a societal innovation is essential. Furthermore, a multidisciplinary development approach is necessary. ${ }^{10}$ Relevant stakeholders should collaborate, and research should consist of qualitative and quantitative elements. ${ }^{7}$ From this perspective, we, as researchers, started the eLabEL project in 2013, together with entrepreneurs, patients and healthcare professionals. eLabEL was aimed at establishing a Living Lab in which patients, healthcare professionals, entrepreneurs and researchers could collaborate during the selection, integration, implementation and evaluation of eHealth in primary healthcare. ${ }^{11}$ According to the European Network of Living Labs, we defined a Living Lab as a user-centred, open innovation ecosystem based on a systematic user cocreation approach, integrating research and innovation processes in real life communities and settings. ${ }^{12}$ In this project the focus was on two types of eHealth technologies: 1) online communication services which can be used by the entire general practice population and 2) eHealth for self-management purposes for those with a chronic somatic condition. Box 1 provides a description of the eLabEL project and Table 1 of the characteristics of the participating primary healthcare centres.

\section{Methods}

A qualitative design was used to understand the processes of adoption of eHealth in our project. We systematically analysed all reflective and process-based notes from meetings with healthcare professionals, the scientific project members, members of the management team of the Centre for Care Technology research, members of societal organisations, healthcare insurers and enterprises. Furthermore, data from interviews and focus groups on the needs and expectations of healthcare professionals and patients were included in the analyses, as well as interviews on adoption and implementation of eHealth. Thirty patients with a chronic disease participated in focus group interviews in the first year of the project. In these focus groups the following themes were discussed: 1) the impact of the chronic disease on patients' daily life 2) their opinions and needs regarding selfmanagement and 3) their expectations and needs regarding, and willingness to use, 
eHealth for self-management purposes. ${ }^{13}$ In addition, thirty healthcare professionals (including managers) were interviewed in the first months of the project. Themes discussed in these interviews were: 1 ) the centres technical infrastructure, 2) positive and negative work-related experiences with information technology and 3) future expectations and needs of eHealth. ${ }^{14}$ Eight care managers were interviewed in 2016. In these interviews the expected facilitating and inhibiting factors for adoption and implementation of the eHealth tools was discussed.

Textbox 1 The eLabEL project as illustration

The eLabEL project was conducted from September 2013 until December 2016 in the Netherlands. We aimed at the establishment of Dutch Living Labs in which integrated eHealth applications would become part of regular healthcare. Concurrently, we aimed to study the consequences of the integration of eHealth applications in primary care, as well as technical barriers and facilitators.

Seven primary healthcare centres participated in eLabEL. These were recruited via the network of the participating research partners or positively responded to the recruitment call which was published in a press release and at the projects' website. In these centres at least one general practitioner, physical therapist, practice nurse and nurse assistant provided healthcare to the community. Participating practices varied in type of organization, experiences with eHealth, patients' characteristics and region. Characteristics of these healthcare centres can be found in Tabel 1. Patients of these primary healthcare centres were also invited to participate. Ten enterprises participated in the Living Labs. These were mainly small and medium sized enterprises (SMEs) and offered different eHealth applications or services, varying from videoconferencing and online coaches for patients with chronic diseases to activity sensors and data warehousing. These SMEs were recruited via the network of the participating research partners. Some of them already participated in prior research projects. Also four research institutes, collaborating in the Centre for Care Technology Research (CCTR, www.caretechnologyresearch.nl), participated. These profit and non-profit organisations collaborated to select and integrate mature eHealth technologies for implementation in primary care. One or two members of each research institute coordinated the project.

At the start of the project needs and expectations of patients and healthcare professionals were investigated via focus groups and interviews. These needs were linked to eHealth applications developed by the SMEs. The final eLabEL package exists of the following eHealth applications: a service to provide online video consultations, an online self-management coach for people with COPD, an online coach for patients under treatment by the physiotherapist to support them in doing exercises at home and an application developed to coordinate multidisciplinary care around a patient. These applications were integrated in one infrastructure with single sign on for patients.

Table 1 Characteristics of the participating primary healthcare centres

\begin{tabular}{lllll}
\hline & Organization & Number of patients (2013) & $\begin{array}{l}\text { Region of the } \\
\text { Netherlands }\end{array}$ & Remarks \\
\hline 1 & Healthcare centre & Ca.13,000 & Mid & Located in deprived \\
2 & Healthcare centre & Ca. 8,000 & South & urban area \\
\hline 3 & General practice & Ca. 3,500 & South & Located in deprived \\
4 & Healthcare centre & Ca. 5,000 & West & urban area \\
5 & General practice & Ca. 5,500 & North & Patients mainly students \\
6 & Healthcare centre & Ca. 14,500 & Mid & \\
\hline 7 & General practice & Ca. 6,500 & North & \\
\hline
\end{tabular}


For the analyses we used a coding scheme based on four theoretical models. Wagemakers' model (2010) focuses on collaboration among multidisciplinary organisations in healthcare. ${ }^{15}$ Nystrom's model (2014) was used because of its focus on different role approaches within a collaboration. ${ }^{16}$ The model of Geels (2002) describes new technologies as arising and maturing within existing technology systems. ${ }^{17}$ Fleuren et al. (2004) state that the success rate of an innovation is dependent on the level of the innovation itself, end-users, organisation and social-political context. ${ }^{18}$ A summary of the results was shared with the SMEs and healthcare professionals for their confirmation. More information about these theoretical models can be found in Appendix 1.

\section{Analysis per stakeholder}

\section{Patients}

eLabEL aimed at a user-centred design. Patients were intended to be actively involved in the selection and implementation of eHealth solutions. This way, we expected to stimulate the use of eHealth by patients. However, active patient involvement was only achieved to a minor extent. In addition, we found that patient involvement does not directly guarantee eHealth usage on a broad scale, because not every patient seems willing to use eHealth.

The first way to involve patients was by organising focus groups to investigate their expectations and needs regarding eHealth. Patients had to be recruited by healthcare professionals to participate in these group interviews. However, it was difficult for them to encourage patients to participate. According to the healthcare professionals, one of the main reasons was that patients were tired of participating in research. Therefore, organizing patient involvement was more time consuming than expected. In addition to the focus group interviews, we attempted to set up a patient panel for the active involvement of patients during the entire project. However, this resulted in only a few positive responses. We were more hesitant to encourage healthcare professionals to recruit more patients for this panel, as the first study already required significant effort. Furthermore, throughout the project actively involving patients to incorporate the patient perspective in the project became of secondary importance. The focus of eLabEL shifted toward the development of an integrated eHealth structure and the investigation of barriers for its slow development and implementation. Moreover, patients did not have the possibility of using eHealth, due to difficulties in the integrated eHealth structure. As a result, healthcare professionals did not offer it to their patients.

Despite the difficulties in involving patients, we did organise five focus groups with patients with a chronic condition. Detailed results are published by Huygens et al. ${ }^{13}$ Briefly, it showed that patients reported expected benefits regarding the use of eHealth for self-management purposes. For example a patient with diabetes reported 
'If you can monitor automatically, you get customised care more quickly. Currently, you're going to the care practice four times a year, and in the period in between you stay at the same value [of insulin], while you maybe should have changed it in the meantime, but you didn't know that' (focus groups, patient with diabetes).

However, many patients also did not feel a need to use eHealth. It seemed that the perceived benefits of using eHealth should outweigh the negative consequences of frequently having to take action to deal with the disease, which reminds patients about having a disease. A patient with a cardiovascular condition that had little impact on his daily life mentioned the following:

'The disadvantage is that I'm feeling more like a patient [because of frequent monitoring]: man suffers most from the suffering he fears' (focus groups, patient with a cardiovascular condition).

\section{Healthcare professionals}

The role of the healthcare professionals was to actively participate in the Living Lab settings. They were expected to provide input regarding their own needs and requirements regarding eHealth and its implementation. In addition, they had to use the applications in their daily care processes, and encourage and support their patients to use them. Our intention was that healthcare professionals would implement and use eHealth without the help of the research team. However, we found that the organisation of primary healthcare was inadequate and not sufficiently equipped for doing so as we explain in the upcoming section.

The participating healthcare professionals stressed the potential benefits of eHealth. Professionals identified the rising development of eHealth technologies, the emergence of different eHealth initiatives and their opportunities for better healthcare. In addition, care professionals indicated that they were interested in using eHealth to distinguish themselves from other care organisations. Providing extramural care, monitoring patients at a distance, empowering and supporting self-management of patients, providing more intensive care in less time, providing care during out-of-office hours and increasing the quality of care, were frequently mentioned anticipated benefits of eHealth. Healthcare professionals believed that by using eHealth for people with mild conditions, they could save time and provide extra time to those with more severe conditions.

After deciding which eHealth technologies they wanted to use, it was not just a matter of connecting the technology. We experienced many difficulties in the implementation of eHealth in the care practices. Firstly, healthcare professionals needed support for eHealth usage, including clear instruction material, a helpdesk and most importantly time to gain experience with eHealth, as they had not worked with the 
selected eHealth-applications previously. In addition, for healthcare professionals it was unclear how eHealth could be successfully integrated into their daily work. Work flow, responsibilities and roles needed to change, and they did not know how to approach this. Moreover, eHealth was not integrated into the electronic medical records or protocols. This made it difficult for the healthcare professionals to imagine how to integrate eHealth into their daily care processes. Furthermore, healthcare professionals expected and experienced problems regarding motivating patients to use eHealth. Clear instruction material and tips (for example, from other care professionals) to encourage and convince patients to use eHealth were needed. In addition, healthcare professionals indicated that they did not want to innovate without the help and encouragement of other healthcare professionals within and outside their own organisation. It appeared that the innovation should fit with the ambitions and plans of the local care community.

So, healthcare professionals needed support on different levels during the implementation, more than we expected. For these support activities funding was needed, which was not covered by the budget for the project. Several care practices tried to apply for eHealth funding. However, we experienced that it was complex for them to organise this. Often, they lacked knowledge, expertise or resources to apply for eHealth funding. Professionals mentioned that in the current financial model they had to pay the costs (time and money) for eHealth implementation, while the health insurer would receive the proposed benefits in terms of cost reductions (also known as the wrong pocket problem). In addition, healthcare professionals already experienced a high time pressure in regular care processes and in keeping up with bureaucratic and legal changes, resulting in a lack of time to adopt eHealth. Moreover, in most practices, eHealth was not mentioned in vision and mission statements. Furthermore, the care professionals and managers who agreed to participate in the eLabEL project where not the ones that actually had to work with the applications in real practice. An 'eHealth minded' care manager does not guarantee the actual use of eHealth by his/her colleagues when there is no clear vision on eHealth in the care organization or space for innovation. The aforementioned reasons resulted in low priority for eHealth implementation. As summarised by one of the managers:

'I am supporter of such innovations in healthcare, but I also see that they conflict with every day practice. General practitioners are up to their ears in work. They have no time for implementation. Primary healthcare professionals experience extreme pressure due to the substitution from secondary to primary care, which is bothering them. Besides, it is still unknown what the purpose and target population of eHealth is and why we would use it. That is scary. Then, you can imagine why eHealth has low priority' (interview manager primary healthcare centre, 9 March 2016). 


\section{Entrepreneurs}

The entrepreneurs' role in eLabEL was to bring in mature and evidence based eHealthapplications, in conjunction with patients and healthcare professionals, and to combine the different applications into one infrastructure via a single sign-on. To realise a sustainable, intelligent and interoperable ICT infrastructure, which was necessary for eLabELs' mission, the individual applications as well as the infrastructure should meet the national and European requirements for data-exchange, -safety and -privacy. The entrepreneurs were also asked for knowledge and financial investments.

Participating entrepreneurs started in eLabEL with the expectation that collaboration with research institutes would help them to enter a new market, i.e. primary healthcare. They felt they needed to collaborate with other entrepreneurs as they were not big enough to enter the market on their own. They expected collaboration with research institutes as an important surplus value: it would add a scientific basis for their applications and therefore could create additional market value. They valued the intensive collaboration among the SMEs resulting in small alliances of two or three SMEs, as well as the experiences of participating in the project as a whole.

During the project, it came to the fore that the entrepreneurs did not have the technical knowledge that was needed to set up a sustainable interoperable ICT infrastructure and that their eHealth applications were not fully mature, nor evidence based. Furthermore, the entrepreneurs were continuously considering whether investments in eLabEL would result in future revenues (mainly in the short term). As the SMEs differed in their motivation and in weighing investments, it proved hard to create a shared vision statement on the integration of the different eHealth applications, the investment strategy and a joined entity to assign intellectual properties to. The main reason for the struggles experienced in the cooperation among SMEs, was that the SMEs differed in their convictions of future revenues because of uncertainties in the financial market and that it was not possible to make a positive business case. An individual investment in the eHealth infrastructure was considered as unwise and too risky by each SME and therefore they opted for a joint investment. However, the business case and corresponding business model should still be positive. Questions like who will pay, who is the customer and who is the user were difficult to answer during the whole project, as the primary healthcare market was a new and therefore relatively unknown market for the SMEs. This resulted in continuous discussions on the business model. One of the SME's explained it as:

'The healthcare market is unknown. Who should pay for it? How can we sell it? The Business Model is unclear. For medical care the healthcare insurance should pay. For non-medical care a patient or healthcare organization should pay. This is difficult in primary healthcare' (meeting entrepreneurs, 16 September 2014) 


\section{Healthcare insurers and policymakers}

In the eLabEL project the expected role of policymakers and healthcare insurers was that of enabling the healthcare professionals in experimenting with the use of eHealth in primary care. More precisely, we expected that healthcare insurers would provide financial support for the appointment of practice nurses.

Several discussions were held with healthcare insurers and policymakers. Time after time it was clear that we had a shared ambition: healthcare insurers and policymakers agreed that it was necessary to work on an integrated infrastructure for eHealth applications in order to transform traditional primary healthcare into technologysupported healthcare. In their view, the Dutch financial legislation offers prospects for financing eHealth applications as there are policy rules, conditions for reimbursement and incentives for innovation.

Simultaneously, healthcare insurers were reserved. They needed a business case and insight into cost-effectiveness of the infrastructure that we were developing before they would think about reimbursement or investments. We could not achieve this in the project and therefore, they did not want to support the project. It seemed that healthcare insurers were mostly interested in short-term effects. In actual practice, the Dutch regulations and legislation seemed to act inconsistently: they argue to stimulate eHealth on one side, but require cost-effectiveness studies first on the other side. However, to carry out cost-effectiveness studies in real practice, implementation of eHealth needs legislation and financial regulations first.

Instead of investments by healthcare insurance, healthcare organisations themselves might be able to invest in eHealth-applications. However, in the Dutch payfor-performance based healthcare system, the use of eHealth-applications that lower the number of consults will also lower the healthcare professionals' revenues. Actually, investments by the healthcare organisations will lead to lower costs for the healthcare insurers, but also lower income for the healthcare practices. This was explained by one of the managers as follows:

'eLabEL is aimed at more efficient care and better quality of care, with the ideal result that patients are more satisfied. But, this should not result in cost savings only for the healthcare insurance sector. <...> The shared savings principle might be worthwhile' (meeting entrepreneurs and primary healthcare managers, 6 November 2014).

\section{Discussion}

Roughly four years after starting the eLabEL project, we conclude that, despite the hard work and collaboration of many stakeholders, it was not possible to really change 
healthcare in these Living Labs at this moment in time. One might say that the eLabEL consortium failed in its ambition. However, we gathered in-depth information about the complexity of innovations in primary healthcare and this information will help many researchers, entrepreneurs and policy makers in setting up the next initiatives on this topic. Our experiences in eLabEL taught us that successful use of eHealth needs more than enthusiastic partners. It also depends on their efforts, their willingness to invest time or money and shared vision statements. Although it is not easy because of different contexts, values and expectations, we still believe that collaboration between all four groups of stakeholders, i.e. patients, healthcare professionals, entrepreneurs and healthcare insurers/policymakers is essential. Moreover, we argue that policy, especially the healthcare insurance market, should be added as a field to Eysenbachs' definition of eHealth. $^{8}$

Were we naive when starting eLabEL? We might be: we knew we were ambitious, but looking back, we realise we had unrealistic expectations and our goals were not specific enough. Nevertheless, SMEs were willing to collaborate and to invest as they were ready to step into a new market. Additionally, healthcare organisations also felt the urge to participate. What we did not foresee was the struggle 1) to convince healthcare insurers to support healthcare professionals in our project and 2) to create a positive business model. In fact, it were those factors that led to an impasse: without commitment of healthcare centres or insurers, no positive business model could be created and SMEs could not invest in the eLabEL infrastructure. However, without investments in the eLabEL infrastructure, healthcare professionals were not convinced of its added value. Moreover, without financial support by healthcare insurers they were not motivated or able to use it. This made it impossible for the researchers to collect the evidence that healthcare insurers were asking for.

It is clear from our observations that a number of actions should be done differently in future projects to enforce the implementation of eHealth in primary care. These actions will be discussed in the following sections and are listed in Box 2.

From the patients' perspective, it turned out that it is not easy to actively involve patients in research projects. Considering the importance of their participation, especially in eHealth projects, ${ }^{19}$ they should be supported in participating in the project. In addition, incentives for care practices seem to be needed to recruit patients for participation. Patients' expectations of the benefits of using eHealth play an essential role in their actual use. Therefore, it is essential that Living Labs as set up in eLabEL awake patients' interest by offering relevant eHealth tools. Patients' expectations are not only dependent on the technology, but also on the way in which general practices offer, promote and use it. ${ }^{20,21}$ Care professionals should be supported in informing patients about the possibilities, uses and reasons for implementation, focussing on the benefits eHealth can bring. However, whether patients will actually use eHealth will always be personal and differ among patients. Monitoring which patients benefit the 
most from the use of eHealth and those that do not, seems to be important to develop optimal implementation strategies.

From the care organisations' perspective, it appeared that healthcare managers and professions were not ready for implementing eHealth tools without support. Implementing eHealth requires it to be a fundamental part of mission and vision. Only then decisions on budget and support can be made. We found that the process of adapting and implementing eHealth is too complicated to organise next to regular caregiving activities for primary healthcare professionals. Next to this, we learned that involving a primary healthcare centre in the plans is not sufficient. The use of eHealth goes beyond the own practice borders as primary healthcare professionals often operate close to other healthcare professionals in their region. This makes the innovations even more complex as those parties also need to be involved. ${ }^{22}$ Nowadays, it is common knowledge that implementation of innovations, including eHealth, is difficult and progresses only slowly. ${ }^{23-25}$ Lau et al. (2016) stated in a recent systematic review of reviews that: implementing any type of change in primary care is likely to be complex and that relevant barriers and facilitators are dynamic and likely to change over time. ${ }^{23}$ Theoretical models show that the innovation process, or implementation infrastructure, are important parts of implementation, next to the intervention characteristics, the organisational structure, the context and the individuals. ${ }^{26,27}$ Moreover, it is shown that a greater knowledge of essential adjustments in healthcare provider workflow, roles and responsibilities is needed. ${ }^{28}$ Our study provides a real-world view on these topics showing that Dutch primary care organisations, mainly small organisations, do not have the managerial power that is needed for complex innovations like large-scale eHealth implementation. Primary care organisations probably will benefit from infrastructures that support them in the implementation process.

From the entrepreneurs' perspective it is important to have shared vision statements and a business model concept as early as possible. Clearly defined short- and long term goals are needed. In addition, trust in each other and commitment of all parties is important. Knowledge of the potential cost-effectiveness of eHealth is an important requirement for all stakeholders. The use of an early Health Technology Assessment can provide insight into potential outcomes, drivers and barriers. Moreover, we should realise that SMEs might have difficulties, due to lack of knowledge, in developing interoperable eHealth, when facing different Dutch and European requirements on data-safety, -exchange and -privacy. Furthermore, in developing, adapting, selecting, and implementing eHealth tools they should work as closely as possible with the end-user, i.e. healthcare professionals and patients. Active user involvement is a time-consuming process. Developers should balance the need for input from users, with the availability of resources such as time and funding. ${ }^{29}$ To remain competitive within a fast moving market, it is important to develop quickly. ${ }^{30}$ However, we recommend that the need assessment phase should not be neglected; this seems of 
major importance for the development of eHealth from which patients can experience benefits and might be an important trigger to actually use eHealth.

The implementation of eHealth is not yet a fully recognised aspect of primary healthcare organizations which makes it difficult to fit eHealth locally. Furthermore, inconsistencies in policy rules hinder improvements and innovations. For projects like eLabEL, it would help when policymakers and healthcare insurers would allow experiments in which standard regulations can be (partly) neglected to fully explore new financing models. This can only be arranged when policy makers and healthcare insurers are involved from the beginning of the project. However, such experiments are not a structural solution for broad-scale implementation of eHealth. Moreover, financial support does not guarantee the large-scale use of eHealth. ${ }^{31}$ Broad-scale implementation will need strategies that not only focus on financial models that stimulate innovation, but also on requirements needed for societal innovations. ${ }^{32,33}$

In conclusion, we believe that for optimal and sustainable use of eHealth, patients should be actively involved, primary healthcare professionals need to be encouraged in their management, entrepreneurs should work closely with healthcare professionals and patients, and government needs to focus on new healthcare models stimulating innovations. Only when all these parties act together, starting in local communities with a small range of eHealth tools, the potential of eHealth will be realised.

Textbox 2 Lessons learned from a Living Lab on broad adoption of eHealth in primary healthcare

Patients need support to actively participate in eHealth projects and those projects need to be relevant for the patients

Incentives for care practices are needed to recruit patients for participation in eHealth projects

Primary care practices need support to adequately inform patients and monitor which patients benefit from the use of eHealth

The community in which a primary healthcare system operates needs to be involved in eHealth projects

Primary care practices need support and managerial power for the implementation and innovation processes

Collaborated eHealth entrepreneurs need trust in each other, shared vision statements and early commit to short- and long term goals

A business model concept is needed early in eHealth projects and essential for collaboration

Strategies are needed focusing on financial models that stimulate innovation and on requirements needed for societal innovations

Patients, primary healthcare professionals, entrepreneurs and government need to act together in eHealth projects 


\section{References}

1. Henderson C, Knapp M, Fernandez JL, Beecham J, Hirani SP, Cartwright M, et al. Cost effectiveness of telehealth for patients with long term conditions (Whole Systems Demonstrator telehealth questionnaire study): nested economic evaluation in a pragmatic, cluster randomised controlled trial. BMJ. 2013;346:f1035.

2. Flodgren G, Rachas A, Farmer AJ, Inzitari M, Shepperd S. Interactive telemedicine: effects on professional practice and health care outcomes. The Cochrane database of systematic reviews. 2015;9.

3. de Lusignan S, Mold F, Sheikh A, Wyatt JC, Quinn T, Cavill M, et al. Patients' online access to their electronic health records and linked online services: A systematic review in primary care. BMJ Open. 2014;4:e006021.

4. Wildevuur SE, Simonse LW. Information and communication technology-enabled person-centered care for the "big five" chronic conditions: scoping review. J Med Internet Res. 2015;17(3):e77.

5. Peeters JM, Wiegers TA, Friele RD. How technology in care at home affects patient self-care and selfmanagement: a scoping review. Int J Environ Res Public Health. 2013;10(11):5541-64.

6. van Dyk L. A review of telehealth service implementation frameworks. Int J Environ Res Public Health. 2014;11(2):1279-98.

7. van Gemert-Pijnen JE, Nijland N, van Limburg M, Ossebaard HC, Kelders SM, Eysenbach G, et al. A holistic framework to improve the uptake and impact of eHealth technologies. J Med Internet Res. 2011;13(4):e111.

8. Eysenbach G. What is e-health? J Med Internet Res. 2001;3(2).

9. Vitacca M, Mazzù M, Scalvini S. Sociotechnical and organizational challenges to wider e-Health implementation. Chron. Respir. Dis. 2009;6(2):91-97

10. Van Velsen L, Wentzel J, Van Gemert-Pijnen JE. Designing eHealth that Matters via a Multidisciplinary Requirements Development Approach. JMIR Res Protoc. 2013;2(1):e21.

11. Vermeulen J, Huygens M, de Witte LP, Oude Nijeweme-d'Hollosy W, van Velsen L, Swinkels ICS, et al. eLabEL: Technology-supported Living Labs in Primary Care. eTELEMED 2015: The Seventh International Conference on eHealth, Telemedicine, and Social Medicine; 2015; Lisbon Portugal.

12. ENoLL. Frequently Asked Questions. What is a Living Lab? http://www.openlivinglabs.eu/FAQ [accessed 2016-01-29].

13. Huygens MWJ, Vermeulen J, Swinkels ICS, Friele RD, van Schayk OCP, de Witte LP. Expectations and needs of patients with a chronic disease toward self-management and eHealth for self-management purposes. BMC Health Serv Res. 2016;16(232).

14. Oude Nijeweme-d'Hollosy W, van Velsen L, Huygens MWJ, and Hermens H. Requirements for and Barriers towards Interoperable eHealth Technology in Primary Care. IEEE Internet Comp. 2015;19(4):10-19

15. Wagemakers A, Koelen MK, Lezwijn J, Vaandrager L. Coordinated action checklist: a tool for partnerships to facilitate and evaluate community. Glob Health Promot. 2010;17(3):12.

16. Nyström A-G, Leminen S, Westerlund $M$, Kortelainen $M$. Actor roles and role patterns influencing innovation in living labs. Industrial Marketing Management. 2014;43(3):13.

17. Geels FW. Technological transitions as evolutionary reconfiguration processes: a multi-level perspective and a case-study. Res Policy. 2002;31(8-9):19.

18. Fleuren $M$, Wiefferink K, Paulussen T. Determinants of innovation in healthcare organization. Literature review and Delphi study. Int J Qual Health Care. 2004;16(2):17.

19. Latulippe K, Hamel C, Giroux D. Social health inequalities and eHealth: a literature review with qualitative synthesis of theoretical and empirical studies. J Med Internet Res. 2017;19(4).

20. Wells S, Rozenblum R, Park A, Dunn M, Bates DW. Organizational strategies for promoting patient and provider uptake of personal health records. J Am Med Inform Assoc. 2015;22(1):10.

21. Wolcott V, Agarwal R, Nelson DA. Is provider-secure messaging associated with patient messaging behavior? J Med Internet Res. 2017;19(4).

22. Timmermans S, Berg M. Standardization in action: achieving local universality through medical protocols. Soc Stud Sci. 1997;27(2):33. 
23. Lau R, Stevenson F, Nio Ong B, Dziedzic K, Treweek S, Eldridge S, et al. Achieving change in primary care causes of the evidence to practice gap: systematic reviews of reviews. Implement Sci. 2016;11(40):39.

24. Peeters JM, Krijgsman JW, Brabers AE, de Jong JD, Friele RD. Use and uptake of eHealth in General Practice: a cross-sectional survey and focus group study among health care users and general practitioners. JMIR Medical Informatics. 2016;4(2):10.

25. Ross J, Stevenson F, Lau R, Murray E. Factors that influence the implementation of e-health: a systematic review of systematic reviews (an update). Implement Sci. 2016;11(146).

26. L.J. D, Aron DC, Keith RE, Kirsh SR, Alexander JA, Lowery JC. Fostering implementation of health services research findings into practice: a consolidated framework for advancing implementation science. $B M C$ Implementation Science. 2009;4(50).

27. Feldstein AC, Glasgow RE. A Practical, Robust Implementation and Sustainability Model (PRISM) for integrating research findings into practice. Jt Comm J Qual Patient Saf. 2008;34(4):16.

28. Irizarry T, DeVito Dabbs A, Curran CR. Patient Portals and Patient Engagement: A State of the Science Review. J Med Internet Res. 2015;17(6):e148.

29. de Beurs D, van Bruinessen I, Noordman J, Friele R, van Dulmen S. Active involvement of end users when developing Web-based mental health interventions. Frontiers in Psychiatry. 2017;8(72).

30. Money AG, Barnett J, Kuljis J, Craven MP, Martin JL, Young T. The role of the user within the medical device design and development process: medical device manufacturers' perspectives. BMC Med Inform Decis Mak. 2011;11(1)

31. Huygens MWJ, Swinkels ICS, Verheij RA, Friele RD, Van Schayk OCP, de Witte LP. Understanding the use of emailconsultation in primary care using a retrospective observational study with data of Dutch electronic health records [manuscript accepted by BMJ open].

32. Janssen M. Situated novelty: a study on healthcare innovation and its governance: Health Care Governance (HCG) [PhD dissertation]. Roterdam: Erasmus University Rotterdam, 2016.

33. Krijgsman J, Swinkels I, Lettow B, Jong J, Out K, Friele R, et al. Meer dan techniek: eHealth monitor 2016. 2016. http://www.nictiz.nl/page/Publicaties/eHealth-monitor [accessed 2017-08-10]. 


\section{CHAPTER 6}

\section{Appendix 1 Theoretical models}

An extensive and systematically analysis was performed based on all documentation which was written and collected during the first 21 months of the project, including all notes of meetings, documentation of bilateral sessions, and progress reports, as well as reports of the interviews and focus groups with respectively healthcare professionals and patients. We used four theoretical models to structure the data:

1. Wagemakers et al. (2010) states that collaboration among multidisciplinary organizations, like science, business and healthcare, is important and enlarges the chances on successful innovations in healthcare. Cooperation leads to a socially desirable climate which stimulates uptake of innovations in several levels. ${ }^{15}$ This model structures the way how the different partners in eLabEL collaborated.

2. Nyström et al. (2014) states that innovations are increasingly the result of cooperation between organizations and of network structures including public-private-people-partnerships. The success of such partnerships depends on the way how partners collaborate, which roles they take and which roles they obtain by others. ${ }^{16}$ They define four categories to describe different role approaches within a collaboration:

a. Roles that are predetermined by the actors in the network.

b. Roles that are created in a social structure, such as a network.

c. Roles that are used as a resource to control resources or establish structure.

d. Roles that are determined by actions and based on openness and common goals of the network.

We used these roles to describe the relations between the partners.

3. Geels (2002) states that new technologies arise and mature within existing technology systems. Factors like financial incentives, strategies of consortium partners, competition, and new insights influence (the success of) innovations. ${ }^{17}$ Geels' model was used to describe eLabEL as innovation within an existing technological system.

4. Fleuren et al. (2004) assumes that innovations have various determinants and that its' implementation has various phases. ${ }^{18}$ The success rate of an innovation is dependent on the level of the innovation itself, end-user, organization, and social-political context.

The research group combined the elements of these four models in a coding scheme. The coding scheme was tested in a subset of the documents. All researchers $(n=6)$ coded this subset. The coded documents were discussed by the research group $(n=6)$ to ensure all researchers applied the scheme in the same way. The research group discussed the findings and minimally adapted the scheme. Subsequently, the researchers performed content analyses of the documents by using this coding scheme. Documents were thematically allocated among the members. Each set of documents was coded and then summarized by one researcher. Each summary was then checked by a researcher of another research institute. 



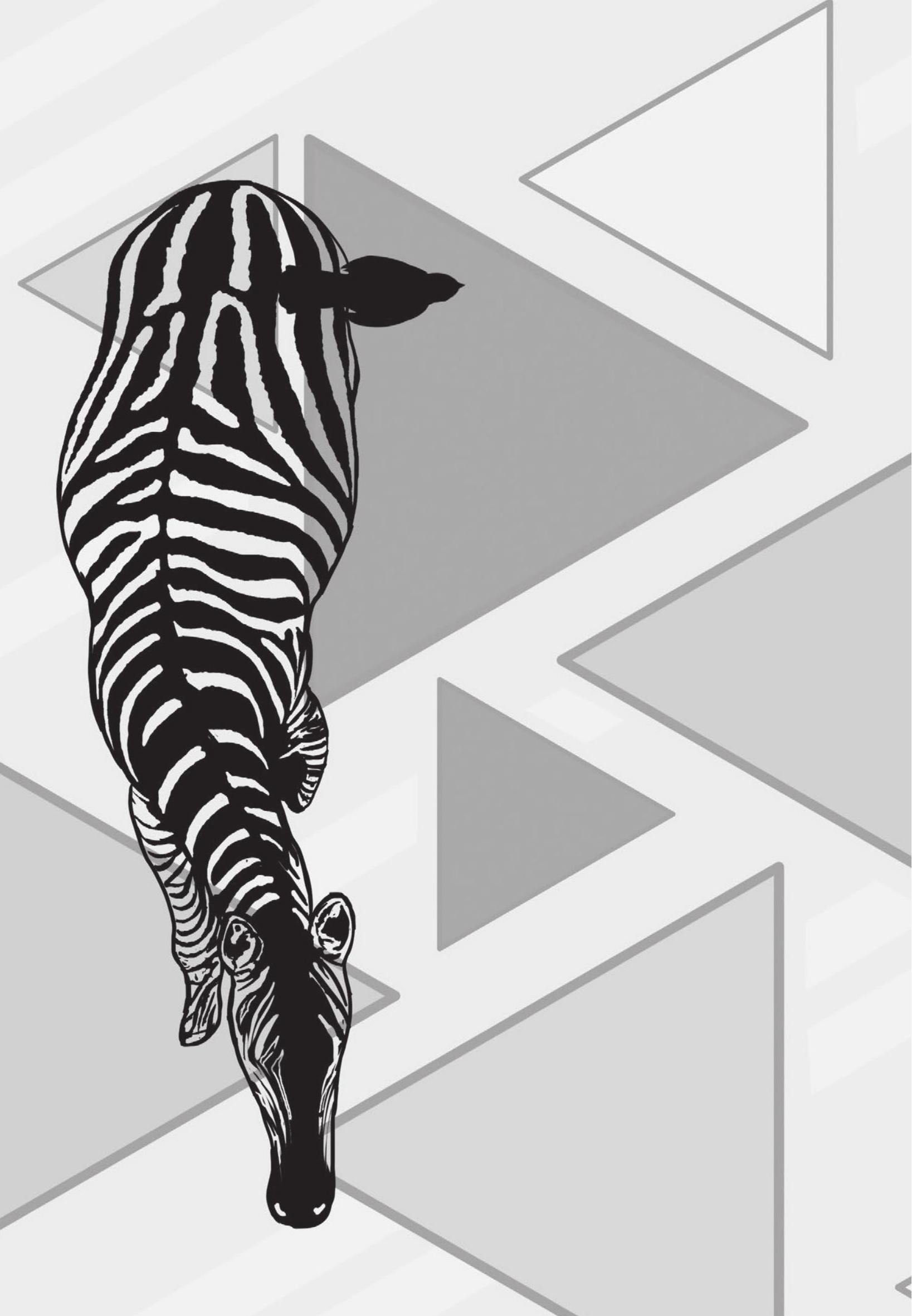




eHealth is expected to contribute to the challenges in primary care by improving the quality and efficiency of care and self-management. eHealth services such as online coaches, monitoring applications and patient portals are rapidly being developed. However, despite high expectations, many eHealth technologies are not being implemented and used in real practice. The main focus of this dissertation was on the patient perspective regarding eHealth in primary care, with the aim of investigating patients' interest in the use of it. The secondary aim was to explore the needs for successful implementation of eHealth in primary care from a broader perspective. The underlying objectives were to investigate:

1. patients' expectations and needs concerning eHealth in primary care;

2. patients' actual use and willingness to use eHealth in primary care;

3. aspects and characteristics that influence patients' willingness to use eHealth;

4. the lessons learned from a broad-scale eHealth implementation project.

eHealth includes a wide range of applications that can be used for different purposes and target groups. The focus of this dissertation was on online communication services that can be used by the entire general practice population (Chapters 2 and 5) and eHealth for self-management purposes for people with a chronic somatic condition that can be used in primary care (Chapters 3 and 4). These studies were conducted as part of the eLabEL project that aimed to establish living labs in which integrated eHealth applications would become a part of regular health care. One study discussed our lessons learned from this project, focusing on the perspective of patients, health care professionals, entrepreneurs and health care policymakers (Chapter 6).

This final chapter describes the main findings of Chapters 2 to 6 and discusses considerations of, and reflections on, the main findings, as well as recommendations for eHealth developers and entrepreneurs, care professionals, patients, policy and research.

\section{Summary of the main findings}

\section{Patients' general expectations of, and needs regarding, eHealth}

Patients' general expectations of, and needs towards eHealth were investigated in a focus group study with patients with chronic somatic diseases (Chapter 3 ). ${ }^{1}$ The expected benefits of eHealth reported by patients were: the prevention of further complaints by the investigation of real-time declines; getting advice on whether a consultation is needed based on up-to-date health parameters; and doing more at home instead of going to the care practice. However, a substantial number of patients were also less interested in using eHealth, because they felt that eHealth would frequently remind them about their disease, would lead to a reduction in personal care, and would result in 
feelings of anxiety because of having to take measurements themselves or because of not knowing what to do with deviant data from those measurements. To make eHealth work, the benefits should outweigh the disadvantages of frequently having to take action to deal with the disease. In addition, patients should be clearly informed about the possibilities of, and reasons for, eHealth implementation. Furthermore, patients should be given the choice as to whether or not to use eHealth and it should not replace, but complement, personal care.

\section{Patients' actual use of, and willingness to use, eHealth in primary care}

Studies focusing on online communication services aimed at enabling the general practice population to communicate with the general practice (Chapters 2 and 5) ) $^{2,3}$ and self-monitoring of health parameters by people with a chronic somatic disease (Chapter $4)^{4}$ showed that such services are barely used in the Netherlands. Although a substantial number of people are willing to use such services, it should be taken into account that not all patients are willing to use eHealth.

A cross-sectional study among people who had contacted their general practitioner at least once in the past year showed that Internet communication services aimed at facilitating contact with the general practice were not frequently used by the Dutch general practice population in 2012/2013 (Chapter 2). ${ }^{2}$ Repeat prescription request services via the Internet were most used by patients (approximately 10\%). A substantial number of participants that did not use the online services did have a positive intention towards using them in the future, varying from approximately 15\% (Internet video consultation) to $50 \%$ (having access to medical data). Remarkably, many participants did not know whether they wanted to use an Internet communication service to contact the general practice, or did not know whether the service was available in their general practice.

A study about the use of email-consultations in primary care, using data from electronic medical records of Dutch primary care practices in 2010 and 2014, showed again that the use of email-consultations is low (Chapter 5 ). ${ }^{3}$ In 2010, about a third of the general practices declared at least one email-consultation. This increased to approximately half of the general practices in 2014. However, less than one per cent of the patients that had at least one GP consultation (home visit, face-to-face, telephone or email-consultation) had an email-consultation in 2014. The use of such consultations varied greatly among general practices.

Self-monitoring is a key aspect of patients' self-management and is frequently applied in digital (eHealth) applications. A cross-sectional study among a Dutch panel of people with chronic somatic diseases revealed that not all patients seem willing to selfmonitor clinical parameters (such as weight, blood pressure, blood glucose levels and lung function). The proportion of patients that were willing to self-monitor varied from $71 \%$ (patients with diabetes) to $43 \%$ (patients with a neurological disorder) (Chapter 4$){ }^{4}$ 
Aspects and characteristics that influence patients' willingness to use eHealth in primary care

In this dissertation we investigated different aspects and characteristics that can influence patients' willingness to use eHealth. These can be divided into: constructs of the Unified Theory of Acceptance and Use of Technology (UTAUT); disease-specific characteristics; and patient-specific characteristics.

\section{Constructs of the Unified Theory of Acceptance and Use of Technology (UTAUT)}

The UTAUT model was applied to two online services aimed at facilitating communication with the general practice: Internet appointment planning and asking questions via the Internet (Chapter 2). ${ }^{2}$ The study revealed that all constructs of the UTAUT model (effort expectancy, performance expectancy, facilitating conditions and social influence), along with trust and attitude, had a significant association with the intention towards using these services. However, moderate to high correlations were found between the constructs. Therefore, it should be questioned whether these subscales measured different independent constructs. In addition, many participants answered that they did not know how to evaluate the use of these services, which might indicate that Internet services for communicating with the general practice are not a major issue in Dutch society.

\section{Disease-specific characteristics}

Disease-specific characteristics seem to play an important role in patients' willingness to use eHealth as well. A focus group study with people with diabetes, chronic obstructive pulmonary disease (COPD) or a cardiovascular condition revealed that these patient groups differ in terms of expectations and needs regarding self-management and eHealth for self-management purposes (Chapter 3 ). ${ }^{1}$ People with diabetes reported most needs and benefits regarding eHealth and were most willing to use it. They reported that their own behaviour (nutrition, weight loss and medication) directly influenced their health, indicating that they perceive that their disease is more controllable by their own behaviour, which could influence their interest in eHealth for self-management purposes. In contrast, people with a cardiovascular condition expected fewer benefits from eHealth, because their disease had little impact on their life. Therefore, the benefits that patients expected from using eHealth to support self-management and their perceived controllability over their disease seem to play an important role in patients' willingness to use eHealth for self-management purposes. The relationship between disease controllability and patients' willingness to self-monitor was further investigated in Chapter $4{ }^{4}$ This cross-sectional study provided the first evidence that patients' willingness to self-monitor might indeed be associated with disease controllability. In addition, Chapter 5 revealed that patients who had an emailconsultation in 2014 differ from those that had a telephone or face-to-face consultation in terms of diagnosis: most email-consultations were performed for the diagnostic 
categories psychological, endocrine, metabolic and nutritional, and circulatory problems. $^{3}$

\section{Patient-specific characteristics}

Mixed results were found regarding patient-specific characteristics that influence patients' willingness to use eHealth. A lower age, higher level of education and rating the Internet as easy to use were associated with a positive intention towards using Internet appointment planning and asking questions via the Internet (Chapter 2). ${ }^{2}$ Gender and having no, or at least one, chronic disease had no influence. Moreover, patients that had an email-consultation were older than patients that had a telephone or face-to-face consultation (Chapter 5). ${ }^{3}$ Interestingly, looking at the patients that had most emailconsultations, i.e. patients with diabetes, email consultation users were younger than patients that had a telephone or face-to-face consultation for diabetes. Looking at patient characteristics that have a relationship with patients' willingness to use selfmonitoring applications (Chapter 4), age and multimorbidity (having two or more diseases) did not play a role. ${ }^{4}$ In contrast, males and more highly educated people were significantly more willing to self-monitor. This influence of gender and education level was not found in the group that was most willing to self-monitor: patients with diabetes. In addition, patients' perceived general self-efficacy and the severity of health problems were not related to patients' willingness to self-monitor, which was contrary to our expectations based on our focus group study (Chapter 3$).^{1}$

\section{Lessons learned from a broad-scale eHealth implementation project}

Lessons learned from the eLabEL project were based on the analysis of reflective and process-based notes from all project meetings and discussed from the perspective of patients, health care professionals, entrepreneurs and health care policymakers (Chapter 6). ${ }^{5}$ These stakeholders all act within their own contexts and with their own values and expectations. We have learned that for optimal and sustainable use of eHealth, patients should be actively involved, primary health care professionals need to be supported in their management, entrepreneurs should work closely with health care professionals and patients, and the government needs to focus on new health care models that stimulate innovations. Only when these parties all act together, the potential of eHealth can be fulfilled. 


\section{Methodological considerations}

\section{Study design}

The studies for this dissertation were conducted as part of the eLabEL project that aimed to establish living labs in which integrated eHealth applications would become a part of regular health care. In accordance with the European Network of Living Labs, we defined a living lab as "a user-centred, open innovation ecosystem based on a systematic user co-creation approach integrating research and innovation processes in real-life communities and settings". ${ }^{6}$ A key element of a living lab setting is doing research "in the wild', which has the advantage that, in this case, eHealth could be studied in everyday primary care practice. The real-life setting is the leading factor which means that when practice changes, research should change as well. During this three-year project we intensively guided and followed the process of co-creation and implementation of integrated eHealth technology. Although eHealth did not actually become a part of regular health care in these living labs, it provided important in-depth information on the development and implementation of eHealth from different perspectives. However, because eHealth was not properly implemented in these living labs, the use of eHealth by patients and aspects that influenced their use could not be studied. Therefore, secondary data were used in three studies to support our living lab experiences. These data sets included large samples that were, to a large extent, representative of the general practice population (Chapters 2 and 5) and the population with a chronic somatic disease in the Netherlands (Chapter 4). The advantage of using these data sets was that it resulted in greater validity and more generalizable findings. ${ }^{7}$ In addition, study items of the studies were part of nationwide research about health care and eHealth in general, so participants were not recruited for the specific topics of the studies, which minimizes selection bias. One limitation is that data were not collected for the specific research questions. Therefore, exact measures for these questions were not assessed. In addition, because these studies showed low numbers of actual users of eHealth, the main focus of this dissertation was on patients' willingness to use eHealth. Aspects that influence patients' actual use of eHealth could only be studied in one study. This is a limitation, as there are indications that there is a difference between factors that influence patients' acceptance of eHealth in the pre-implementation phase (when eHealth has not yet been used) and post-implementation phase (when patients have used and experienced a technology). ${ }^{8}$ Nevertheless, the use of secondary data, mixed with the experiences gathered in the living lab settings, provided new insights into the patient perspective regarding eHealth in primary care and resulted in many recommendations for future eHealth projects. 


\section{Patient involvement}

The importance and added value of actively involving patients in health care research is being emphasized more and more. ${ }^{9,10}$ In eHealth projects, patient involvement and engagement in research, development and implementation is frequently recognized as an essential element in encouraging its adoption. ${ }^{11-14}$ People from the general practice population were involved in every study of this dissertation. Two methods of patient involvement were used: 1) active involvement of patients by giving them the opportunity to express their own ideas, needs and expectations using a qualitative study (involving patients as 'subjects'); and 2) involvement of patients by asking them to evaluate items based on theoretical constructs and hypotheses imposed by the researchers using quantitative studies or by analysing data from electronic health records (involving patients as 'objects'). Most studies in this dissertation focused on the latter, which should not be seen as a single approach to investigating patients' interest in the use of eHealth. The quantitative studies were useful for investigating the current status of eHealth usage and factors that could influence patients' willingness to use eHealth. However, underlying reasons for these could not be studied. Moreover, in both quantitative and qualitative studies we experienced that patients had difficulties in evaluating the use of eHealth. Because many people had never used an eHealth technology, they could probably not clearly imagine what the possibilities of eHealth could be. In a quantitative study this seemed to have resulted in many 'don't know' responses to fixed items on a questionnaire regarding constructs that could influence their intention to use eHealth. By studying patients as 'subjects' instead of 'objects', more in-depth information about underlying concepts can be investigated, such as dayto-day situations, habits, behaviour and health concerns, which can subsequently be linked to (unexpected) eHealth needs, interests and usage.

Originally, the eLabEL project aimed to involve patients more actively in the living labs. However, we only achieved this to a limited extent. First of all, patients had to be recruited by the primary care practice, which was time-consuming for the health care professionals. Since eLabEL activities performed by the general practices were not financially covered by the project, these tasks were an addition to their regular care processes in which they already experienced high time pressure. With the help of care professionals we attempted to set up a patient panel with a view to involving patients actively throughout the project, but this resulted in only a few positive responses. Because the recruitment of participants for the first patient study in the living labs required so much effort from the health care professionals, we were also more hesitant about approaching them to recruit more patients for this panel. In addition, during the project, the focus was shifted more towards the development of an integrated eHealth structure and the investigation of barriers for its slow development and implementation. Because eHealth was not properly implemented, patients did not have the possibility to use it. Therefore, as we have already discussed, we made use of existing data sets to 
explore the patient perspective regarding eHealth, using the living lab experiences as basic findings.

\section{Reflection on the main findings}

\section{Why is eHealth barely used by patients in primary care?}

Our studies indicate that eHealth was barely used by patients in the Netherlands from 2010 to $2014 .^{2}$ The annually published Dutch eHealth monitor shows that digital communication between patients and care professionals in primary care was still not common in 2016, although a substantial number of general practices offered eHealth services. ${ }^{15}$

In this dissertation, several reasons are described for the low usage of, and willingness to use, eHealth by patients. First of all, many patients have a lack of knowledge and information about the possibilities and benefits of eHealth, and the reasons for its implementation. Often, they are not aware of the availability of eHealth services in their general practice. We did not study how care professionals promote, support and motivate patients to use eHealth. However, this seems to play a major role in eHealth implementation and patients' eHealth usage. For example, a study about organizational strategies for promoting the uptake of personal health records (PHRs) found that the single most effective strategy for promoting patient PHR use was encouragement by their trusted health professional to do so. ${ }^{16}$ In addition, other research found that provider messaging behaviour, in particular provider-initiated and response messaging levels, was related to the willingness of patients to send secure messages. $^{17}$

Furthermore, eHealth can only be (effectively) used by patients who are in a position to use it well. Patients should have access to home services that can run the eHealth applications (digital and/or mobile devices with access to the Internet), the skills to use it, and/or the tendency to search for assistance, information or services (helpseeking behaviour). ${ }^{18}$ In the focus group study, several patients reported questioning their ability to use eHealth. The ability to use eHealth is better known as 'eHealth literacy', which is defined as "the ability to seek, find, understand and appraise health information from electronic sources and apply the knowledge gained to addressing or solving a health problem" ${ }^{19}$ A low socio-economic status is found to be related to a low level of eHealth literacy ${ }^{20}$ and eHealth usage. ${ }^{21-23}$ Also, in our studies we found that patients with a low socio-economic status were less interested in using eHealth. However, this does not directly mean that all patients with a sufficiently high socioeconomic status are able and willing to use eHealth. For instance, in a recent report about resilience (Dutch: redzaamheid) it is stated that people who are not able to perform resilience tasks (comparable to self-management tasks, such as making a plan, 
taking action, persevering and coping with temptations) are associated with, but not limited to, those with a low socio-economic status. ${ }^{24}$ Personality characteristics, such as temperament, self-control and conviction, have an influence as well. The name of the report describes this clearly: 'Knowing is not yet doing' (Dutch: Weten is nog geen doen). A highly educated focus group participant in one of our studies reported the following: "There is no lack of information... What we need is a little bit of discipline. Yes, I don't have it myself, but I know I need it."

In addition, even if patients are aware of the possibilities of eHealth for their health condition, and have the confidence, access and skills to use it, this does not directly mean that they are willing to use such services. We found that patients are less interested in the use of eHealth for self-management purposes when they do not expect to receive benefits from using it. These expected benefits regarding eHealth for selfmanagement purposes differ among disease types. ${ }^{1}$ In particular, patients with a disease that can be better kept under control by the patients' behaviour (disease controllability) expected more perceived benefits from the use of eHealth, and seemed more willing to use it. ${ }^{1,4}$ It can be expected that other disease-related factors play a role in patients' willingness to use eHealth as well, such as disease burden and course of disease. Van Houtum and colleagues (2013) showed that a decrease in self-rated health relates to an increase in self-management support needs, while an improvement in health relates to a decrease. Furthermore, they found that patients who perceived their course of disease as episodic and/or progressively deteriorating have a greater need for self-management support than patients who perceive their disease as stable. ${ }^{25}$ Although we did not find a relation between patients' perceived general health problems and their willingness to self-monitor health values, patients in the focus group study who mentioned that their disease had little impact on their life did not feel the need to use eHealth for selfmanagement purposes. Moreover, patients' perceived need to use eHealth is found to be an important factor in the acceptance of care technology by older adults, which is found to be influenced by cognitive and physical health status. ${ }^{8,26}$

\section{Is the infrequent use of eHealth a major issue?}

eHealth is often touted as a panacea to increase the effectiveness and quality of care. Therefore, the low use of eHealth is seen as a missed opportunity to improve the current problems in health care. It is indeed a major issue for patients who could benefit from using it, but do not have the opportunity, access and skills to do so. The question is: for which patient groups can eHealth actually be useful, and within these groups, who is being left behind?

Up till now, there has been very limited evidence of the effectiveness of eHealth in everyday practice. ${ }^{27-29}$ Current evidence on eHealth and care technologies is mainly based on clinical trials and isolated eHealth applications, which does not mean that it also works in daily care practice. Therefore, it is difficult to say what the consequences 
are of the low use of eHealth and for which patients. Also, in this dissertation no effect studies have been conducted. However, we found indications that some disease types seem more convenient for eHealth usage than others. A recent systematic meta-review about the benefits of telehealth interventions to support self-management among chronic disease groups shows that findings varied among disease types. ${ }^{30}$ The strongest evidence base, although still inconsistent among reviews, was found for improvements in glycated haemoglobin in type 2 diabetes (through remote blood glucose monitoring and telephone interventions) and for reduced mortality and hospital admissions in heart failure conditions (through physiological telemonitoring and telephone support interventions). In asthma, COPD and cancer, evidence was more insufficient and inconclusive. In addition, in a recent randomized controlled trial study in non-insulintreated patients, no improvement of glycaemic control was found after one year by selfmonitoring blood glucose level once daily. ${ }^{31}$ Interestingly, this patient group is often advised by clinicians to self-monitor. These findings support our view that eHealth does not seem to be relevant for every patient group. It should not be assumed that eHealth is effective for every patient; rather, it should be well-considered which patients can benefit from which type of eHealth applications in what situations.

eHealth in primary care should be implemented and organized in a way that it can be reached and used by those patients for whom it is beneficial. These patients should have equal opportunities to use eHealth services. If this is not the case it will lead to a 'digital divide' of widening inequalities in health care. ${ }^{32,33}$ Subsequently, it is up to the patient to make an informed choice as to whether or not to use eHealth. Support should be provided to enable patients to make adequate decisions regarding use or non-use.

\section{What is needed to stimulate the use of eHealth?}

The chairman of the EU task force on eHealth mentioned in 2012 that "in health care we lag at least 10 years behind virtually every other area in the implementation of IT solutions". ${ }^{34}$ Although many initiatives have been taken in the last few years, eHealth is still often not being implemented in a way that it can be routinely and efficiently used in daily practice. In the eLabEL project we experienced many obstacles that impede the implementation of eHealth in primary care from different perspectives. In this section, recommendations for eHealth developers and entrepreneurs, health care professionals, patients, policy and research that seem necessary in order to stimulate the implementation and use of eHealth in primary care will be discussed. In this dissertation the patient was put at the centre of attention. However, during this project we experienced more and more that the patient perspective cannot be studied in isolation; eHealth implementation is a multi-layered challenge in which all stakeholders involved need to contribute to overcome the obstacles and finally create a momentum of change. 


\section{eHealth developers and entrepreneurs}

eHealth applications should meet the needs of users to increase the benefits they can bring. This includes both individual and disease-specific needs. To develop eHealth that is tailored to the needs of the users, it is important to include them in the entire development process. This starts in the very first idea phase by investigating current problems and barriers in regular care processes from the perspective of both patients and care professionals. The needs and target group should first clearly be identified and defined before solutions and functionalities can be developed. With a more top-down approach, it is more likely that eHealth will not match the user needs. ${ }^{35}$ In addition, throughout the development process, a special focus should be placed on involving vulnerable patient groups, such as patients with a low socio-economic status, to ensure that eHealth can be used by a broad patient group. If patients that are at possible risk of non-use due to individual characteristics are included, and developers respond to their needs at each development stage, it might be possible to reduce the 'digital divide' of widening inequalities in health care. ${ }^{18}$ Active user involvement is a time-consuming process; throughout the development process, developers should balance the need for input from users with the availability of resources such as time and funding. ${ }^{35}$ It is important to develop quickly in order to remain competitive within a fast-moving market. ${ }^{36}$ However, we recommend that the needs assessment phase should not be neglected: this is of major importance for the development of eHealth from which patients can experience benefits, in comparison with regular care.

Finally, the role of eHealth developers and entrepreneurs does not end with the delivery of the application. Providing clear information material via, for example, brochures, videos, help desks and training is important as well. For patients this should include information about how and when to use the eHealth application. For care professionals this should also include when, how and to whom to offer the application. In addition, guidance needs to be provided about how to integrate the application into regular care processes. This should include technical as well as process-based support, which should be tailored to the care organization. ${ }^{37}$ In addition, monitoring how eHealth is used in daily practice and what is needed to improve its benefits should be an ongoing process as usage can change and technology has to be updated regularly. Co-creation with patients, care professionals and researchers is needed to develop useful eHealth applications and implementation strategies. The role of the developers is to bring needs from practice and technology together.

\section{Care professionals}

Care professionals are crucial for the successful implementation and use of eHealth. Care managers are responsible for choosing relevant eHealth applications to offer and for implementing them well. In addition, practising care professionals are responsible for making the final decision about how and to whom they offer eHealth applications and in what situations. Several barriers in the Dutch health care system, which will be discussed 
in the section about policy recommendations, often prevent care managers from being innovative. However, it is also a matter of being willing to give time and attention to innovating and implementing eHealth. It seems that often care managers tend to prefer regular care to new innovative alternatives, even though these could offer potential benefits (status quo bias). ${ }^{38}$ Contributing to successful eHealth implementation demands maximum effort, power, motivation and courage from managers and care professionals. This is only possible when clear vision and mission statements regarding eHealth have been developed. In addition, when discussing this with their eHealth insurer, a joint long- and short-term vision could be established, in which multi-annual agreements could be made, based, for example, on the 'shared savings' principle. ${ }^{38}$ Care managers should have an active role in starting discussions about such arrangements and in encouraging health insurers to develop clear eHealth regulations.

Furthermore, after deciding to use an eHealth application, care professionals play a major role in informing patients about the application. This includes promoting its availability, but also informing them about the possibilities and reasons for implementation, which should be focused on the benefits it can bring. Moreover, patients should be informed about the usage of the application and the shared responsibilities that come with it. In addition, for patients it should be clear whom they can contact when they need help, and within what time span they will get a response (e.g. within 48 hours). By clearly informing and supporting patients, uncertainties about availability, usage, safety and added value can be reduced. In addition, in offering eHealth for self-management purposes, care professionals should well-consider to whom they offer it, and at what point in time. When the disease can be managed by the patient without the use of eHealth, the possibility of experiencing benefits seems low, which increases the possibility of non-use. Therefore, monitoring which patients benefit the most from the use of eHealth and those that do not is important. Starting to work with eHealth with patients that are most willing to use it is recommended to gather short-term benefits, which could be a motivation to use it in a broader patient group, bearing in mind that not all patients are willing to use it. In addition, monitoring which patients can benefit from the use of it, but do not have the skills or opportunity to use it, should be of special attention.

Finally, it is essential that care professionals share their experiences with developers and colleagues in order to contribute to better eHealth. By sharing experiences from real practice, developers could improve and update their applications and care professionals could learn from each other. Learning networks of innovating care professionals and managers might help to exchange knowledge and experiences and to develop best practices. In addition, participation in research projects is important in order to study further the effect of eHealth on the quality, efficiency and cost-effectiveness of care in real practice. 


\section{Patients}

Nowadays, patients are often positioned at the end of the eHealth cycle; when eHealth is not developed, purchased and offered, they do not have the opportunity to use it. However, patients could play a more prominent role in eHealth implementation by addressing their eHealth needs to their care providers. If many patients ask for eHealth, the care provider will be forced to reflect upon their vision of it. It is expected that more 'pull force' and involvement on the part of patients who have the courage to actively ask for eHealth could provide the impetus for a broad-scale implementation of eHealth. ${ }^{38}$ Obviously, patients can only do this when they know about the possibilities of eHealth, which is currently lacking. In addition, there are a substantial number of patients who are sceptical about using eHealth due to expectations that eHealth leads to a reduction of their quality of care and to viewing eHealth as a poor substitution for personal health care. For example, one patient from one of our focus groups said: "In whose interest is it to develop these technologies and innovative things anyway? It's the result of less money and fewer doctors". ${ }^{1}$

Patient associations could play a major role in clearly informing patients about the possibilities of eHealth. ${ }^{38}$ In this way, patients could create their own view of eHealth founded on evidence-based information obtained from an independent source. In addition, national eHealth initiatives that are currently being (or soon to be) launched, such as 'patient-included' conferences, the 'care innovation shop' (Dutch: zorginnovatiewinkel) (in which citizens can experience the possibilities of eHealth), the national eHealth week, and independent valid websites about the available eHealth options ${ }^{39,40}$ could contribute as well. However, whether patients actually use eHealth will always be a personal matter and differ among patients. Most importantly, patients should be open to considering using it. In addition, care professionals should be open to discussing eHealth needs with their patients, which can be further enhanced by creating an atmosphere in which patients feel empowered to ask for eHealth.

\section{Policy}

Despite the effort of the aforementioned stakeholders, eHealth might not find its way into practice when there are no policy rules, conditions for reimbursements and incentives for innovation. The Dutch regulations and legislation seem to be inconsistent: on the one hand, eHealth is acknowledged as having potential and being beneficial; on the other hand, in the procurement policy of 2018 of the four most influential health insurers in the Netherlands, explicit eHealth regulations are still missing. ${ }^{41}$

A fundamental barrier for eHealth implementation seems to be the 'wrong pocket problem'. In the current situation, health care organizations need to invest time and money, while the health insurer would receive the proposed benefits in terms of cost reduction. Furthermore, due to the fact that the Dutch health care system is partly based on 'pay for performance', the use of eHealth can even decrease their revenues when eHealth usage results in a lower number of consultations. In addition, 
arrangements for financial support from health insurers can only start when eHealth has been proven to be effective, for which time and money are needed. Health insurers can contribute to the implementation of eHealth when they become more open to cocreating in potential eHealth projects, focusing more on long-time instead of short-time benefits and considering 'shared savings' principles.

The lack of eHealth financing is often emphasized in policy reports as an important reason why eHealth does not reach daily care practice. ${ }^{38-40}$ However, it should be taken into account that financial support does not guarantee the large-scale use of eHealth, as we have seen in the low use of email-consultations in the Netherlands, although there are reimbursement opportunities. ${ }^{3}$ It seems that the next move should be taken by the government to create a better eHealth landscape for broad-scale implementation. According to a recently published Dutch interdepartmental policy research report, ${ }^{40}$ the government can use three strategies to create a better eHealth landscape on different levels: 1) facilitating strategies: for example by clearly informing and communicating about the prevailing eHealth regulations and legislation and opportunities to innovate, and by supporting conditional insurance package admission opportunities for potential eHealth applications, so that effectiveness can be studied in daily practice; 2) stimulating strategies: such as increasing the opportunity for benefit sharing between participating stakeholders, to reduce the wrong pocket problem, and providing support for care professionals in terms of education and insurance arrangements; 3) intervening strategies: by choosing, for example, potentially effective eHealth projects to focus on and realizing the conditions for success, and exploring opportunities for new financial models. When applying these strategies there should always be a balance between the establishment of clear and fixed guidelines on the one hand, and leaving space, which is needed to innovate, on the other.

Denmark is one of the world's leading countries in terms of eHealth integration. Its success has been the result of nation-level strategies with clear goals and a commitment to coordinate the adoption of eHealth. In addition, based on the case of Denmark, a permanent national infrastructure that supports health information exchange and ensures that all systems adhere to the required interoperability standards seems crucial for the success of eHealth. ${ }^{42}$ In the Netherlands, this is far from optimal yet. All stakeholders should join forces to create a better eHealth landscape and to face challenges to advance successful eHealth implementation. It seems that the Dutch government can play a key role in coordinating and supporting this.

\section{Researchers}

It should be clear that eHealth implementation is a complex process in which many stakeholders are involved. In addition, eHealth goes beyond just using technology and therefore it should also be studied in a broader context. The technology acceptance model (TAM) ${ }^{43}$ for predicting patients' eHealth usage is too focused on using technology, as individual, disease and external factors play a role as well. Qualitative studies are 
recommended to explore how the proposed aspects and characteristics play a role in patients' willingness to use eHealth. Field observations (in the home and practice setting) and interviews with the intended users are recommended to understand the users' day-to-day rituals and habits, which is necessary in order to develop eHealth that fits into patients' daily life. ${ }^{44}$

In addition, the patient perspective regarding eHealth should not be studied in isolation. Implementation models such as the 'Consolidated Framework For Implementation Research' (CFIR) ${ }^{45}$ and the 'Measurement Instrument for Determinants of Innovations' (MIDI) ${ }^{46}$ can provide an alternative approach to gain insight into the full picture that comprises eHealth. These models consist of multiple domains, including intervention characteristics (e.g. evidence strength and quality), outer setting (e.g. patients' needs and resources and the sociopolitical context), inner setting (e.g. organizational culture and leadership engagement), characteristics of the individuals involved and the process of implementation (e.g. planning, evaluating and reflecting).

The complexity and characteristics of eHealth interventions demand new thinking on research methodologies to evaluate their effectiveness. The traditional randomized controlled trial (RCT) approach does not fit in the way technological interventions are rapidly being updated and improved. ${ }^{47}$ Furthermore, its effectiveness can only be proven when eHealth is fully integrated into daily care routines, and the preferred way to implement it might change between care organizations. In the eLabEL project a living lab approach is used, which we still see as being an appropriate approach for developing and studying eHealth interventions. In an open research and innovation ecosystem, involving users as a participative force for co-creating values, experimentation and evaluation can take place in a real-life context through: 1) socio-economic; 2) socioergonomic (user-friendliness); 3) socio-cognitive (intuitive level); and 4) adoptability perspectives (potential level of adoption). ${ }^{48}$ However, the time and effort that are needed to build a sustainable living lab should not be underestimated. Equal and active participation on the part of all stakeholders is needed, which is a challenge when no financial resources are available to support this. In particular, providing incentives for participating practices is recommended in order to encourage care professionals to spend time to participate, but also to recruit patients to do so. In addition, our aim to set up ten living labs in different regions in the Netherlands, in which eHealth solutions should be fully integrated into primary care, was, in retrospect, too ambitious. Starting with small experimental regions, which can be fully arranged as living labs, seems to be a better approach. In addition, in small regions it seems more likely that conditional arrangements can be made regarding regulations and legislation, which are needed to speed up the process of implementing eHealth in daily practice. Furthermore, in these living labs a focus on (cost) effectiveness should be of major importance in selecting the eHealth interventions with the most potential and in stimulating their implementation on a broad scale. The use of an early Health Technology Assessment (early HTA) could be one strategy for informing stakeholders about the potential future performance of the 
application. $^{49}$ This can be applied to potential eHealth applications that are still in development and before market strategies have been developed, by modelling potential outcomes. This may convince health insurers to create reimbursement opportunities and primary care practices to implement eHealth so eHealth can be further developed in daily practice.

\section{Final remarks}

eHealth implementation in primary care is a multi-layered challenge in which all stakeholders act together within their own layer and with their own values, expectations and challenges. It comprises a societal innovation, in which all actors should think, feel and behave differently. ${ }^{15}$ For entrepreneurs it is a new kind of business in an unknown and uncertain market. In practice, eHealth provides alternative ways of providing treatment and patient-provider communication, in which responsibilities for health and disease change. In terms of policy, it requires new approaches to regulations, legislation and financing models, while evidence of effectiveness is missing. As for research, it demands new thinking on research methodologies to develop and evaluate eHealth. All stakeholders need time and support to shape the new eHealth concept guiding the implementation of eHealth in primary care in the right direction. 


\section{References}

1. Huygens MW, Vermeulen J, Swinkels IC, Friele RD, van Schayck OC, de Witte LP. Expectations and needs of patients with a chronic disease toward self-management and eHealth for self-management purposes. BMC Health Serv Res. 2016;16(1):232.

2. Huygens MW, Vermeulen J, Friele RD, van Schayck OC, de Jong JD, de Witte LP. Internet services for communicating with the general practice: barely noticed and used by patients. Interact J Med Res. 2015;4(4):e21.

3. Huygens MW, Swinkels IC, Robert AV, Friele RD, van Schayck OC, de Witte LP. Understanding the use of email consultation in primary care using a retrospective observational study with data of Dutch electronic health records. BMJ Open. 2017; In press.

4. Huygens MW, Swinkels IC, de Jong JD, Heijmans MJ, Friele RD, van Schayck OC, et al. Self-monitoring of health data by patients with a chronic disease: does disease controllability matter? BMC Fam Pract. 2017;18(1):40.

5. Swinkels ICS, Huygens MWJ, Schoenmakers TM, Oude Nijeweme-d'Hollosy W, van Velsen L, Vermeulen J, et al. Lessons learned from a Living Lab on broad adoption of eHealth in primary healthcare. Under review. 2017.

6. ENoLL. Frequently Asked Questions. What is a Living Lab? http://www.openlivinglabs.eu/FAQ [accessed 2017-08-10].

7. Smith E. Using secondary data in educational and social research. Berkshire: Open University Press McGraw-Hill Education, 2008.

8. Peek ST, Wouters EJ, van Hoof J, Luijkx KG, Boeije HR, Vrijhoef HJ. Factors influencing acceptance of technology for aging in place: a systematic review. Int J Med Inform. 2014;83(4):235-48.

9. Schipper K. Patient participation \& knowledge [PhD dissertation]. Amsterdam: VU University, 2012.

10. de Wit MPT. Patient participation in rheumatology research: a four-level responsive evaluation [PhD dissertation]. Amsterdam: Vrije Universiteit Amsterdam. 2014.

11. Domecq JP, Prutsky G, Elraiyah T, Wang Z, Nabhan M, Shippee N, et al. Patient engagement in research: a systematic review. BMC Health Serv Res. 2014;14(1):89.

12. Shah SGS, Robinson I. Benefits of and barriers to involving users in medical device technology development and evaluation. Int J Technol Assess Health Care. 2007;23(01):131-7.

13. Ross J, Stevenson F, Lau R, Murray E. Factors that influence the implementation of e-health: a systematic review of systematic reviews (an update). Implement Sci. 2016;11(1):146.

14. Glasgow RE. eHealth evaluation and dissemination research. Am J Prev Med. 2007;32(5):S119-S26.

15. Krijgsman J, Swinkels I, Lettow B, Jong J, Out K, Friele R, et al. Meer dan techniek: eHealth monitor 2016. 2016. http://www.nictiz.nl/page/Publicaties/eHealth-monitor [accessed 2017-08-10].

16. Wells S, Rozenblum R, Park A, Dunn M, Bates DW. Organizational strategies for promoting patient and provider uptake of personal health records. Am Med Inform Assoc. 2014; 22(1):213-222.

17. Wolcott V, Agarwal R, Nelson DA. Is provider-secure messaging associated with patient messaging behavior? Evidence from the US Army. J Med Internet Res. 2017;19(4):e103.

18. Latulippe K, Hamel C, Giroux D. Social health inequalities and eHealth: a literature review with qualitative synthesis of theoretical and empirical studies. J Med Internet Res. 2017;19(4):e136.

19. Norman CD, Skinner HA. eHealth literacy: essential skills for consumer health in a networked world. J Med Internet Res. 2006;8(2):e9.

20. Chesser A, Burke A, Reyes J, Rohrberg T. Navigating the digital divide: a systematic review of eHealth literacy in underserved populations in the United States. Inform Health Soc Care. 2016;41(1):1-19.

21. Kontos E, Blake KD, Chou W-YS, Prestin A. Predictors of eHealth usage: insights on the digital divide from the health information national trends survey 2012. J Med Internet Res. 2014;16(7):e172.

22. Newhouse N, Lupiáñez-Villanueva F, Codagnone C, Atherton H. Patient use of email for health care communication purposes across 14 European countries: an analysis of users according to demographic and health-related factors. J Med Internet Res. 2014;17(3):e58. 
23. Bertelsen P, Petersen LS, editors. Danish citizens and general practitioners' use of ICT for their mutual Communication. MedInfo. Amsterdam: IOS Press, 2015.

24. Wetenschappelijke Raad voor het Regeringsbeleid (WRR). Weten is nog geen doen: een realistisch perspectief op redzaamheid. 2017. https://www.wrr.nl/publicaties/rapporten/2017/04/24/weten-is-noggeen-doen [accessed 2017-08-10].

25. van Houtum L, Rijken M, Heijmans M, Groenewegen P. Self-management support needs of patients with chronic illness: do needs for support differ according to the course of illness? Patient Educ Couns. 2013;93(3):626-32.

26. Chen K, Chan AH. A review of technology acceptance by older adults. Gerontechnology. 2011;10(1):1-12.

27. Wildevuur SE, Simonse LW. Information and communication technology-enabled person-centered care for the "big five" chronic conditions: scoping review. J Med Internet Res. 2015;17(3):e77.

28. Peeters JM, Wiegers TA, Friele RD. How technology in care at home affects patient self-care and selfmanagement: a scoping review. Int J Environ Res Public Health. 2013;10(11):5541-64.

29. Flodgren G, Rachas A, Farmer AJ, Inzitari M, Shepperd S. Interactive telemedicine: effects on professional practice and health care outcomes. Cochrane Database Syst Rev. 2015

30. Hanlon P, Daines L, Campbell C, McKinstry B, Weller D, Pinnock H. Telehealth interventions to support selfmanagement of long-term conditions: a systematic metareview of diabetes, heart failure, asthma, chronic obstructive pulmonary disease, and cancer. J Med Internet Res. 2017;19(5): e172.

31. Young LA, Buse JB, Weaver MA, Vu MB, Mitchell CM, Blakeney T, et al. Glucose self-monitoring in noninsulin-treated patients with type 2 diabetes in primary care settings: a randomized trial. JAMA Intern Med. 2017;177(7):920.

32. Gunning E, Richards E. Should patients be able to email their general practitioner? BMJ. 2014;349:g5338

33. Kontos E, Blake KD, Chou W-YS, Prestin A. Predictors of eHealth usage: insights on the digital divide from the Health Information National Trends Survey 2012. J Med Internet Res. 2014;16(7):e172.

34. European Union. eHealth Task Force Report: Redesigning health in Europe for 2020. Brussels, 2012.https://ec.europa.eu/digital-single-market/en/news/eu-task-force-ehealth-redesigning-healtheurope-2020 [accessed 2017-08-10].

35. de Beurs D, van Bruinessen I, Noordman J, Friele R, van Dulmen S. Active involvement of end users when developing Web-based mental health interventions. Front Psychiatry. 2017;8.

36. Money AG, Barnett J, Kuljis J, Craven MP, Martin JL, Young T. The role of the user within the medical device design and development process: medical device manufacturers' perspectives. BMC Med Inform Decis Mak. 2011;11(1):15.

37. Janssen M. Situated novelty: a study on healthcare innovation and its governance: Health Care Governance (HCG) [PhD dissertation]. Roterdam: Erasmus University Rotterdam, 2016.

38. Raad voor Volksgezondheid en Samenleving (RVS). Implementatie van e-Health vraag om durf en ruimte. 2017. https://www.raadrvs.nl/publicaties/item/implementatie-van-e-health-vraagt-om-durf-en-ruimte [accessed 2017-08-10].

39. Schippers EI, van Rijn MJ. Kamerbrief voortgangsrapportage e-health en zorgvernieuwing. 2016. https://www.rijksoverheid.nl/documenten/kamerstukken/2016/10/06/kamerbrief-voortgangsrapportagee-health-en-zorgvernieuwing [accessed 2017-08-10].

40. Interdepartementale beleidsonderzoek (IBO). Innovatie in de zorg: vernieuwing in de zorg, zorg voor implementatie. 2017. https://www.rijksoverheid.nl/documenten/rapporten/2017/04/24/ibo-innovatie-inde-zorg [accessed 2017-08-10].

41. de Wildt JE. Globale plannen zorgverzekeraars op 1 april gepubliceerd: Wat brengt het zorginkoopbeleid 2018? De eerstelijns. 2017

42. Kierkegaard P. eHealth in Denmark: a case study. J Med Syst. 2013;37(6):9991.

43. Davis FD. A Technology Acceptance Model for Empirically Testing New End-User Information Systems: Theory and Results [PhD dissertation]. Cambridge, MA: Massachusetts Institute of Technology; 1985.

44. van Gemert-Pijnen JE, Nijland N, van Limburg M, Ossebaard HC, Kelders SM, Eysenbach G, et al. A holistic framework to improve the uptake and impact of eHealth technologies. J Med Internet Res. 2011;13(4):e111. 


\section{CHAPTER 7}

45. Damschroder L, Aron DC, Keith RE, Kirsh SR, Alexander JA, Lowery JC. Fostering implementation of health services research findings into practice: a consolidated framework for advancing implementation science. Implement Sci. 2009;4(1):50.

46. Fleuren M, Paulussen T, Van Dommelen P, Van Buuren S. Measurement instrument for determinants of innovations (MIDI). Leiden: TNO, 2014.

47. Baker TB, Gustafson DH, Shah D. How can research keep up with eHealth? Ten strategies for increasing the timeliness and usefulness of eHealth research. J Med Internet Res. 2014;16(2):e36.

48. Pallot M, Trousse B, Senach B, Scapin D, editors. Living lab research landscape: from user-centred design and user experience towards user cocreation. In First European Summer School "Living Labs". 2010.

49. Manetti S, Burns RM, Turchetti G. Evidence-gathering across industry and academia on early Health Technology Assessment (HTA) of medical devices: survey design and piloting. EMBEC \& NBC. 2017;631-4. 


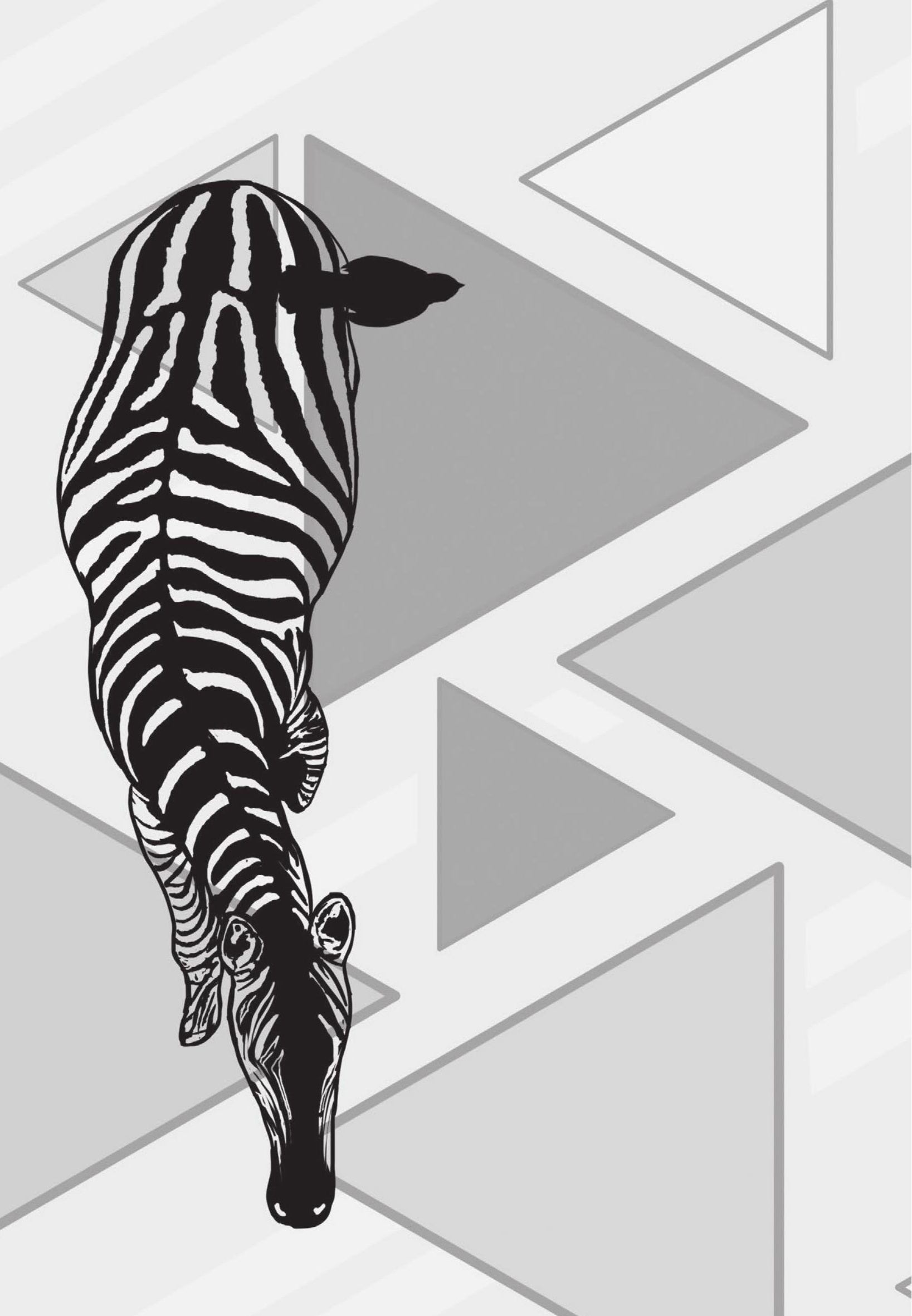




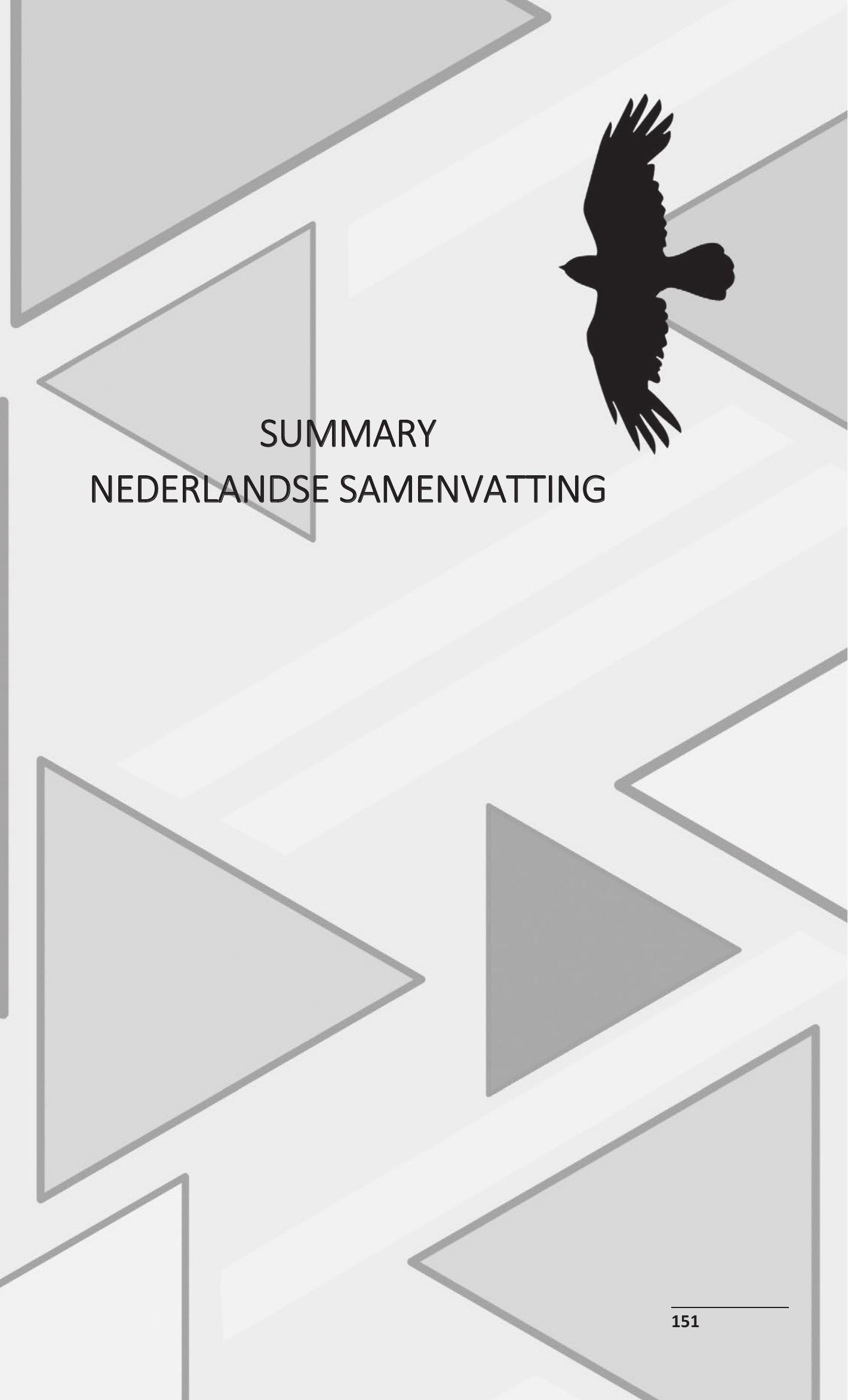





\section{Summary}

Smart devices, such as mobile phones with Internet are becoming more and more essential in daily life. It is expected that digital solutions can also contribute to health care. This is better known as eHealth. Primary care is facing challenges due to an increasing care demand as a result of the growing number of elderly and people with a chronic condition. In addition, care is shifting from secondary to primary care. Online patient portals, healthcare apps and self-monitoring applications are rapidly being developed, aiming to improve the quality and efficiency of health care. However, as yet, eHealth is not in widespread use in daily care practice. There are still many uncertainties regarding the usefulness and the broad-scale implementation of eHealth. This dissertation aimed to investigate the patient perspective regarding eHealth needs and uses. In addition, the broader context of eHealth implementation in the Netherlands has been studied.

The studies in this dissertation were undertaken in a broader context as part of the eLabEL project. The aim of this project was to establish 'Living Labs' in which eHealth applications could be implemented, used and studied in a real-life setting. eLabEL aimed to offer eHealth applications as integrated electronic support. In this project, patients, primary healthcare professionals, eHealth entrepreneurs and researchers collaborated.

In the chapters 2, 3, 4 and 5 eHealth is studied from the perspective of the patient. What do patients expect from eHealth, do they use it, are they willing to use it, and which aspects influence their use? In Chapter 5 we found that the use of eHealth by patients is dependent on the care professional. Therefore, we investigated the broader context of the eHealth landscape in Chapter 6: it turned out that in addition to patients and care professionals, also eHealth developers and entrepreneurs, health insurers and policymakers play a determining role in the use of eHealth in primary care. In Chapter 7 , the studies of this dissertation are discussed and it is described how every stakeholder involved in eHealth can contribute to implement eHealth on a broad scale, in which every perspective has its own challenges.

Chapter 2 shows the current use of online care services whereby patients can contact their primary care professionals via the Internet. This cross-sectional questionnaire study is conducted in 2013 in a sample of 546 Dutch participants that had contacted their general practitioner at least once in the past year. We found that the actual use of such services by patients was very low. Online video consultation was the least used service $(0 \%)$, requesting prescription refill by Internet was the most used service (10\%). Nevertheless, a substantial number of non-users had a positive intention to use such services in the future. This varied from $15 \%$ (online video consultation) to approximately $50 \%$ (online access to personal medical data). In addition, it is investigated which factors have an influence on the positive intention to use online care services. This was proved to be influenced by effort expectancy, performance expectancy, trust, attitude, 
facilitating conditions and social influence. Moreover, patients with a lower age, higher level of education, as well as patients who experienced the use of Internet as easy, had more often a positive intention to use online care services. Remarkably, many patients did not know whether an online care service was available in their primary care practice. Furthermore, many participants answered that they did not know how to evaluate the use and functioning of the online care service. This seemed to indicate that the Dutch population has no strong view regarding the use and possibilities of Internet services for communicating with the general practice.

Chapter 3 presents the results of a focus group study that aimed to investigate expectations and needs of 30 people with diabetes, chronic obstructive pulmonary disease (COPD) or a cardiovascular condition, regarding self-management and eHealth for self-management purposes, their willingness to use eHealth, and possible differences between these patient groups regarding these topics. We found that every patient group had similar general requirements for eHealth in terms of usability, reliability and privacy. In addition, it was reported that the patient, not the care professional, should choose whether or not to use eHealth. Moreover, participants reported that eHealth should support care and not replace personal care. Besides similarities, we also found differences between patient groups. In general, people with diabetes reported the most needs and benefits regarding self-management aspects and were most willing to use eHealth. Participants with diabetes mentioned that their own behaviour regarding, for example, nutrition and medication, directly influenced their health, and that eHealth could support them to influence their behaviour. In contrast, people with a cardiovascular condition mentioned having fewer needs for self-management support because their chronic condition had little impact on their daily life. Patients with COPD had mixed opinions regarding self-management support. This patient group more often mentioned, in contrast to patients with diabetes and a cardiovascular condition, that their health status had declined during the past years, and were wondering how their disease would further develop in the upcoming years. This might indicated that patients with COPD perceived to have less control over their disease. We concluded that patients' expected benefits of eHealth and their perceived controllability over their disease seem to be important in patients' willingness to use eHealth for selfmanagement purposes. This indicates that there are differences between patient groups in the extent to which eHealth for self-management purposes can be of interest for them.

The relationship between disease controllability and patients' willingness to use eHealth is further investigated in a cross-sectional study which is presented in Chapter 4 . The focus of this study was on the willingness to self-monitor health data by patients with a chronic condition, which is an important aspect of many eHealth applications. The controllability that patients have over their disease is partly determined by the disease; 
therefore we defined this as disease-specific. Besides disease-specific aspects there are also aspects that can differ between patients. Patient-specific aspects that we included were perceived self-efficacy, perceived health problems and patient characteristics. In this study we used data of 627 Dutch participants with seventeen chronic somatic disease types of a national panel. An expert panel of medical doctors and physiotherapists were asked to assess for seventeen chronic disease types the extent to which patients, in general, can independently keep their disease in control. In this study we found that patients' willingness to self-monitor differs greatly among disease types. Patients with diabetes (71.0\%), asthma (59.6\%) and hypertension (59.1\%) were most willing to self-monitor. In contrast, patients with rheumatism (40.0\%), migraine (41.2\%) and other neurological disorders (42.9\%) were less willing to self-monitor. In addition, we found indications that there is a relationship between disease controllability scores and patients' willingness to self-monitor. Against our expectations no evidence is found of a relationship between general self-efficacy and patients' willingness to self-monitor. In addition, no relationship is found between the severity of problems that patients experience with daily functioning and patients' willingness to self-monitor. Further research should investigate how disease controllability influences willingness to selfmonitor, and what other disease- and patient specific factors play a role in patients' willingness to self-monitor.

Chapter 5 reveals a study regarding the use of email-consultation in Dutch general practice (GP), in which we investigated the actual use of email-consultation in 2010 and 2014 in comparison with other GP consultations. Since 2006 the costs of emailconsultation in primary care can be reimbursed in the Netherlands. For this study we used routine electronic health record data for the years 2010 and 2014. In 2010200 general practices were included (734 122 registered patients) and in 2014434 (1 630 386 registered patients). In $201032 \%$ of the general practices registered at least one email-consultation, rising to $53 \%$ in 2014. However, the actual use of it was low; in 2014 email-consultations comprised still less than one percent of the total number of GP consultations (home visits, face-to-face-, telephone- and email-consultations) in general practices that registered at least one email-consultation. In addition, we found that patients' email-consultation usage is dependent on its provision by the general practice: in general practices with a higher number of registered patients, located in more urban areas and with a younger patient population email-consultation was more often used. Furthermore, patients that had an email-consultation differ from those that had a telephone or face-to-face consultation in age and diagnosis; overall, patients who consulted their GP by email were older, and more often email-consultations were used for issues related to psychological, endocrine, metabolic, nutritional and circulatory health problems. Email-consultation was most used for the specific disorder of diabetes, (as percentage of al GP consultations in that disease group). Remarkably, patients with diabetes consulting their GP by email were younger in comparison with patients that 
consulted their GP by phone or face-to-face. The lack of reimbursement is frequently mentioned as reason why eHealth is not yet fully adopted in primary care. However, the low use of email-consultation shows that reimbursement opportunities did not directly guarantee its usage. Due to the fact that the use of email-consultation highly varied between general practices, we recommend that the implementation of emailconsultation should further be investigated in a broader context; from both patient and provider perspective. Benefits and barriers regarding the use of email-consultation by patients and care professionals should be further investigated using qualitative studies. Investigating why it works in 'good practices' and why it is less frequently used in others will give more insight in the process that is needed to successfully implement and use email-consultation.

The final study of this dissertation describes the findings and experiences of the eLabEL project. In Chapter 6 the most important lessons learned of this project are presented. These are set up after a systematically analyses of reflective and process-based notes from all meetings of the project partners, interview data and data of focus groups from care professionals, care managers and patients. The results showed that large-scaled implementation of eHealth depends on the effort of and interaction and collaboration between four groups of stakeholders: 1) patients, 2) healthcare professionals, 3) eHealth developers and enterprises, and 4) people responsible for healthcare policy (healthcare insurers and policy makers). We concluded that for optimal and sustainable use of eHealth, patients should be actively involved, primary healthcare professionals need to be reinforced in their management, entrepreneurs should work closely with healthcare professionals and patients, and the government need to focus on new health care models stimulating innovations. Only when these parties will all act together, eHealth can be successfully implemented.

Chapter 7 provides a summary of the main findings of the studies of this dissertation. In addition, considerations regarding the study design and patient involvement are discussed. Besides, we discussed that eHealth is barely used by patients in primary care because of a lack of: 1) knowledge and information about the possibilities and benefits of eHealth, 2) ability and skills to use eHealth and 3) expected benefits of eHealth which is influenced by disease-specific aspects. Furthermore, we discussed that the infrequent use of eHealth is a major issue for those patients who can benefit from the use of it, but do not have the opportunity, access and skills to use it. However, studies of this dissertation show that this does not include all patient groups, as eHealth seem not be relevant for every patient. In the last section of this chapter I describe what is needed to stimulate the use of eHealth in primary care. Because we found that the patient perspective cannot be studied in isolation, I describe this on the basis of recommendations for eHealth developers and entrepreneurs, healthcare professionals, patients, policy and researchers. 
eHealth entrepreneurs are recommended to spend time and money for active user involvement. In particular to investigate patients' needs at the start of the development process. In addition, it is important that information material is provided with the eHealth application. For patients this should include information about how and when to use the eHealth application. For healthcare professionals this should also include when, how and to whom to offer the application. Furthermore, co-creation with patients, care professionals and researchers is needed to bring needs from practice and technology together in useful eHealth applications.

Healthcare managers and care professionals are recommended to create a clear eHealth vision and actively discuss this with health insurers. In this way multi-annual (financial) agreements can be made. Furthermore, care professionals play a major role in informing patients about the application. By doing this uncertainties about availability, usage, safety and added value can be reduced. In addition, care professionals are recommended to well-consider to whom they offer eHealth, and at what moment in the disease process. It is important to monitor which patient groups can benefit the most from the use of eHealth, and within this group, who do not have the skills or opportunity to use it. Finally, it is essential that care professionals share their experiences with developers and colleagues to contribute to better eHealth. In addition, participation in research projects is important in order to study further the effect of eHealth on the quality, efficiency and cost-effectiveness of care in real practice.

Patients could play an important role in the broad-scale implementation of eHealth too. Patients are recommended to address their eHealth needs to their care providers. If many patients ask for eHealth, the care provider will be forced to reflect upon their vision of it. Obviously, patients can only do this when they know about the possibilities of eHealth, which is currently lacking. Patient associations and national initiatives focussing on patients could play a major role in clearly informing patients about the possibilities of eHealth. However, most importantly, patients should be open to considering using it and care professionals should be open to discussing eHealth needs with their patients. This can be further enhanced when care professionals create an atmosphere in which patients feel empowered to ask for eHealth.

It seems that health insurers and the government should also contribute to the broad-scale implementation of eHealth. Health insurers can contribute to the implementation of eHealth when they become more open to co-creating in potential eHealth projects, focusing more on long-time instead of short-time benefits and considering new financial models, such as the 'shared savings' principle. It seems that the role of the government should be to coordinate and support eHealth initiatives to create a better eHealth landscape for broad-scale implementation.

Researchers are recommended to investigate user needs, so eHealth applications can be developed which can be beneficial in comparison with regular care, and which fit into patients' daily life. To investigate the implementation of eHealth, it is recommended to use models in which the broader context of eHealth can be studied; models based on 
the Technology Acceptance Model are too much focussed on technical aspects of eHealth. In addition, we discuss that a living lab approach is an appropriate approach to study eHealth in daily practice. However, when using such approach, it should not be underestimated that equal and active participation on the part of all stakeholders is needed, which is a challenge when no financial resources are available to support this. Starting with small experimental regions, which can be fully arranged as living labs, is recommended. Moreover, it is discussed that a focus on expected (cost) effectiveness is important in an early stage at the development process. Positive outcomes may convince health insurers to create reimbursement opportunities and primary care practices to implement eHealth so eHealth can be further developed in daily practice.

The implementation and use of eHealth in primary care is dependent on the effort of many stakeholders. All stakeholders should act together within their own layer and with their own values, expectations and challenges. All stakeholders should collaborate and need time and support to shape the new eHealth concept guiding the implementation of eHealth in primary care in the right direction. 


\section{Nederlandse samenvatting}

'Slimme' apparaten zoals mobiele telefoons met Internet worden steeds meer onmisbaar in het leven van alledag. De verwachting is dat digitale oplossingen ook kunnen bijdragen in de zorg. Dit wordt ook wel eHealth genoemd. Door een steeds grotere zorgvraag door het stijgend aantal ouderen en mensen met een chronische aandoening staat de huisartsenzorg onder druk. Daarnaast worden er steeds meer taken overgeheveld van de tweede naar de eerste lijn. Online patiëntportalen, zorg apps en thuismeet-apparaatjes worden in grote getalen ontwikkeld met als doel de kwaliteit en efficiëntie van zorg te verbeteren. Toch wordt eHealth in de dagelijkse praktijk nog maar weinig gebruikt. Er zijn nog veel vraagstukken over het nut en het grootschalig gebruik van eHealth. Dit proefschrift richt zich voornamelijk op het perspectief van de patiënt met als hoofddoel het onderzoeken van de behoefte aan en het gebruik van eHealth. Daarnaast is ook de bredere context van eHealth implementatie in Nederland bestudeerd.

De studies in dit proefschrift zijn uitgevoerd in het kader van het eLabEL project. Dit project is opgezet om gezondheidscentra in te richten als 'Living Lab' waarbij eHealth in de dagelijkse praktijk kon worden ingezet, gebruikt en onderzocht. eLabEL trachtte om eHealth applicaties als geïntegreerde elektronische ondersteuning aan te bieden. In dit project werden patiënten, zorgverleners, eHealth ontwikkelaars, ondernemers en onderzoekers nauw betrokken.

In de hoofdstukken 2, 3, 4 en 5 is het perspectief op eHealth vanuit de patiënt onderzocht. Wat verwachten patiënten van eHealth, gebruiken ze het, willen ze het gebruiken en welke aspecten spelen daarbij een rol? In Hoofdstuk 5 vonden we dat het gebruik van eHealth door patiënten afhankelijk is van de zorgaanbieder. In Hoofdstuk 6 zijn we daarom naar het bredere eHealth landschap gaan kijken: daarbij bleek dat naast patiënten en zorgverleners, ook eHealth ontwikkelaars, ondernemers, zorgverzekeraars en beleidsmakers een bepalende rol spelen in het gebruik van eHealth in de eerstelijnszorg. In hoofdstuk 7 worden alle studies uit dit proefschrift bediscussieerd en wordt besproken hoe elke eHealth stakeholder kan bijdragen om eHealth op grote schaal in te zetten, waarbij elk perspectief zijn eigen uitdagingen heeft.

Hoofdstuk 2 staat in het teken van het gebruik van online diensten waarmee patiënten via Internet contact kunnen maken met hun huisarts. Deze vragenlijststudie is in 2013 uitgevoerd onder 546 mensen die minstens één keer in het afgelopen jaar contact hadden met hun huisarts. We vonden dat het daadwerkelijk gebruik van zulke online zorgdiensten door patiënten erg laag was. Online video consultatie werd het minste gebruikt (0\%), het aanvragen van online herhaalrecepten het meeste (10\%). Toch stond een aanzienlijk deel van de mensen die de online diensten niet hadden gebruikt wel positief tegenover het gebruik ervan in de toekomst. Dit varieerde van 15\% (online video consultatie) tot bijna 50\% (online inzicht verkrijgen in persoonlijke medische gegevens). 
Daarnaast hebben we onderzocht welke factoren invloed hebben op een positieve intentie om deze online zorgdiensten te gebruiken. Dit bleek beïnvloed te worden door de verwachte inspanning om de dienst te gebruiken en het nut van de dienst, het vertrouwen in en houding tegenover de dienst, faciliterende omstandigheden en sociale invloed. Ook bleken mensen met een lagere leeftijd en een hoger opleidingsniveau, evenals mensen die het gebruik van Internet als gemakkelijk ervoeren, vaker een positieve intentie te hebben om een online zorgdienst te gebruiken. Opvallend was dat veel mensen niet wisten of een online zorgdienst aangeboden werd in hun huisartsenpraktijk. Tevens antwoordden een groot aantal mensen dat ze niet wisten hoe ze het gebruik en de werking van een online zorgdienst moesten beoordelen. Het lijkt er daarom op dat de Nederlandse bevolking geen sterke mening heeft over het gebruik van online zorgdiensten in de huisartsenpraktijk.

In hoofdstuk 3 worden de resultaten gepresenteerd van een focusgroep studie, waarin onder 30 mensen met diabetes, chronische obstructieve long ziekte (COPD) en hart- en vaatziekte gevraagd is wat hun verwachtingen en behoeften zijn met betrekking tot zelfmanagement en eHealth ter ondersteuning van zelfmanagement. Daarbij is gekeken of er verschillen zijn tussen deze drie ziektegroepen. We vonden dat elke ziektegroep dezelfde algemene vereisten had voor eHealth op het gebied van gebruikersgemak, betrouwbaarheid en privacy. Ook werd door elke groep vermeld dat de patiënt zelf moet kunnen kiezen of ze eHealth willen gebruiken en dat eHealth persoonlijke zorg moet ondersteunen en niet vervangen. Naast overeenkomsten vonden we ook verschillen tussen de ziektegroepen. Over het algemeen hadden mensen met diabetes de meeste behoefte aan en vermeldden ze de meeste voordelen van zelfmanagement. Ook waren ze het meest bereid om eHealth ter ondersteuning van zelfmanagement te gaan gebruiken. In de diabetes groep werd vaak gezegd dat hun eigen gedrag met betrekking tot bijvoorbeeld voeding en medicatie direct invloed had op hun gezondheid. Patiënten met diabetes verwachtten dat eHealth hen kon ondersteunen om dit gedrag positief te beïnvloeden. In tegenstelling tot de diabetes groep gaven mensen met een hart- en vaatziekte vaker aan dat ze weinig behoefte hadden aan ondersteuning bij zelfmanagement, omdat hun ziekte weinig invloed had op hun dagelijkse leven. Mensen met COPD hadden gemengde meningen over zelfmanagement ondersteuning. Deze groep gaf, vergeleken met mensen met diabetes en een hart- en vaatziekte, vaker aan dat hun gezondheid de laatste jaren achteruit was gegaan en vroegen zich af hoe de ziekte zich verder zou ontwikkelen. Dit leek erop te wijzen dat mensen met COPD minder controle hebben over hun ziekte. Uit deze studie concludeerden we dat de verwachte voordelen van eHealth en de mate van controle die mensen zelf hebben over hun ziekte belangrijke aspecten zijn die invloed hebben op de bereidheid van patiënten om eHealth ter ondersteuning van zelfmanagement te gaan gebruiken. Dit duidt erop dat er verschillen lijken te zijn tussen patiëntgroepen in de mate waarin bepaalde eHealth toepassingen ter ondersteuning van zelfmanagement voor hen van belang kunnen zijn. 
De relatie tussen de mate van controle die mensen hebben over hun ziekte en de bereidheid om eHealth te gebruiken is verder onderzocht in Hoofdstuk 4. Hierbij lag de focus op de bereidheid van mensen met een chronische ziekte om zelfstandig gezondheidswaarden te meten, wat een belangrijk aspect is in veel eHealth toepassingen. De controle die mensen hebben over de ziekte wordt deels bepaald door de ziekte; daarom hebben we dit als ziekte-specifiek aspect gedefinieerd. Daarnaast zijn er aspecten die verschillen tussen patiënten. Patiënt-specifieke aspecten waar we naar hebben gekeken zijn ervaren zelf-effectiviteit, ervaren gezondheidsproblemen en patiëntkarakteristieken. Deze studie is gedaan onder 627 mensen met 17 verschillende chronische aandoeningen. Aan een expert panel bestaande uit artsen en fysiotherapeuten hebben we gevraagd of ze voor elke chronische ziekte konden aangeven in hoeverre patiënten, in het algemeen, de ziekte zelfstandig onder controle kunnen houden. In deze studie hebben we gevonden dat de bereidheid van mensen om zelfstandig gezondheidswaarden te meten sterk varieerde tussen chronische ziekten. Mensen met diabetes (71.0\%), astma (59.6\%) en hypertensie (59.1\%) waren het meeste bereid om zelfstandig gezondheidswaarden te meten, in tegenstelling tot mensen met reuma $(40.0 \%)$, migraine $(41.2 \%)$ en andere neurologische aandoeningen $(42.9 \%)$ die minder bereid waren dit te doen. Daarnaast vonden we aanwijzingen dat er een relatie kan zijn tussen de mate van ziektecontrole en de bereidheid van patiënten om gezondheidswaarden te meten. Tegen onze verwachtingen in vonden we geen bewijs dat er een relatie bestaat tussen algemene zelf-effectiviteit en de bereidheid om gezondheidswaarden te meten. Ook vonden we geen relatie tussen de ernst van problemen die patiënten ervaren met het dagelijks functioneren en de bereidheid van patiënten om zelfmetingen te doen. Vervolgonderzoek is nodig om uit te zoeken hoe ziektecontrole invloed heeft op de bereidheid van patiënten om zelfstandig gezondheidswaarden te meten en welke andere ziekte- en patiënt-specifieke factoren hierop van invloed zijn.

Hoofdstuk 5 beschrijft een studie over het gebruik van e-mailconsulten in Nederlandse huisartsenprakijken, waarbij we het gebruik in 2010 en 2014 hebben afgezet tegen andere huisartsenconsulten. Sinds 2006 kan een e-mailconsult door de huisarts gedeclareerd worden. Voor deze studie hebben we gegevens gebruikt uit huisartsinformatiesystemen in 2010 en 2014. De dataset bestond uit 200 huisartsenprakijken in 2010 (734.122 geregistreerde patiënten) en 434 huisartsenpraktijken in 2014 (1.630.386 geregistreerde patiënten). In 2010 werd in 32\% van de huisartsenprakijken minstens één e-mailconsult gedaan, in 2014 is dit gestegen tot $53 \%$. Toch bleef het daadwerkelijke gebruik erg laag; e-mailconsulten omvatten minder dan $1 \%$ van het totale aantal huisartsenconsulten. Ook vonden we dat het gebruik van e-mailconsulten erg varieerde tussen praktijken: in praktijken met een grotere patiëntpopulatie, gelegen in een stedelijk gebied en met een jongere patiëntpopulatie vonden meer e-mailconsulten plaats. Daarnaast vonden we verschillen 
tussen mensen die een e-mailconsult hebben gehad en mensen die een telefonischen/of praktijkconsult hebben gehad; patiënten die een e-mailconsult hebben gehad waren over het algemeen ouder en het consult ging vaker over psychische, stofwisselings- of bloedaandoeningen. De meeste e-mailconsulten werden gedaan voor diabetes (hierbij hebben we gekeken naar het percentage e-mailconsulten in vergelijking met alle huisartsenconsulten binnen een ziekte). Opvallend was dat mensen met diabetes die een e-mailconsult hebben gehad juist jonger waren, in vergelijking met mensen met diabetes die een telefonisch- en/of praktijkconsult hebben gehad. Het gebrek aan vergoeding wordt vaak gezien als één van de belangrijkste redenen dat eHealth niet gebruikt wordt in de praktijk. Het lage gebruik van e-mailconsulten geeft echter aan dat vergoeding niet direct leidt tot gebruik. Omdat het gebruik van emailconsulten erg varieerde tussen praktijken bevelen we aan om vervolgstudies over de implementatie van e-mailconsulten te richten op het bredere perspectief; vanuit zowel patiënten als zorgaanbieders. Door middel van kwalitatieve studies kunnen voordelen en belemmeringen die ervaren worden door patiënten en zorgaanbieders in kaart worden gebracht. Het wordt aanbevolen om deze studies uit te voeren in praktijken die veel emailconsulten gebruiken en in praktijken die e-mailconsulten aanbieden, maar weinig gebruiken. Onderzoeken waarom het in sommige praktijken beter werkt dan in andere zal inzicht geven in het proces dat nodig is om e-mailconsulten succesvol te implementeren en gebruiken.

De laatste studie van dit proefschrift beschrijft de bevindingen en ervaringen in het eLabEL project. In Hoofdstuk 6 zijn de belangrijkste geleerde lessen van dit project weergegeven. Deze zijn opgesteld na een analyse van notulen van projectbijeenkomsten van alle partners van dit project en (groep)interviews met patiënten, zorgverleners en zorgmanagers. De resultaten laten zien dat de grootschalige implementatie van eHealth afhankelijk is van de inzet, interactie en samenwerking van vier groepen stakeholders: 1) patiënten, 2) zorgverleners, 3) eHealth ontwikkelaars en entrepreneurs en 4) stakeholders die verantwoordelijk zijn voor zorgbeleid, zoals zorgverzekeraars en beleidsmakers. We concluderen dat eHealth succesvol kan worden ingezet en gebruikt als patiënten actief worden betrokken in het ontwikkel- en implementatieproces, als zorgverleners ondersteund en aangemoedigd worden om hun organisatie op eHealth in te richten, als eHealth ontwikkelaars nauw samenwerken met patiënten en zorgverleners en als de overheid zich richt op het ontwikkelen van nieuw financiële modellen om zorginnovaties te stimuleren. Alleen wanneer al deze partijen nauw samenwerken zal eHealth succesvol kunnen worden ingezet.

In Hoofdstuk 7 zijn de belangrijkste bevindingen van de studies uit dit proefschrift beschreven. Daarnaast zijn de belangrijkste overwegingen met betrekking tot het studiedesign en patiëntbetrokkenheid bediscussieerd. Er wordt bediscussieerd dat eHealth weinig gebruikt wordt door patiënten door een gebrek aan: 1) kennis en 
informatie over de mogelijkheden en voordelen van eHealth, 2) mogelijkheden en vaardigheden om het te gebruiken en 3) verwachte meerwaarde van eHealth wat gerelateerd is aan ziekte-specifieke kenmerken. Het lage gebruik van eHealth kan een groot probleem zijn voor patiënten die kunnen profiteren van het gebruik van eHealth, maar die niet de mogelijkheid, toegang en vaardigheden hebben om het te gebruiken. Studies uit dit proefschrift laten echter zien dat dit niet de gehele patiëntpopulatie omvat; eHealth is niet voor iedere patiënt even relevant. In de laatste sectie van dit hoofdstuk beschrijf ik wat nodig is om het gebruik van eHealth in de eerstelijnszorg te stimuleren. Omdat we vonden dat het patiënten perspectief niet op zichzelf staand bestudeerd kan worden doe ik dit aan de hand van aanbevelingen voor eHealth ontwikkelaars en entrepreneurs, zorgverleners, patiënten, beleid en onderzoek.

eHealth entrepreneurs wordt aanbevolen geld en tijd vrij te maken voor het betrekken van gebruikers, met name om de behoefte van patiënten te onderzoeken aan het begin van het ontwikkeltraject. Daarnaast is het belangrijk dat informatiemateriaal bij de eHealth applicatie wordt geleverd, zodat patiënten weten hoe ze de applicatie kunnen gebruiken en zorgverleners inzicht krijgen wanneer, hoe en aan wie ze de applicatie kunnen aanbieden. Daarnaast is samenwerking met patiënten, zorgverleners en onderzoekers nodig om behoeften uit de praktijk om te zetten in zinvolle eHealth technologie.

Zorgmanagers en zorgverleners wordt aanbevolen om een duidelijke eHealth visie te creëren, waarmee ze zelf actief in gesprek kunnen gaan met zorgverzekeraars, zodat gezamenlijke (financierings)afspraken gemaakt kunnen worden. Daarnaast spelen zorgverleners een belangrijke rol in het informeren van patiënten over eHealth, zodat onduidelijkheden over beschikbaarheid, gebruik, veiligheid en meerwaarde verminderd kunnen worden. Tevens wordt zorgverleners aanbevolen om goed te overwegen aan wie ze eHealth aanbieden en op welk moment in het ziekteproces. Het is belangrijk dat er goed in de gaten wordt gehouden welke patiëntgroepen de meeste meerwaarde van eHealth ondervinden en, binnen deze groep, wie niet in staat zijn om eHealth te gebruiken. Daarnaast is het belangrijk dat ervaringen worden gedeeld met andere zorgaanbieders en ontwikkelaars en wordt deelgenomen aan onderzoeksprojecten zodat het effect van eHealth op de kwaliteit, efficiëntie en kosteneffectiviteit onderzocht kan worden in de dagelijkse praktijk.

Ook patiënten kunnen een actieve rol spelen in de opschaling van eHealth. Hen wordt aanbevolen om actief met hun zorgverlener in gesprek te gaan over eHealth. Hierdoor kunnen zorgverleners gestimuleerd worden om een eHealth visie te creëren. Hiervoor zullen patiënten wel een goed beeld moeten hebben over de mogelijkheden van eHealth. Patiëntorganisaties en nationale initiatieven gericht op patiënten kunnen hierbij een belangrijke rol spelen. Het is vooral belangrijk dat patiënten het gebruik van eHealth overwegen en dat zorgverleners een open sfeer creëren waarin de patiënt zich bevoegd voelt om om eHealth te vragen. 
Tevens lijkt er een rol weggelegd voor zorgverzekeraars en de overheid. Zorgverzekeraars zouden kunnen bijdragen aan de grootschalige inzet van eHealth als ze meer bereid zijn om deel te nemen aan en samen te werken binnen potentiele eHealth projecten, als ze zich meer richten op de voordelen op lange termijn en als ze nieuwe vergoedingsstructuren, zoals het 'shared savings' principe, overwegen. Daarnaast ligt het voor de hand dat er een rol voor de overheid is weggelegd om eHealth initiatieven te coördineren en ondersteunen, zodat er een beter eHealth 'landschap' gecreëerd kan worden.

Onderzoekers wordt aanbevolen om gebruikersbehoeften in kaart te brengen, zodat eHealth-toepassingen kunnen worden ontwikkeld die een meerwaarde opleveren in vergelijking met reguliere zorg en die past in het dagelijkse leven van de patiënt. Om de implementatie van eHealth te bestuderen worden modellen aanbevolen die het brede perspectief van eHealth omvatten; in modellen gebaseerd om het 'Technology Acceptance Model' wordt eHealth vooral als technologie bestudeerd. Daarnaast stellen we dat een living lab benadering een goede methode is om eHealth in de dagelijkse praktijk te onderzoeken. Daarbij moet niet onderschat worden dat gelijkwaardige en actieve participatie van alle partijen een uitdaging is, vooral als hier geen financiële middelen voor zijn. Aanbevolen wordt om living labs kleiner en regionaal op te zetten. Daarnaast wordt besproken dat er tijdens de ontwikkeling van eHealth in een vroeg stadium een focus moet komen op de verwachte (kosten)effectiviteit van eHealth. Een positieve uitkomst kan zorgaanbieders en zorgverzekeraars overtuigen om deel te nemen aan eHealth projecten, zodat eHealth verder ontwikkeld kan worden in de dagelijkse praktijk.

Het moge duidelijk zijn dat de implementatie en het gebruik van eHealth in de eerstelijnszorg afhankelijk is van de inzet van verschillende partijen. Al deze partijen werken samen binnen hun eigen perspectief en met hun eigen waarden, verwachtingen en uitdagingen. ledereen zal moeten samenwerken en heeft tijd en ondersteuning nodig om de grootschalige implementatie van eHealth in de juiste richting te leiden. 



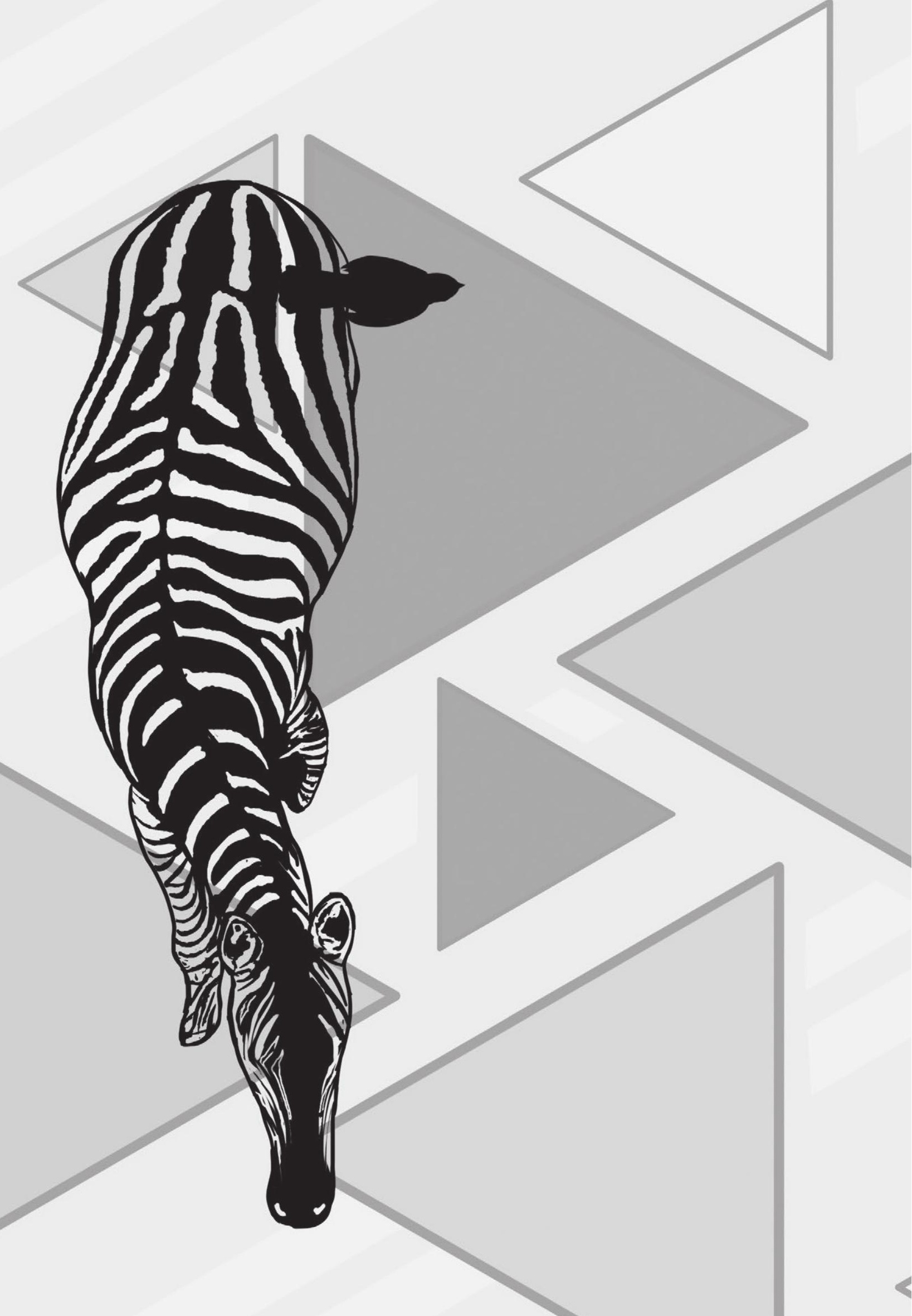



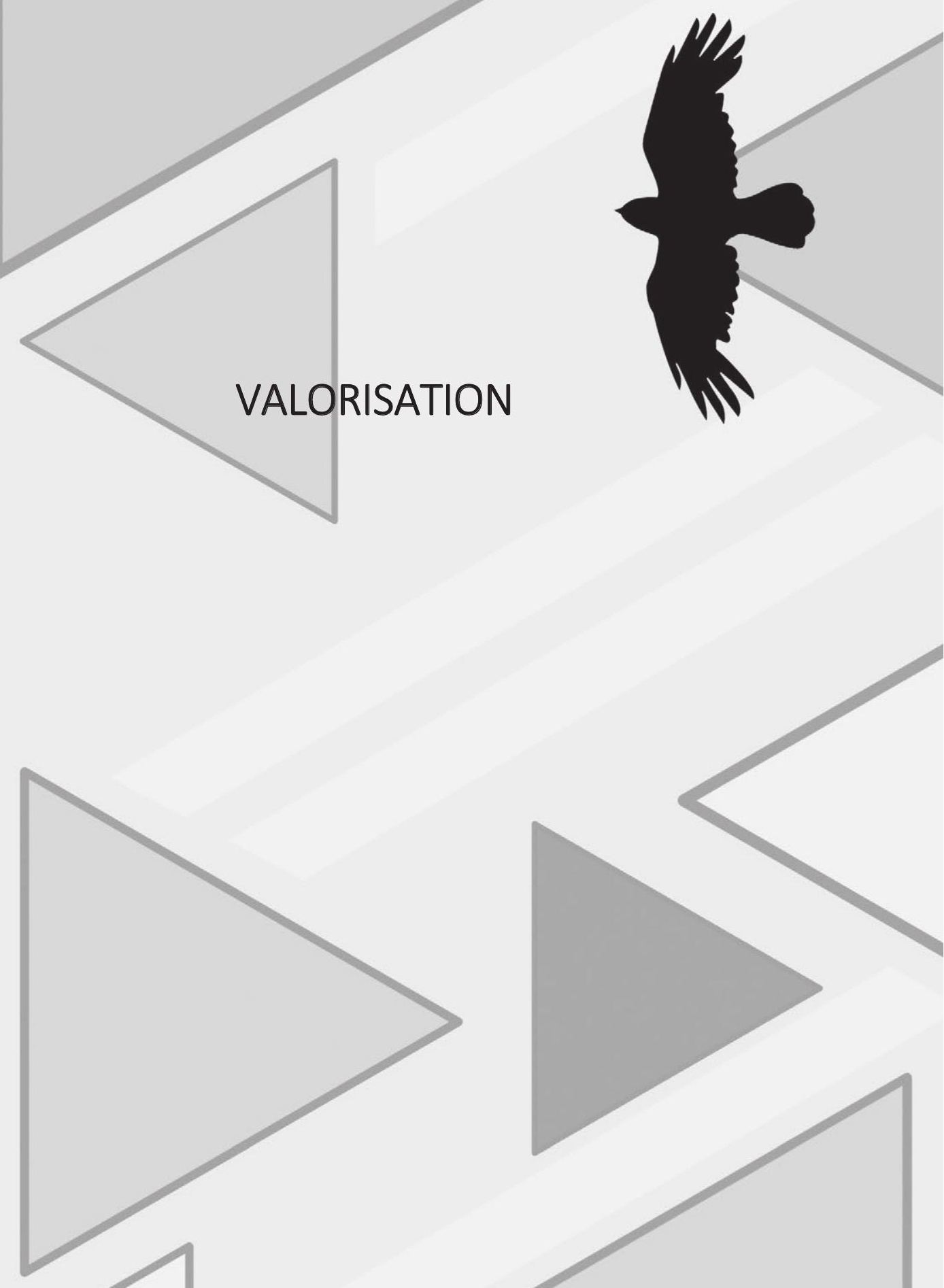



\section{Valorisation}

In this valorisation addendum, the relevance of the outcomes of this dissertation for patients, care professionals, eHealth developers and entrepreneurs, policymakers and researchers will be discussed. In addition, efforts that have been done to disseminate the findings to these stakeholders, as well as activities that will be done to continue dissemination are presented.

\section{Relevance of the findings and the eLabEL project}

Dutch primary care is facing challenges due to the growing number of elderly and people with a chronic condition, resulting in an increasing care demand. At the same time, the labor force that provides care to this growing group of patients is decreasing. These trends and challenges are not unique to the Netherlands; similar trends can be observed worldwide. The view that eHealth can contribute to these challenges in health care is endorsed by the European Union ${ }^{1}$ and the World Health Organization. ${ }^{2}$ Still, the broadscale implementation and use of eHealth is low around the world. The studies of this dissertation provide insights into the patient perspective regarding eHealth and present recommendations for stakeholders involved in eHealth that are needed to stimulate the implementation of it. The studies of this dissertation are mainly focused on the Dutch health care setting, but are relevant to eHealth stakeholders worldwide.

In the previous years many eHealth projects and initiatives have been set up. In comparison with other eHealth projects the eLabEL project was unique in three ways. First, the focus was not on developing new eHealth technologies, but on the integration of existing eHealth applications developed by different small- and medium-sized enterprises (SME's). To achieve this, an intensive collaboration among SME's had to be set up. Second, using a living lab approach eHealth could be implemented and studied in real practice, and patients, health care professionals and eHealth developers and entrepreneurs were actively involved. Third, the research team of this project consisted of researchers with different backgrounds that work at four different research institutes in the Netherlands. Therefore, we could tackle eHealth aspects from different perspectives, related to technology, business and health sciences.

The relevance and potential of the eLabEL project was acknowledged by all stakeholders of the project. Small- and medium-sized enterprises (SME's) that participated in eLabEL acknowledged the fact that they need to collaborate with other entrepreneurs as they were not big enough to enter the market on their own. In this project we set up an intensive collaboration among SME's, which resulted in small alliances of two or three SME's, who are now exploring future eHealth collaboration projects. In addition, in this project we brought industry and primary care practice together, which was valued by both eHealth entrepreneurs and primary care professionals. Furthermore, care professionals mentioned that it was unclear what 
technologies they can benefit most from, and what is needed to implement them. Projects like eLabEL give them the opportunity to experiment with eHealth and to inform them about the possibilities. In addition, care professionals valued the intensive involvement in the project, in particular the fact that they could mention their eHealth needs and concerns. The latter was also mentioned by patients during the needs assessment interviews. In addition, although not actively participating in the project, health insurers and policymakers mentioned to share the eLabEL ambitions and need for the development of an integrated infrastructure for eHealth applications in order to transform traditional primary healthcare into technology-supported healthcare. In 2014, the potential and uniqueness of the eLabEL project was awarded with the 'high potential primary care transformation award' by the Jan van Es institute.

Converting the scientific outcomes of the studies of this dissertation to a social meaning was a main focus during the entire PhD trajectory. Because of the living lab approach and co-creation with patients, care professionals and eHealth developers and entrepreneurs, the outcomes can be directly applied in the real-life setting. The findings are of relevance for the aforementioned stakeholders as well as policy makers and researchers. Findings are valuable far across the borders of the project, as we developed general 'lessons learned' and recommendations for the implementation and use of eHealth in primary care. We state that the implementation of eHealth is a multi-layered challenge; only when all stakeholders act together within their own layer and with their own values, expectations and challenges, the potential of eHealth will be realized. At the end of the General Discussion Chapter of this dissertation (Chapter 7) it is discussed how our findings are valuable to and could be applied by patients, care professionals, eHealth developers and entrepreneurs, policy and research.

\section{Dissemination of findings}

As mentioned, the findings of this dissertation are directly shared with participating patients, care professionals and eHealth developers and entrepreneurs within the eLabEL project. We did this by organizing meetings with project partners (individual and multi-disciplinary meetings) and by sending brief summaries of interview results and newsletters. Interested people outside the project could also subscribe to these newsletters. In addition, a website was launched to share information about the eLabEL project, including news facts and research results. ${ }^{3}$ Furthermore, a short video about the project was developed, which explains the aim and vision of the project for a lay audience. This video can be reached via the eLabEL website and YouTube. ${ }^{4}$

The eLabEL project was set up by the Centre for Care Technology Research, in which four research institutes collaborate: Maastricht University, Twente University, TNO and Nivel. ${ }^{5}$ One or two researchers of each institute actively participated as project members in the eLabEL project, and took care that results of the projects were shared inside their organization and with their research partners. 
Scientific results of this dissertation are published in four types of international journals (open access) focusing on digital health care, health services research and primary care. In addition, results are presented at international scientific conferences in which researchers from different backgrounds participated including ICT, policy and integrated care. To disseminate results outside science, we published our results in various national societal journals focusing on digital care and primary care. Furthermore, we presented the results of our studies at national conferences to an audience of Dutch health care professionals, health care managers and patients.

During the last year of the project/PhD trajectory the focus was on exploring the way of eHealth adoption in primary care, based on experiences that we gathered in the eLabEL project. This included successes and failures from the perspective of different stakeholders involved in eHealth implementation. Findings of this study are presented in Chapter 6 of this dissertation. The ambition of the eLabEL project was to implement and integrate eHealth applications in a way that they would become part of regular health care. Unfortunately, we did not achieve this goal. However, that we did not reach our intended project goal does not mean that this project has failed. We have learned important aspects regarding the adoption of eHealth in primary care from the perspective of different stakeholders, and what is needed to successfully implement eHealth in future projects. By sharing our experiences, other projects can learn from our successes and failures. In our opinion, this is an important aspect of knowledge dissemination.

In addition, eLabEL is not the only eHealth project that experienced difficulties in the implementation of eHealth in daily practice. ZonMw, who partly funded the project, recognizes our struggles and appreciates the way how we described and share the successes and failures of the project.

\section{References}

1. European Union. eHealth Action Plan 2012-2020-Innovative healthcare for the 21st century. Brussels, 2012. https://ec.europa.eu/digital-single-market/en/news/ehealth-action-plan-2012-2020-innovativehealthcare-21st-century [accessed 2017-10-04].

2. World Health Organization (WHO). Global Observatory for eHealth http://www.who.int/goe/en/ [accessed 2017-10-04].

3. eLabEL. http://www.caretechnologyresearch.nl/elabel/ [accessed 2017-10-04].

4. eLabEL video. https://www.youtube.com/watch?v=AC_uQ4AaUZI [accessed 2017-10-04].

5. Centre for Care Technology Research (CCTR). http://www.caretechnologyresearch.nl/ [accessed 2017-1004]. 


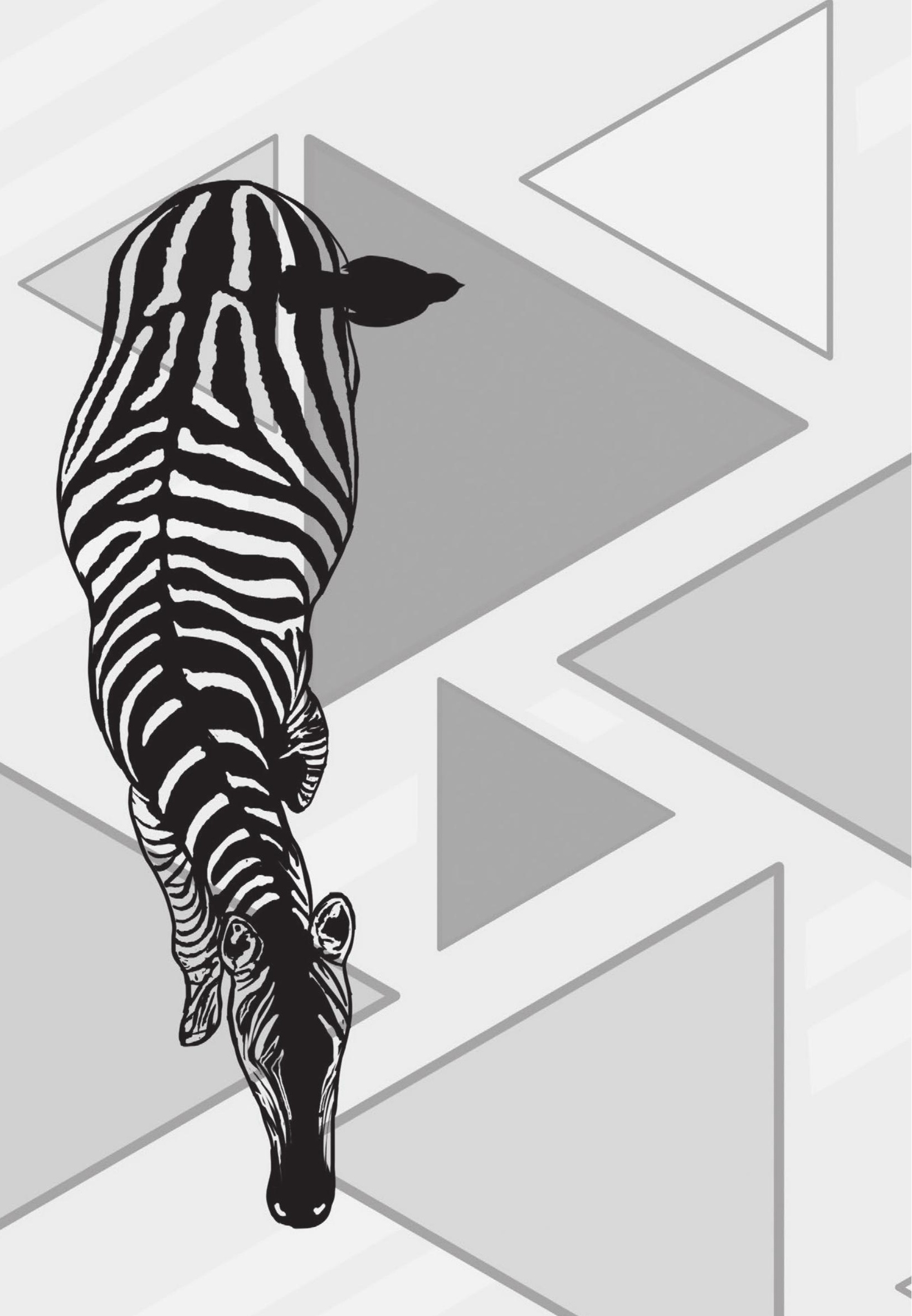




\section{DANKWOORD ABOUT THE AUTHOR LIST OF PUBLICATIONS}
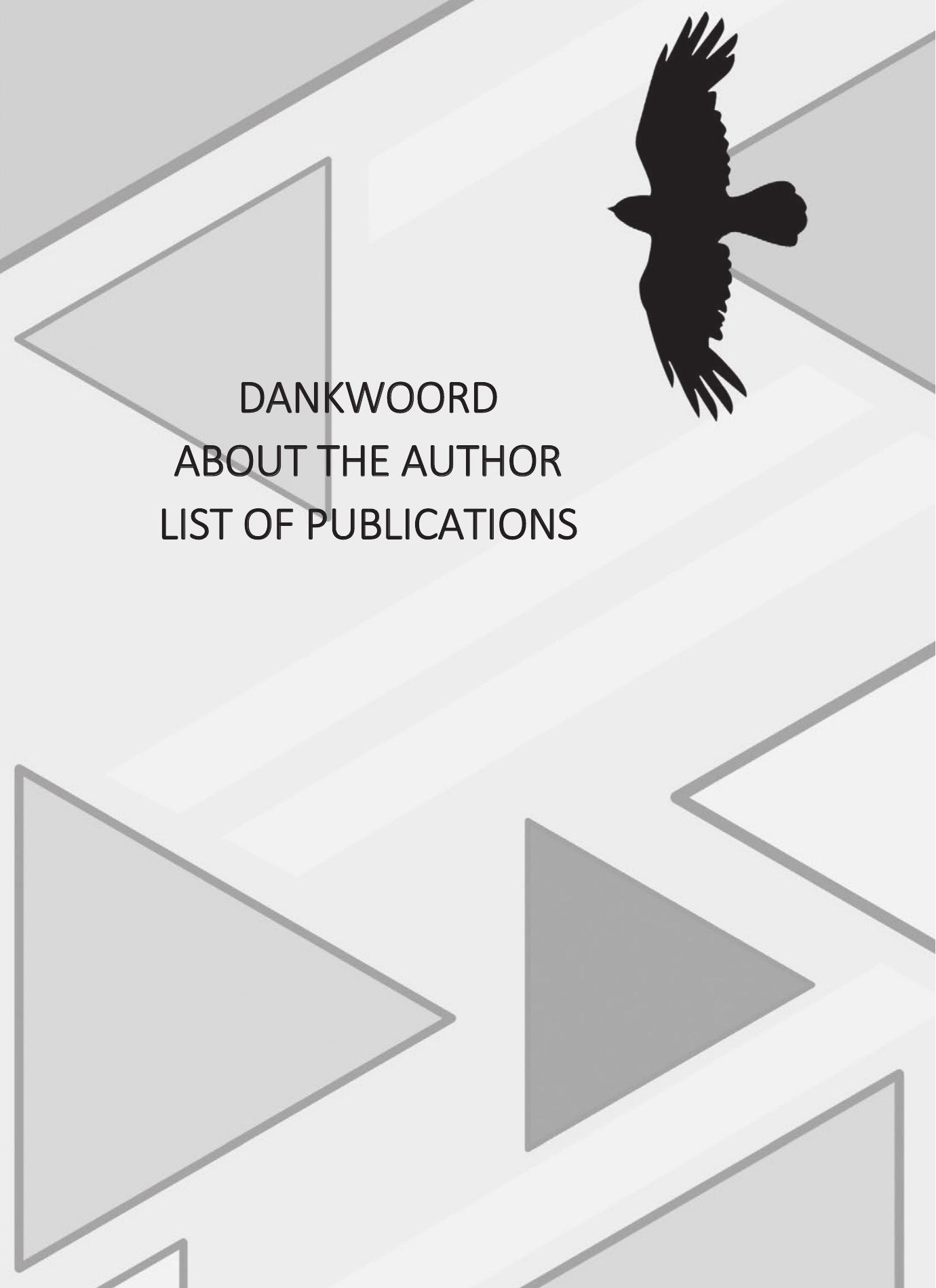



\section{Dankwoord}

Ongelofelijk, het is af! Dit dankwoord is echt het allerlaatste hoofdstuk wat ik nog moet schrijven voor dit boekje. Vanaf het moment dat ik leerde lezen droomde ik er van om ooit nog eens een boek te schrijven. Dat mijn eerste boek een proefschrift zou worden, had ik nooit kunnen denken. Het ging dan ook niet helemaal zonder slag of stoot. Eén ding is in ieder geval zeker: in mijn eentje had ik het nooit gered tot dit laatste hoofdstuk. Dat ondersteuning en samenwerking belangrijk is, geldt niet alleen voor promotieonderzoek, maar ook voor het ontwikkelen en implementeren van eHealth. Daarbij heb je de perspectieven van alle betrokken stakeholders nodig om het volledige eHealth landschap in kaart te brengen en kan alleen door middel van samenwerking eHealth succesvol geïmplementeerd worden. Dit staat dan ook symbool op de kaft van dit boekje: je hebt de hulp van iemand anders nodig (de achterkant van zijn/haar boekje) om het volledige beeld te zien (en laat vervolgens na het lezen van de General Discussion je fantasie het werk doen om het beeld in relatie tot mijn promotieonderzoek te verklaren!). Graag wil ik hierbij iedereen bedanken die me de afgelopen jaren op wat voor manier dan ook heeft geholpen met dit proefschrift. Natuurlijk wil ik ook een aantal mensen in het bijzonder danken.

Allereerst mijn promotieteam. Beste Luc, dank voor het vertrouwen dat je altijd in me had. Ondanks alle hobbels en tegenslagen die voorbij kwamen in dit project, ben je altijd in mij als onderzoeker blijven geloven. Vooral ook toen ik dat zelf al lang niet meer in zag of wilde zien. Je liet me altijd mijn gang gaan en antwoordde op alles: "het komt wel goed" en "het gaat toch prima". Uiteraard ga ik niet toegeven dat je daar gelijk in hebt gehad ;-). Beste Roland, je zat altijd vol met nieuwe inzichten, ideeën en gedachtespinsels. Na elk overleg daagde je me uit om mijn stukken net iets 'spannender' te maken. Na vier jaar bleek ik hier een beetje in te zijn doorgeslagen en zei uitgerekend jij: "ik ga je nu tot enige voorzichtigheid manen... het is me wat". Heb ik toch goede leermeesters gehad, bedankt! Beste Onno, je was altijd positief en complimenteus, maar je kwam tevens met goede suggesties om mijn stukken te verbeteren. Dank hiervoor! Naast deze 'hoge heren' had ik het geluk om samen te mogen werken met twee vrouwelijke co-promotoren. Beste Joan, we hebben samen het eLabEL project vanuit Maastricht opgezet. Jouw enthousiasme en positiviteit waren zeer aanstekelijk! Je hebt me naast een hele hoop gezelligheid ook de belangrijkste aspecten van wetenschappelijk onderzoek geleerd. Als ik weer eens zat te 'zwemmen' hoorde ik vaak jouw stem in mijn hoofd die zei: "denk aan je onderzoeksvragen!". Wat vond ik het jammer dat je na twee jaar de UM ging verlaten voor een nieuwe job in Eindhoven. Bedankt voor de leuke en leerzame tijd en veel geluk in Eindhoven (het enige pluspuntje hiervan is dat je Limburgse tongval weer is ingewisseld voor die Brabantse G!). En gelukkig was daar toen Ilse die me wilde 'adopteren' bij het Nivel. Beste Ilse, je hebt me altijd het gevoel gegeven dat ik welkom was bij het Nivel. De vele uren treinen naar Utrecht waren het 
dan ook meer dan waard. Je maakte altijd tijd voor me vrij, maar daagde me ook uit om eerst zelf mijn visie te creëren. Ook ben je de enige die nooit heeft gezegd dat het dom zou zijn als ik zou stoppen met mijn PhD. Je liet me mijn eigen dingen uitzoeken en zorgde precies voor de juiste inhoudelijke en persoonlijke ondersteuning daarbij. Dank hiervoor!

Ook wil ik een woordje richten aan iedereen van het eLabEL consortium. Allereerst wil ik de praktijken bedanken voor hun durf om deel te nemen aan het project. Zonder enthousiaste zorgverleners en patiënten had dit project nooit gestart kunnen worden. Dankjulliewel voor alle input, tijd en geduld! Daarnaast wil ik de bedrijven bedanken. Het creëren van een eLabEL entiteit en platform bleek enorm complex. Toch ben ik er van overtuigd dat we veel ingrediënten hebben verzamelend om soortgelijke projecten in de toekomst verder op te zetten. Tenslotte, projectteamleden, bedankt voor de samenwerking! Poeh, wat bleek dit project een uitdaging. We hebben met $z$ 'n allen geprobeerd om het project zo goed mogelijk op te zetten en in leven te houden. Helaas is dit niet helemaal gelukt, maar hebben we er wel enorm veel van geleerd. Wendy, collega promovenda uit Twente, ook jij hebt het gewoon geflikt om een eLabEL proefschrift af te leveren! Super goed gedaan, ik kijk uit naar jouw promotie!

Daarnaast wil ik alle panelleden en medewerkers bedanken van het 'Consumentenpanel Gezondheidszorg' en het 'Nationaal Panel Chronisch zieken en Gehandicapten', beide opgezet door het Nivel. Judith de Jong en Monique Heijmans, bedankt dat we gebruik konden maken van deze data en voor de samenwerking. Robert Verheij, bedankt voor de samenwerking en data van 'Nivel Zorg Registratie'. Ik had twee jaar geleden nooit kunnen denken dat ik nog een dataset van meer dan een miljoen patiënten zou gaan analyseren. Lucas van der Hoek en Peter Spreeuwenberg, bedankt voor jullie hulp bij de statistische analyses.

De leden van de beoordelingscommissie, Prof. Nico van Meeteren, Prof. Miriam Vollenbroek, Dr. Erik van Rossum, Dr. Persijn Honkoop, onder voorzitterschap van Prof. Jean Muris wil ik graag bedanken voor het beoordelingen van mijn proefschrift.

Collega's van HSR, bedankt voor alle gezellige lunches, koffietjes, wandelingen, vlaai momenten, gang gesprekken en borrels! Zonder jullie was mijn PhD tijd een stuk minder leuk geweest! Mirre, we kunnen vanuit onze appartementen bijna naar elkaar zwaaien. Het was altijd leuk als ik je op de fiets tegenkwam en die etentjes en theetjes houden we erin! Wie weet worden we binnenkort weer wel buurtjes! Maartje, vaak kwam jij even langs op kamer 0.036. Soms om te checken of het wel ok met me ging, soms om promotie struggles te delen, maar vaak ook voor de gezelligheid! Jij had altijd overal een oplossing voor: van een nieuwe theemok, slimme inzichten tot een bijpassend liedje ("You can try to put me in a box, but I'm doing it my own damn way!"). Dankjewel! Technology ladies, bedankt voor alle eHealth overleggen en natuurlijk de toffe conferenties in Lissabon en (bijna) Porto! Voor een gezamenlijke eHealth sessie zou ik nog wel overwegen om ooit nog eens een artikel te schrijven. Studenteassistenten April en Marijn, bedankt voor jullie ondersteuning bij de focusgroepen en vragenlijsten. Brigitte en alle secretaresses van mijn team, bedankt voor de secretariële 
ondersteuning! Het viel vaak niet mee om drie 'hoge heren' op hetzelfde moment bij elkaar te krijgen, maar toch wisten jullie altijd een gaatje in de agenda's te vinden.

En dan mijn roomies uit kamer 0.036! Ron, het eerste jaar vergezelde je ons één dag in de week. Later liep je nog regelmatig binnen voor een praatje en goede verhalen over het ziekenhuis, de Geriatric Giants of de hond. Altijd even enthousiast en opgewekt! Vincent, jij gaf onze kamer een internationaal en kunstzinnig tintje. Bedankt hiervoor! Ruth! Jij zorgde de laatste maanden voor een frisse wind in onze kamer. Super gemotiveerd en enthousiast pak jij alles aan. Leuk om te zien en om de start van je project mee te maken. Kamergenootjes van het Nivel, Jeanine, Corelien en Wietske; bedankt voor de leuke en leerzame gesprekken! Jeanine en Corelien, heel veel succes met de allerlaatste lootjes van jullie proefschrift!

Inge, kamergenootje vanaf het eerste uur! Ik heb beloofd om een speciale alinea aan je te wijden, dus hier komtie dan! Vaak heb ik me afgevraagd hoe wij het minstens 8 uur per dag met elkaar hebben uitgehouden, want we zijn zo ontzettend verschillend. Jij bent een bedenker met een iets wat spiritueel kantje en een passie voor het onderwijs. Ik ben meer een nuchtere doener die een hekel heeft aan het PGO systeem. Maar misschien zijn die verschillen juist wel waarom we het zo goed kunnen vinden. We hebben altijd iets om over te praten of discussiëren, want alles, maar dan ook echt ALLES is besproken binnen de vier muren van onze kamer. Jij was de stabiele factor tijdens de afgelopen 4 jaar (behalve dan die ene dag dat jij voorgoed mijn plek innam, inclusief uitzicht op de gele muur, omdat je een fancy nieuw bureau wilde!). Vanaf week één heb je me geïntroduceerd op de afdeling, heb je me voorgesteld aan je vrienden en me rondgeleid in Maastricht. Je bent een open boek en hebt mij ook het vertrouwen gegeven dat ik alles aan je kwijt kon. Je kent alle details van mijn project, alle frustraties en successen en promotieplan A tot en met Z. Je wist vaak overal een positieve draai aan te geven (of zeurde lekker mee met de gebruikelijke zin: "ik word hier zo chagrijnig van!"), en zowel dieptepunten als hoogtepunten werden 'gevierd' met koffie en taart ("With coffee and cake anything = possible!") of prosecco met bitterballen. Lieve Inge, bedankt voor alles en super leuk dat je als paranimf achter me staat tijdens de verdediging! Ik weet zeker dat ook jij je PhD glansrijk gaat afmaken. Vanaf nu ga ik je echt nooit meer collega noemen, maar een hele goede vriendin!

Naast collega's wil ik ook een aantal andere mensen bedanken die vooral zorgden voor de mentale ondersteuning in de afgelopen vier jaar. Lieve Karlijn, toen je mijn onderhuurcontract tekende voor mijn studentenkamer in 'Huize Bond' had ik nooit kunnen bedenken dat we zulke goede vriendinnen zouden worden. Toen ik na een half jaar weer terug kwam, kon jij gelukkig naar de zolder verhuizen. Ik heb nog steeds goede herinneringen aan alle bbq's, etentjes en spice girl avondjes daar! Na Eindhoven begon jij je promotie avontuur in Nijmegen en ik die in Maastricht. Maar ook op afstand bleven we veel contact houden tijdens uren durende telefoongesprekken of app conversaties. Bedankt dat je me altijd een luisterend oor biedt, zowel op promotie- als persoonlijk vlak. En of we nu wandelen door de rijstvelden in Vietnam, achterop de motor zitten bij 
Dong en Jung (ofzoiets) of de Macarena dansen in Portugal, ik heb altijd lol met je! Ik vind het super leuk dat je mijn paranimf wilt zijn! Succes met de allerlaatste loodjes voor je PhD en ik ben heel benieuwd naar onze volgende bestemming!

Vincent, bedankt voor alle support, adviezen, spellingschecks (waarschijnlijk vind je weer wat fouten in dit stuk;-)) en bovenal ontspanning! Ik wens je veel geluk in Rotterdam!

Eleana, toch grappig dat een driedaagse cursus een vriendschap kan opleveren! Bedankt voor het leuke (en effectieve!) schrijfweekend, de sauna dagen en koffietjes in het AZM. Ik krijg altijd energie en inspiratie als ik je spreek en wens je veel succes met de afronding van je PhD en huisartsenopleiding!

Miranda en Nikki, jullie zorgden op donderdag voor sportieve afwisseling na een dag werken. Ook al was Rob niet altijd even complimenteus ("wat zien jullie er weer moe uit, hard gewerkt ofzo dames?"), met jullie was het altijd gezellig! De tennistrainingen zijn inmiddels ingewisseld voor etentjes, maar ook dat is altijd leuk!

Tim! Bedankt voor alle leuke tussenstops in Eindhoven tijdens het treinen van Utrecht naar Maastricht. De theetjes houden we erin, evenals het elkaar spammen met reisfoto's!

Maxi! 6 years ago we met each other in Stockholm during our KTH semester. I have great memories of all the dinners, kayak trips and sightseeing activities we did there! Since then, at least once a year we make a trip together. You are always in for everything and I'm looking forward to our next trip! Vielen dank!

Lieve Lisanne, vanaf de eerste dag dat we elkaar zagen bij BT zijn we vriendinnen. We wonen nu al ruim 8 jaar niet meer in dezelfde stad, maar dat maakt niks uit! Laatst zei je tegen me dat je niet zo goed weet wat je moet vragen als het over mijn promotieonderzoek gaat. Maar ik wil je juist bedanken voor alle keren dat je me niet aan mijn promotie hebt laten denken. Hoe fijn was het om tijdens het werk een uitgebreid app verslag te krijgen over onze favoriete series BZV of TI. En na een suf conferentiehotel in Barcelona was het heerlijk om een chill hostel met je te delen. Daarnaast hebben we altijd een goede reden om Aladdin te kijken! Jij zorgde juist voor de beste afleiding en ontspanning, dus dank daarvoor! Ook de rest van de meiden uit 'Den Haag', bedankt voor de leuke vrouwenavondjes!

'Vriendinnen van thuis', ook jullie verdienen natuurlijk een woordje van dank! Vrijwel elk weekendje richting Berge werd gecombineerd met een bezoekje aan jullie. Kim, jij wist altijd precies de juiste activiteiten te bedenken om me te ontstressen! Vaak volkomen spontaan. Super leuk dat jij nu ook in de eHealth branche gaat werken. Hopelijk heb je nog wat aan dit proefschrift! Loes, jij bent het typische voorbeeld van een nuchtere Brabander. Nadat ik jou heb gesproken sta ik weer helemaal met beide benen op de grond. Fem! Vriendinnen vanaf de peuterspeelzaal. Soms bedenk ik me weleens waarom we vroeger eigenlijk vriendinnen zijn geworden; jouw favoriete speelgoed waren je autootjes, terwijl ik me uren kon vermaken met Barbies (toch grappig dat uitgerekend jij psychologie bent gaan studeren en ik op de TU terecht ben gekomen). Maar blijkbaar hebben we elkaar als peuter goed uitgekozen, want we zijn ons 25-jarig jubileum al voorbij! Dat moeten we nog vieren! Goede gelegenheid voor ons 
droomreisje naar New York? Bedankt voor alle leuke jaren en ik weet zeker dat er nog veel gaan komen! Ik vind het super stoer van je dat je in februari gaat beginnen met de GZ opleiding, in combinatie met je werk en gezinnetje. Veel succes!

Naast collega's en vrienden was er ook altijd de familie die vol interesse mijn 'studie' ontwikkelingen volgde. Met name 'de oudjes' waren altijd goed op de hoogte. Oma V, u heeft wel eens gezegd "goh, krijgen we toch nog een professortje in de familie erbij, wie had dat ooit gedacht!". Nou oma, die prof titel gaat het hem niet worden, maar met dr. ben ik al dik tevreden! Ik weet zeker dat ook beide oma's hier trots op zouden zijn geweest. Opa, zoals ik in mijn master thesis schreef vroeg u me in ons laatste gesprek wat ik nou precies zou gaan worden. Ik was toen bezig met mijn afstudeerproject en had nog geen idee wat ik daarna zou willen gaan doen, dus antwoorde ik: "opa, ik word ingenieur!". Waarop u direct zei "oh, nou zo zie je er niet uit". Ik heb me sindsdien vaak afgevraagd of dat nou een compliment was of niet. Ik ben ook heel benieuwd hoe $u$ zou reageren als $u$ wist dat ik ook nog eens voor de doctors titel zou gaan. Vast met nog meer verbazing! Maar zeker met trots.

Broertje! Zonder jou was ik waarschijnlijk nooit zo ver gekomen. Tijdens de HAVO, $\mathrm{HBO}$ en TU was je altijd bereidt me te helpen met de technische vakken, waardoor ik steeds een stapje verder kon komen. Ook tijdens mijn PhD belde je regelmatig op als je wist dat ik een dipje had, wat ik altijd fijn vond (ook al wist ik dat deze telefoontjes vaak aangestuurd waren door pa en ma ;-)). Stiekem heb ik jou altijd als groot voorbeeld gezien en had ik ook geen beter voorbeeld kunnen wensen! Ik vind het super leuk om je nu als trotse papa te zien van twee mooie meisjes (en ben ik trotse tante!). Ik weet zeker dat je nu ook een groot voorbeeld bent voor Sara en Lise. Ook ben ik natuurlijk blij met mijn toekomstige schoonzus! Maikel en Carola, ik kijk uit naar jullie bruiloft!

Lieve pap en mam, wat ben ik blij dat ik jullie via deze weg eens kan bedanken, want normaal zijn we niet van dat kleffe gedoe. Bedankt voor alle kansen die jullie mij hebben gegeven, of waarbij jullie me gestimuleerd hebben om ze te grijpen! Waar ik ook heen ga, welke beslissingen ik ook maak, jullie staan altijd achter me of reizen me achterna. Door jullie heb ik geleerd dat alles mogelijk is, als je er maar volledig voor gaat. Mam, je laat je echt nooit uit het veld slaan, ook al zit het met de gezondheid weleens goed tegen. Pap, jij bent het voorbeeld dat je met een hoop doorzettingsvermogen en creativiteit heel ver kan komen. Ook al ben ik al 12 jaar het huis uit, ik weet dat jullie deur altijd open staat. De laatste stukken voor mijn proefschrift heb ik bij jullie thuis geschreven, want zoals papa zegt: "Die Erelse grond doet wonderen". Het is super leuk om jullie te zien genieten tijdens de vele camperreisjes die jullie nu maken. Dat reizen heb ik dus niet van een vreemde. Pap en mam, bedankt dat jullie me laten zien dat er zoveel moois te beleven is, niet alleen op reis. Want wat is het altijd fijn om weer 'thuis' te komen. Als ik later als ik groot ben maar een klein beetje word zoals jullie, zal ik heel gelukkig zijn!

Martine Huygens, oktober 2017, Maastricht 



\section{About the author}

Martine Huygens was born in Heerle (Noord-Brabant), the Netherlands, on March 27, 1988. After completing her secondary education (HAVO) at the Mollerlyceum in Bergen op Zoom, she moved to The Hague to study the bachelor program Human Kinetic Technology at the The Hague University of Applied Sciences (HBO). During this bachelor she did, amongst others, a three-month internship in an orthopaedic centre in Blantyre (Malawi) and a minor in Human Movement Sciences at the VU University of Amsterdam. In 2009 she obtained her bachelor of engineering degree (Ing.). Martine continued her education at

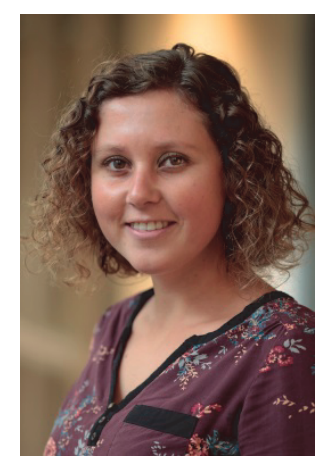
the Eindhoven University of Technology to study Human Technology Interaction. In 2010 she first obtained her premaster for this program, in 2013 her Master of Science degree (Ir.). During this two-year master program she studied one semester at the KTH Royal Institute of Technology in Stockholm (Sweden) and she conducted her master thesis at Philips Design and Philips Research in Eindhoven.

In September 2013, Martine started working as PhD candidate at the Department of Health Services Research at Maastricht University. As a PhD candidate she conducted research as part of the eLabEL project that was set up by the Centre for Care Technology Research (CCTR). This project aimed to establish living labs in which integrated eHealth applications would become a part of regular health care. In this project, patients, health care professionals, eHealth entrepreneurs and researchers collaborated. In particular, her task was to study the patient perspective in this project. 



\section{List of publications}

\section{International articles}

- Huygens MWJ, Swinkels ICS, Verheij RA, Friele RD, van Schayck OCP, and de Witte LP. Understanding the use of email consultation in primary care using a retrospective observational study with data of Dutch electronic health records. BMJ Open. 2017; In press.

- Huygens MWJ, Swinkels ICS, de Jong JD, Heijmans MJWM, Friele RD. van Schayck OCP, de Witte LP. Self-monitoring of health data by patients with a chronic disease: does disease controllability matter? BMC Fam Pract. 2017;18:40.

- Huygens MWJ, Vermeulen J, Swinkels ICS, Friele RD, van Schayck OCP, de Witte LP. Expectations and needs of patients with a chronic disease toward self-management and eHealth for self-management purposes. BMC Health Serv Res. 2016;16:232.

- Huygens MWJ, Vermeulen J, Friele RD, van Schayck OCP, de Jong JD, and de Witte LP. Internet services for communicating with the general practice: barely noticed and used by patients. Interact J Med Res. 2015;4(4):e21.

- Oude Nijeweme-d'Hollosy W, van Velsen L, Huygens MWJ, and Hermens H. Requirements for and Barriers towards Interoperable eHealth Technology in Primary Care. IEEE Internet Comp. 2015;19(4):10-19.

\section{National articles}

- Hochstenbach LM*, Huygens MWJ', Swinkels ICS*, Verwey R*, van der Weegen S*, Willard S*. Geleerde lessen uit e-health onderzoek. ICT\&health. 2017.

- Huygens MWJ and Swinkels ICS. Visie en financiën noodzakelijk voor brede invoering eHealth. Pharm weekbl. 2016; 151-20.

- Swinkels ICS, Huygens MWJ, van Velsen L, Janssen YJFM. Praktijkervaringen met de implementatie van eHealth in de eerstelijnszorg. De Eerstelijns. 2016.

\section{Conference proceedings and abstracts}

- Huygens MWJ, Swinkels ICS, Friele RD, van Schayck OCP, and de Witte LP. The eHealth lifecycle: Do's and Don'ts. Patient expectations of eHealth benefits differ substantially between chronic conditions. EHMA 2016 Annual Conference, 14-16 June, Porto, Portugal.

- Huygens MWJ, Vermeulen J, Friele RD, van Schayck OCP, and de Witte LP. Needs and preferences of patients with a chronic condition towards using care technology to support self-management. 15th International conference for integrated care, 25-27 March, Edinburgh, Scotland. 
- Vermeulen J, Huygens MWJ, de Witte LP, Swinkels ICS, Oude Nijeweme-d'Hollosy W, van Velsen L, and Janssen YJFM. eLabEL: technology-supported living labs in primary care. 7th International conference on eHealth Telemedicine and Social Medicine, 22-27 February 2015, Lisbon, Portugal (full paper).

- Huygens MWJ, Vermeulen J, and de Witte LP. Expectations of middle-aged and elderly persons towards using telecare technologies and eHealth applications in primary care. 6th International conference on eHealth Telemedicine and Social Medicine, 23-27 March, 2014, Barcelona, Spain (full paper). 


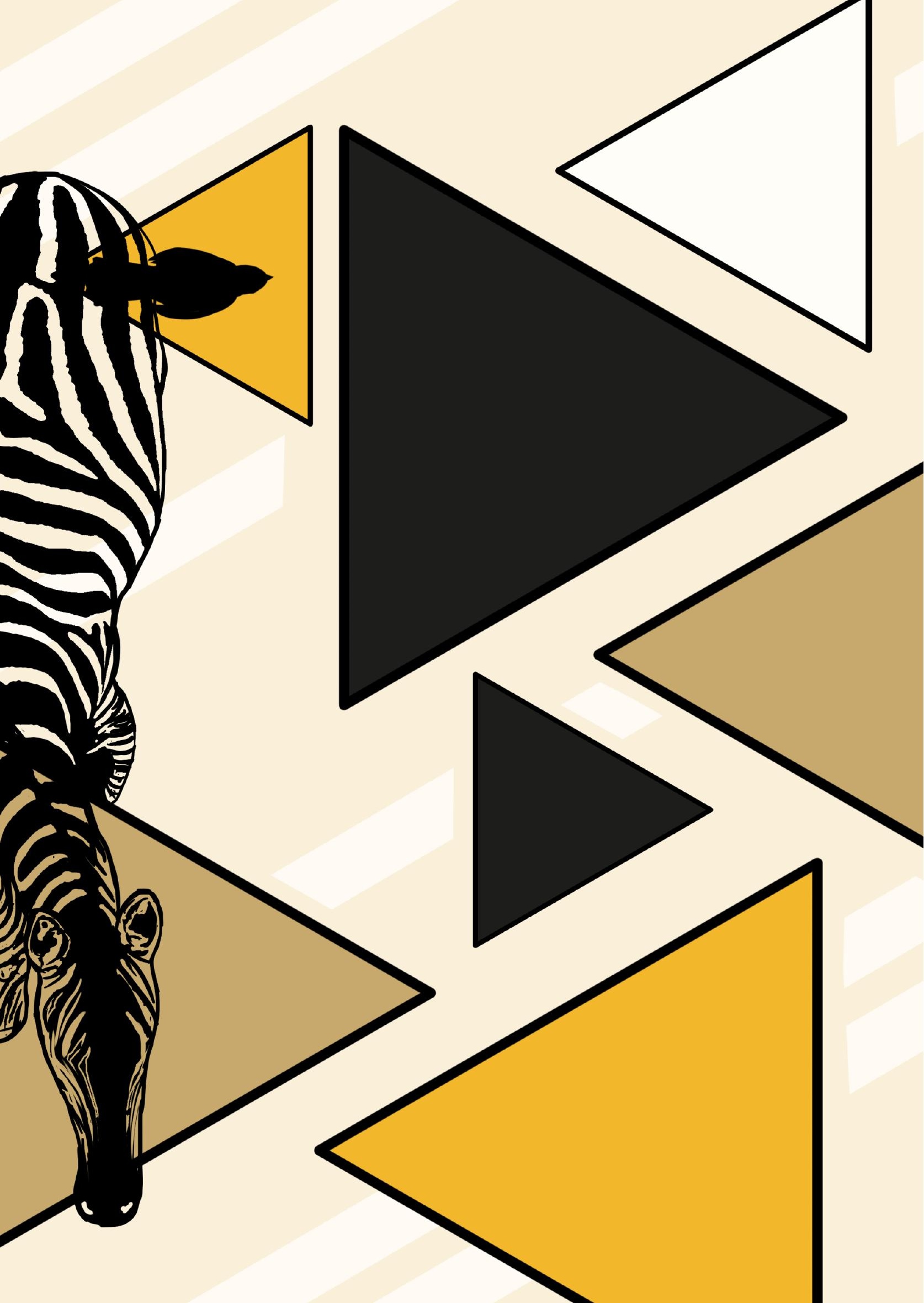

